
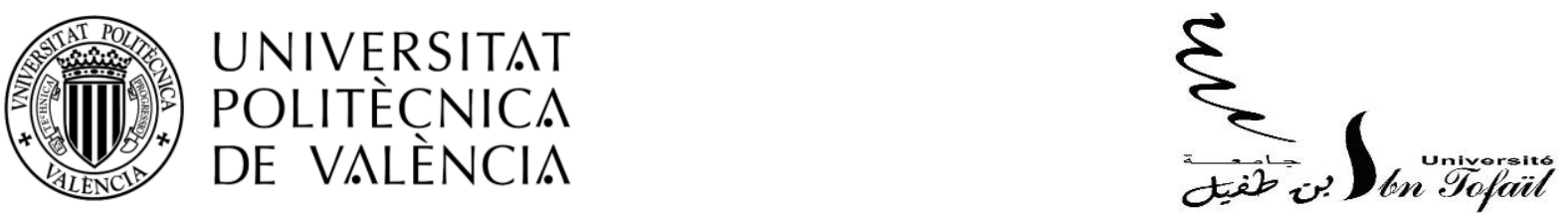

\title{
Elaboration and characterization by electrochemical technique CZTS thin layers for photovoltaic application
}

\author{
Doctoral thesis \\ To obtain the degree of Doctor of \\ Universitat Politècnica de València (UPV) \\ And \\ University Ibn Tofail of Kenitra (UIT)
}

Author:

Hanae Toura

Supervisors:

Prof. Dr. Bernabé Marí Soucase

Prof. Dr. Ebn Touhami Mohamed

Universitat Politècnica de València

October, 2020 


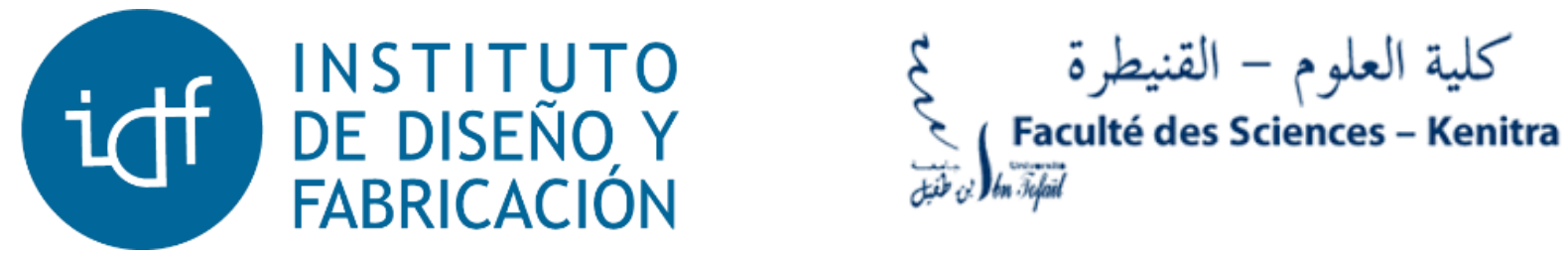

Group d'Optoelectronica i Semiconductors - Departament de Física Aplicada - Institut de Disseny i Fabricació (IDF) Universitat Politècnica de València - España *****

Laboratory Materials and Environment Engineering: Modeling and Application - Department of Chemistry - University Ibn Tofail - Morocco 


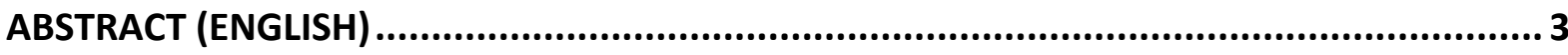

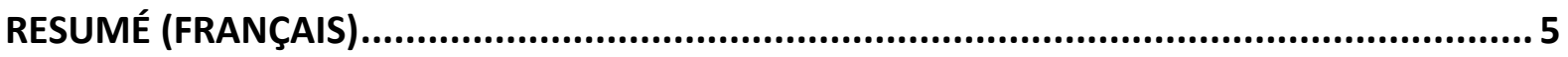

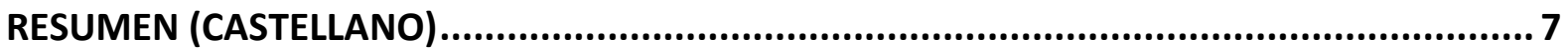

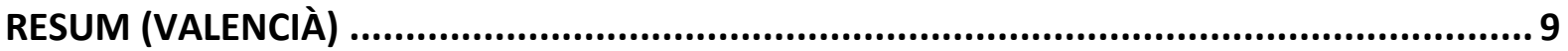

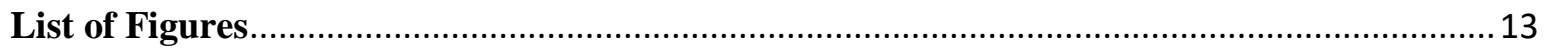

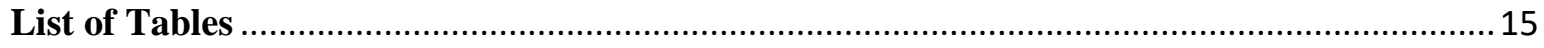

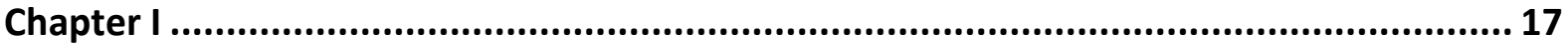

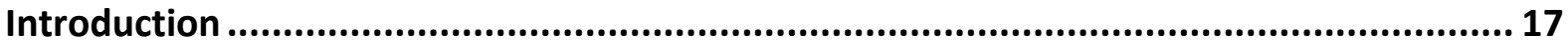

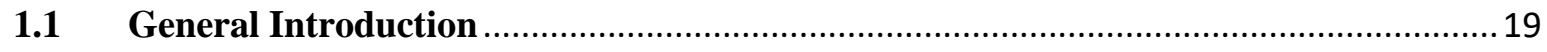

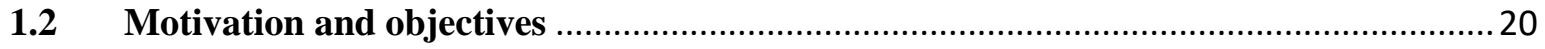

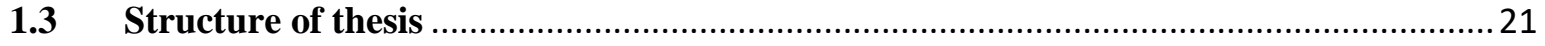

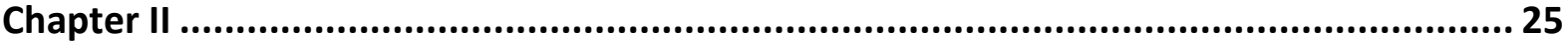

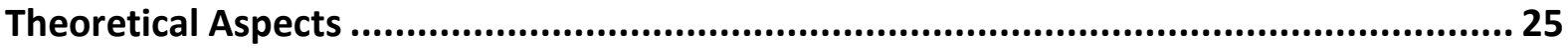

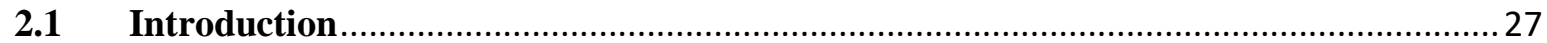

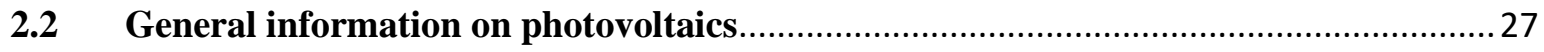

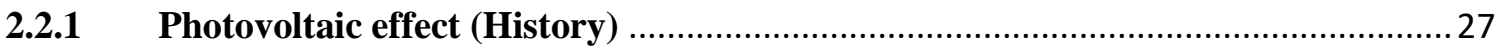

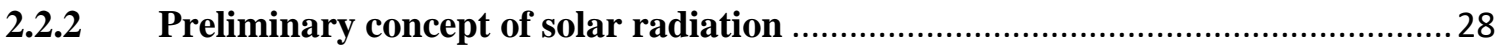

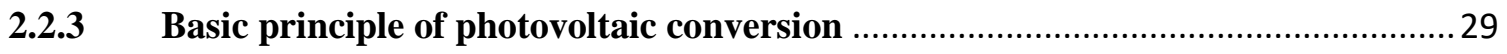

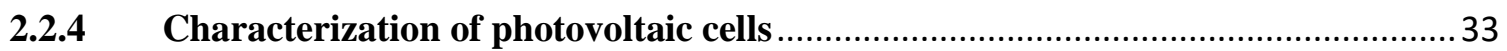

2.2.5 Electrical modeling of a photovoltaic cell .................................................................... 35

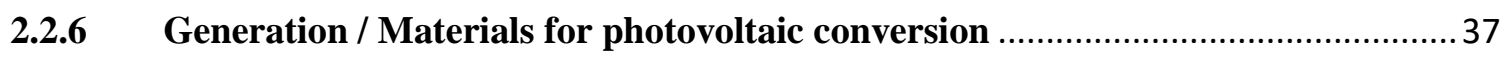

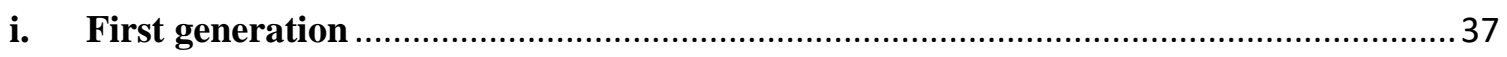

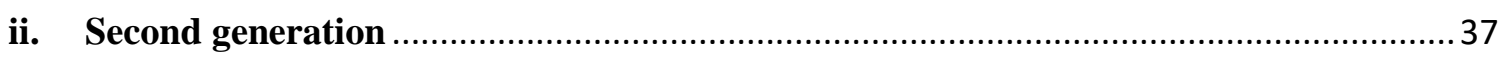

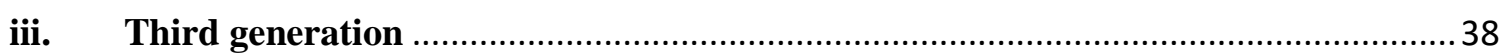

2.2.7 Importance and benefits of solar photovoltaic energy .......................................... 39

2.2.8 Current research: While respecting the environment, the production of energy

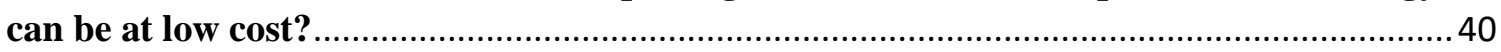

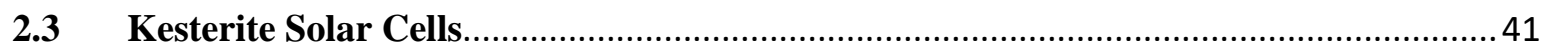

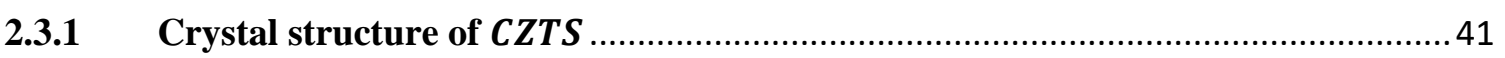

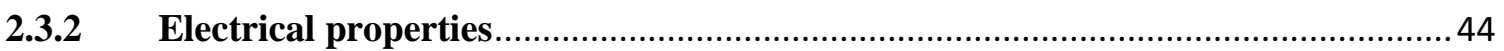

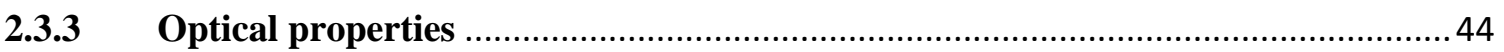

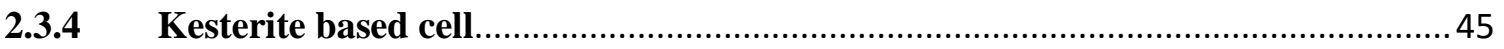

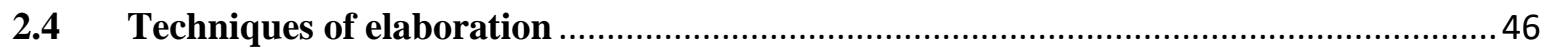

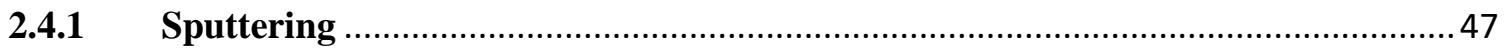

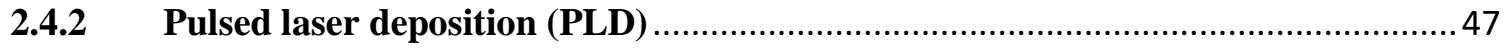




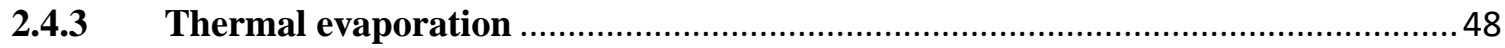

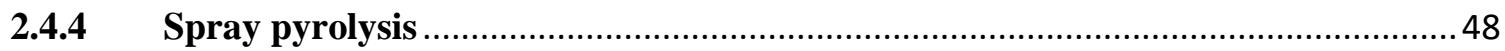

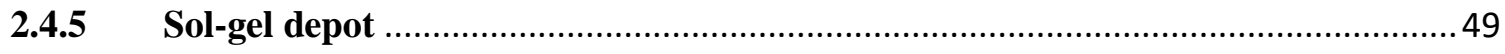

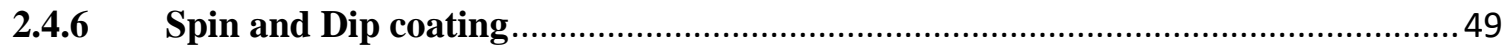

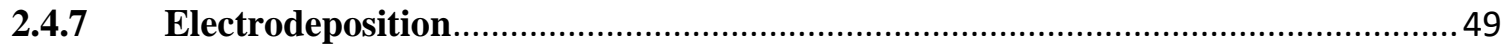

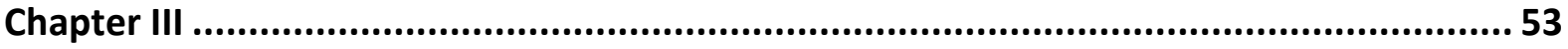

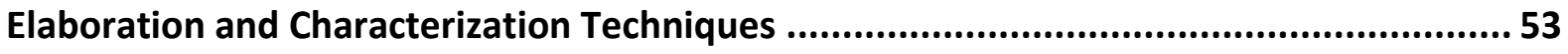

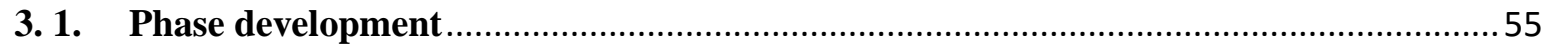

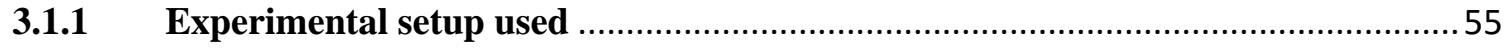

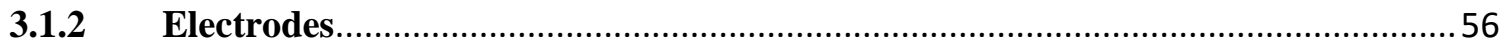

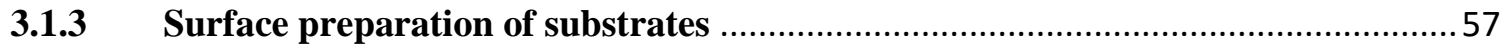

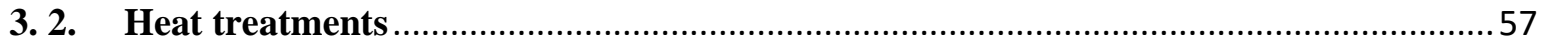

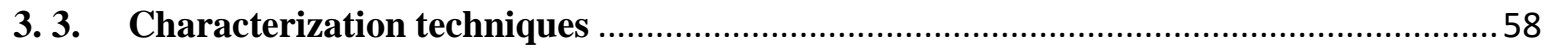

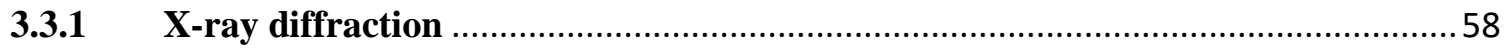

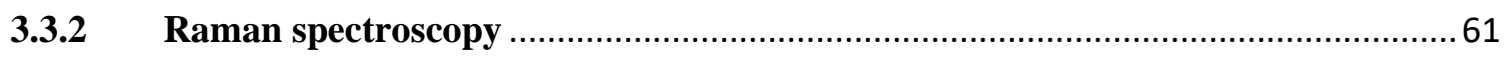

3.3.3 Field emission scanning electron microscopy (FESEM) ..................................... 62

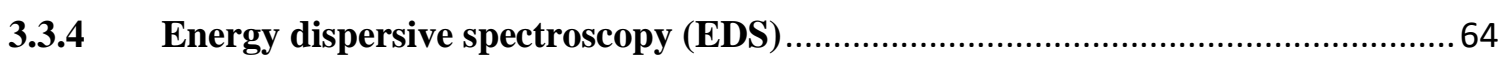

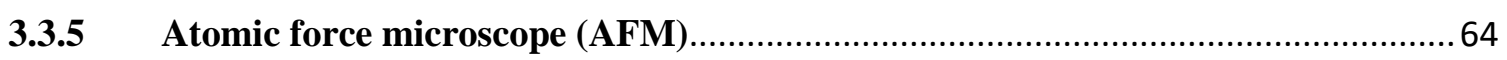

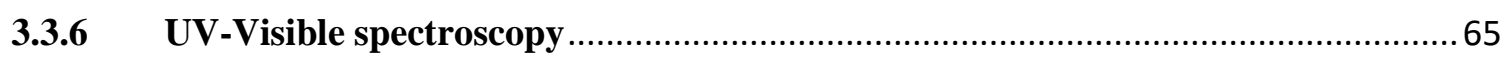

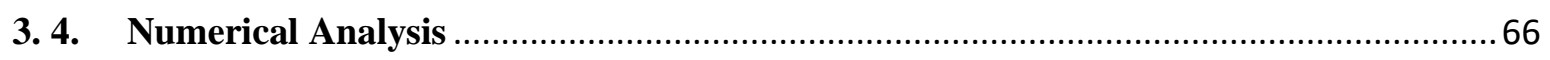

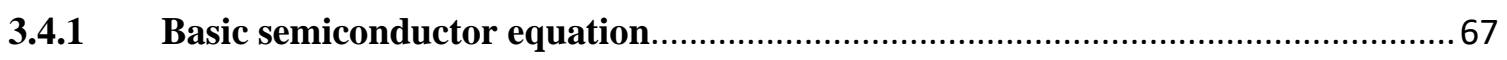

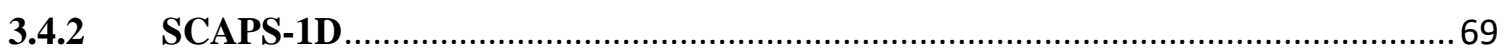

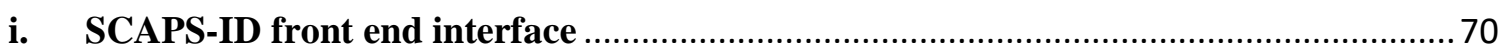

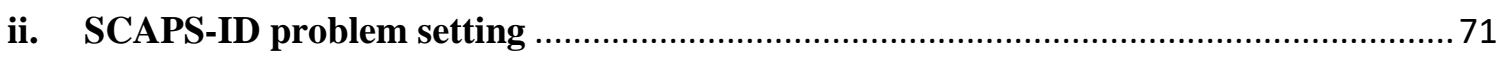

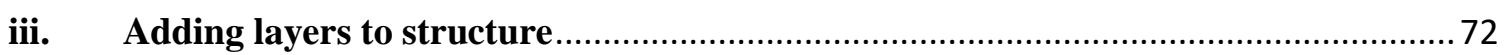

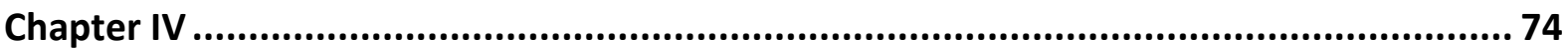

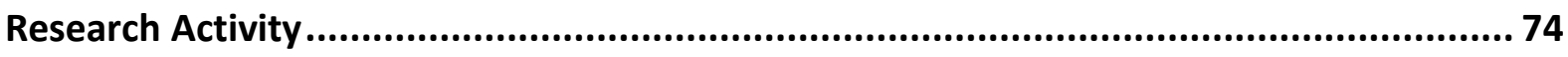

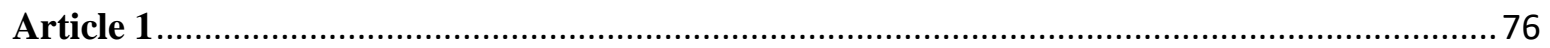

Effect of complexing agent on the morphology and annealing temperature of CZTS kesterite

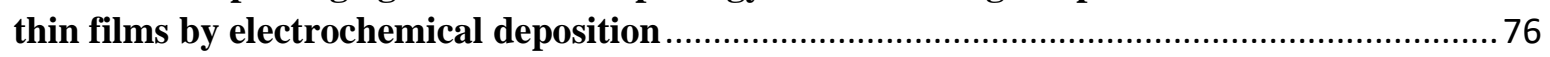

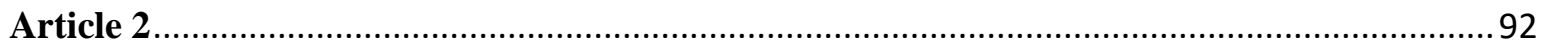

Back contact effect on electrodeposited CZTS kesterite thin films experimental and numerical

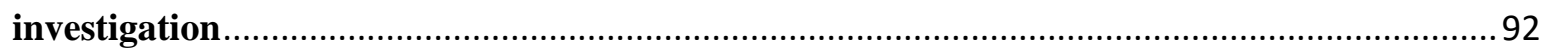

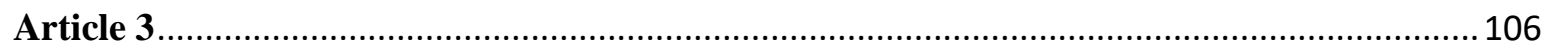

Single step electrochemical deposition for the fabrication of CZTS kesterite thin films for solar cells. 


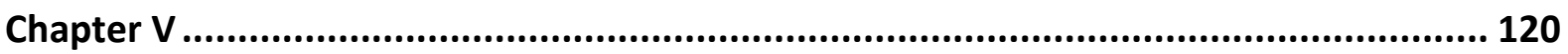

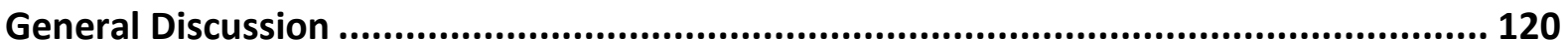

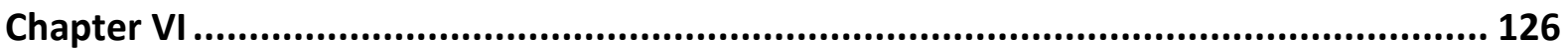

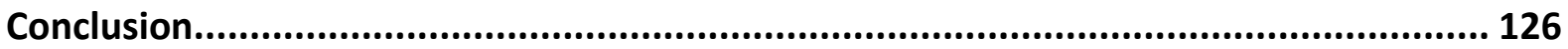

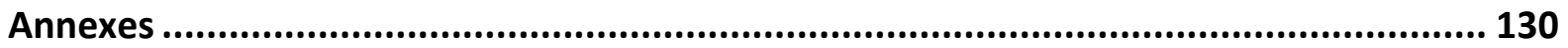

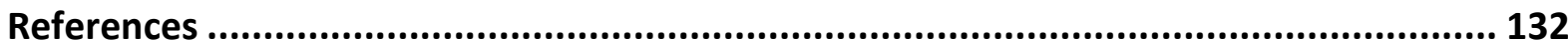




\section{Acknowledgements}

My thanks, above all, to Almighty GOD for the will, health and patience that he has given me during all these long years of study so that I can reach this stage. My parents are the source of my success and my pride. That they find here, the expression of my gratitude and my great love.

This work was carried out in the framework of international supervision in the Optoelectronics and semiconductor group, department of Applied Physics, Institute of Design and Manufacturing of the Polytechnic University of Valencia, Spain under the supervision of Professor Bernabé Marí Soucase and the Laboratory of Materials and Environment Engineering: modeling and application, Department of Chemistry of the Ibn Tofail University of Kenitra, Morocco under the direction of Professor Mohamed EbnTouhami.

I would particularly like to thank Professors EbnTouhami and Soucase who supervised me and ensured the scientific monitoring of this work during these years. You have been great supervises always concerned with the good progress of this work from all points of view. Thank you for providing me with the inspiration and the efforts and above all the confidence and the interest.

I would like to thank the Moroccan Center for Scientific and Technical Research and the Doctoral school of the Polytechnic University of Valencia for the financial assistance they have allocated.

I also extend my sincere thanks to the UPV Electron Microscopy Service and to Mr Ángel Sans Tresserras for their help to learn how to work with characterization techniques.

I express all my gratitude to my parents Mr Toura and Mrs Baghlouli that they were the main motivation to carry out this work.

Special thanks to my husband Rajji for having supported and encouraging me throughout my course, as well as my brothers Soufiane and Youness for their help and their support and especially their love.

I would like to thank all of my friends, especially my work group, Dr. Yousaf and Dr. Faisal who supported me. At the end, thank to them for their encouragement and their presence. 


\section{ABSTRACT (ENGLISH) \\ Elaboration and characterization by electrochemical technique CZTS thin layers for photovoltaic application}

The increase in energy needs, particularly in terms of environmental protection, has greatly stimulated research in the field of photovoltaic conversion in recent years. Solar radiation provides an excellent resource for producing clean and sustainable electricity without toxic pollution or global warming, but in terms of high demand for energy for electricity production as well as the toxicity or scarcity of components constitute the solar cells, this solar transformation technology is still somewhat limited. Because these parameters constitute the main environmental concerns surrounding the photovoltaic industry. The compound $\mathrm{Cu}_{2} \mathrm{ZnSnS}_{4}$ (CZTS) can be considered as one of the most promising absorbent layer materials for low cost thin film solar cells. The abundance and non-toxicity of the constituent elements this promising material is the subject of this work. Obviously, this leads us to think about optimizing the other parameters influencing the formation of thin layers by the electrodeposition method. An electrochemical deposition technique which offers an advantageous alternative from an economic point of view and especially from the possibility of using large surface substrates.

The initial focus was on determining the optimal parameters for the CZTS quaternary thin film development process. The electrodeposition is implemented by the technique of polarization of a potentiostatic electrode. Because this technique is based on the deposition potential of each substance constituting the electrolytic bath, a study has been conducted on the effect of the factors of complexity in order to assimilate these reduction potentials. Then, the annealing process which is a necessary step in the formation of absorbent layers in CZTS was mastered, under the influence of the complexity factor so as to reduce the annealing temperature while preserving the properties of the material. High quality kesterite films with a compact morphology and a well-defined crystal structure at low temperatures were synthesized using $\mathrm{Na} 2 \mathrm{SO} 4$ as the complexing agent. Subsequently, the CZTS kesterite films were prepared on different conductive substrates (ITO, FTO and Mo / glass) due to specifying the effect of back contact. The best behavior is a specific combination of the parameters studied. This work made it possible in particular to master the composition of the films deposited, the annealing process as well as the necessary characterization techniques. Finally, our strategy implements a digital simulation of the CZTS solar cell using the SCAPS-1D software. After the experimental visualization of the thin layers of CZTS on different conductive substrates, modeling by the 
SCAPS-1D software of the CZTS solar cell device showed that the back-contact Mo mounts the best performances.

Keywords: Kesterite, CZTS, complexing agents, annealing temperature, simulation SCAPS, back contact, electrodeposition. 


\section{RESUMÉ (FRANÇAIS)}

Élaboration et caractérisation par voie électrochimique des couches minces en CZTS pour application photovoltaïque

L'augmentation des besoins énergétiques, notamment en matière de protection de l'environnement, a fortement stimulé la recherche dans le domaine de la conversion photovoltaïque ces dernières années. Le rayonnement solaire fournit une excellente ressource pour produire de l'électricité propre et durable sans pollution toxique ni réchauffement climatique, mais en termes de forte demande d'énergie pour la production de l'électricité ainsi que la toxicité ou la rareté des composants constituent les cellules solaires, cette technologie de transformation solaire est encore un peu limitée. En raison que ces paramètres constituent les principales préoccupations environnementales entourant l'industrie photovoltaïque. Le composé $\mathrm{Cu}_{2} \mathrm{ZnSnS}_{4}$ (CZTS) peut être considéré comme l'un des matériaux de couche absorbante les plus prometteurs pour les cellules solaires en couches minces à faible coût. L'abondance et la non-toxicité des éléments constitutifs ce matériau prometteur fait l'objet de ce travail. De toute évidence, cela nous amène à réfléchir pour optimiser les autres paramètres influençant la formation de couches minces par la méthode d'électrodéposition. Une technique de dépôt par voie électrochimique qui offre une alternative avantageuse du point de vue économique et surtout de la possibilité d'utiliser des substrats de grande surface.

Initialement, l'accent était mis sur la détermination des paramètres optimaux pour le processus d'élaboration de couches minces du quaternaire CZTS. L'électrodéposition est mise en œuvre par la technique de polarisation d'une électrode potentiostatique. En raison, que cette technique reposant sur le potentiel de dépôt de chaque substance constituant le bain électrolytique, une étude a été menée sur l'effet des facteurs de complexité afin de rapprocher ces potentiels de réduction. Ensuite, Le processus de recuit qui est une étape nécessaire dans la formation de couches absorbantes en CZTS a été maîtriser, sous l'influence du facteur de complexité en raison de réduire la température de recuit tout en conservant les propriétés du matériau. Des films de kësterite de haute qualité avec une morphologie compacte et une structure cristalline bien définie à basse température ont été synthétisés en utilisant $\mathrm{Na} 2 \mathrm{SO} 4$ comme agent complexant. Par la suite, les films de kestérite CZTS ont été préparés sur différents substrats conducteurs (ITO, FTO et Mo / verre) en raison de spécifier l'effet du contact arrière. Le meilleur comportement est une combinaison spécifique des paramètres étudiés. Ces travaux ont permis notamment de maîtriser la composition des films déposés, le processus de recuit ainsi que les techniques de caractérisation nécessaire. Finalement, notre stratégie met en œuvre 
une simulation numérique de la cellule solaire CZTS à l'aide du logiciel $S C A P S-1 D$. Après la visualisation expérimentale des couches minces de Czts sur différent substrats conducteur, une modélisation par le logiciel SCAPS-1D du dispositif CZTS cellules solaires a montré que le Mo contact arrière monte les meilleures performances.

Mots-clés : Kestérite CZTS, agents complexant, température de recuit, simulation par SCAPS, contact arrière, électrodéposition. 


\section{RESUMEN (CASTELLANO)}

\section{Elaboración y caracterización por medios electroquímicos de capas delgadas en CZTS para}

aplicación fotovoltaica

El aumento de las necesidades energéticas, particularmente en términos de protección del medio ambiente, ha estimulado en gran medida la investigación en el campo de la conversión fotovoltaica en los últimos años. La radiación solar proporciona un recurso excelente para producir electricidad limpia y sostenible sin contaminación tóxica o calentamiento global, pero en términos de alta demanda de energía eléctrica, así como la toxicidad o escasez de componentes que constituyen las células solares, esta tecnología de transformación solar todavía es algo limitada. En consecuencia estos parámetros constituyen las principales preocupaciones ambientales que rodean a la industria fotovoltaica.

El compuesto $\mathrm{Cu}_{2} \mathrm{ZnSnS}_{4}$ (CZTS) puede considerarse como uno de los materiales absorbentes más prometedores para las células solares de película delgada de bajo costo. La abundancia y la no toxicidad de los elementos constitutivos de este prometedor material es el tema de este trabajo. Este objetivo nos ha llevado a pensar en optimizar los parámetros que influyen en la formación de capas delgadas por métodos electroquímicos. La técnica de deposición electroquímica o electrodeposición catódica ofrece una alternativa ventajosa desde un punto de vista económico y especialmente ofrece la posibilidad de utilizar sustratos de gran superficie.

El enfoque inicial fue determinar los parámetros óptimos para el proceso de desarrollo de película delgada cuaternaria de CZTS. La electrodeposición se implementó mediante la técnica de polarización de un electrodo por el método potenciostático, o sea a potencial constante. Debido a que esta técnica se basa en el potencial de deposición de cada sustancia que constituye el baño electrolítico, se ha llevado a cabo un estudio sobre el efecto de los factores de complejidad para acercar estos potenciales de reducción. Una vez fueron depositadas las capas, se continuó con el estudio del proceso de recocido, que es un paso necesario en la formación de capas absorbentes de CZTS bajo la influencia del factor de complejidad, debido a que conviene reducir la temperatura de recocido mientras se intenta conservan las propiedades del material.

Se sintetizaron películas de kesterita de alta calidad con una morfología compacta y una estructura cristalina bien definida a bajas temperaturas usando $\mathrm{Na}_{2} \mathrm{SO}_{4}$ como agente acomplejante. Posteriormente, las películas de kesterita CZTS se prepararon en diferentes sustratos conductores (ITO, FTO y Mo / vidrio) para estudiar el efecto del contacto posterior. 
Comprobamos que el mejor comportamiento se produce para una combinación específica de los parámetros estudiados.

En particular este trabajo nos ha permitido controlar la composición de las películas depositadas, dominar el proceso de recocido y usar las técnicas de caracterización necesarias para evaluar la composicion, calidad y propiedades optoelectrónicas de las capas de CZTS sintetizadas.

Finalmente, nuestra estrategia implementa una simulación digital de la célula solar CZTS utilizando el software SCAPS-1D. Después de la visualización experimental de las capas delgadas de CZTS en diferentes sustratos conductores, el modelado por el software SCAPS1D del dispositivo de células solares CZTS demostró que el contacto trasero Mo ofrece los mejores rendimientos.

Palabras clave: kesterita CZTS, gentes complejantes, temperatura de recocido, simulación SCAPS, contacto posterior, electrodeposición. 


\section{RESUM (VALENCIÀ)}

El-laboració i caracteritzación por mitjans electroquímics de capas primes de CZTS per aplicacions fotovoltaiques

L'augment de les necessitats energètiques, particularment en termes de protecció de l'entorn, ha estimulat en gran mesura la investigació en el camp de la conversió fotovoltaica en els últims anys. La radiació solar proporciona un recurs excel-lent per produir electricitat neta i sostenible sense contaminació tòxica ni escalfament global, però en termes de l'alta demanda d'energia elèctrica, així com la toxicitat o escassetat de components que constitueixen les cèl-lules solars, aquesta tecnologia de transformació solar encara trova barreres limitadores. En conseqüència aquests paràmetres constitueixen les principals preocupacions ambientals que envolten a la indústria fotovoltaica.

El compost $\mathrm{Cu}_{2} \mathrm{ZnSnS}_{4}$ (CZTS) pot considerar-se com un dels materials absorbents més prometedors per a les cèl-lules solars de pel-lícula prima i de baix cost. L'abundància i la no toxicitat dels elements constitutius d'aquest prometedor material és el tema d'aquest treball. Aquest objectiu ens ha portat a treballar en l'optimització dels paràmetres que influeixen en la formació de capes primes de CZTS per mètodes electroquímics. La tècnica de deposició electroquímica o electrodeposició catòdica ofereix una alternativa avantatjosa des d'un punt de vista econòmic i especialment ofereix la possibilitat d'utilitzar substrats de gran superfície.

L'enfocament inicial va ser determinar els paràmetres òptims per al procés de desenvolupament d'una pel-lícula prima quaternària de CZTS. La electrodeposició es va implementar mitjançant la tècnica de polarització d'un elèctrode pel mètode potenciostàtic, o siga a potencial constant. Aquesta tècnica es basa en el potencial de deposició de cada substància que constitueix el bany electrolític es diferent i per tant s'ha dut a terme un estudi sobre l'efecte dels factors de complexitat per tal apropar aquests potencials de reducció de tots els components involucrats. Un cop van ser dipositades les capes, es va continuar amb l'estudi del procés de recuit, que és un pas necessari en la formació de capes absorbents de CZTS sota la influència del factor de complexitat, a causa de la reducció de la temperatura de recuit mentre es conserven les propietats de l'material.

Es van sintetitzar pel-lícules de kesterita d'alta qualitat amb una morfologia compacta i una estructura cristal-lina ben definida a baixes temperatures usant $\mathrm{Na}_{2} \mathrm{SO}_{4}$ com a agent acomplexant. Posteriorment, les pel-lícules de kesterita CZTS es van preparar en diferents substrats conductors (ITO, FTO i Mo / vidre) per estudiar l'efecte del contacte posterior sobre 
les capes fines. Obtinguerem que el millor comportament és una combinació específica dels paràmetres estudiats.

En particular aquest treball ens ha permès controlar la composició de les pel·lícules dipositades, controlar el procés de recuit i usar les tècniques de caracterització necessàries per avaluar la composició, qualitat i propietats optoelectròniques de les capes de CZTS depositades.

Finalment, en la nostra estratègia es va implementar una simulació numérica d'una cèl·lula solar de CZTS utilitzant el programari SCAPS-1D. Després de la visualització experimental de les capes primes de CZTS en diferents substrats conductors, el modelatge pel programari SCAPS-1D del dispositiu fotovoltaic de CZTS va demostrar que el contacte posterior de Mo és el que ofereix el millor rendiment.

Paraules clau: kesterita, CZTS, agents complexants, temperatura de recuit, simulació SCAPS, contacte posterior, electrodeposició. 


\section{Acronyms}

\begin{tabular}{|c|c|}
\hline Symbol & Explanation \\
\hline TWh & Terawatt hours \\
\hline$P V$ & Photovoltaic \\
\hline IEA & International Energy Agency \\
\hline НОМо & Highest Occupied Molecular Orbital \\
\hline LUMO & Lowest Unoccupied Molecular Orbital). \\
\hline QDSSCS & Quantum dot-sensitized solar cells \\
\hline DSSCs & Dye sensitized solar cells \\
\hline oscs & Organic solar cells \\
\hline PSCs & Perovskite solar cells \\
\hline$A r$ & Argon gas \\
\hline $\mathrm{H}_{2} \mathrm{~S}$ & Sulfur powder \\
\hline$X R D$ & $\mathrm{X}$-ray diffraction \\
\hline$E M C C D$ & Electronically enhanced multichannel Charge Coupled Device \\
\hline FESEM & Field emission scanning electron microscopy \\
\hline$S E M$ & Scanning electron microscopy \\
\hline EDS & Energy dispersive spectroscopy \\
\hline AFM & Atomic force microscope \\
\hline$S i$ & Silicon \\
\hline Ge & Germanium \\
\hline$C d$ & Cadmium \\
\hline$T e$ & Tellurium \\
\hline In & Indium \\
\hline Ga & Gallium \\
\hline $\mathrm{Fe}$ & Iron \\
\hline$Z n$ & Zinc \\
\hline$S n$ & Tin \\
\hline Se & Selenium \\
\hline$S$ & Sulfide \\
\hline$a-S i$ & Amorphous silicon \\
\hline CGS & Copper gallium selenide, $\mathrm{CuGaSe}_{2}$ \\
\hline CIGS & Copper indium gallium selenide, $\mathrm{Cu}(\mathrm{In}, \mathrm{Ga}) \mathrm{Se}_{2}$ \\
\hline CZTS & Copper zinc tin sulfide, $\mathrm{Cu}_{2} \mathrm{ZnSnS}_{4}$ \\
\hline CZTSe & Copper zinc tin selenide, $\mathrm{Cu}_{2} \mathrm{ZnSnSe}_{4}$ \\
\hline
\end{tabular}




\begin{tabular}{|c|c|}
\hline CFTS & Copper iron tin sulfide, $\mathrm{Cu}_{2} \mathrm{FeSnS}_{4}$ \\
\hline CFTSe & Copper iron tin selenide, $\mathrm{Cu}_{2} \mathrm{FeSnSe}_{4}$ \\
\hline 1 Sun & Used as a synonym for AM1.5 illumination \\
\hline $\mathrm{ZnO}$ & Zinc Oxide \\
\hline CdS & Cadmium sulfide \\
\hline$E P H$ & Electron hole pair \\
\hline$C-S i$ & Crystalline silicon \\
\hline TCO & Transparent conduction oxide \\
\hline RE & Reference electrode \\
\hline$N R E L$ & National Renewable Energy Laboratory \\
\hline$L_{\text {diff }}$ & Diffusion length \\
\hline $\boldsymbol{k}$ & Boltzmann's constant \\
\hline$T$ & Environment temperature \\
\hline CBO & Conduction band offset \\
\hline$G$ & Recombination rate \\
\hline$R_{s h}$ & Shunt resistance \\
\hline$R_{s}$ & Series resistance \\
\hline EHP & Electron-hole pair \\
\hline$I_{e}$ & Electron current \\
\hline$I_{h}$ & Hole current \\
\hline$l$ & Length of the intrinsic semiconductor \\
\hline$S C A P S$ & Solar Cell Capacitance Simulator \\
\hline AMPS & Analysis of Microelectronics and Photonics Structures \\
\hline AFORS - HET & Automat FOR Simulation of HETero structures \\
\hline$A S A$ & Amorphous Semiconductor Analysis \\
\hline$E B$ & Energy band \\
\hline$E_{f}$ & Fermi energy \\
\hline$V_{t h}$ & Threshold voltage \\
\hline$I_{L}$ & Photocurrent \\
\hline$I_{0}$ & Reverse saturation current of solar cell/ Diode leakage current \\
\hline$I_{D}$ & Diode current \\
\hline$A M$ & Air-mass \\
\hline
\end{tabular}




\section{List of Figures}

\section{Chapter II:}

Figure 2.1: The spectrum of solar radiation 28

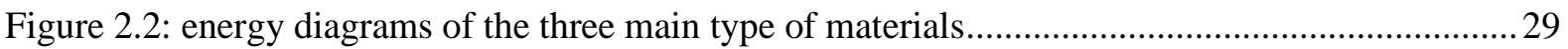

Figure 2.3: Representation of covalent bonds in a silicon crystal lattice............................................. 30

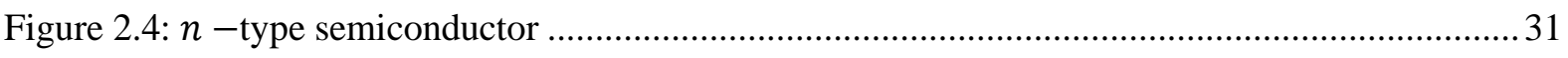

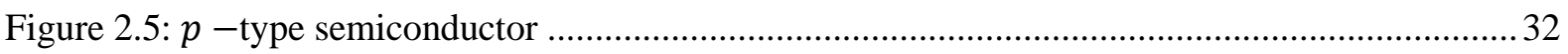

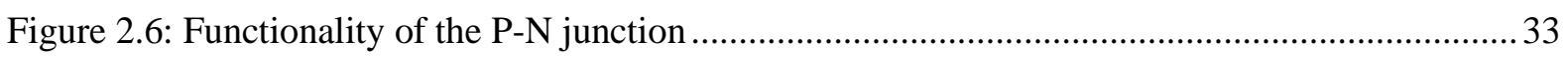

Figure 2.7: Characteristic current voltage (IV) of a solar cell, under dark and illumination ................33

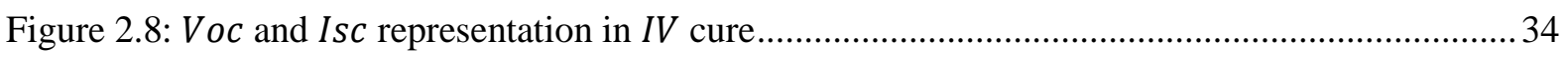

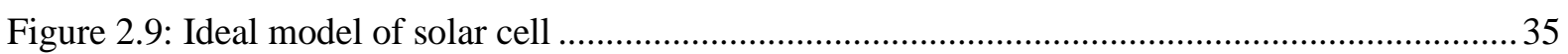

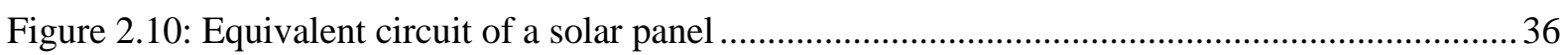

Figure 2.11: Different types of solar cell technologies and current development trends [30] ..............39

Figure 2.12: Content and the world trading price of the elements used in light absorbers $C d T e, C u I n S e 2$ and $\mathrm{Cu} 2 \mathrm{ZnSnS4}$ for thin film solar cells.

Figure 2.13: representative diagram of the different compounds possible by the substitution of the

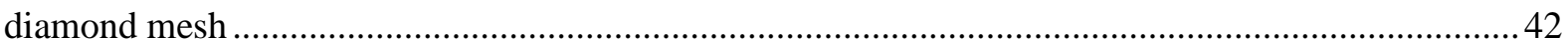

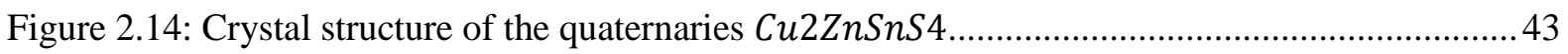

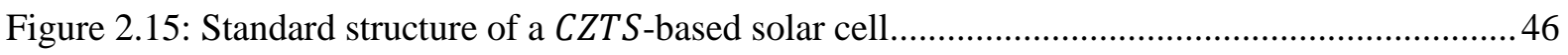

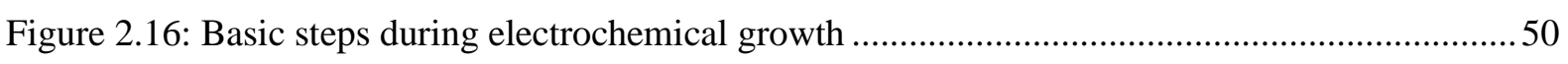

\section{Chapter III:}

Figure 3.1 : Schematic diagram of electrochemical deposition setup .................................................55

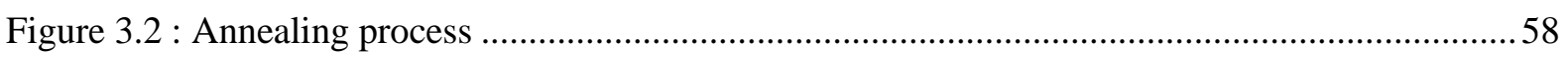

Figure 3.3 : Schematic representation of the interference conditions predicted by Bragg's law. ..........59

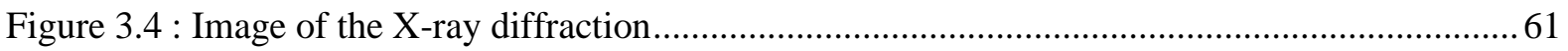

Figure 3.5: Simulated $\mathrm{Cu}-\mathrm{K} \alpha$ X-ray diffraction patterns of kesterite Cu2ZnSnS4, CuSnS3 and

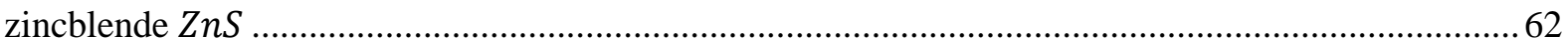

Figure 3.6: Image of the scanning electron microscopy (FESEM) a Zeiss ULTRA 55 .......................63

Figure 3.7: Image of atomic force microscopy Bruker's multimode 8 (AFM) ..................................... 65

Figure 3.8: Schematic representation of the UV-Visible spectrophotometer ........................................66

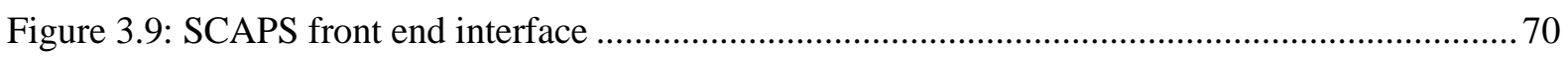

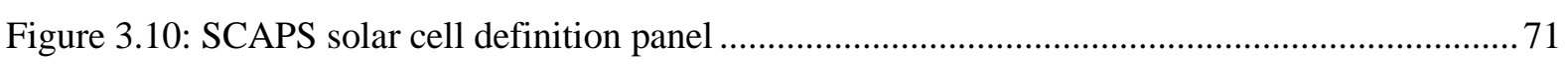

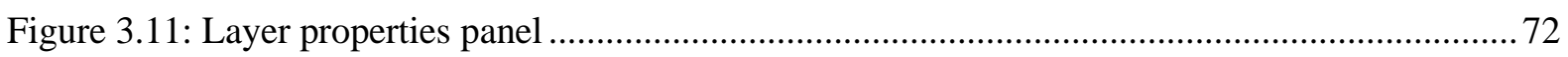

Chapter IV:

Article 1

Figure 1 : Schematic diagram of electrochemical deposition setup .80 
Figure 2: Annealing process

Figure 3 : Cyclic voltammetry curves of the electrolyte containing (a) Solution 1: Trisodium citrate and tartaric acid as complexing agents, (b) Solution 2: Trisodium citrate, tartaric acid, and sodium sulfate as complexing agents.

Figure 4 : X-ray diffraction patterns of CZTS films electrodeposited at different temperature of annealing .84

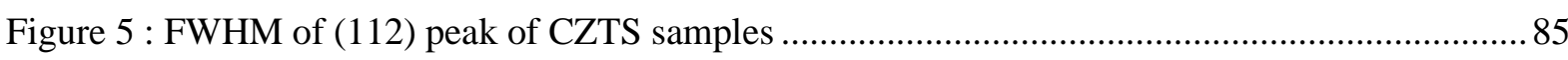

Figure 6 : Raman spectra of CZTS thin films at different annealing temperature ................................ 86

Figure $7:$ SEM surface morphological images of $\boldsymbol{C Z T S}$ films at different annealing temperatures ... 88

Figure 8: Two-dimensional topographical spatial maps of $\boldsymbol{C Z T S}$ thin films.

Figure 9 : Variation of $(\boldsymbol{a h v}) \mathbf{2}$ as a function of photon energy $(\boldsymbol{h v})$ for deposited CZTS films at a different temperature of annealing

Article 2

Figure $1:$ XRD spectra of sulfurized CZTS samples grown at different glass supports . .97

Figure 2 : Raman spectra of CZTS films deposited on diverse substrates.........................................98

Figure 3 : CZTS films SEM images on (A) ITO, (B) FTO and (C) Mo substrates ............................ 99

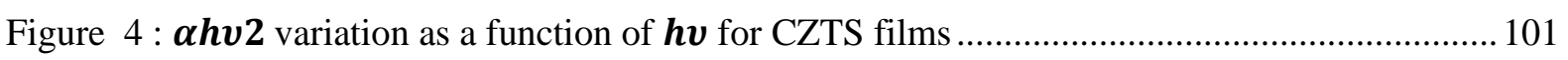

Figure 5 : Different metals and semiconductor Schottky junction and band formation .................... 103

Figure $6: J-V$ characteristics of ITO, FTO, Mo used as back contacts......................................... 104

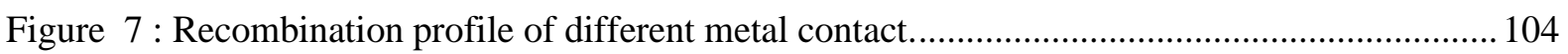

Article 3

Figure 1 : Autolab PGSTAT 302N potentiostatic setup

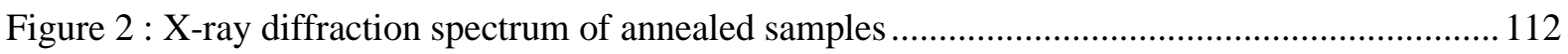

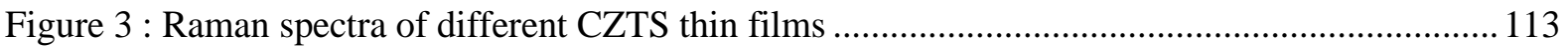

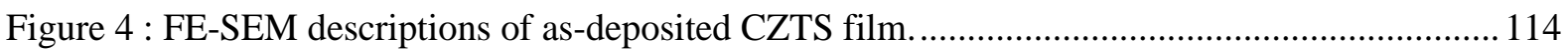

Figure 5 : FE-SEM descriptions of annealed $\boldsymbol{C Z T S}$ film samples with cross-sectional morphology. 116

Figure 6 : EDS spectrum of annealed CZTS kesterite thin films................................................... 116

Figure $7:$ Transmittance spectrum of annealed CZTS kesterite thin films .....................................117

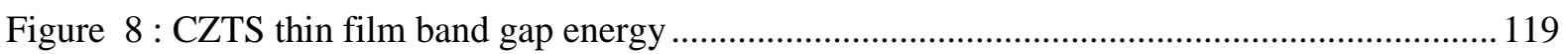




\section{List of Tables}

\section{Chapter II:}

Table 2.1 : The positioning of the atom's constituent the compound CZTS.

Chapter IV:

Article 1

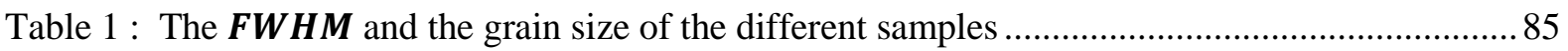

Table 2 : Elemental and composition ratios of prepared CZTS thin films.........................................8 89

Article 2

Table 1 : CZTS films composition deposited on different glass substrates ..................................... 100

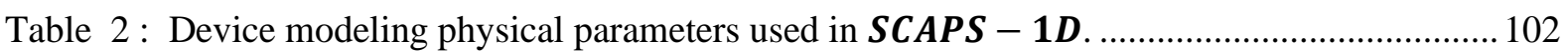

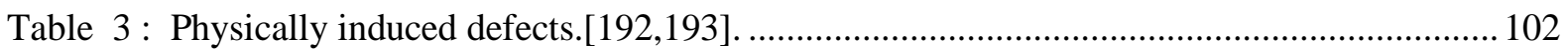

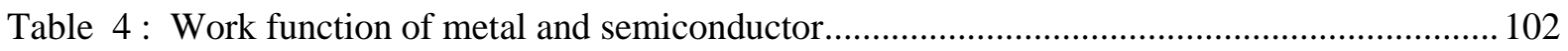

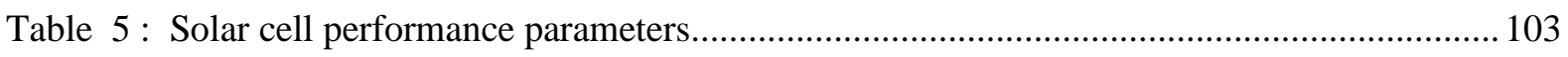

$\underline{\text { Article } 3}$

Table 1: Structural parameters of the different annealed samples ................................................. 112

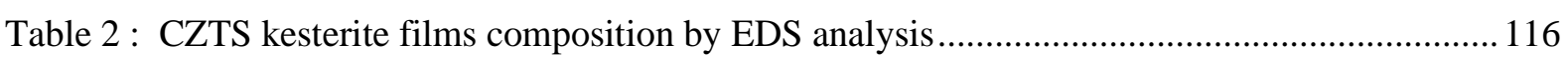

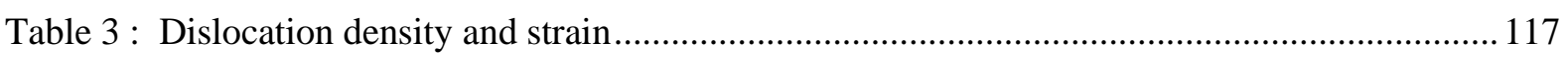

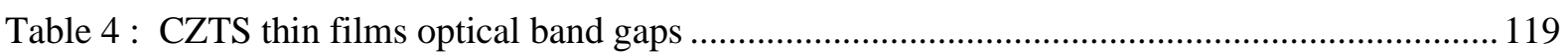


ChaPTER I

Introduction 


\subsection{General Introduction}

The increase in population on a global scale, the economic take-off of the large emerging countries leads to an increase in the need for energy resources. Some of them, non-renewable or highly polluting for the environment, require careful management to guarantee development. Fossil fuels, which will run out in the short or medium term, no longer meet the requirements of sustainable development. In addition, they can produce several environmental problems such as pollution and the production of greenhouse gases. For this reason, the priority should be given to renewable energies. Today requires new resources, other resources available in unlimited quantities that preserve the environment and life.

Given the current climate context, it is desirable that we develop renewable energy sources. Among the various alternatives to fossil fuels, solar power seems to be one of the most promising long-term solutions. In 2018, 26556 terawatt hours (TWh) of electricity were produced worldwide, $26 \%$ of which came from renewable sources. This Figure is expected to increase by $55 \%$ by 2040, according to the International Energy Agency (IEA)[1]. Photovoltaics and wind power represent more than half of this growth. Solar photovoltaics is promised a great future thanks to the expected progress, to lower costs, its simplicity and its versatility. Although capacity additions remained flat in 2018, solar PV generation increased $31 \%$ in 2018, and represented the largest absolute generation growth of all renewable technologies, slightly ahead of wind and hydropower. At a time when the energy transition is more than ever a priority, solar energy has become a solution of choice for producing clean and renewable energy. It is therefore clear that this source, the sun, has enough energy available to meet the annual energy needs of the entire planet if an efficient way to harvest this solar energy can be developed. Indeed, the significant production costs linked to the manufacture of solar cells are one of the major obstacles which contribute to making this energy uncompetitive. In addition, in the event that production costs could be reduced, large-scale production of solar cells will be limited by the scarcity of certain necessary elements such as silicon, indium or cadmium. However, thin film solar cells have been the subject of a great deal of research.

Second generation thin-film technology is developed to increase yields while reducing manufacturing costs. Most materials of this generation are distinguished by a direct gap and a small thickness of a few micrometers $(1$ to $3 \mu \mathrm{m})$ that is sufficient to absorb the useful part of the solar spectrum. Unlike silicon, with an indirect gap and a thickness of the wafer on the order of $150 \mu m$. Even with this remarkable advantage that specifies this generation, the use of 
the materials $\mathrm{Cu}(\mathrm{In}, \mathrm{Ga}) \mathrm{Se}_{2}$, (CIGS) or tellurium of cadmium (CdTe) which dominated mainly thin layers cells could in the future be limited. Firstly, by the rarity and high cost of elements such as indium and tellurium and secondly by the toxicity of Cadmium and Selenium [2]. In this context, it seems wise to develop new materials for photovoltaics panels based on abundant elements. For this purpose, the kesterite materials $C u_{2} \operatorname{ZnSn}(S, S e)_{4}$ have attracted growing interest over the last years, the enthusiasm aroused due to the abundance, low cost as well as the non-toxicity of the chemical elements which constitute it for production of thin-film solar cells. Besides, the CZTS material has excellent physical properties, such as direct band gap energies (ranging from $1.0 \mathrm{eV}$ to $1.5 \mathrm{eV}$ ) and high absorption co-efficient $\left(>104 \mathrm{~cm}^{-1}\right.$ ), which makes it a feasible option for photovoltaic thin film technologies. The best solar cell currently produced using CZTSSe gave a yield of $12.6 \%$ [3]. This result is certainly below the performance of other thin-film cells, but it remains very encouraging when we know that research on this material did not intensify until 2010 after the results obtained by IBM. CZTS is an inherently difficult material to work with due to its complexity. As well as many secondary phases (in particular $\mathrm{Cu}_{2} \mathrm{SnS}_{3}$ and $\mathrm{ZnS}$ ) can coexist in the absence of carefully controlled reaction conditions [4]. These are the main factors that limit the performance of CZTS-based cells. The formation of a pure phase material is difficult because its thermodynamic stability window is quite narrow, in addition, the Sn compounds are volatile and the CZTS decomposes at high temperatures. In our thesis work, we adopted an in-depth study to bring about a reduction in the annealing temperature of the prepared thin layers to avert these limiting factors. At the same time, with a view to reducing the costs of manufacturing while controlling the deposit process, the electrodeposition is proposed as an elaboration method. It can be used as a method of depositing metals, semiconductors and thin films. Compared to other deposition techniques, which employ sophisticated and therefore very expensive experimental devices. The electrodeposition is an inexpensive technique, easy to implement, with the possibility of depositing large areas and the deposition can be made at room temperature which is very important. These characteristics make electroplating one of the most requested methods for developing the different constituent layers of the solar cell.

\subsection{Motivation and objectives}

The strong demand for clean energy directs the world towards solar energy. Clean, inexhaustible and non-polluting energy. In commercial products, semiconductor materials and devices are widely used in various applications and play an important role. These materials 
become the foundation of modern technologies. Due to good performance, low cost manufacturing, reliability and stability of thin films solar cells and with the increase demand for PV devices at low cost with higher energy conversion efficiency drives researchers in the world to explore for thinner, low-cost processing, cheaper materials with more efficient device structures.

- The quaternary CZTS has been of great interest for the manufacture of absorbent thin films for photovoltaic applications due to the abundance as well as the non-toxicity of the elements of composition.

- Elaboration of thin layers by a cheaper and an ease to implement technique what defines the electrochemical technique.

- Optimization of operational parameters for a synthesis of thin layers at low cost while keeping the specific properties of the materials in question.

- The film growth process requires mastery of back contact which influence directly the resulting bulk properties, including the formation of interfacial voids and potentially resistive secondary phases.

With the intention to model these objectives, the thesis was developed according to the structure specified in the following paragraph.

\subsection{Structure of thesis}

The first chapter carries an introduction, in which the framework of this thesis is defined.

In the second chapter, we present a bibliographic study concerning the photovoltaics solar cells and more precisely Kesterite solar cells. Chapter structure will be divided into three main section. As a start, the first part deals with general information on photovoltaics while clarifying the importance of photovoltaic energy in our system. In this context, a brief definition of solar cells, as well as the principle of photovoltaic conversion, will be devoted to finding out the operating principle of photovoltaic devices. Next, an exhibition of the main characteristics of PV cells with electrical modeling will also be explained in detail. Then, an overview of the different generations of solar cells, with an insight into the new challenge for the development of low-cost PV cells are introduced. After that, emphasis will be on Kesterite solar cells. This part exposes a detailed discussion on the CZTS material including the structural, optical and electrical properties, which will be followed by a description of the experimental techniques most requested for the development of this semiconductor. Foremost, the methods usually used 
in the literature were presented and discussed for obtaining thin layers of CZTS. Furthermore, we have chosen to focus on the description of the deposition technique: Electrodeposition, used for the realization of our own samples of CZTS thin films.

Chapter three is largely dedicated to the deposition process used for the development of CZTS thin layers, as well as the techniques for characterizing these layers. In addition, we have a look at the process of simulating these layers by SCAPS. For it, we will end this chapter with an overview of the basics of numerical simulation by SCAPS software for the modeling of a solar cell.

Chapter four constitutes the main body of the thesis. It will be devoted to the articles published in indexed scientific journals. The first article is about the electrodeposition of CZTS thin layers taking into account the effect of complexing agent. The second article stages the different back contact of CZTS thin layers that can be used on electrodeposition. While the third article deals with the effect of annealing temperature on CZTS thin films.

The first article is entitled "Effect of complexing agent on the morphology and annealing temperature of CZTS kesterite thin films by electrochemical deposition" [4], as I am a little bit more chemist than physicist, I insisted to deposited my first article in the journal "Current applied physics" with an impact factor of 2.28. At the beginning I did not intend to look for the best journals with a high impact factor, but rather I was looking for a journal in physics to have the confidence to be able to move forward on this subject. This article is dedicated to the development of CZTS thin layers by the electrochemical experimental technique. The aim has been to decrease the annealing temperature of these thin layers, which requires significant energy. For it, a study on the addition of a complexing agent to the development process was the case.

The second article "Back contact effect on electrodeposited CZTS kesterite thin films experimental and numerical investigation" [5] as title, is published in the Q1 journal "Solar energy" with an impact factor of 4.67. This article combines practical work with the theoretical side. In this context, the study is focused first on the development of CZTS thin layers by the technique of electrodeposition on different conductive substrates. Furthermore, in order to highlight the effect of back contact on the cell device, a simulation of CZTS -based cell with $C d S$ and $\mathrm{ZnO}$ buffer layer and window layer respectively, by means of SCAPS modeling software has been performed. 
The third article presented in this thesis is titled "Single step electrochemical deposition for the fabrication of CZTS kesterite thin films for solar cells" [6]. This article is published in "Applied surface science" $Q 1$ journal, the impact factor of the latter is of the order of 6.18. The development of the CZTS absorbent layer by the electrochemical method accompanied by an examination of the annealing temperature in the presence of sulfur was the objective of this article.

After having detailed in brief the work carried out during this thesis, chapter four reveals a general discussion of the main results of this thesis while recalling the important points of the research. Finally, chapter five presents the general conclusion summarizes all the results obtained, opens up perspectives and presents some proposals for the continuation of our work. 
Chapter II

\section{Theoretical Aspects}




\section{$2.1 \quad$ Introduction}

Nowadays and with the very strong demand for energy, so-called fossil energies (oil, gas, coal) it turns out that can no longer be used. These types of energies are not renewable, they are exploiting with a long process of transformation of organic matter which limits their use. On the one hand, energy resources or reserves are starting to diminish, which has put the price in the last decade in total increase, and on the other hand the release of a large amount of greenhouse gases (mainly carbon dioxide produced by human activity) that contribute significantly to air pollution and global warming.

Otherwise, there is considerable potential for economic, industrial, social and new growth development through renewable energies. Some, such as wind and hydro energy, have been in use for thousands of years, but they are not profitable enough because they do not produce a lot of energy per unit area or on the side of their installation that is not available everywhere. Others, identical to geothermal energy that is not $100 \%$ renewable because it requires electricity and the quite low efficiency of biomass energy, solar energy dazzle the world with yield improvement due to the current technology of thin-film materials, we find solar energy is the most abundant, reachable and truly renewable energy source. The conversion of this energy into electricity is done in a direct way to produce thermal energy by the photothermal effect or electricity by the photovoltaic effect.

This chapter presents the state of the art of solar cells. In this context, we show the importance of solar energy and the operation principle of photovoltaic solar cells. As our work concerns the development of $\mathrm{Cu}_{2} \mathrm{ZnSnS}_{4}$ thin layers by the electrodeposition technique, we are interested to give an overview of the fundamental properties of CZTS compounds. The crystal structure of these compounds as well as the electrical and optical properties and the CZTS based cell, are reviewed. Then, we will end this chapter with a brief description of the techniques and experimental methods most used for the deposition of this material and also some general information on the numerical analysis software used in this study which is SCAPS-1D.

\subsection{General information on photovoltaics}

\subsubsection{Photovoltaic effect (History)}

Solar cell or also called photovoltaic cell is a key device that converts solar radiation into electrical energy according to the photovoltaic effect. This process is manifested when a semiconductor absorbs light. The photovoltaic effect was discovered in 1838 by the French physicist Antoine Henri Becquerel. One year later, the electrical effects across two electrodes 
immersed in a highly conductive solution produced under the influence of solar rays have been presented to the academy of sciences by his son Alexandre-Edmond Becquerel [7]. Later, in 1883 that the first functional solar cell was built by Charles Fritts, but that remained unusable and stilled long in abeyance due to poor performance until the Second World War. In 1954, three American researchers, Chapin, Pearson and Prince working for Bell Laboratories have managed to develop the first solar system made of silicon with an efficiency of $6 \%$. During 1970s, where photovoltaic technology has progressed steadily, the governments and industries start investing in photovoltaic technology, considerable efforts have been made to develop and reduce costs for photovoltaic cells to be used for terrestrial applications [8,9]. The photovoltaic industry has finally taken off to be in permanently progression.

\subsubsection{Preliminary concept of solar radiation}

The combination of several colors different seems as if we see just one white color, and this is the case of sun's light. The sun consists mainly of gas, whose melting continues to produce a phenomenal amount of energy. This energy results in the radiation emission composed of wavelengths, mainly between $0.2 \mu \mathrm{m}$ and $3 \mu \mathrm{m}$. On the surface of the earth, the solar spectrum is no longer the same than in space, because it is weighted by the absorption of molecules present in the atmosphere $\left(\mathrm{O}_{3}, \mathrm{CO}_{2}, \mathrm{H}_{2} \mathrm{O}, \ldots\right)$. Climatic conditions and the presence of particles (aerosols) also influence the actual value of the spectrum. The electromagnetic radiation of infrared, visible and ultraviolet light is the main radiation emitted by sunlight. Although, the solar irradiance is the power received from sun per unit area (watt per square meter, $\mathrm{W} / \mathrm{m}^{2}$ ) it constitutes $99 \%$ of the total incoming power in the soil-atmosphere-ocean system which is estimated at 173 petawatts. Each of the visible and invisible radiations of the solar spectrum has a different energy. Figure 2.1 represents the spectrum of solar radiation.

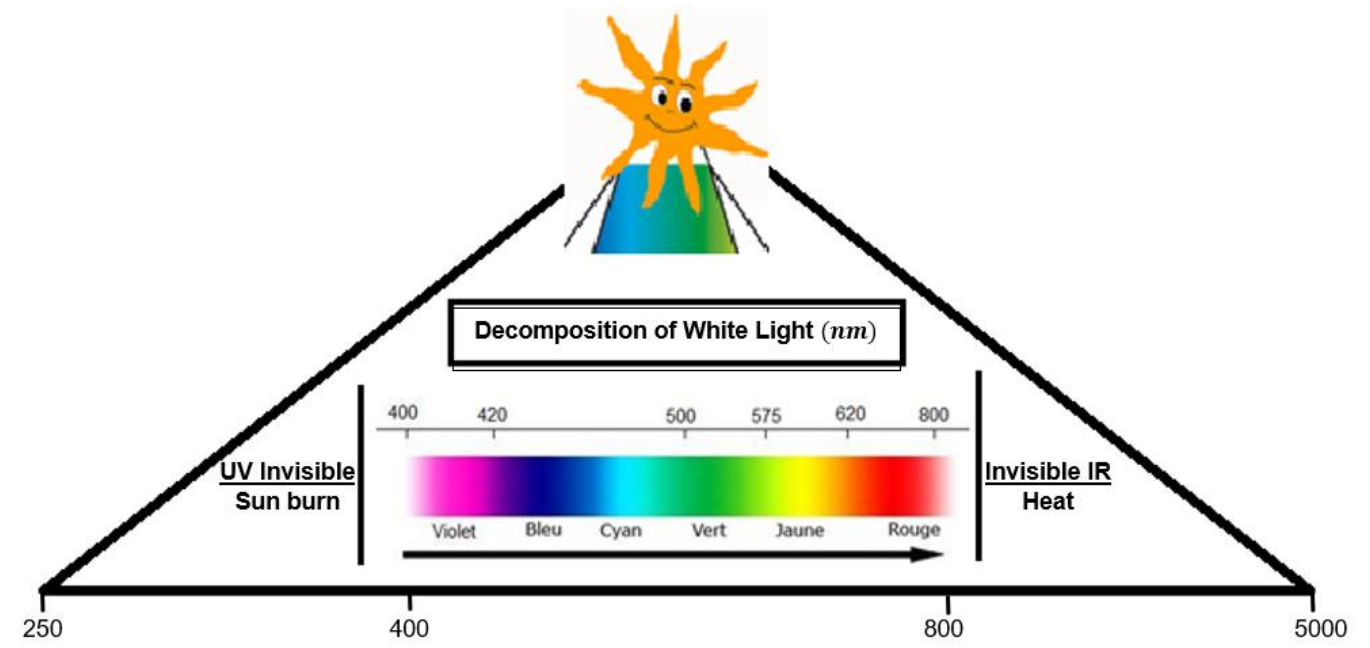

Figure 2.1: The spectrum of solar radiation 


\subsubsection{Basic principle of photovoltaic conversion}

The conversion of sunlight into electricity is performed by semiconductor materials. The easy absorbance of light and the generation of a field and an electric tension give the otherness of these materials. This type of material is distinguished by its electrical properties between the conductor and an insulator. The conductors are the materials that conduct the electric current in a movement of free electrons, and it depends on the nature of the materials and also their size. In terms of energy band, conductors are the materials whose conduction and valence bands overlap. On the contrary, insulators present large gap energy between the valence and conduction band which makes it difficult to move electrons between these two bands and requires enough energy. Insulators are materials that inhibit the flow of electrical current under normal conditions. Therefore, from Figure 2.2 we see that the forbidden band of the semiconductor material is located between the conductor and the insulator. In order to participate in electric current, the electrons constituting the semiconductor need external energy to pass from a valance band to a conduction band. In photovoltaic cell, the semi-conduction materials are doped to form P-N structure as an internal electric field. The p-type (positive) material has the tendency to give up electrons and acquire holes while the n-type (negative) material accepts electrons. Although the electrical properties of semiconductors are strongly dependent upon temperature, the increase in temperature reinforce the conductivity of semiconductor materials unlike metals [10].

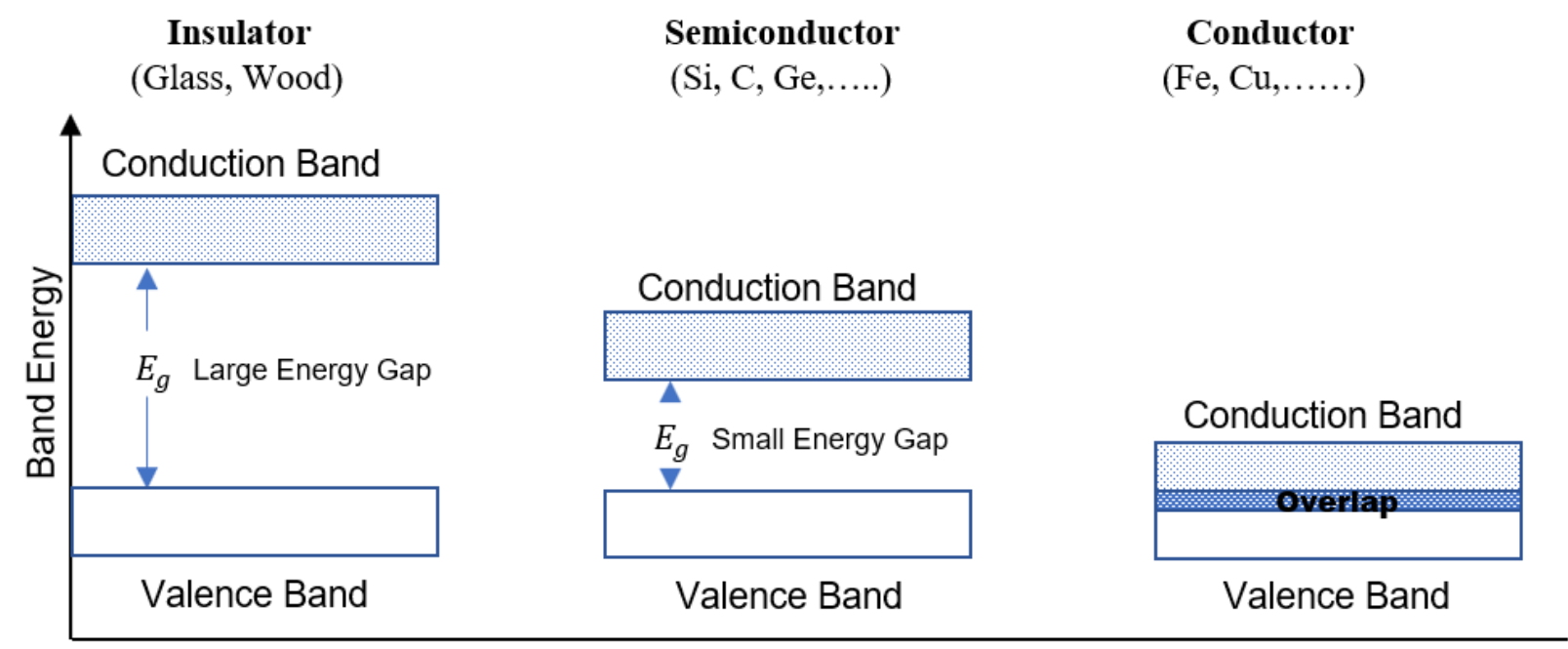

Figure 2.2: energy diagrams of the three main type of materials Additionally, the band gap $(E g)$ of these materials is a few $\mathrm{eV}, \mathrm{Eg}$ represent the energy defined between its valence band (denoted $E v$ ) and its conduction band (denoted $E c$ ).

The energy of photon $\mathrm{E}=h v ; \quad E=h . c / \lambda$

Prohibited bandwidth $E g=E c-E v$. 


\section{i. Silicon solar panels}

Most solar panels are made of silicon ( $\mathrm{Si}$ ). This material belongs to group IVA of the periodic table and consists of fourteen negatively charged electrons surrounding a nucleus of fourteen positively charged protons and fourteen electrically neutral neutrons.

According to the electronic configuration of Silicon $\left(1 s^{2} 2 s^{2} 2 p^{2} 3 s^{2} 3 p^{2}\right)$, only the four exteriors electrons (visualized in the valence layer) have available for the chemical bond.

Silicon: $\left(1 s^{2} 2 s^{2} 2 p^{2} 3 \boldsymbol{s}^{2} \mathbf{3} \boldsymbol{p}^{2}\right)=4$ valence electrons

The atom of Si has 2 electrons in the orbital s and 2 others in the orbital p, thus a rearrangement of the orbitals in order to be able to accommodate in an identical way the atoms is necessary, this recombination is called hybridization $(s p)$.

$$
\text { Valence electrons of silicon: }\left(3 s^{1} 3 p_{x}{ }^{1} 3 p_{y}{ }^{1} 3 p_{z}{ }^{1}\right)
$$

The formation of covalent bonds between two Si atoms, where the electrons are shared equally by the atoms involved is susceptible to form a silicon crystal.
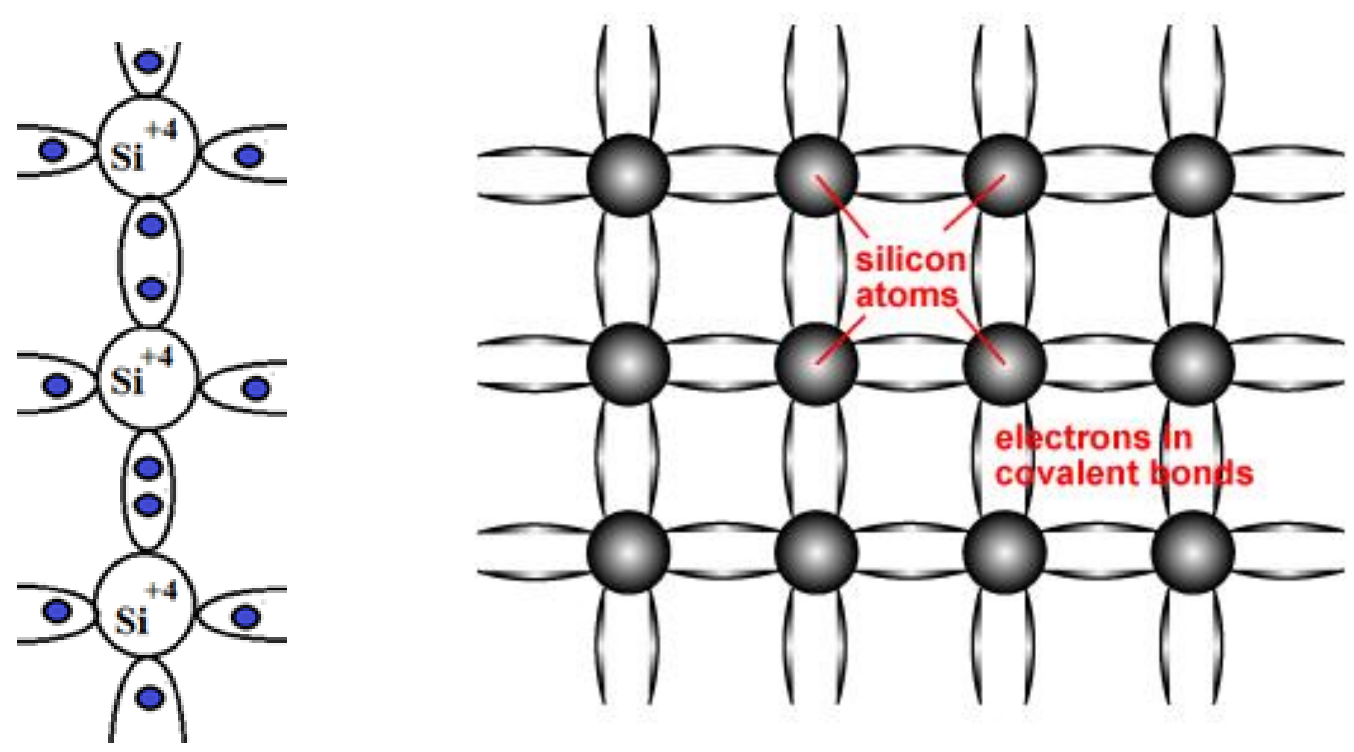

Figure 2.3: Representation of covalent bonds in a silicon crystal lattice.

At temperature conditions close to absolute zero, the electrons remain in their bonding positions and the silicon crystal behaves like a real electrical insulator. For a photovoltaic application comes the need for doping of this material to make it more active. In silicon, the energy of the covalent bond is of the order of 1.1 electron volts which correspond to that of a photon in the near infrared of the electromagnetic spectrum.

\section{ii. Pentavalent doped semiconductor (n-type)}

$\mathrm{N}$-type semiconductors are formed by doping pentavalent materials in the structure of pure silicon semiconductors $(\mathrm{Si})$ in order to change the electrical characteristics of the crystal. The next element of silicon in the periodic table is phosphorus; this element presents fifteen 
electrons and fifteen protons whose five electrons in the valence layer. Therefore, the availability of 5 electrons to form chemical bonds gives phosphorus its distinct chemical properties. The pentavalent doping phosphorus atoms share the four valence electrons in covalent bonds with four neighboring silicon atoms. The fifth electron of the phosphorus atom is relatively loosely bound with its parent atom. Thus, at room temperature, the presence of the thermal energy of the crystal is capable of separating these fifth electrons from their parent phosphorus atom and releasing them to move freely around the crystal. These free electrons have no incomplete covalent bond or hole in the crystal which makes them always ready to conduct the current in the semiconductor. Subsequently, the stationary phosphorus atom now exhibits a positive electric charge due to the dissociation of the fifth electron. The said atom gives the semiconductor the name of the n-type or negative-type semiconductor as much as it is doped by the donor impurities.

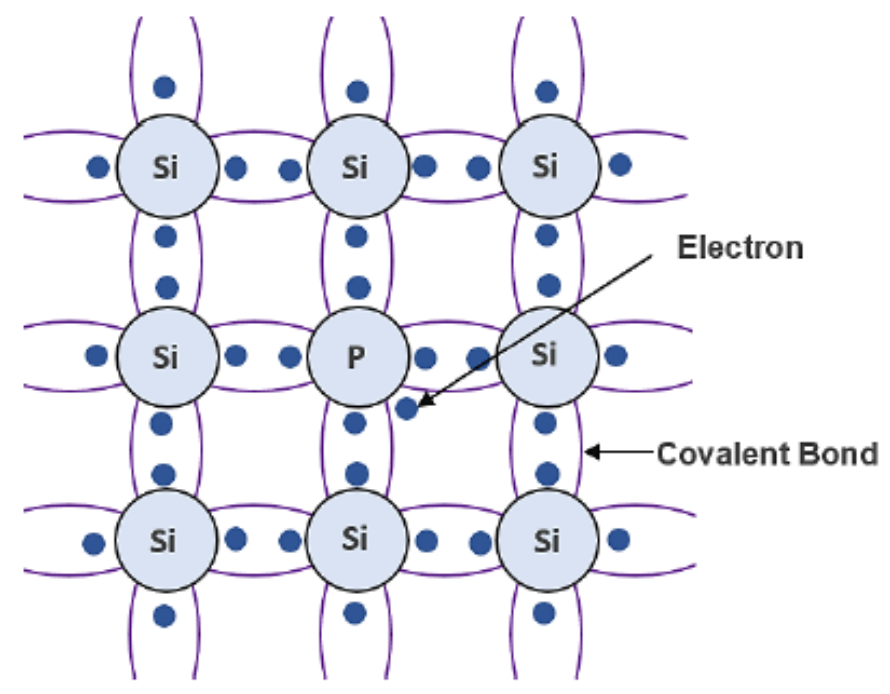

Figure 2.4: $n$-type semiconductor

\section{iii. Trivalent doped semiconductor (p-type)}

The opposite type (p-type) of semiconductor can be created by doping trivalent impurity atoms such as boron $(B)$. In this case, some atoms in the pure silicon structure will be replaced by the boron atom that is to say substitution with boron. Boron with five protons and five electrons including three electrons in the valence layer, it can form only three covalent bonds. In another meaning, to create three complete covalent bonds the association of three valence atoms of a boron atom is done with a valence electron of three neighboring silicon atoms. This implies that there will be one silicon atom for each boron atom where the fourth valence electron remains unpaired. Therefore, this incomplete bond generates the formation of a hole and always attracts the electron to fulfil this lack, implying that the crystal remains unstable, a large number of covalent bonds are continuously broken to complete other incomplete covalent bonds and a 
hole seems to disappear from another neighboring hole. The hole created within the structure behaves like a positive charge and as each of the holes can accept an electron the material obtained is called p-type silicon or positive-type semiconductor.

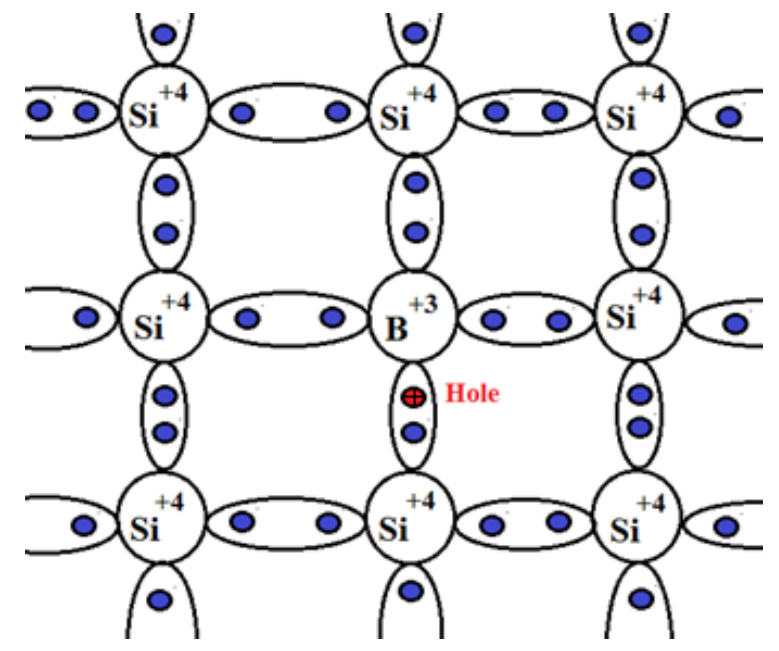

Figure 2.5: $p$-type semiconductor

\section{iv. P-N Junction formation}

The junction $\mathrm{p}-\mathrm{n}$ is formed when the two types of semiconductors with excess of electrons and excess of holes which corresponds to the type $n$ and $p$ respectively are brought into contact with each other. When that is realized, free electrons close to the contact surface of the n-type semiconductor get many adjacent holes of p-type material. Thus, free electrons near its contact surface jump to adjacent holes of p-type material to recombine. This change between electrons hole does not only concern the free electrons but also the electrons in the valence layer. Consequently, after a few moments, there will be the formation of a negative charge layer (excess of electrons) and a positive charge layer (positive ions) in the p-type and n-type semiconductors respectively along the contact surface. Therefore, due to the positive and negative charge layer, there will be an electric field when superimposing P-N doped layers [11]. Photons of solar radiation whose energy is greater than the width of the forbidden band are able to be absorbed. By accepting the energy of the photons, the electrons of the valence band of the semiconductors pass into the conduction band, their absence in the valence band are shaped by a hole and thus create electron-hole pairs. The displacement of the charge carriers towards the zone $\mathrm{n}$ for the electrons and towards the zone $\mathrm{p}$ for the holes is spontaneously creating a depletion zone. The peculiarity of this zone, which neglects the tendency of the electrons to recombine with the holes, obliges the electrons to go through an external circuit to join the holes while the flow of electrons is only possible in one direction and holes in the 
opposite direction to the electrons. This phenomenon generates a continuous electric current called photocurrent [12].

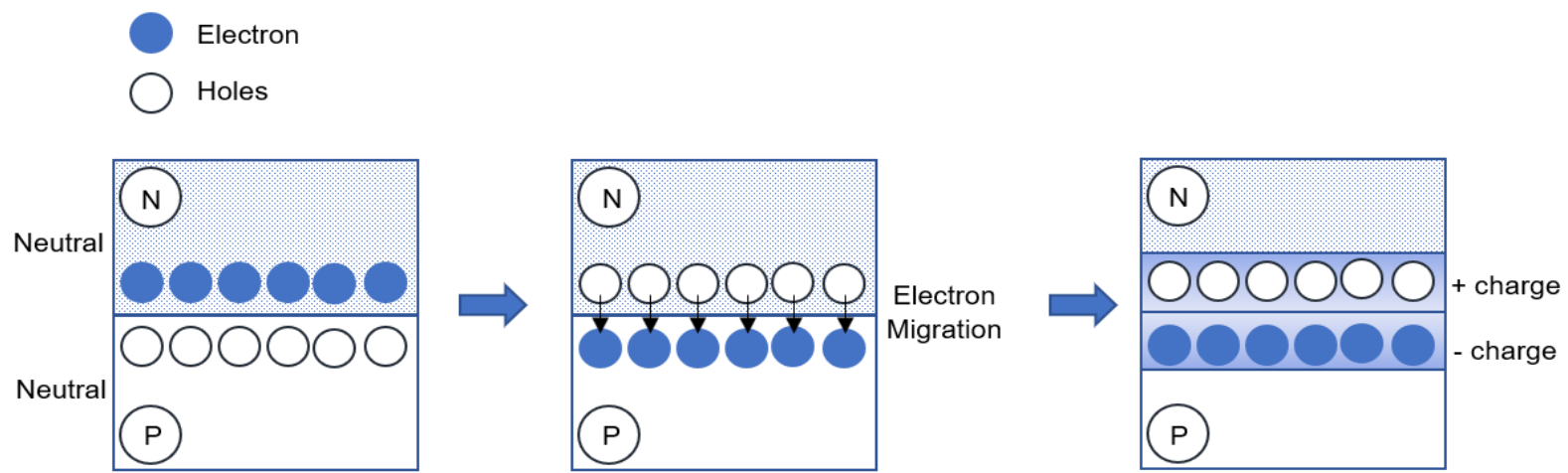

Figure 2.6: Functionality of the P-N junction

\subsubsection{Characterization of photovoltaic cells}

\section{i. Characteristic Current / Voltage}

The electrical power delivered by a photovoltaic cell which thus directly converts a portion of the light energy into electrical energy is the product of the voltage by the current it generates. The operation of solar cells as an electric dipole gives them access to be defined by their own current-voltage graph (curve $I V$ ) it's the variation of the current as a function of the voltage, as well as the superposition of the latter in conditions of darkness and illumination defined the curve $I V$ for photovoltaic device.

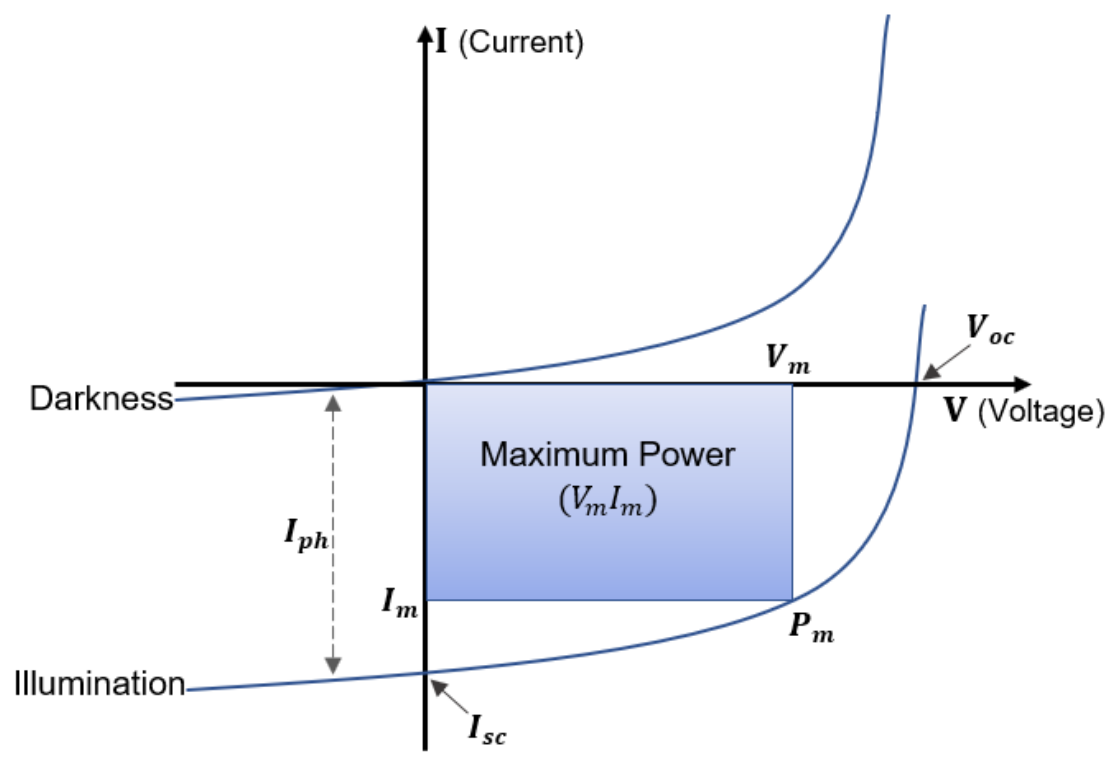

Figure 2.7: Characteristic current voltage (IV) of a solar cell, under dark and illumination

\section{ii. Short circuit current}

This is the current obtained at short-circuit expressed in $m A$, it presents the value of the current which passes through the photovoltaic cell under the light when the voltage at its terminals is 
zero $(V=0)$. So, the electrical power provided by the cell is also zero. The short-circuit current mainly depends on the mobility of the charge carriers and the temperature. Their value increases linearly with the illumination intensity.

\section{iii. Open circuit voltage}

The measured voltage when no current flows in the cell $(I=0)$ determines the open circuit voltage, it is expressed in volts. This voltage depends to the type of solar cell (particularly the p-n junction, the Schottky junction), active layer materials, the HOMO level of the donor (Highest Occupied Molecular Orbital) and the LUMO level of the acceptor (Lowest Unoccupied Molecular Orbital). Additionally, it varies little with intensity light and decreases with temperature [13-15]. The open circuit voltage is defined by equation 2.1 for which the dark diode provides a current equal to the short-circuit current.

$$
\begin{gathered}
V_{c o}=\frac{k T}{q} \ln \left(\frac{I_{c c}}{I_{0}}+1\right) \\
I_{0}=\text { diode saturation current }
\end{gathered}
$$

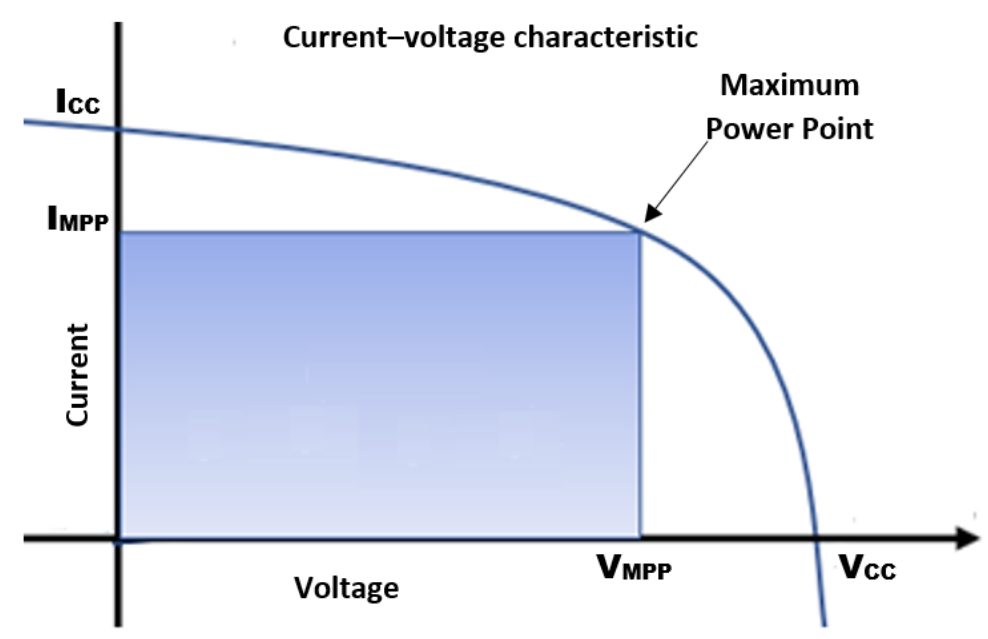

Figure 2.8: $V_{o c}$ and $I_{S C}$ representation in $I V$ cure

\section{iv. Fill factor $\mathbf{F F}$}

The current-voltage characteristic of a photovoltaic cell highlights a Maximum Power Point MPP, which defines the product of the maximum voltage $V_{\max }$ and the maximum current $I_{\max }$ delivered by the photovoltaic cell. The ratio of the maximum power $P_{\text {max }}$ to the product opencircuit voltage and short-circuit current set the form factor $[15,16]$. Noting that this parameter qualifies the quality of the PV cell, so the efficiency of the solar cell is obtained as follows:

$$
F F=\frac{P_{\text {max }}}{V_{o c} I_{s c}}=V_{\text {max }} \cdot \frac{I_{\text {max }}}{V_{o c} I_{s c}}
$$




\section{v. Energy conversion efficiency}

The energy conversion efficiency is defined by the ratio between the maximum power delivered by the cell $\left(P_{\max }\right)$, and the incident light power $\left(P_{\text {in }}\right) \cdot[17]$

$$
\eta_{M}=\frac{P_{\text {max }}}{P_{\text {in }}}=\frac{I_{M} \cdot V_{M}}{P_{o}}=F F \cdot \frac{I_{c c} \cdot V_{c o}}{P_{o}}
$$

\section{vi. External quantum efficiency}

The external quantum efficiency EQE or Incident Photon to Current conversion Efficiency IPCE is introduced to detail the characteristics of the form factor and the yield as a function of the wavelength. EQE is defined by the ratio of the number of electrons circulating in the external circuit connected to the cell, on the number of photons incident on the surface.

\subsubsection{Electrical modeling of a photovoltaic cell}

The creation of an equivalent model of a solar cell on the electrical plane is useful to understand the behavior of the latter. As mentioned previously, when exposing solar cells to light a photo current proportional to solar radiation is generated, the necessity of recombination of the electrons with the holes reinforces them passing through an external circuit. Then, a photo tension is generated according to the electrons that are delivered under the voltage created in the PN junction. Whilst the product of these two processes is the electrical power. In darkness, the device of solar cell is not active at this time and therefore functions as a diode. So, the ideal model for solar cell consists of a constant current source and a single diode connected in parallel, the configuration is shown in Figure 2.9. The addition of two resistors to this model, one in parallel and the other in series to represent the losses indicate the most popular equivalent circuit to a solar cell $[18,19]$. Figure 2.10 shows the equivalent circuit of solar panel.

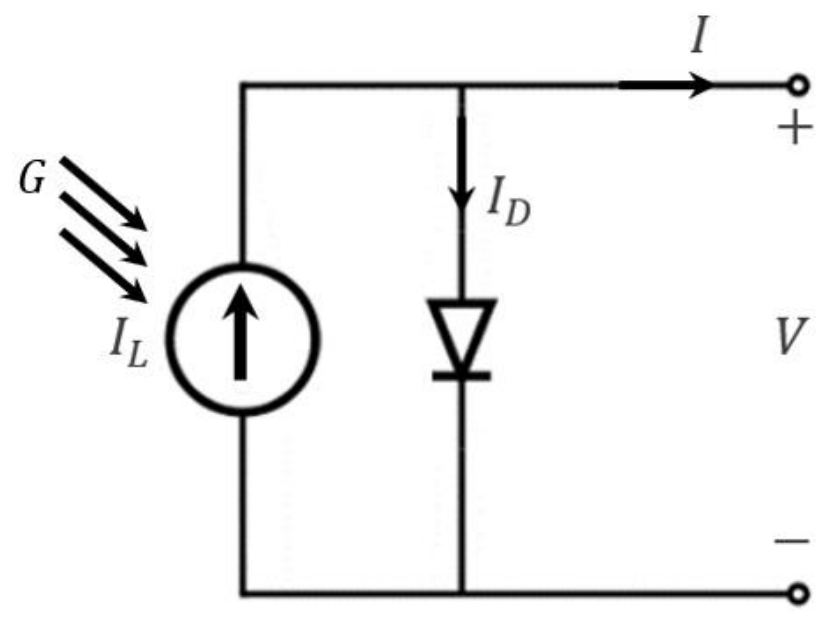

Figure 2.9: Ideal model of solar cell 


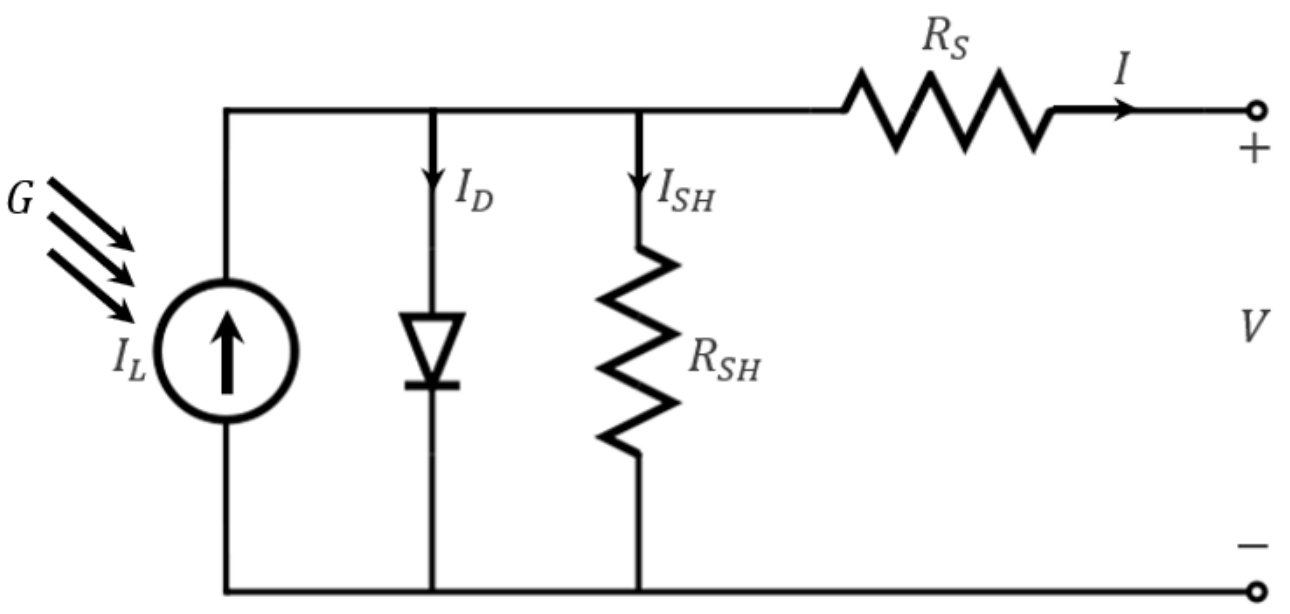

Figure 2.10: Equivalent circuit of a solar panel

At this point, the output current I defined by I-V characteristics in the case of ideal model solar cell is given by this relation.

$$
I=I_{p v}-I_{D}
$$

Where, $I_{p v}$ is the photocurrent delivered by the constant current source, $I_{D}$ is the reverse saturation current corresponding to the diode

Whereas nothing is ideal, so in the case of equivalent circuit of solar panels the integration of the shunt resistance current $\mathrm{I}_{\mathrm{sh}}$ becomes necessary.

Thus, the output current of the solar panel will be the difference of the current.

$$
I=I_{p v}-I_{D}-I_{S H}
$$

According to Shockley equation and Ohm's law, the current diverted through the diode and the current derived through the shunt resistor will be respectively given by the following equations:

$$
\begin{gathered}
I_{D}=I_{0}\left[\exp \left(\frac{q V}{m k T}\right)-1\right] \\
I_{S H}=\frac{V}{R_{S H}}
\end{gathered}
$$

Where, $I_{0}$ is the diode reverse bias saturation current, $q$ is the electron charge, $K$ is the Boltzmann's constant (1.381 10-23 Joules/Kelvin), $\mathrm{T}$ the cell temperature, $\mathrm{m}$ is the diode ideality factor, $V$ is the voltage across the parallel resistor and $R_{S H}$ is the shunt resistor.

Therefore, the output current $I$ for the equivalent circuit of solar panel will be done by the equation follow

$$
I=I_{p v}-I_{0}\left[\exp \left(\frac{q\left(V_{a}+I R_{S}\right)}{m k T}\right)-1\right]-\frac{V_{a}+I R_{S}}{R_{S H}}
$$


Whilst that the voltage $V$ across the parallel resistor and the diode covers the voltage across the output $V_{a}$ and the voltage across the series resistor $I R_{S}$

\subsubsection{Generation / Materials for photovoltaic conversion}

The necessary energy to produce of solar cells is important, while the energy produced by the panel during the entire period of its operation largely reimburses this energy. To collect this energy we estimate an operation of 2 or 3 years depending on the technology of manufacturing with an expected service life of 30 years. Solar cells are generally classified into three generations as a function of time and the categories of materials used in their manufacture [20].

\section{i. First generation}

The first generation of solar cells is known by silicon. They present the earliest and the most common solar cells marketed about $80 \%$ of the solar panels. This success is due to the abundance of the silicon element that comes right behind the presence of oxygen and the mastering of the process of fabrication. The classification of silicon solar cells depends on the manufacturing method of platelets (Wafers). There are two distinct categories; during the cooling of the molten silicon; the formation of a single large crystal or of several crystals defines the monocrystalline or polycrystalline silicon respectively. Monocrystalline cells consisting of very pure crystals are obtained by strict and progressive control of the silicon cooling system. These cells are known by their best performance due to the excellent crystalline and electronic qualities [21,22]. Furthermore, the lifetimes of these devices are quite important and can reach 30 years, which softens their high cost. On the other side, the high manufacturing cost and sometimes the limit of availability of these cells directs the research towards a more simplified method of crystallogenesis. The cooling of molten silicon in flat-bottom parallelepiped crucibles produces polycrystalline cells whose crystals are oriented irregularly. These types of cells are the most used because of the performance / price ratio more interesting.

\section{ii. Second generation}

However, with a view to reducing manufacturing costs, reducing thickness, as well as using high materials, a new generation of photovoltaic solar cells has emerged. A second generation that makes it easy for manufacturers to create very flexible, light and easy-to-install photovoltaic panels. Amorphous and nanocrystal silicon ( $a-S i$ and $n c-S i$ ) based thin films solar cells, Cadmium Telluride/Cadmium Sulfide (CdTe/CdS) solar cells, Copper-IndiumSelenide (CIS) and Copper-Indium-Gallium-Diselenide (CIGS) solar cells representing this generation [23,24]. The second generation of solar panels is specified by possibility to be 
growth on flexible substrates and on large area. Though, wafer based solar cell cannot be produced on its dimensions. Furthermore, their costs are also less, and they present an aesthetic visual than the first generation. For this category of solar cells, CIGS present the highest efficiencies of thin film cells at $21.6 \%$ followed by $C d T e$ cells by an efficiency of $21.4 \%$ a and the a-Si as last ranking. As much as these materials were introduced as a response to high material usage and cost of silicon solar cell, their use presents some drawbacks such as the environment contamination, rarity, toxicity and the high cost of some components (essentially Indium and Cadmium) [25]. In addition, the performances of these solar cells remain lower than those of the first generation.

\section{iii. Third generation}

Along with these two generations, there are promising new technologies that most of the cells are not yet commercially proven it is the 3rd generation of solar cells. Research today tends towards the easiest process of fabrication with a low temperature technology. This generation of solar cells is intended to solve the disadvantages of the other two first. It consists of looking for a high efficiency and low cost. The third generation solar cells includes four types, the organic solar cells, quantum dot-sensitized solar cells (QDSSCS), dye sensitized solar cells (DSSCs) and hybrid perovskite solar cells [26]. These last two types have been made an excellent progress in these last years. In the first case, the organic solar cells (OSCS) used usually a polymer as a semi-conductor. This solar cells (OSCS) is distinguished by the thin thickness (around 100-200nm), the partial transparency of the photoactive layer and the flexibility of the active layer which makes them ideal to be applied on flexible devices [27]. For the ( $Q D S S C S)$ or super lattice technologies, the mastery of the area where sunshine is very important and focusing the concentrated light on the cell gives the susceptibility to be used in concentrated PV technologies. The (DSSCs), presents a good plasticity, transparency and a sample fabrication procedure. The gaps that the loss of electrons must be controlled during the excitation state and draw an appropriate architecture to maximize photon absorption for high efficiency graphene- $\mathrm{TiO}_{2}$ nanocomposites [28]. Besides, recent research focuses on the new technology, perovskite solar cells (PSCs). Detailing the material development, the organic inorganic (PSCs) achieve remarkable efficiency in small period. Nowadays, the applications are starting to make their way out of research laboratories into the real world working on device stability and reliability. Oxford PV and The U.K. renewables technology developer released a certified power conversion efficiency of $28.0 \%$ been generated by a monolithic solar cell in tandem perovskite / silicon [29]. 
These three generations are gathered in Figure 2.11 which presents the different types of solar cell technologies

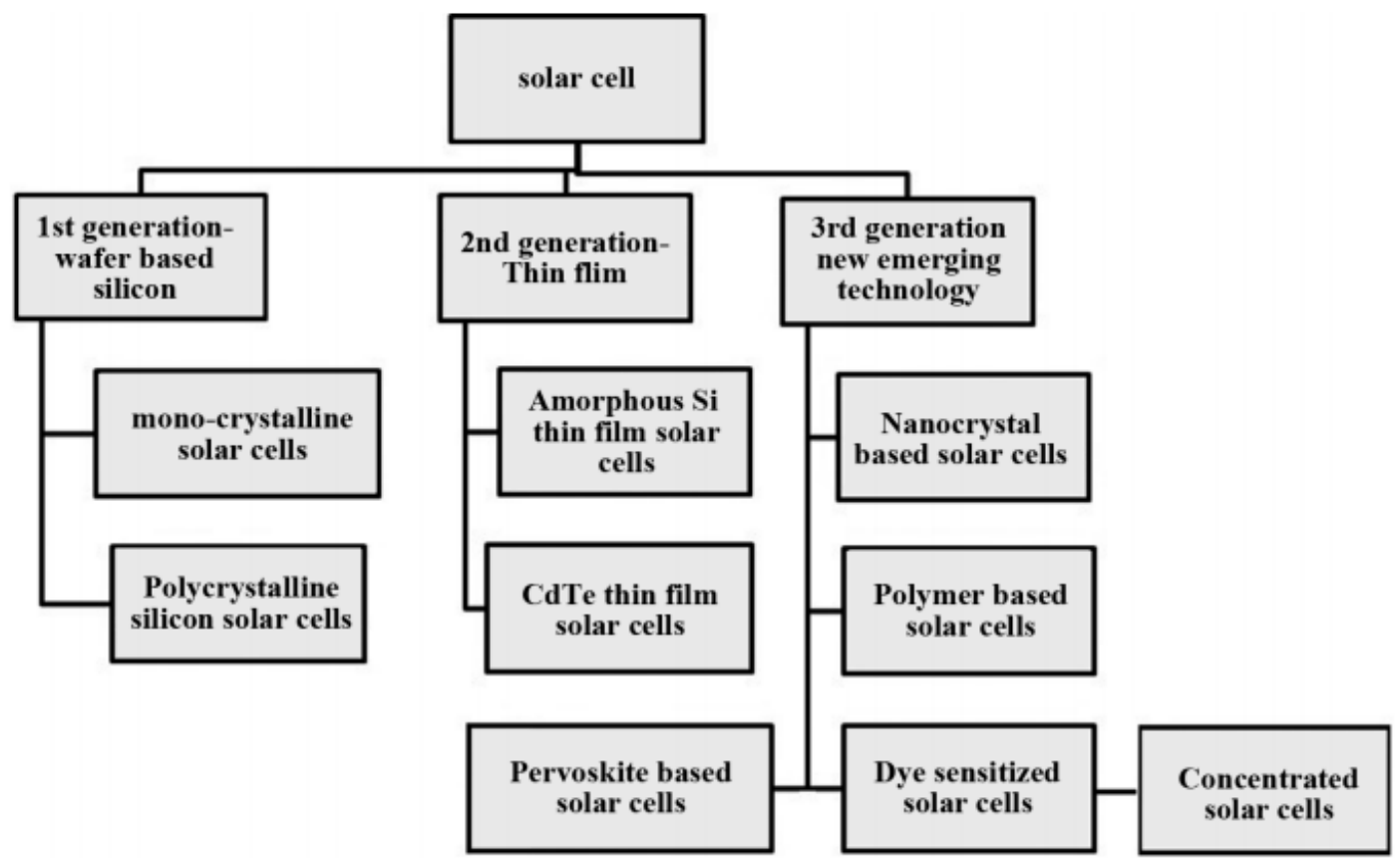

Figure 2.11: Different types of solar cell technologies and current development trends [30]

\subsubsection{Importance and benefits of solar photovoltaic energy}

Far from the burning of fossil fuels and gas emissions appears solar radiation continuously. The sun produces much more energy than we can consume, the number is 10,000 times global energy consumption. Solar energy presents a lot of advantages:

i. It is a clean energy; it does not pose any risk to the environment.

ii. Renewable source available, when we use solar energy to produce electricity we do not deplete or alter the resource.

iii. Solar panels last about 25 years with low maintenance almost negligible and occasional cleaning.

iv. The production of solar cells can be made to any dimension and shapes according to the energy needs.

v. The constituent components of solar cells such as silicon, glass faces and aluminum frames are recyclable, namely recover and reuse.

vi. Electricity production in a direct way due to the photoelectric phenomenon of photovoltaic panels.

vii. Photovoltaic cells do not require any movement, which explains the rarity of breakdowns and wear compared to other systems. 
viii. The solar panels can be fixed on the ground or on the roofs for maximum exposure to the sun without any interference with the residential lifestyle.

The high cost of manufacturing solar panels limits their use for large scale electricity generation. It is therefore useful to think of cheaper processes such as the use of new materials that include organic materials [31].

\subsubsection{Current research: While respecting the environment, the production of energy can be at low cost?}

The weight, the high price and the rigidity of silicon solar cells push researchers to find other solutions for solar radiation absorption. These limiting factors give rise to thin-layer cells, so named because their absorption zone is only a few micrometers thick. The so-called thin-film photovoltaic cells are of great interest given their optoelectrical properties for the absorption of light while it arrives in the second generation of solar cells after silicon. The interest of using much finer absorber materials about 2 microns thick classifies the thin layers in CIGS and CdTe according to the most eminently used materials today. But because of the rarity and the high price of indium (In) and tellurium ( $\mathrm{Te}$ ) elements as well as the toxicity of cadmium, can constitute a brake for this sector. Figure 2.12 illustrate the reserves and the costs of the various constituent elements of the absorber semiconductor materials used in the CIGS, CdTe and CZTS thin-film sectors [32]. On the other hand, the CZTS-based photovoltaic (PV) sector has recently taken a renewed interest [33]. The abundance, the low cost and the non-toxicity of the elements constituting this material are motivating elements making the CZTS compound, a future absorber for the elaboration of solar cells.

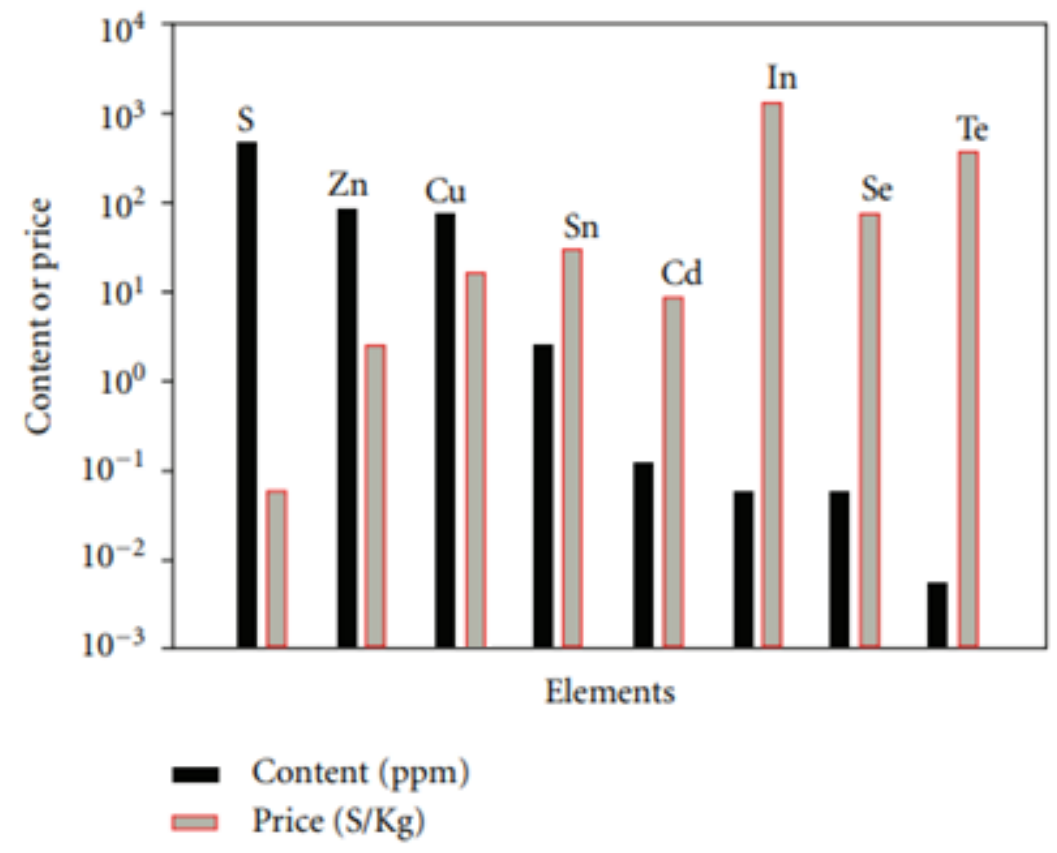


Figure 2.12: Content and the world trading price of the elements used in light absorbers CdTe, CuInSe 2 and $\mathrm{Cu}_{2} \mathrm{ZnSnS}_{4}$ for thin film solar cells .

According to the interest of the development of solar cells at low cost while respecting the environment, we will present in the following part of chapter the fundamental properties of CZTS absorber material, as well as the main production techniques used for its manufacturing.

\subsection{Kesterite Solar Cells}

Photovoltaic conversion requires the use of a photoconductive layer, called absorbent layer, which transforms light radiation into electron-hole pairs. Subsequently, these carriers created are collected by making a junction on the surface of this absorbent layer. The CZTS $\left(\mathrm{Cu}_{2} \mathrm{ZnSnS}_{4}\right)$ active layer is a quaternary semiconductor of $I_{2}-I I-I V-V I_{4}$ type, [34] composed of the metallic elements copper $(\mathrm{Cu})$, zinc $(\mathrm{Zn})$, tin $(S n)$ and sulfur $(S)$ that introduce the advantage of use only non-toxic and abundant materials [35]. These elements are widely present in the earth's crust, especially in comparison to the indium and gallium compounds that form the CIGS. The metallic chalcogenide CZTS is a new type of absorber for thin film solar cells, allowing full registration in a dimension of sustainable technology. CZTSbased technology uses materials that avoid heavy metals and are readily available at a lower cost. Under these materials, the goal is to create the next generation of solar technology that lowers the cost of photovoltaic electricity production.

\subsubsection{Crystal structure of CZTS}

Silicon is part of the 4th column of the periodic table which is generally the simplest semiconductor. This compound has 4 valence electrons, each atom of which is surrounded by four neighbors located in the corners of a regular tetrahedron. This explains why they crystallize in the diamond mesh. This structure forms the source of a family of structures based on the location of atoms on two substructures. Figure 2.13 shows a wide range of structures that can be derived [36].

The quaternary $\mathrm{Cu}_{2} \mathrm{ZnSn}(\mathrm{S}, \mathrm{Se})_{4}$ composites are $\mathrm{I}_{2}-I I-I V-V I_{4}$ semiconductors. They are derived from $\mathrm{CuInSe}_{2}$ (CIS) structure of chalcopyrite by isoelectronic replacement of indium atoms by an equal number of zinc and tin atoms, that is to say, the atom of group $I I I$ is replaced by two atoms of groups $I I$ and $I V$. This last structure is itself derived from the structure of $C d T e$ in which the atoms of group $I I$ are replaced by atoms of group $I$ and $I I I$ which give a structure of the type: $I-I I I-V I_{2}$. According to the symmetry, the CZTS and CZTSe compounds crystallize in two tetragonal structures: kesterite and stannite [37]. Figure 2.14 
illustrates the two crystalline structures where the anions in its two structures follow a compact cubic type arrangement and the cations occupy half of the tetrahedral sites, while the position of the anions can be occupied by sulfur S or Selenium Se according to the desired structure CZTS or CZTSe respectively. Owing to the positioning of atoms we can distinguish between the stannite with the space group I42m and the kesterite structure with I4 as the space group.

The semiconductor family

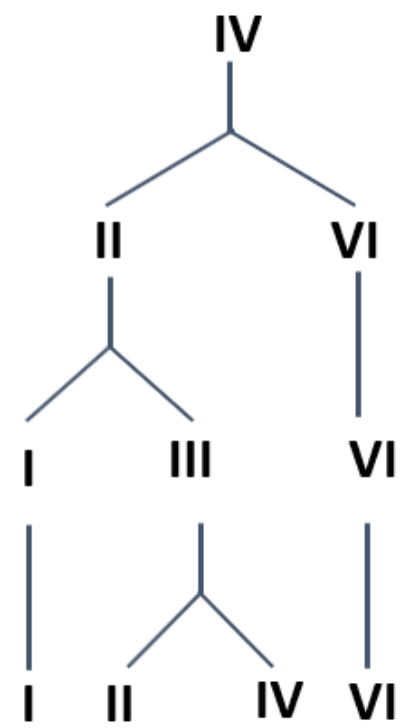

Materials

Si

CdTe, $\mathrm{ZnO}, \ldots$

Culns, CulnSe

$\mathrm{CuZnSnS}_{4}, \mathrm{CuZnSnSe}_{2}, \ldots$

CulnGaS $2, \mathrm{CulnGaSe}_{2}, \ldots$

Figure 2.13: representative diagram of the different compounds possible by the substitution of the diamond mesh 


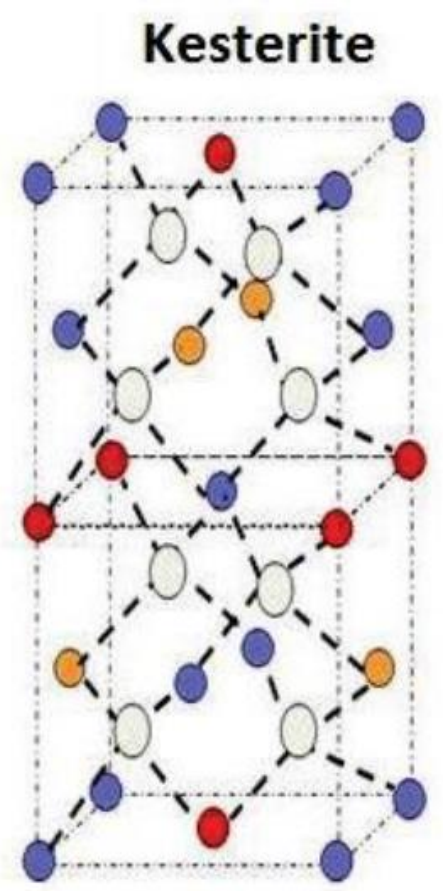

(a)

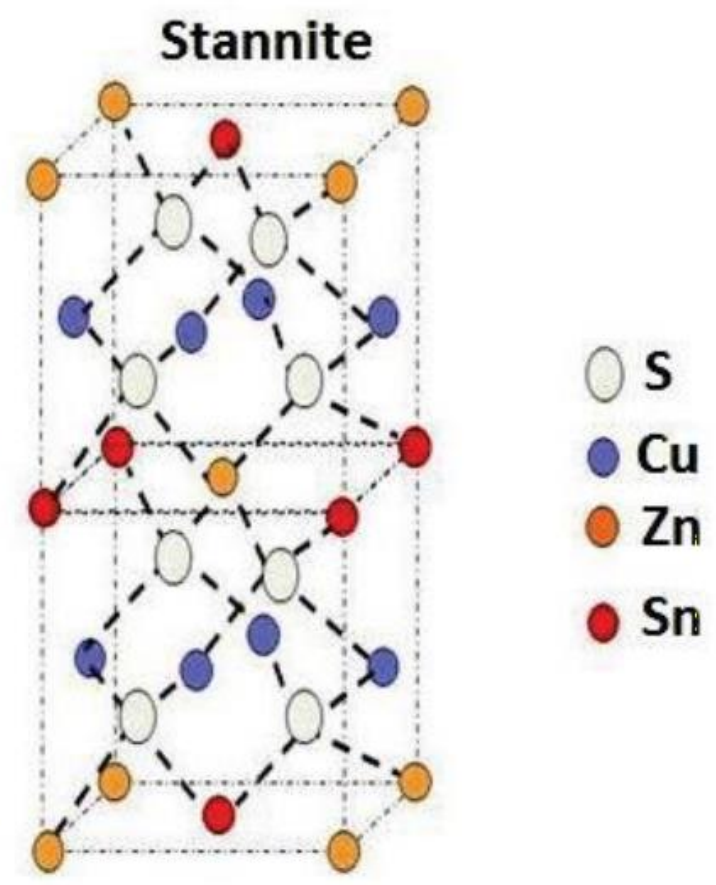

(b)

Figure 2.14: Crystal structure of the quaternaries $\mathrm{Cu}_{2} \mathrm{ZnSnS}_{4}$

The stannite structure differs from the Kësterite only by the positioning of $\mathrm{Cu}^{+}$and $\mathrm{Zn}^{+2}$ ions, as well as the $\mathrm{Sn} 4+$ cations keep the same position in $2 b(0,0,1 / 2)$ in the two structures [38]. Whilst the kesterite structure shows a stack of the type $(-[\mathrm{CuSn}]-[\mathrm{CuZn}]-[\mathrm{CuSn}]-$ $[\mathrm{CuZn}]-)$ allowing the copper atoms to occupy positions $2 a(0,0,0)$ and $2 d(0,1 / 2,3 / 4)$ and at zinc atoms positions $2 c(0,1 / 2,1 / 4)$, the stannite structure has $\mathrm{ZnS}$ and $\mathrm{Cu} 2$ layers which alternate with each other the stannite structure has mutually alternating $\mathrm{ZnS}$ and $\mathrm{Cu} 2$ layers whose copper atoms are positioned in $4 \mathrm{~d}(0,1 / 2,1 / 4)$ and those of Zinc in $2 a(0,0,0)$. The cation stacking sequences on the $\mathrm{c}$ axis differ from these two structures as well as their formation energies differ very little (about $3 \mathrm{meV}$ per atom), so we can have both types of structures in a material. While the kesterite structure has the lowest energy so it would be the most stable [39].

The atoms and their positions for the two structures, kesterite and stannite are respectively presented in the Table 2.1. For the sulfur atom (S) it occupies half of the tetrahedral sites. Their parameters of the conventional mesh are $a=5.44 \AA, c=10.88 \AA$ for kesterite and $a=5.44 \AA$, $c=10.75 \AA$ for stannite $[40]$.

Table 2.1 : The positioning of the atom's constituent the compound CZTS

\begin{tabular}{|c|c|c|c|c|c|}
\hline \multicolumn{3}{|c|}{ Kesterite (I-4) } & \multicolumn{3}{c|}{ Stannite (I-42m) } \\
\hline Atomes & Sites & Positions & Atomes & Sites & Positions \\
\hline
\end{tabular}




\begin{tabular}{|c|c|c|c|c|c|}
\hline $\mathrm{Cu}$ & $2 \mathrm{a}$ & $(0,0,0)$ & $\mathrm{Cu}$ & $4 \mathrm{~d}$ & $(0,0.5,0.25)$ \\
\hline $\mathrm{Cu}$ & $2 \mathrm{c}$ & $(0,0.5,0.25)$ & $\mathrm{Sn}$ & $2 \mathrm{~b}$ & $(0.5,0.5,0)$ \\
\hline $\mathrm{Zn}$ & $2 \mathrm{~d}$ & $(0.5,0,0.25)$ & $\mathrm{Zn}$ & $2 \mathrm{a}$ & $(0,0,0)$ \\
\hline $\mathrm{Sn}$ & $2 \mathrm{~b}$ & $(0.5,0.5,0)$ & $\mathrm{S}$ & $8 \mathrm{i}$ & $(\mathrm{x}, \mathrm{y}, \mathrm{z})$ \\
\hline $\mathrm{S}$ & $8 \mathrm{~g}$ & $(\mathrm{x}, \mathrm{y}, \mathrm{z})$ & & & \\
\hline
\end{tabular}

\subsubsection{Electrical properties}

The electrical behavior of semiconductors is generally modeled, the result characteristics for the movements of charge carriers under the effect of an electric or magnetic field (electrical conductivity, Hall effect, photoconductivity, etc.), designates the main electrical characteristics of this type of material. Generally, the composition of conventional photovoltaic materials, in particular, silicon often proceeds voluntarily to the $\mathrm{n}$ and $\mathrm{p}$ doping of these semiconductors to form the p-n junction. Contrariwise, the semi-conductor CZTS present $p$-type conduction [41]. Its residual doping is intrinsic and inherent in the crystalline defects of the material. The impurities or defects in the crystal lattice cause charge carriers to collide with the ions. While the average free path, which characterizes the average distance traveled by an electron between two successive shocks, is an important parameter specific to the structural state of the material [42]. In multi-component systems the control of doping also affects the concentration of native defects and stoichiometry, inadequate stoichiometry causes secondary phase segregation [43]. More specifically, a low copper rate with an excess of zinc and tin are found to be beneficial for improving electrical performance. Noting that, the resistivity of the films decreases with an increase in the amount of copper in the precursor solution, this implies that films with low resistivity are not suitable for manufacturing solar cells. Whereas, zinc deficiency is favorable for segregation of conductive phases, CuxS and CTS $\left(\mathrm{Cu}_{2} \mathrm{SnS}_{3}\right)$, causing short circuits in the cell $[44,45]$. In fact, the doping of the material CZTS occurs by internal faults; $\mathrm{Cu}$ atoms placed on atoms of $\mathrm{Zn}$ ( $\mathrm{Cu}$ atoms, sitting on the places of $\mathrm{Zn}$ atoms) cause $p$ conductivity [46]. The literature has shown that the composition of the CZTS layers, as well as the techniques for their development, influence the electrical conductivity and carrier mobility values. The large population of intrinsic defects can cause high concentrations of carriers in samples, which leads to a change in conductivity [47].

\subsubsection{Optical properties}

The kesterite compounds meet the main requirements in order to compete with the more established ones thin-film technologies. The principle of the absorption process in semiconductors depends on the energy incident photons and the band structure of the 
compound. The optic absorption threshold is characterized by the minimum energy of the photon which is capable of achieving the transition of an energy electron $E_{1}$ from the valence band towards the conduction band under the existence of an energy level $E_{2}$ such that: $E_{2}-E_{1}=h v$. The valence electrons, the free charge carriers (electrons or holes) and the electrons linked to impurities or to crystal defects can participate in the absorption processes at low energy values, on the other hand the electrons strongly linked to the crystal lattice (deep layer electrons) requires higher values [48].

Many authors have done studies on the optical properties of thin films. The properties of having high optical absorption coefficients $\left(>10^{4} \mathrm{~cm}^{-1}\right)$, allowing to absorb the light with a few microns thin layers, as well as, the direct bandgaps (1.0 eV for CZTSe [49,50], $1.5 \mathrm{eV}$ for CZTS [51-53])close to the ideal value for single-junction solar cells makes CZTS a promising material for photovoltaic applications [54]. The gap energy is determined by several characterization techniques, namely transmission and reflection spectra, electro-reflectance and photoluminescence [55]. The transitions between energy bands can be described by the following relation:

$$
(\alpha h v)=A(h v-E g)^{n}
$$

Where hv is the energy of the incident radiation, $\mathrm{A}$ is a constant and $\mathrm{n}=1 / 2,3 / 2$ or 2 , depending the nature of optical transition: direct transition allowed, direct transition prohibited, and indirect transition allowed respectively.

\subsubsection{Kesterite based cell}

The solar cell device structure consists of a p-type and n-type materials to create the $p-n$ junction, back and front contacts to collect the current.

In its most widespread configuration given in Figure 2.15, CZTS cell is formed by a stack of several thin film materials deposited successively. A substrate generally in a glass covered by a thin layer in Mo or ITO or else FTO. This layer constitutes the rear ohmic contact of the cell, it ensures the adhesion between the active layer of the cell (the absorbent layer) and the substrate. On it, the most important layer in the photovoltaic cell is the absorbent layer, in our case $\mathrm{Cu}_{2} \mathrm{ZnSnS}_{4}$. CZTS absorbent layer (i.e. the area where the hole-electron pairs are generated under illumination) sees its presence. This layer contains an absorbent composed of copper, zinc, tin, and sulfur under p-type doping and with a thickness of a few micrometers. The absorber layer can be grown using vacuum and non-vacuum techniques in one-step or twostep processes [56]. In one-step processes, all elements are incorporated simultaneously, while 
for two-step processes, the elements are first deposited at ambient or near-ambient temperature, followed by an annealing step. This last process allows the use of fast and low-cost techniques for precursor deposition. To form the first part of the $p-n$ heterojunction the absorbent layer must be covered with a material of type $n$. The buffer layer or alternatively the lightly doped $n$ layer is generally formed by cadmium sulfide $(C d S)$ and this one presents the most promising buffer layer for $C Z T S / C d S$ heterojunctions [57]. In this regard, the buffer layer must have a prohibited bandwidth $\left(E_{g}(C d S)>E_{g}(C Z T S)\right.$ and a higher carrier density than the absorber so that the incident photons can reach the absorber and the space charge extends deep into the absorber. Subsequently, there is a window layer known by its transparency to incident radiation which gives it a role quite important role to improve the energy conversion efficiency of solar cells [58]. The window layer itself usually consists of three thin, transparent layers with different electrical/optical properties. Generally, there is first a high intrinsic $\mathrm{ZnO}$ layer of some nanometer non-conductive, to prevent leakage current between the absorbent layer and the upper contact. Then a layer of zinc oxide doped aluminum, conductive and strongly doped $N$ to recover the electrons. Finally, Ohmic contact, such as a $\mathrm{Ni} / \mathrm{Al}$ grid, can be added to collect current more efficiently.

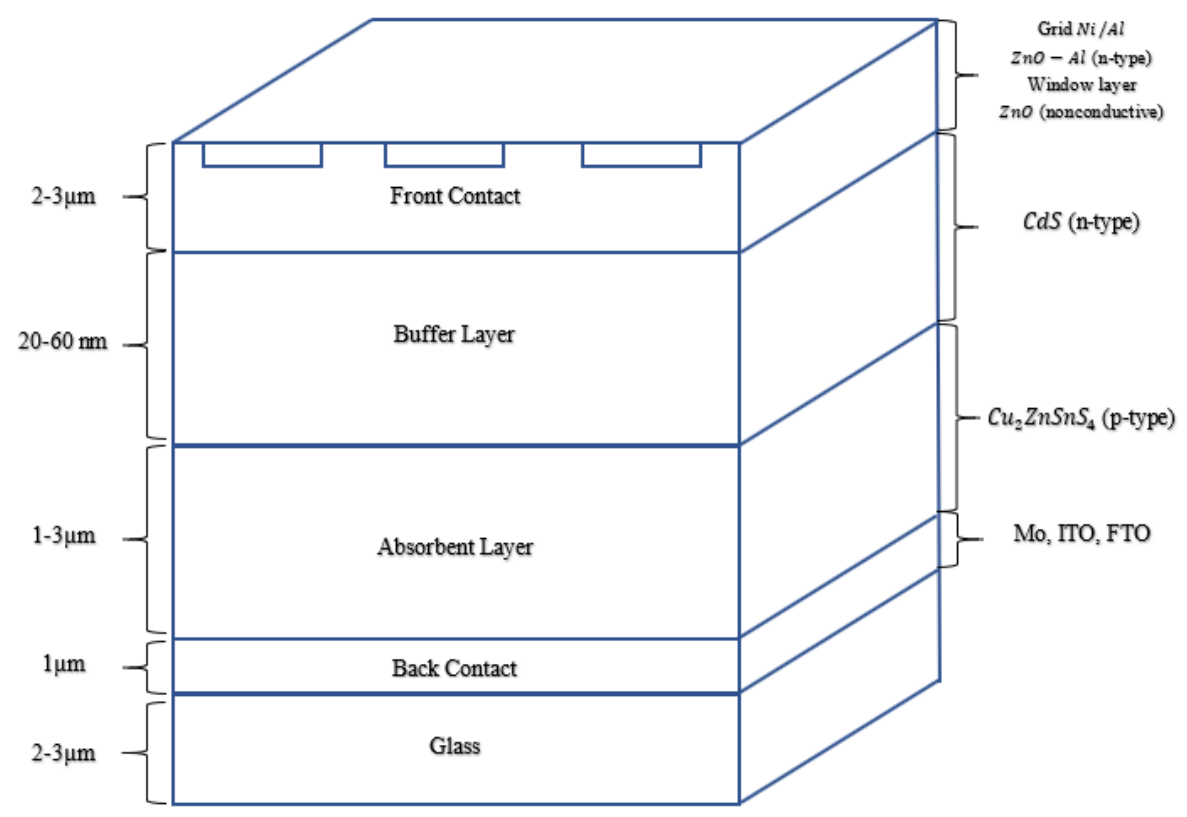

Figure 2.15: Standard structure of a CZTS-based solar cell.

\subsection{Techniques of elaboration}

The choice of a thin layer deposition technique involves several factors such as, the nature of the materials to be deposited, the desired thickness of the deposit, the shape of the substrate, etc. In recent years, dramatic improvements in the performance of kesterite devices have been 
produced by a number of different techniques. As research on kesterite continues, development techniques can be separated into two main categories of techniques, vacuum and non-vacuum deposition methods in one-step or two-step processes. In one-step processes, all elements are incorporated simultaneously, while for two-step processes, the elements are first deposited at ambient or near-ambient temperature, followed by an annealing step. The kesterite can be incorporated into the precursor or during the annealing step.

\subsubsection{Sputtering}

The sputtering is an industry compatible and relatively low-cost vacuum deposition technique. The sputtering technique can be used to deposit CZTS layers on large surfaces with a high deposition rate and reproducibility of the process [59]. Ito and Nakazawa [60] are the first who prepared CZTS thin layers by this method. The basic principle of sputtering is to bombard a target (cathode) using a neutral gas (usually argon) to atomize the atoms constituting the target. These ejected particles are not in their thermodynamic equilibrium state and thus deposit on a substrate placed in the chamber. the presence of the substrate as much as the anode and the target under a voltage of some $K v$ applied between these two terminals, causes an electric discharge in the gas under low pressure (10 to 500 mtorr). The target can be a simple element or a compound. There are different types cathode sputtering systems [61], depending on the mode of plasma creation or the nature of the target (conductive or insulating): direct current diode, direct current triode, or high frequency.

The layers of CZTS prepared by this method exhibited varying resistivity with the deposition parameters such as the potential applied to the substrate, the deposition rate, the argon pressure and frequency. Sputtering deposition of CZTS layer using single-phase CZTS target offers the advantages of uniform composition, smooth surface morphology and relatively simple process [62].

\subsubsection{Pulsed laser deposition (PLD)}

Pulsed laser deposition is a physical deposition technique based on the laser ablation of a target placed in a room with a controlled atmosphere (under ultra-vacuum). The interaction between the laser and the target leads to an ejection of matter formed by the atoms, ions or even by aggregates. This means that, the energy being supplied by the impact of a high intensity laser beam sent to a target made of material that we want to deposit, produces an ablated material which condenses on a substrate placed in front of the target [63]. This technique involves the ablation of a target and allows obtaining crystalline high-quality materials. The laser ablation 
deposition technique has great versatility thus offering the possibility of varying several parameters (substrate temperature, nature and pressure of the gas, total number of laser pulses, ...) to reach the objectives $[64,65]$. The major factor limiting the use of the laser ablation deposition technique for applications industrial is the ejection of microparticles that come from the target when the laser is absorbed under the surface layer.

\subsubsection{Thermal evaporation}

Vacuum evaporation is based on a thermal principle grounded on two elementary processes. First, a heating which allows the material to reach its melting point, then, in a second time, its vaporization point. Then, this first process is followed by the solid-state condensation of the material evaporated on the substrate to be covered. The vaporization of the source material can be generated by Joule effect, by induction or by using an intense and energetic electron beam. As well as the depositions are carried out under high vacuum in order to impart high purity to the layers [66,67]. Thermal evaporation is a particularly popular method but the main weaknesses of this technique are, the need to use sufficient power to vaporize the most refractory compounds, and the deposition of alloys may be disturbed if the different compounds have very different melting temperatures and / or saturation vapor pressures.

\subsubsection{Spray pyrolysis}

Spray pyrolysis is a treatment technique used, in the research, to prepare thin and thick layers, ceramic coatings and even powders. The general principle of spray pyrolysis is based on spraying a solution of different reactive compounds using an atomizer on a heated substrate. A good understanding of the process of, the atomization of the precursor solution, transport and evaporation of droplets, diffusion on the substrate and drying are the key to improving the quality of thin layers [68]. The impact of the droplets on the substrate leads to the formation of a disc-like structure which undergoes thermal decomposition. The formation and size of the disc depends on the volume of the droplet, the temperature of the substrate. However, regulating the temperature of the substrate is important, this allows the activation of the chemical reaction between the compounds. Thus, the type of atomizer can be affected by variations in liquid properties and operating conditions. In particular, air jet, ultrasonic and electrostatic atomizers are the most used in the deposition of thin layers by the pyrolysis spray technique [69]. The first synthesis using this method showed a crystallization of $\mathrm{Cu}_{2} \mathrm{ZnSnS} \mathrm{S}_{4}$ in its stannite form [70]. Then, optimization studies on the deposition time, the nature of the precursors, the temperature of the substrate, etc. Contributed to synthesize the Kesterite phase [71]. 


\subsubsection{Sol-gel depot}

The basic idea of the sol-gel process consists in hydrolyzing a precursor of the solution, by dint of the humidity of the air, in order to obtain a sol (suspension of small macromolecules of size less than $10 \mathrm{~nm}$ ). Thus, the gel (amorphous elastoplastic solid, formed by a cross-linked threedimensional network) is obtained by polymerization of the soil. A thermal pre-treatment for drying at a temperature in the region of $100^{\circ} \mathrm{C}$, followed by thermal annealing at an appropriate temperature, makes it possible to densify this gel, thus leading to a solid material. More specifically, we call the Sol-Gel process, any process which makes it possible to develop a solid, from a solution using a sol or else a gel in the intermediate stage [72]. Among the main factors that control this process, we can cite: the humidity and temperature of the preparation room, the $\mathrm{pH}$ of the solution, the nature of the catalyst and the concentration of the deposition solution [73].

\subsubsection{Spin and Dip coating}

The need for spin-coating and dip-coating deposition techniques is combined to deposit sol-gel films of controlled thickness.

The spin-coating or centrifugation consists in pouring the sol or the gel prepared by the sol-gel method onto a substrate rotated by a spinner. The excess liquid is ejected under the action of centrifugal force, and the thickness of the deposit is then a function of the speed of rotation of the substrate and the deposition time [74]. While, the dip-coating or quenching consists of dipping the substrate in the solution to be deposited and then removing it with a constant speed which conditions the thickness of the deposit $[75,76]$.

\subsubsection{Electrodeposition}

\section{i. Principle}

The techniques which consist in obtaining by electrolytic means, on a surface conductive, one or more metallic coatings, composed of one or more metals fall under the Electrodeposition. The aim is to apply a surface layer on metal to give this surface the various properties desired such as corrosion resistance, optical properties, conductivity, the resistance of contact, hardness, ductility, resistance to wear. In addition, the electrodeposition technique offers some control over the morphology and metal growth phenomena. This technique is used since it is less expensive and can be applied to the manufacture of substrates with complex geometry.

The principle of electrodeposition is exemplified by a redox reaction which is triggered by a current source. For the realization of an electrolytic deposit, the electrode to be covered is 
placed in an electrolysis tank to act as a cathode on which the metal ions are deposited. While the electrolyte or the electrolytic bath which is an ionic conductor that is chosen according to the desired deposit containing the appropriate metal salt.

The metal to be covered or what is called the working electrode is connected to the negative pole of an electricity source. Therefore, under the action of electric current, metal ions $M^{n+}$ positively charged will migrate to the cathode and this can be done by electromigration, convection, diffusion and other forms to get as close to the surface of the cathode for which follow the action of charge transfer to the surface [77]. Then the metal ion is neutralized by the electrons supplied by the cathode and is deposited thereon in the form of metal $M$ according to the reaction.

$$
\begin{aligned}
& O x+n e^{-} \stackrel{1}{\stackrel{2}{\rightleftarrows}} \operatorname{Red} \\
& M^{n+}+n e^{-\frac{1}{\rightleftarrows}} M
\end{aligned}
$$

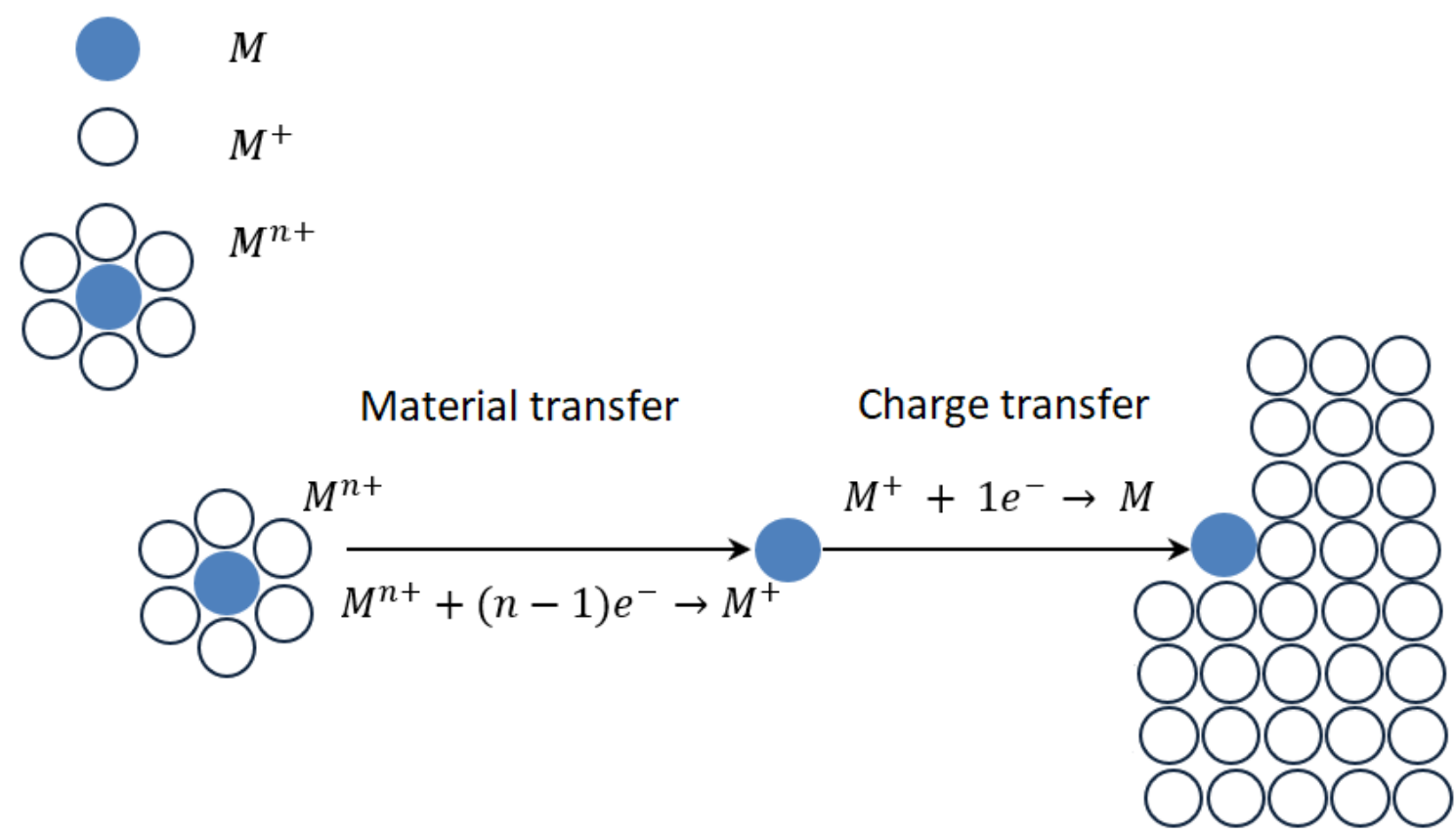

Figure 2.16: Basic steps during electrochemical growth

\section{ii. Thermodynamic aspect}

The reduction reaction (1) can take place when the reduction potential is lower than the reversible potential of the considered reaction. According to the law of Nernst, the equilibrium potential relative of the couple $M^{n+} / M$ is associated by the following equation: 


$$
E_{e q}=E^{0}+\frac{R T}{n F} \cdot \ln \left(\frac{a_{a x}}{a_{r e d}}\right)
$$

Where:

$E^{0}$ : the standard potential of the ox / red couple $(\mathrm{V})$,

$R:$ the ideal gas constant (8.314 J.K-1.mol-1),

$T:$ the temperature at which the reaction takes place $(\mathrm{K})$,

$n$ : the number of electrons involved,

F: The Faraday constant (96,485.338 C / mole of electrons),

$a$ : the activity of the reagent or product ( $a=\gamma *$ concentration $\left[\mathrm{mol} . \mathrm{l}^{-1}\right]$, where $\gamma$ is only very rarely equal to one.

At room temperature $\left(\mathrm{T}=25^{\circ} \mathrm{C}\right), \mathrm{RT} / \mathrm{F}=(8.314 \times 298) / 96485=25.7 \mathrm{mV}$, and after transformation of "ln" into "log", hence a multiplication of the factor RT / F by "ln10", we can rewrite the Nernst equation in the following form, valid at $25^{\circ} \mathrm{C}$ :

$$
E=E^{0}+\frac{0.058}{n} \cdot \log \left(\frac{a_{0 x}}{a_{\text {Red }}}\right)
$$

When the metal electrode is subjected to a potential E different from the potential Eeq, we promote reaction either in direction (1) of reduction, or in direction (2) of oxidation [78]. As well as many electrochemical reactions do not necessarily occur when thermodynamically possible, but require energy additional that we must bring to the system to compensate for the slow charge transfer in order to obtain a given value of the current, this energy is called, overvoltage. This overvoltage is defined as the difference between the potential "E" of the electrode allowing the deposition of the metal and that of Nernst $E_{M n+/ M}$ of the redox couples. This overvoltage is expressed by as follows:

$$
\eta=E-E_{M n+/ M}
$$

\section{iii. Electronic transfer to the semiconductor / electrolyte interface}

Remember that the electronic transfer at the interface of the semiconductors with the electrolyte is only an exchange of electrons between two species, i.e. a deposition-dissolution of a metal on a substrate rendering to the following reduction-oxidation reaction:

$$
M^{n+}+n e^{-\frac{1}{\rightleftarrows}} M
$$


The cathodic current which corresponds to a reduction reaction (1)

$$
I_{c}=I_{0} \exp [((\alpha-1) Z F / R T) \eta]
$$

The anode current which corresponds to an oxidation reaction (2)

$$
I_{a}=I_{0} \exp [((\alpha Z F / R T) \eta]
$$

According to the Butler-Volmer equation, the global current (I) of the reaction is written:

$$
I_{a}=I_{0}[\exp [((\alpha-1) Z F / R T) \eta]-\exp [((\alpha Z F / R T) \eta]]
$$

With:

$\alpha$ : load transfer coefficient.

$\eta$ : is the overvoltage defined by the above equation

$$
\eta=E-E_{M n+/ M}
$$

$I_{0}$ : is the exchange current, it is given by the equation 2.18

$$
\begin{gathered}
I_{0}=Z F\left[M^{n+}\right] K^{0}{ }_{\text {red }} \\
K_{\text {red }}^{0}=K_{0} \exp \left[(-\alpha Z F / R T)\left(E_{M n+/ M}-E_{M n+/ M}^{0}\right)\right]
\end{gathered}
$$

While $K^{0}{ }_{\text {red }}$ is the heterogeneous speed constant for a reduction in equilibrium. The value of the exchange current is essentially linked to that of the speed constant $K_{0}$ therefore to the speed of electronic transfer, but also the concentration of species presents in solution.

At thermodynamic equilibrium, the two reactions take place at the same speed so that the anode (from dissolution) and cathodic (deposition) current are equal to the exchange current $\mathrm{I}_{0}$ and the overall reaction current is zero [79]. Noting that the current cannot pass in particular through the interface electrode / electrolyte only in one direction, if the overvoltage is positive then the current is anodic, and cathodic if the overvoltage is negative. 
Chapter III

Elaboration and Characterization Techniques 
This chapter deals with the deposition process used for the elaboration of CZTS thin layers. Along with characterization and the heat treatment step under argon gas.

\section{1. Phase development}

Atmospheric deposition techniques are advantageous compared to vacuum techniques: the necessary equipment is cheaper; deposits can be made on flexible substrates and with large size while allowing higher production rates. the Electro-deposition process thus has the advantage of being implemented. This process allows the deposition of a layer on a surface by an electrochemical process and involves the exchange of electrons between a solid electrode and ions or molecules in solution.

The electrodeposition of quaternary components is very difficult, because of the difference in the deposition potential of each element. And to deposit these four elements, the individual potentials must generally be brought together. It will be a question of understanding the mechanism of this technique and of optimizing the main parameters making it possible to obtain thin crystallized layers having good morphological and structural properties.

\subsubsection{Experimental setup used}

The electrochemical experiments are carried out on an Autolab Modular Potentiostat/Galvanostat controlled by a computer which records the experimental data. The electrochemical cell is made of PYREX glass with a capacity of $50 \mathrm{ml}$ with three electrodes (Fig 3.1). This cell was provided with a double wall allowing the passage of water to maintain the cell at room temperature even with climate change. Figure 3.1 shows the mounting of the potentiostat apparatus.

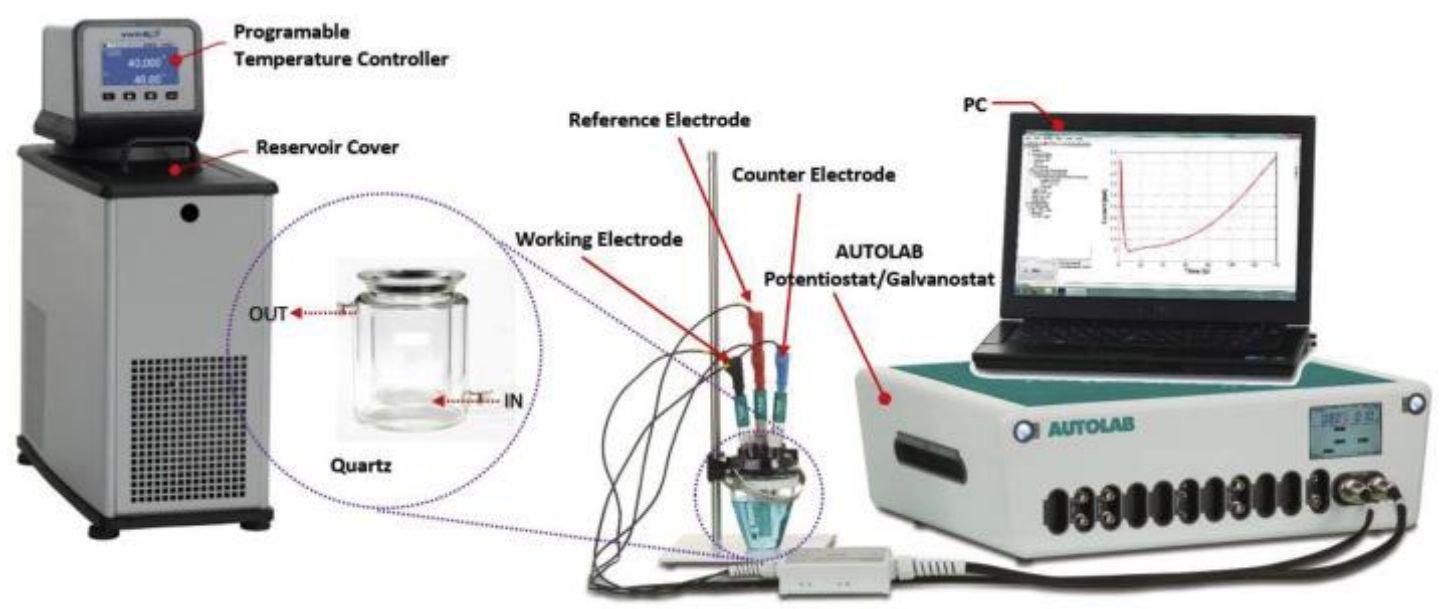

Figure 3.1 : Schematic diagram of electrochemical deposition setup

The electrodeposition is a technique where the deposition can be done at room temperature which is very important. However, there are other parameters that must be controlled. 
i. The potential or the current imposed.

ii. The electrolytic bath (solvent, precursors and concentrations, $\mathrm{pH}, \mathrm{complexing}$ agents).

iii. The nature of the substrate (working electrode) and its surface condition.

Deposits can be made by applying current or voltage pulses. However, as we already mentioned at the beginning that the deposition will be carried out by the potentiostatic mode, because in this case the value of the potential of the imposed electrode is linked to the reactions which are likely to occur. For it, we clench the chronoamperometry which is a method that consists of monitoring the evolution of the current when a voltage is applied to the working electrode. The choice of deposition potentials for the development of metallic layers by chronoamperometry is made from cyclic voltammetry experiments. Whereas, cyclic voltammetry is one of the most effective electrochemical methods for characterizing charge transfer reactions between the electrode and the electrolyte. It is based on the measurement of the current resulting from a linear potential scan. Several consecutive cycles can be executed, each one represented by a plot of the current recorded according to the applied potential, called voltammogram.

In a cell with three electrode, electrochemical deposition of metals is carried out. The electrolytic bath is composed of Copper sulfate (CuSO4), Zinc sulfate ( $\mathrm{ZnSO} 4)$, Stannous sulfate (SnSO4) and Sodium thiosulfate (Na2S2O3), where Trisodium citrate (Na3C6H5O7), Sodium sulfate (Na2SO4) and Tartaric acid (C4H6O6) are added as complexing agents.

\subsubsection{Electrodes}

In order to ensure a chemical reaction of deposition of CZTS absorbent layers, the application of an electric current (used as a driving force) circulating in a conductive liquid (electrolyte) defines the principle of electrodeposition. For these three electrodes used during this work are the following:

\section{i. Reference electrode}

The reference electrode (RE) is Silver/Silver chloride saturated $\mathrm{KCl}(\mathrm{Ag} / \mathrm{AgCl})$. All potential values are measured by compared to a saturated Silver/Silver chloride electrode (DHW). While the standard potential of this reference electrode with respect to the normal hydrogen electrode at $25^{\circ} \mathrm{C}$ is equal to $0.222 \mathrm{~V} / \mathrm{ENH}$. The reference electrode which plays the role of anode in electrochemical cells can maintain a constant potential by changing the experimental conditions. 


\section{ii. Auxiliary electrode}

The counter electrode is a platinum wire. This electrode is used in an electrochemical cell for the purpose of transporting the current passing through the cell while circulating the electrons for the reduction of the compounds present in solution. It is used for a voltammetry analysis.

\section{iii. Working electrode}

The working electrode is typically a cathode where the reduction reaction will take place. In order to ensure conductivity at the electrode level for electrodeposition, Different substrates were used, glasses coated with molybdenum (Mo), indium tin oxide (ITO) and fluorine-doped tin oxide (FTO).

\subsubsection{Surface preparation of substrates}

Substrate surface preparation or cleaning the substrate surfaces could be the most important step in reducing contamination to an acceptable level. It consists of removing all traces of grease and dust, to obtain good adhesion and uniformity of the deposit surface on the support. After cutting the substrates using a diamond-tipped pen, the chemical cleaning process is done according to the following steps:

i. Cleaning the substrates with detergent.

ii. Wash in ethanol at room temperature over $10 \mathrm{~min}$ in an ultrasonic bath to remove traces of grease and impurities stuck to the surface of the substrate.

iii. Rinsing the substrates with acetone also during 10min. The surfaces are often cleaned using an ultrasonic agitator.

Noting that, between each step and another rinsing with deionized water is necessary. Then rinse with distilled water and dry as last step to remove all traces that could affect our electrochemical system.

\section{2. Heat treatments}

The heat treatment is the last step of the electrodeposition approach carried out on samples to obtain well crystallized CZTS thin layers. Figure 3.2 shows the time diagram of heat treatment for CZTS samples. 


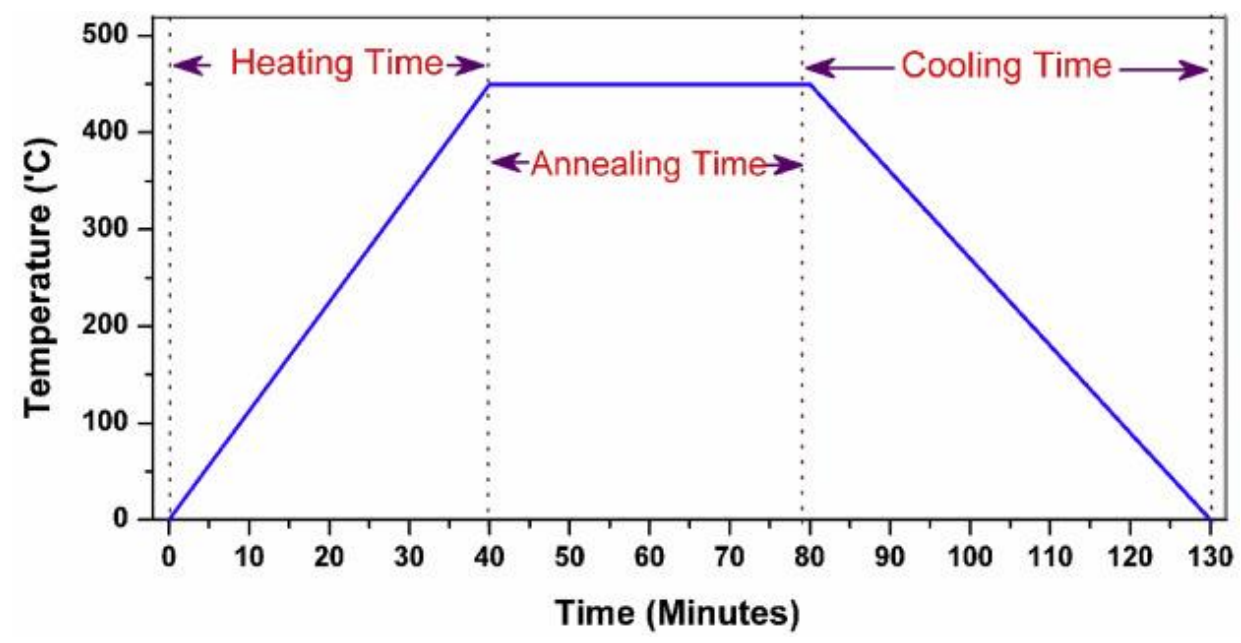

Figure 3.2 : Annealing process

Once dried, the samples deposited by electrodeposition in one step are followed by heat treatment in a tubular furnace under argon gas $(A r)$. Annealing process was conducted at different temperature varying between $350{ }^{\circ} \mathrm{C}$ and $550{ }^{\circ} \mathrm{C}$ in a graphite box with the presence of some milligrams of sulfur powder $\left(H_{2} S\right)$. The duration of annealing procedure gets start during 30 to 45 min owing to sulfurize as-deposited CZTS thin films.

\section{3. Characterization techniques}

A series of structural, morphological, and optical characterization was carried out by various characterization methods in order to extract quantitative or qualitative information about synthesized absorber layer.

\subsubsection{X-ray diffraction}

The X-ray diffraction technique makes it possible to know the state of crystallization of the deposit and to identify the crystallized phases present in a sample in the form of thin layers, massifs or powder. The technique of X-ray diffraction analysis is based on the elastic interaction of a monochromatic beam of $\mathrm{X}$ photons with crystallized matter. The resulting diffraction lead in the obtaining of a diffractometer and allows the determination of the reticular distances of the diffraction planes. The intensity of the beam of rays reflected by the reticular planes first shots of the sample are in phase and give rise to a peak on the recorded diffractometer. 


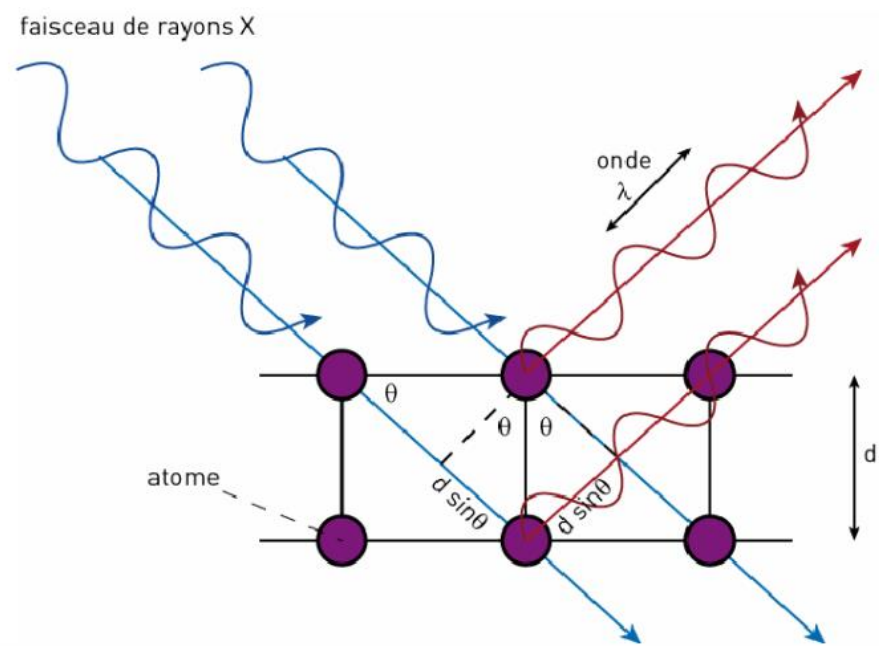

Figure 3.3 : Schematic representation of the interference conditions predicted by Bragg's law.

As shown in Figure 3.3, Bragg's law has shown that there is a simple relationship between the X-ray wavelength, the distance between planes and the diffraction angle.

$$
2 d_{h k l} \sin (\theta)=n \lambda
$$

Where

$d_{h k l}=$ Inter reticular distance separating plans of the same family $(h k l)$.

$\theta=$ The diffraction angles

$n=$ The order of reflection in the family of parallel planes $(h k l)$, positive integer.

$\lambda=$ Radiation wavelength of the incident X-ray beam $(\lambda=1.5418 \AA$ corresponding to the $\mathrm{K} \alpha$ lines of the copper).

The intensity of diffracted radiation and the angular position for which a plane (hkl) checked Bragg's law are revealed by the detector which goes to a computer giving a diffractogram which represents the evolution of the diffracted intensity as a function of the angular position $(2 \theta)$.

The X-ray source consists of a sealed copper anticathode tube $(\lambda=1.5428 \AA)$, coupled to a graphite rear monochromator to filter the $K \beta$ line of copper and possibly the sample fluorescence. The scanning is $20-60^{\circ}(2 \theta)$ and the scanning step is 0.02 . The identification of crystalline compounds is based on the comparison of the experimental values of the reticular distances with the data from the literature. A Rigaku PDXL Software (Integrated X-ray powder diffraction software) makes it possible to study the diffraction spectrum of RX and identify the crystal phases of the sample to be analyzed. For the identification of the phases of the CZTS 
compound, the reference data are taken from JCPD files (26-0575). In Figure 3.4 X-ray diffraction machine is shown.

X-ray diffraction can not only be used to identify the phase crystalline of a material compared to the data by reference category, but also to quantify the size of crystallites and other structural parameters.

In the analysis of a diffraction spectrum, the width of the peaks provides information on the structure of the material studied. We can thus determine the size of the crystallites present in the material. To do this, we must determine the width at mid-height diffraction peaks which is totally related to the size of the crystallites. Debye's Scherrer formula [80] serve for that:

Where:

$$
D=\frac{K \lambda}{\beta \cos \theta}
$$

$D=$ Average size of crystallites (nm),

$K=$ Is the Scherrer constant, which is around 0.9,

$\beta=$ Width at mid-height of the diffraction peak considered,

$\theta=$ Angular position (Bragg angle). 


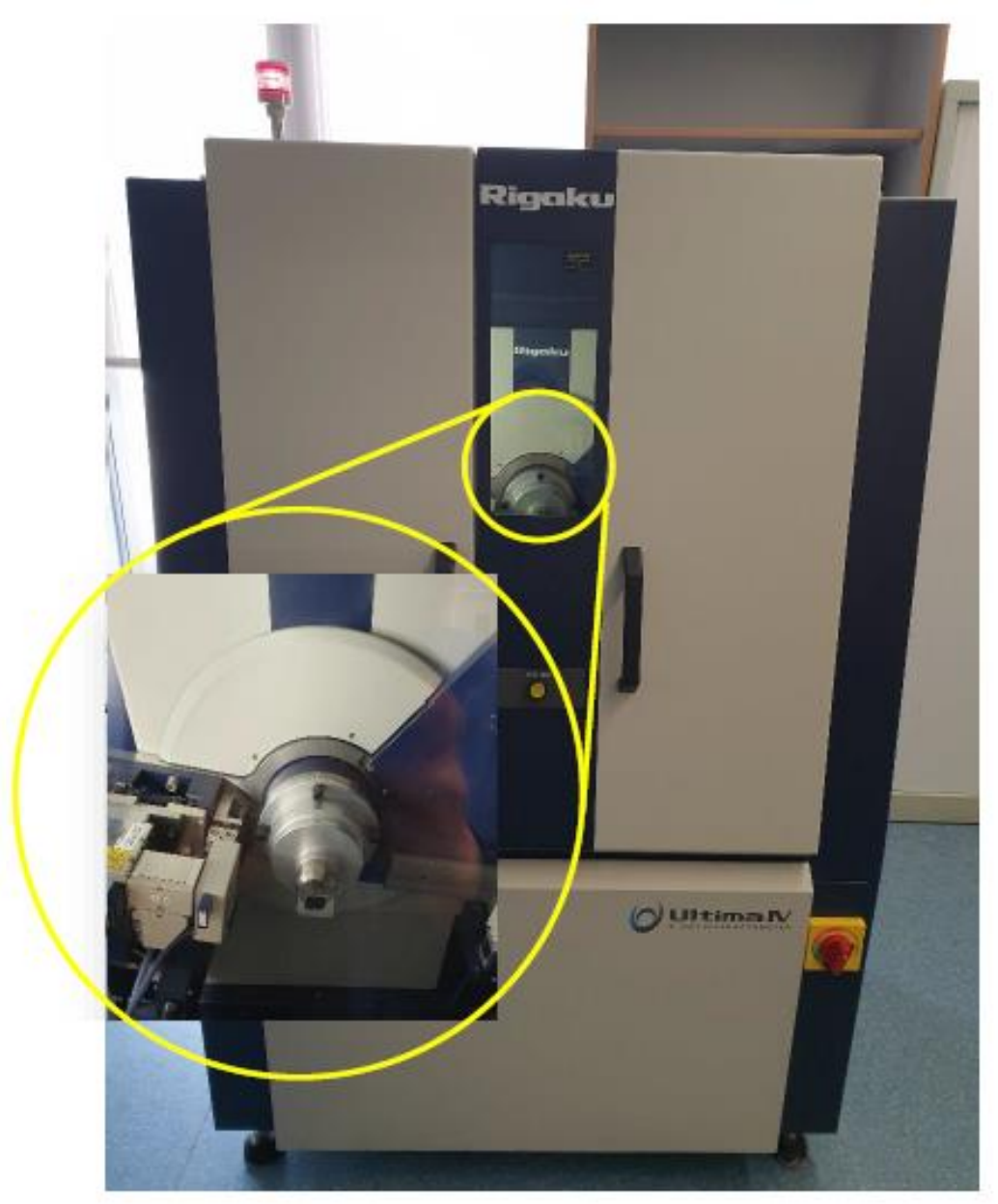

Figure 3.4 : Image of the X-ray diffraction

\subsubsection{Raman spectroscopy}

Raman spectroscopy is widely used as a complement to XRD to characterize the compounds of a material, such as CZTS, whether in powder form, or deposited in thin layers. This technique allows in particular the search for impurities, including small quantities as well as observing the states of a molecule. The Raman spectroscopy is based on the inelastic scattering of photons. The radiation emitted by bombarded molecules contains photons of the same frequency than those of incident radiation, but also photons of different frequencies. This frequency change is called Raman effect.

The principle of Raman spectroscopy consists of interacting a sample by a beam of monochromatic light (Laser) of very high frequency $\left(v_{0}\right)$ with respect to all the vibration frequencies $\left(\mathrm{v}_{v}\right)$ of the sample to be analyzed. That means the operating principle consists in focusing (with a lens) a beam of monochromatic light on the sample and to analyze the light scattered back. This light is collected using another lens and sent to a monochromator, its intensity is then measured with a detector. 
DRX alone does not identify the presence or absence of secondary phases. For this, Raman spectroscopy is a very complementary means of characterization. It is therefore necessary to couple the techniques of DRX and RAMAN spectroscopy to characterize the CZTS material and determine the presence or absence of parasitic secondary phases. Theoretical studies have shown that a stoichiometric sample of structural CZTS ordered kesterite (space group I-4) has 27 optically active Raman modes [81,82]. The most intense Raman scattering peaks in the experimental Raman spectrum of CZTS and CZTSe are at $338 \mathrm{~cm}^{-1}$ and $196 \mathrm{~cm}^{-1}$, respectively. The $\mathrm{ZnS}, \mathrm{CuSnS}_{3}$ phases cannot be detected by X-ray diffraction (XRD) because the positions of their diffraction peaks are almost identical to the CZTS peaks.

Figure 3.5 shows the XRD peaks of those secondary phases. Thereby, in determining the structural properties of our samples, we have imperatively associated with DRX, Raman spectroscopy analyzes. The device used for this purpose is a Horiba Jobin Yvon LabRAM HR spectrometer equipped with an edge filter that cuts Raman signals below $\sim 35 \mathrm{~cm}-1$ and a thermoelectrically cooled Electronically enhanced multichannel Charge Coupled Device (EMCCD). We used a solid-state green laser emitting at $533 \mathrm{~nm}$ with a resolution of roughly $1 \mathrm{~cm}^{-1}$.

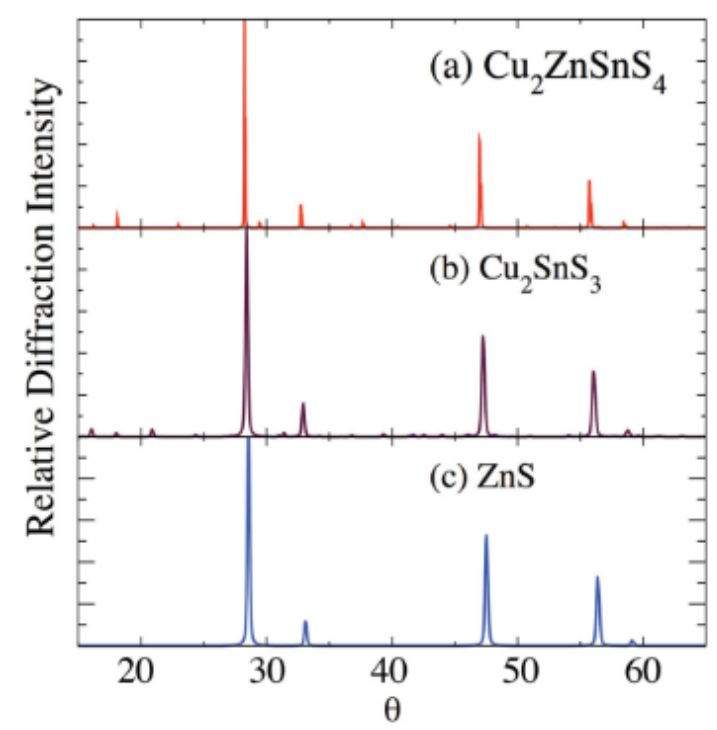

Figure 3.5: Simulated Cu-Ka X-ray diffraction patterns of kesterite $\mathrm{Cu}_{2} \mathrm{ZnSnS}_{4}, \mathrm{CuSnS}_{3}$ and zincblende $\mathrm{ZnS}$

\subsubsection{Field emission scanning electron microscopy (FESEM)}

Electron microscopy at scanning provides information on the morphology and surface appearance of the films. The principle of SEM devices is the existence of an electron beam focused on the surface of the sample to be analyzed. This beam is produced using a device called "electron gun". When the incident electron beam enters the sample, it undergoes multiple interactions with the target atoms which generate numerous phenomena and by-products which 
can be detected and analyzed. The byproducts which include backscattered electrons, secondary electrons and de-excitation are in fact distributed in a volume called diffusion pear. The electron beam sweeping across the sample surface re-emits electrons and photons which are then captured by detectors.

Knowing that scanning electron microscopy (SEM) is devoted to study the surface morphology of thin layers. Analysis of the secondary electrons emitted after interaction of the primary electron beam with the material provides information on the topography of the sample as well as the images produced by collection of backscattered electrons allow more particularly to highlight a chemical contrast i.e. the presence of a chemical element in a sample of material and the content of this element in the sample. In this case, the choice of detector will direct the contrast of the image either on the topography or on the composition, as the energy of the backscattered electrons is greater than that secondary electrons, they generally come from a layer whose thickness is more important than that which characterizes the secondary electrons, which means that the resolution is lower.

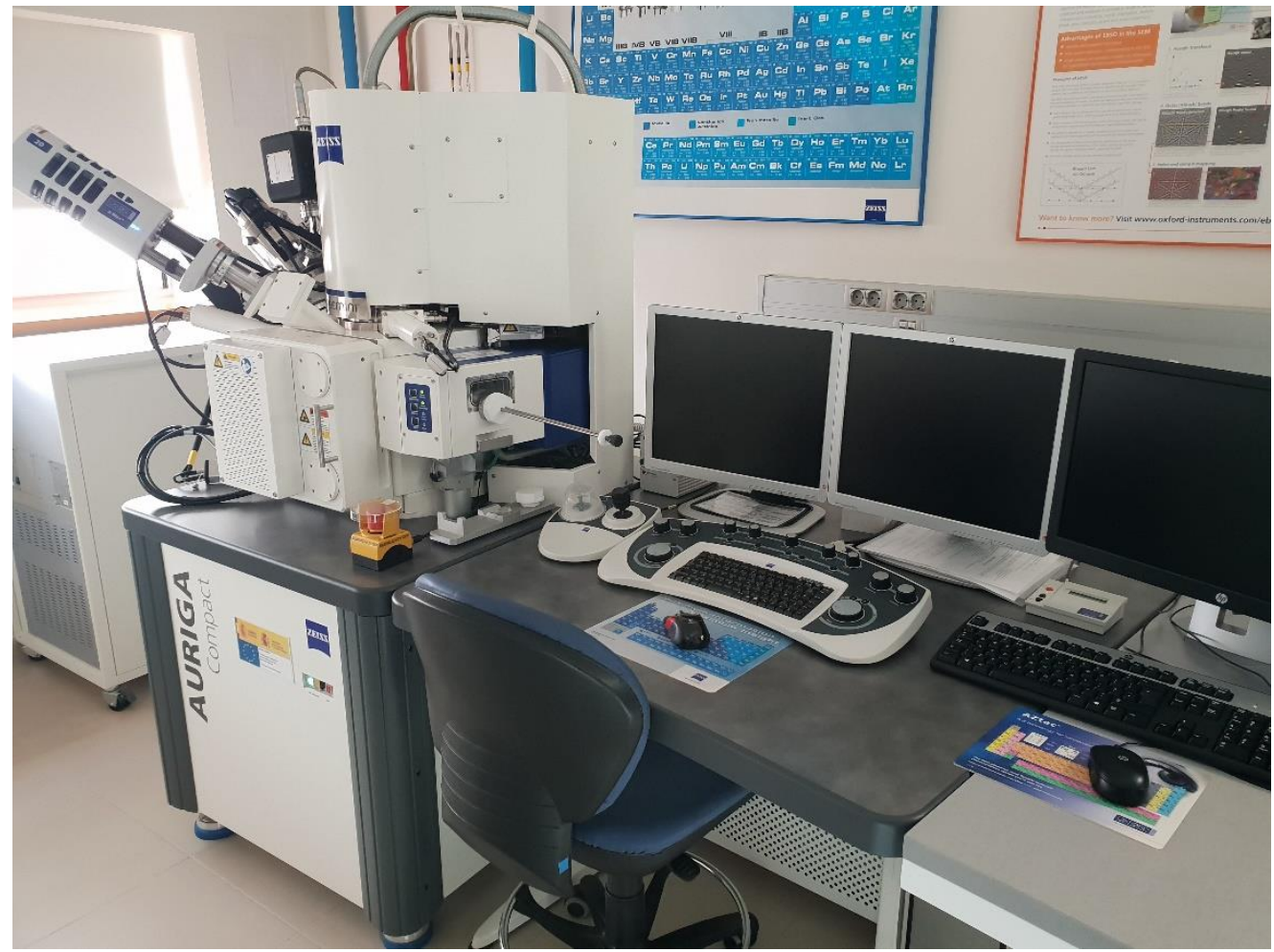

Figure 3.6: Image of the scanning electron microscopy (FESEM) a Zeiss ULTRA 55

The deposited and annealed films are mounted on a platinum object-holder allowing the sample to be moved in the three directions $(\mathrm{x}, \mathrm{y}, \mathrm{z})$ in the sample chamber. It is essential to have the latter one as well as the electronic column which is connected to electromagnetic lenses under vacuum to be able to have a well-formed and defined electron beam. Yet, to ensure vacuum, the SEM device must necessarily be fitted with a vacuum pump system. Figure 3.6 shows the 
instrument used for scanning electron microscopy analyzes (SEM) that is Zeiss ULTRA 55 model equipped with a field emission cannon $30 \mathrm{kV}$. Then, all of the data collected is used by visualization software Image.

\subsubsection{Energy dispersive spectroscopy (EDS)}

The scanning electron microscope is coupled to an energy-dispersing $\mathrm{X}$-ray microanalyzer where a qualitative and quantitative analysis can be obtained by acquiring the concentration of the elements present in the deposit and determining the chemical composition of the samples. When the sample is bombarded with an electron beam, it generates electronic excitations of the core levels of the atoms in the sample. During this electronic excitation, vacant states were created in the inner layers of atoms which, after the relaxation process, will be occupied by electrons of higher electronic levels. This is always accompanied by the emission of X-rays $(\mathrm{K} \alpha, \mathrm{K} \square, \mathrm{L} \alpha$ lines, etc.). and since the energy of these X-rays is characteristic of the atoms which emitted them, hence the possibility of carrying out elementary analysis. The EDS detector makes it possible to capture the $\mathrm{X}$ photons emitted when the atoms of the substrate return to their ground state following their interaction with the electrons of the incident beam of the SEM. Afterwards an identifications of the elements present in the material as a qualitative measurement or an assess the proportion of the various elements which defined a quantitative measurement will be given through a computer that processes the data using a program.

\subsubsection{Atomic force microscope (AFM)}

The atomic force microscope AFM is a high-resolution profile measurement instrument for the observation of objects on a very small scale. AFM allows to analyze a surface point by point thanks to a scanning by a probe made up of a fine point supported by a microlever, this one sweeps the sample to measure the interaction forces between the atom constituting the point and the surface atoms of a sample. The sample is mounted on a piezoelectric tube which allows movements in the three dimensions of space. In view of that these interactions created can be Van der Waals forces, electrostatic forces, magnetic forces or even ion repulsion forces, it depends on the surface characteristics of the sample. Interatomic forces are subsequently detected by reflection of a laser beam on the blade supporting the tip. The height of the tip changes during the cantilever movement and the magnitude of the deflection is plotted as a function of the position of the tip on the surface which creates a topographic map of the surface. The atomic force microscope is used in several modes of operation. Conventional techniques (contact mode, non-contact, tapping) make it possible to obtain a surface topography, while 
other modes make it possible to obtain various information on the physicochemical properties of the sample (MFM, EFM, LFM mode, etc.). Figure 3.7 shows the model used in this study.

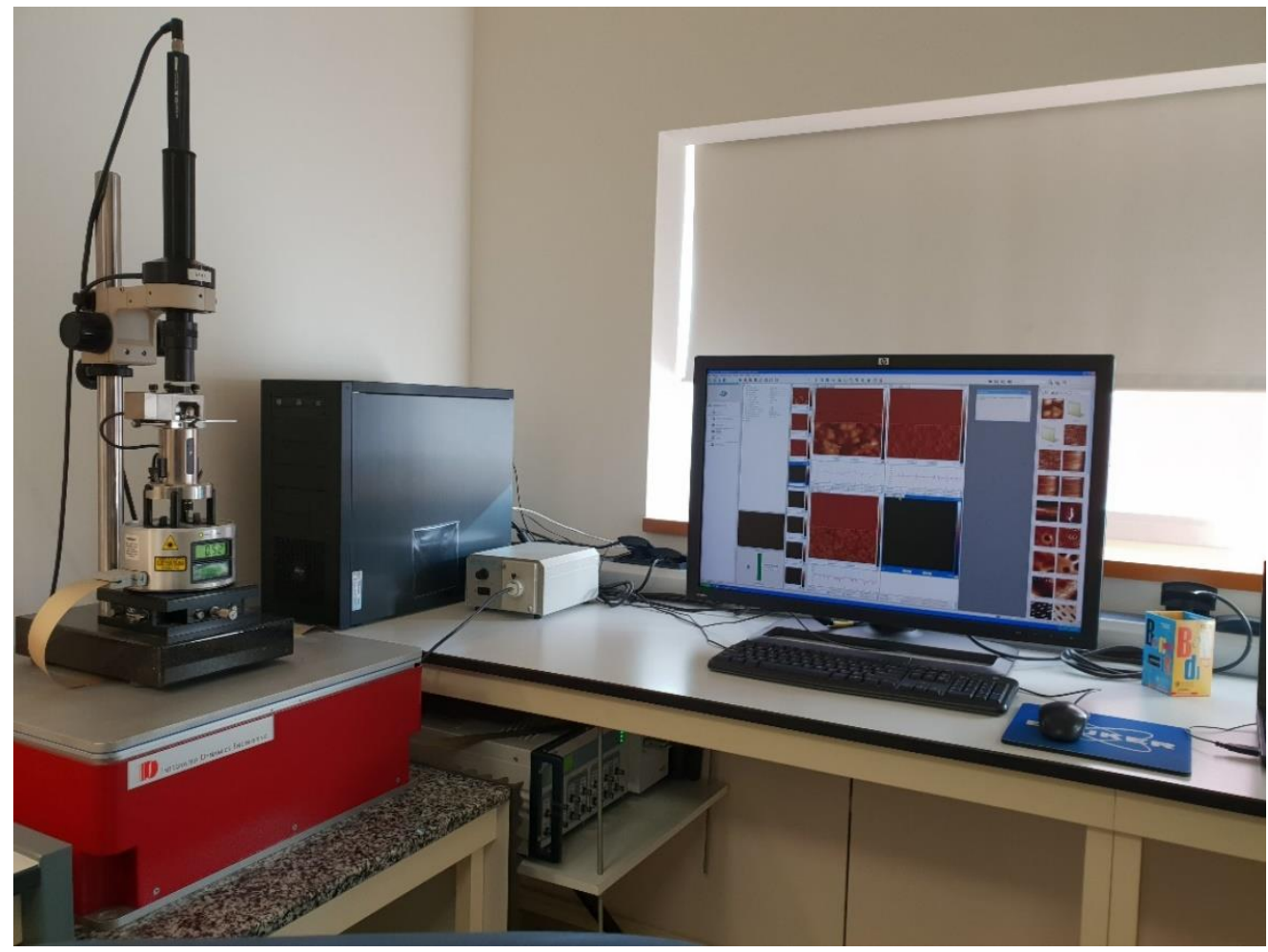

Figure 3.7: Image of atomic force microscopy Bruker's multimode 8 (AFM)

\subsubsection{UV-Visible spectroscopy}

The technique of UV-Visible spectrophotometry is based on the properties of matter and more particularly certain materials, of absorbing certain wavelengths of the UV-Visible spectrum, where the absorbed energy causes disturbances in the electronic structure of atoms. More precisely UV-Visible spectroscopy is an analysis method establish on the transition of an electron constituting an atom or a molecule from a ground state towards an excited state under the effect of an excitation by an electromagnetic wave. These electronic transitions are made in the ultraviolet domain, 200 to $350 \mathrm{~nm}$ and visible between 350 and $800 \mathrm{~nm}$. In spectrophotometric analysis as shown in Figure 3.8, a substantially monochromatic light is used at the output of the radiation source, due to making the polychromatic light a monochromatic beam. Subsequently, this beam is focused on a mirror which transmits it to a beam splitter. After splitting the beam into two equal parts, one of the beams goes through the reference and the other through the sample to be measured. Then the two beams are sent to a photomultiplier and then to a recorder. At this level, the lights will be detected and the ratio I/ I0 (with I the intensity of the transmitted light and I0 the intensity of the incident light) allows to go back to the transmission (\%). Plotting the curves representing the variation in 
transmittance, as a function of the wavelength in the UV-visible range. This technique tells us about some optical properties of the materials such as the estimation of the optical absorption threshold, the absorption coefficient and the optical gap.

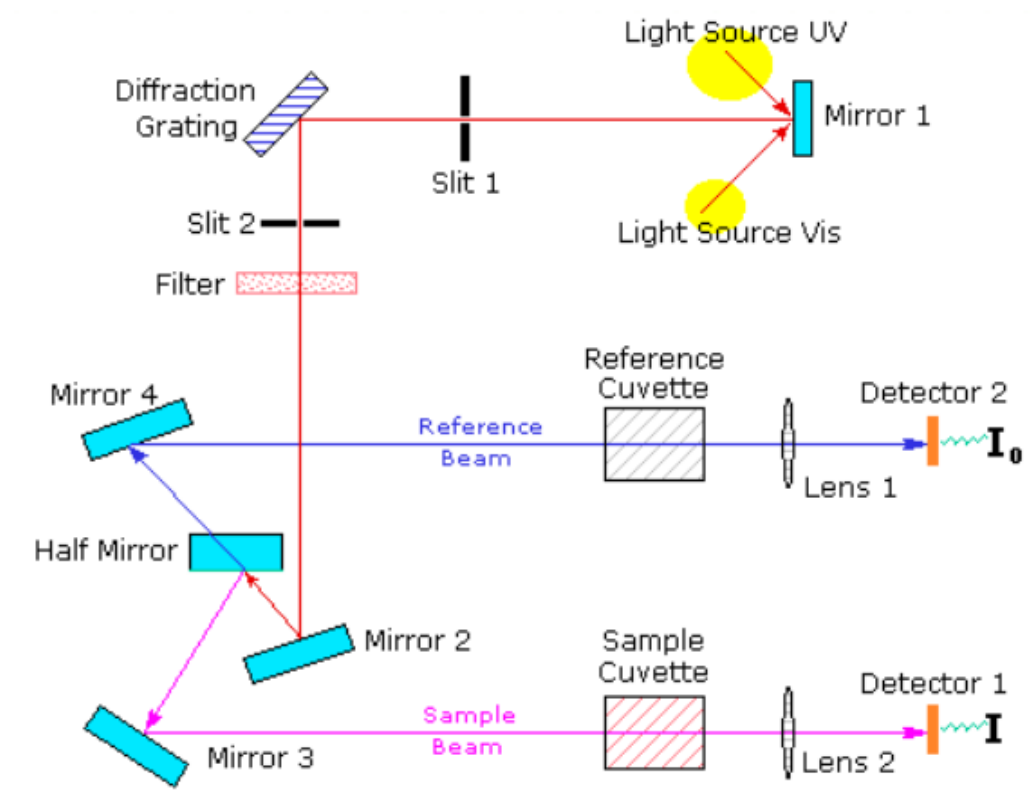

Figure 3.8: Schematic representation of the UV-Visible spectrophotometer

The bandgap energy value of the CZTS material was determined by absorption spectroscopy. Indeed, Tauc's law makes it possible to link absorption coefficient and forbidden band energy according to the formula [83].

$$
\alpha h v=A(h v-E g)^{n}
$$

$\alpha=$ Absorption coefficient

$h v=$ Energy of photons

$E g=$ Band energy prohibited

$A=$ constant

$n=1 / 2$ for the case of direct transition

By exploiting the curve of $(\alpha h v)^{2}$ as a function of $h v$ makes it possible to determine the value of $\mathrm{Eg}$ at the intersection of the tangent of the curve in its linear part and the $\mathrm{X}$-axis.

\section{4. Numerical Analysis}

Performing numerical analysis methods by integrating real life problem into virtual machine environment like computer is considered a high priority job. By integration of computers in numerical problem solving has led the researcher to find an optimum way of performing complex problem solving in an efficient way. With the aid of computers precious time was saved and it was easy to optimize any real time design problem without physically 
implementing it in real test environments [84]. Because of this reason computer-based learning is emphasized over worldwide universities. Computer-based learning systems has helped the researchers in the field of semiconductor devices. As today most of the world market is dominated by semiconductor devices like mobile phones, laptops, computers, streetlights and solar panels. Ion the field of semiconductor devices the most prominent field is solar cell. A semiconductor device can be used to convert sun light in to electrical energy and due to excessive demand of electric energy by consumers solar cell is a good alternate to meet user demands [85-88]. But currently most of the world energy demand is meet by hydel power plants, coal fired thermal power plants, natural gas fired thermal power plants and nuclear power plants [89]. Burning of fossil fuel has a drastic effect on climate change, so extensive research is being done in the field of solar photovoltaics (solar cell) [90-92]. New and improved design for solar cell are developed at a very rapid pace with efficiency reaching to a limit of $22 \%$ [93]. But the cost, availability and stability of these devices for further commercial development is still an issue [94-96]. So, in dealing with these issues of solar cell numerical analysis of solar cell on computer can play a vital role. As Computer allows flexibility in the design of realistic problem, experimentation with different hypotheses can easily be performed. And a complete set of device characteristic can often be easily generated by consuming less amount of time and effort than a small set of hand-calculated single point values.

Based on the discussion above it is evident that for rapid improvement in design and efficiency numerical modelling of photovoltaic solar cells is an imperative approach to assess the practicability of proposed physical structure and its performance. In this chapter effect of physical parameters like thickness of solar cell layers, doping concentration of layers and temperature on solar cell performance will be explained with the aid essential input parameters for solar cell. It is very valuable to take a common baseline or starting point for numerical analysis of solar cell [53]. This numerical investigation will yield fallouts for, predicting the outcome of changes in material properties and testing the practicability of proposed physical explanation.

\subsubsection{Basic semiconductor equation}

To analyze solar cell with the aid of numerical analysis software must be capable of solving basic semiconductor equations. These equations play a key role in analyzing solar cell performance and its possible output [97]. Among these equations the governing equation is Poison's equation for electrostatic potential. Equation 3.4 represent Poison's equation for electrostatic potential [98]. 


$$
\frac{\mathrm{d}^{2} \mathrm{~V}}{\mathrm{dx}^{2}}=\frac{\rho}{\varepsilon}
$$

$\rho$ is density of charge $\left(\mathrm{C} / \mathrm{cm}^{3}\right)$ and $\varepsilon$ is product of semiconductor dielectric constant and permittivity of free space. From charge neutrality equation $\rho$ can be expressed as given in equation 3.5 [99] with assumption that dopant is totally ionized.

$$
\rho=q\left(p-n+N_{D}^{+}+N_{A}^{-}\right)
$$

where $q$ is electronic charge, $p$ is concentration of holes, $n$ concentration of electrons, $N_{A}^{-}$ ionized acceptor dopant carrier concentration and $N_{D}^{-}$is ionized donor dopant carrier concentration. By putting the value of equation 3.5 in equation 3.4 it will become as equation 3.6.

$$
\frac{\mathrm{d}^{2} \mathrm{~V}}{\mathrm{dx}^{2}}=\frac{q\left(p-n+N_{D}^{+}+N_{A}^{-}\right)}{\varepsilon}
$$

And to solve equation 3.6 for $\mathrm{V}$ as a function position value of $\mathrm{x}$ one must have to rearrange the expression for concentration of carriers $(p, n)$.

Second equation called continuity equation, the reason that continuity equation is called governing equation is because drift, diffusion, generation and recombination are analyzed simultaneously. equation 3.7 and equation 3.8 represent continuity equation for concentration change in electron and hole [15].

$$
\begin{aligned}
& \frac{\partial n}{\partial t}=\frac{1}{q} \frac{\partial J_{n}}{\partial x}+\left(G_{n}-R_{n}\right) \\
& \frac{\partial p}{\partial t}=\frac{1}{q} \frac{\partial J_{p}}{\partial x}+\left(G_{p}-R_{p}\right)
\end{aligned}
$$

The output from equation 3.4,3.7 and 3.8 have non-linear dependencies on charge carrier concentration $(p, n)$. So, these equations will be solved with numerical techniques with standard approaches like discretization of equation, discretization of device and set of boundary conditions. To measure current characteristics of solar cell simulator must be able to solve driftdiffusion equation for current in solar cell. The equation for drift-diffusion of charge carriers is given in equation 3.9 and equation 3.10 [100,101].

$$
\begin{aligned}
& J_{n}=q \mu_{n} n \epsilon+q D_{n} \partial n \\
& J_{p}=q \mu_{p} p \epsilon-q D_{p} \partial p
\end{aligned}
$$

$\left(J_{n}, J_{p}\right)$ are the current density for electron and holes, $\left(\mu_{n}, \mu_{p}\right)$ mobility of carriers, $\left(D_{n}, D_{p}\right)$ diffusion coefficient of electron and holes and from Einstein relationship diffusion coefficient is depended upon mobility of carrier with product of carrier lifetime. Relation of $D_{n}$ with mobility of carrier is given in equation 3.11 [102-104]. 


$$
D_{(n, p)}=\sqrt{\mu_{(n, p)} \frac{k T}{q} \tau_{(n, p)}}
$$

other quantities need to solve to find the solution for equation 3.6, 3.7 and 3.8 are generation and recombination $(G, R)$ and this can also be expressed as net recombination in device (U). That is represented in equation 3.12 for n-type semiconductor.

$$
U=\frac{p-p_{0}}{\tau_{p}}
$$

There are different commercially available software and educational software for numerical analysis of solar cell that solve these basic semiconductor equations. The list of software that are available free for educational purpose are listed below.

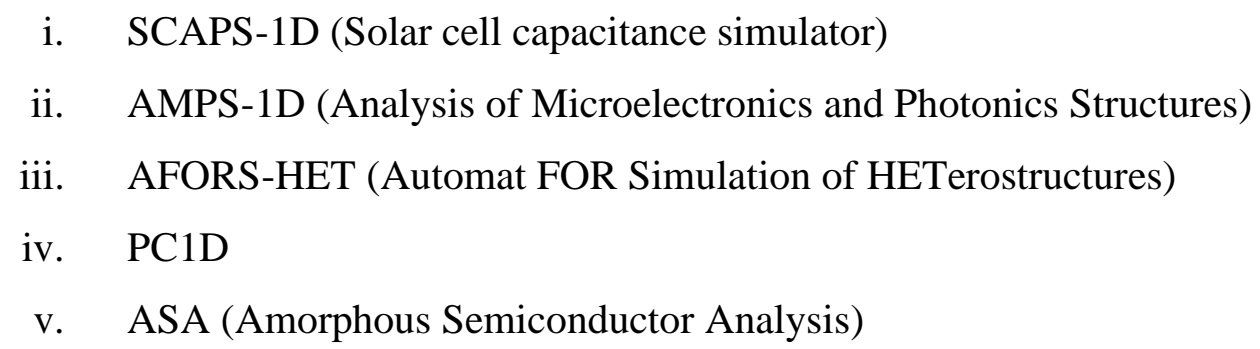

Among these different software's listed above we use SCAPS-1D for our work and the reason for selection of SCAPS is that, extensive literature is available for SCAPS and its possible application for the analysis of solar cell.

\subsubsection{SCAPS-1D}

SCAPS (a Solar Cell Capacitance Simulator) is a one-dimensional solar cell simulation program developed at the Department of Electronics and Information Systems (ELIS) of the University of Gent, Belgium [16]. Several researchers have contributed to its development: Alex Niemegeers, Marc Burgelman, Koen Decock, Stefaan Degrave, Johan Verschraegen.

SCAPS program was originally developed for $\mathrm{CuInSe} 2$ and the CdTe family. Recent developments make the program now also applicable to crystalline solar cells ( $\mathrm{Si}$ and GaAs family) and amorphous cells (a-Si and micromorphous $\mathrm{Si}$ ).

The most recent version, SCAPS 3.7, April 2012, includes:

i. Seven semiconductor layers.

ii. All physical parameters required for solar cell / semiconductor can be modeled in SCAPS. $\left(E_{g}, \chi, \varepsilon, N_{C}, N_{V}, v_{t h n}, v_{t h p}, \mu_{n}, \mu_{p}, N_{A}, N_{D}\right.$, (defects) $\left.N_{t}\right)$.

iii. Recombination profiles in solar cell. (SRH, Auger). 
iv. Defects density in bulk of semiconductor and at interface.

v. Defects with charge type. (Neutral, Single (donor, acceptor), double (donor, acceptor), defined by user).

vi. Defect with different energy distribution: uniform distribution, single level distribution, Gaussian distribution, and band tails.

vii. Work function of working electrodes/contacts for solar cell with optical filter.

viii. Illumination of working structure with different spectra available in literature (AM0, AM1.5D, AM1.5G, monochromatic, white).

ix. Illuminate device from either side. (Front contact, back contact with cutoff filters).

x. Calculate: (Energy band diagram, I $-\mathrm{V}$ curve, $\mathrm{C}-\mathrm{V}$ curve, quantum efficiency, recombination profile with temperature).

xi. Run simulation under batch setting with controlled iteration.

xii. Simulation can be run by writing scripts for SCAPS.

xiii. User can save it personalized setting for startup of SCAPS.

xiv. Friendly user interface.

$\mathrm{xv}$. A built-in curve fitting facility.

\section{i. SCAPS-ID front end interface}

Figure 3.9 shows the front-end interface of SCAPS-1D software. it majorly consists of 4 panels and the overview of these panels is listed below.

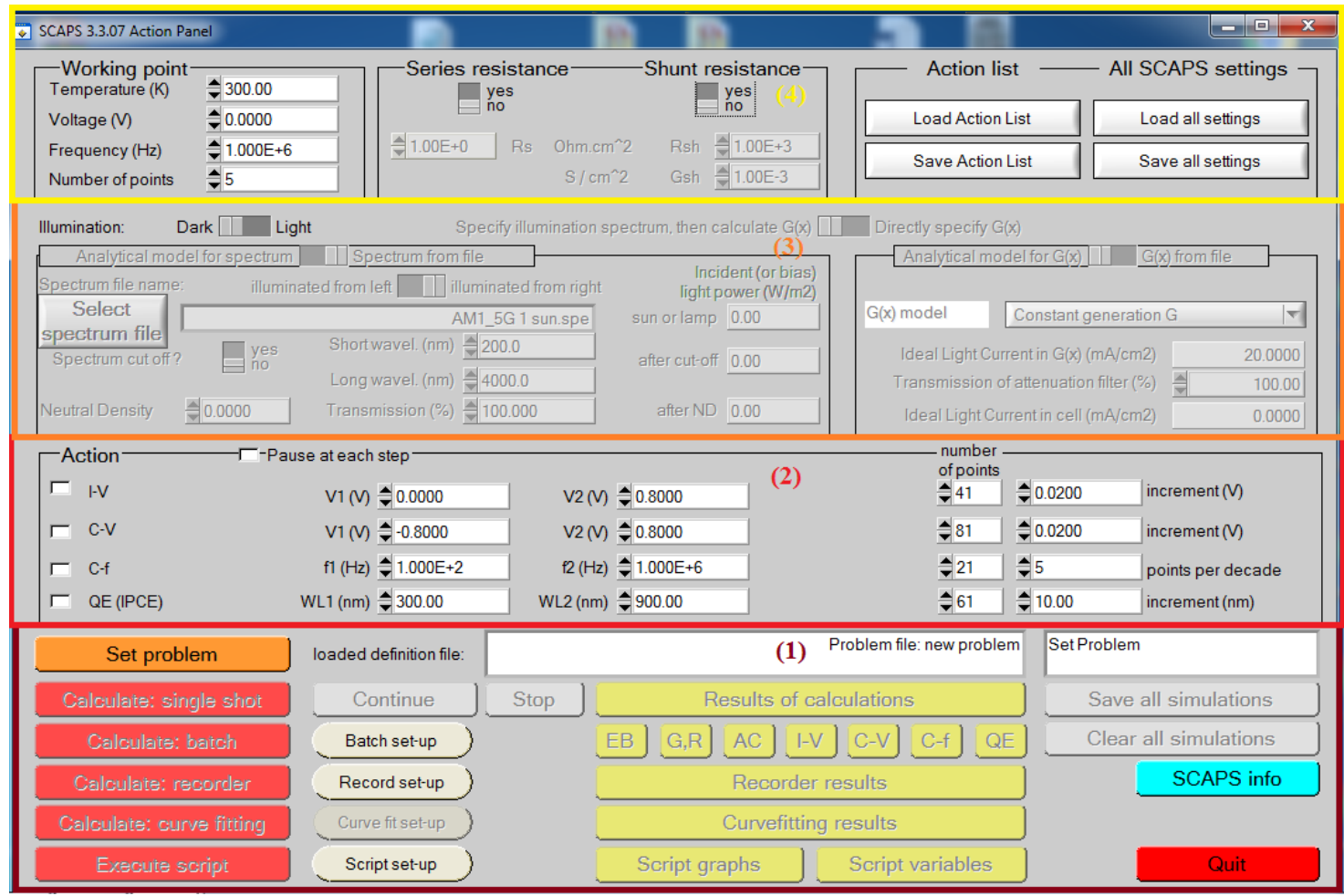

Figure 3.9: SCAPS front end interface 
- Problem definition panel is used to define solar cell structure that we want to define in SCAPS software, analyze simulated output, save data of simulated output and clear simulated history from SCAPS. To define solar cell structure, we need to click on set problem button.

- Action panel is for reading scale setting and this panel consist of $\mathrm{I}-\mathrm{V}$ characteristics scale calibration and setting, $\mathrm{C}-\mathrm{V}$ capacitance voltage setting, $\mathrm{C}-\mathrm{F}$ capacitance frequency setting and QE quantum efficiency setting.

- Illumination panel is for spectrum setting and direction from where solar cell structure will be illuminated

- working point is for setting of operating temperature

\section{ii. SCAPS-ID problem setting}

To set or define problem in SCAPS we click on "Set problem" button and after clicking on set problem button another interface will open. This interface is called "Solar cell definition panel" and in this panel we define the structure of our solar cell. This panel plays a key role in defining solar cell because structure definition and visualization is shown in this panel. To explain this panel, it is divided in to three categories as shown in Figure 3.10.

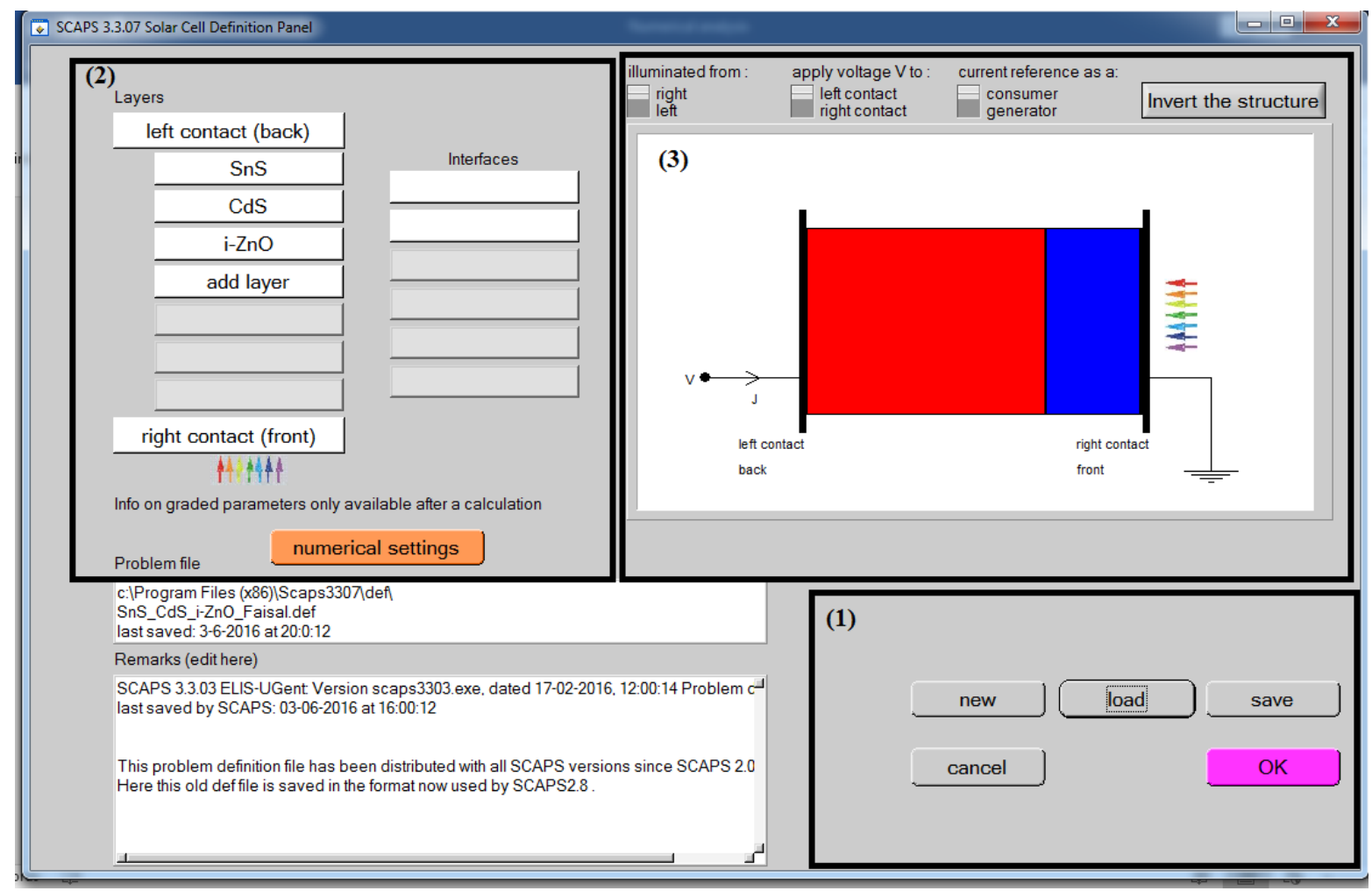

Figure 3.10: SCAPS solar cell definition panel

Explanation of these categories are listed below. 
- Consists of 5 buttons and the function of these buttons is to load a structure file from SCAPS structure definition library or to save already modeled structure in SCAPS definition library. after loading the file or creating new structure we click "OK" to return to the main front-end interface for further analysis.

- This consists of front and back contact and layers that we are going to define for our solar cell structure. From Figure 4.2, it is visible that SCAPS can only support 7 layers structure for numerical analysis of solar cell.

- This section is for visualization of defined solar cell structure with illumination from front or back contact. In this section there are some buttons which are used to define illumination from front or back contact, applied potential and current reference.

\section{iii. Adding layers to structure}

To define layers in SCAPS for construction of solar cell structure we click on add layer as shown in Figure 3.10 section 2. So, by clicking on add layer another panel will open, and this is called "Layer properties panel". In this panel we will set the basic physical parameters for our layer and this shown in Figure 3.11.

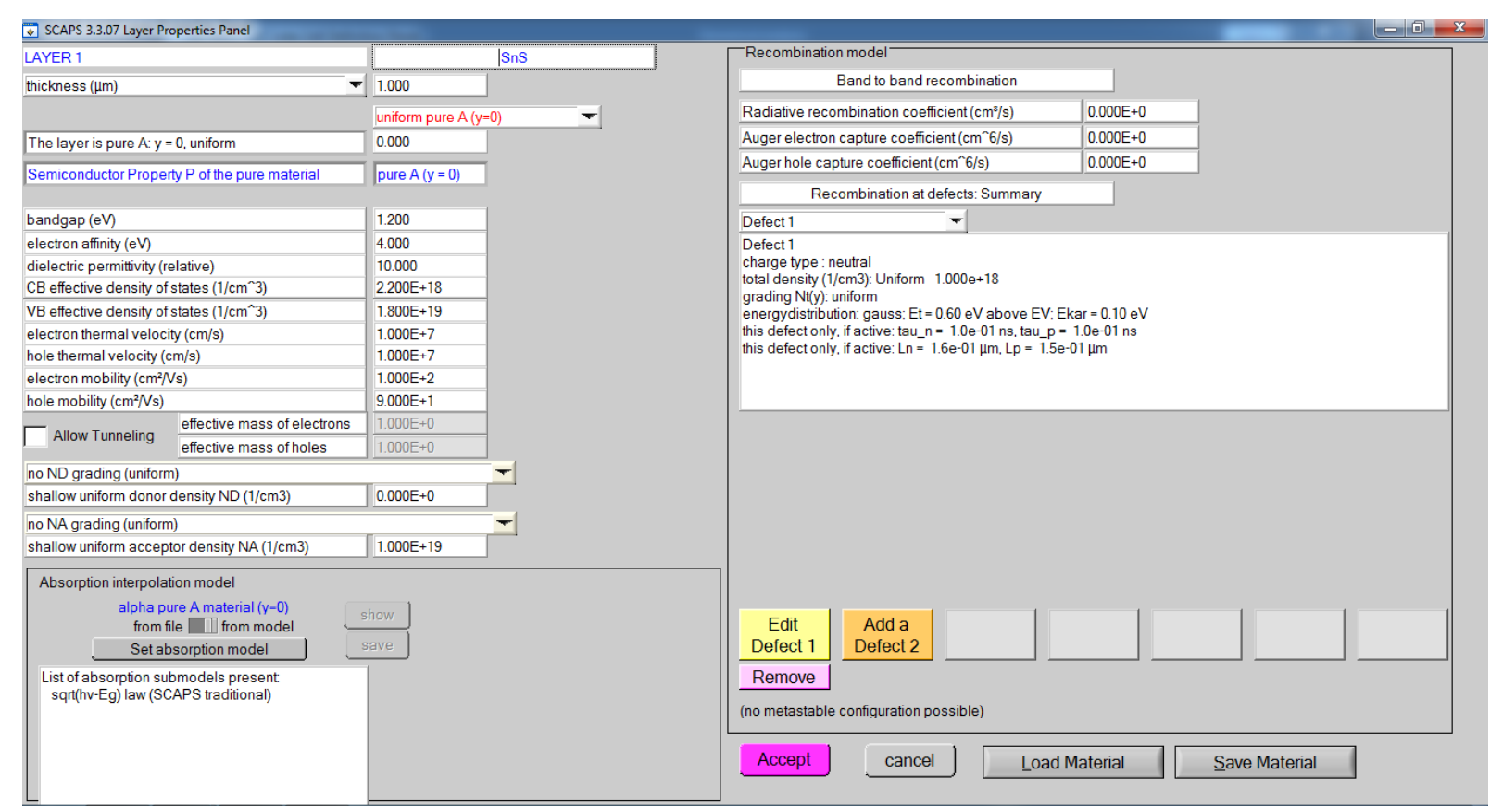

Figure 3.11: Layer properties panel

After setting the problem in SCAPS environment next step was to perform numerical analysis for defined structure and to analyze effect of different physical parameters on solar cell performance like thickness of absorber layer, buffer layer, doping concentration of absorber layer, buffer layer and operating temperature. 
Chapter IV Research Activity 
Article 1

Effect of complexing agent on the morphology and annealing temperature of CZTS kesterite thin films by electrochemical deposition

Current Applied Physics 19 (2019) 606-613

Contents lists available at ScienceDirect

Current Applied Physics

journal homepage: www.elsevier.com/locate/cap

Effect of complexing agent on the morphology and annealing temperature of CZTS kesterite thin films by electrochemical deposition

Hanae Toura ${ }^{\mathrm{a}, \mathrm{b}, *}$, Yousaf Hameed Khattak ${ }^{\mathrm{a}, \mathrm{c}}$, Faisal Baig ${ }^{\mathrm{a}, \mathrm{c}}$, Bernabe Mari Soucase ${ }^{\mathrm{a}}$, Mohamed Ebn Touhami ${ }^{\mathrm{b}}$, Bouchaib Hartiti ${ }^{\mathrm{d}}$

${ }^{a}$ School of Design Engineering, Departamento de Fisica Aplicada, Universitat Politecrica de Valencia, Cami de Vera, Spain

"Laboratory Materials and Environment Bngineering: Modeling and Application, Department of Chemistry, University lbn Tofali, Kenitra, Morocco

'Electrical Engineering Department, Federal Urdu Unversiy of Ars, Science and Technology, Islamabad, Pakistan

Laboratory MAC \& PM, Department of Physics, Hassan II University, Mohammedia, Casablanca, Moroceo

A R T I CLE I N FO

\section{Keywords:}

Kesterite

CZTS

Electrodepositio

Complexing agent

Annealing temperature

Solar cells
A B S T R A C T

$\mathrm{Cu}_{2} \mathrm{ZnSnS}_{4}$ kesterite thin films have been electrochemically deposited on indium doped tin oxide (ITO) coated glass substrates from an aqueous electrolyte solution containing $\mathrm{CuSo}_{4}, \mathrm{ZnSo}_{4}, \mathrm{SnSo}_{4}$ and $\mathrm{Na}_{2} \mathrm{~S}_{2} \mathrm{O}_{3}$ precursors in one step deposition. The purpose of this work is to reduce the cost of fabrication of CZTS thin films with good crystallinity by investigated the effect of complexing agent $\mathrm{Na}_{2} \mathrm{So}_{4}$ with $\mathrm{Na}_{3} \mathrm{C}_{6} \mathrm{H}_{5} \mathrm{O}_{7}$ on annealing temperature of CZTS thin film. Based on the results it was found that good crystal structure was achieved at temperature $350^{\circ} \mathrm{C}$ that is below the reported annealing temperature in the literature. The electrodeposition process was maintained at is be the at roo ter charas peaks. Scuning elcct micros phology with a spherical crystalline geometry and near stoichiometry metal atomic ratio for the different samples prepared. Atomic force microscopy (AFM) analysis confirms these results. From UV-visible spectroscopy, bandgap of around $1.5 \mathrm{eV}$ was estimated for the kesterite thin films. 


\title{
Effect of Complexing Agent on the Morphology and Annealing
}

\section{Temperature of CZTS Kesterite Thin Films by Electrochemical Deposition}

Hanae Toura ${ }^{1,2, *}$, Yousaf Hameed Khattak ${ }^{1,3}$, Faisal Baig ${ }^{1,3}$, Bernabe Mari Soucase ${ }^{1}$, Mohamed Ebn Touhami ${ }^{2}$, Bouchaib Hartiti ${ }^{4}$

${ }^{1}$ School of Design Engineering, Departamento de Fisica Aplicada, Universitat Politecnica de Valencia, Cami de Vera, Spain ${ }^{2}$ Laboratory Materials and Environment Engineering: Modeling and Application, Department of Chemistry, University Ibn Tofail, Kenitra, Morocco ${ }^{3}$ Electrical Engineering Department, Federal Urdu University of Arts, Science and Technology Islamabad, Pakistan ${ }^{4}$ Laboratory MAC \& PM, Department of Physics, Hassan II University, Mohammedia Casablanca, Morocco

*Corresponding Author: hanae.toura@gmail.com

\begin{abstract}
$\mathbf{C u}_{\mathbf{2}} \mathbf{Z n S n S}_{\mathbf{4}}$ kesterite thin films have been electrochemically deposited on indium doped tin oxide (ITO) coated glass substrates from an aqueous electrolyte solution containing $\mathrm{CuSo}_{4}, \mathrm{ZnSo}_{4}, \mathrm{SnSo}_{4}$ and $\mathrm{Na}_{2} \mathrm{~S}_{2} \mathbf{O}_{3}$ precursors in one step deposition. The purpose of this work is to reduce the cost of fabrication of CZTS thin films with good crystallinity by investigated the effect of complexing agent $\mathbf{N a}_{2} \mathbf{S o}_{4}$ with $\mathbf{N a}_{3} \mathbf{C}_{6} \mathbf{H}_{5} \mathbf{O}_{7}$ on annealing temperature of CZTS thin film. Based on the results it was found that good crystal structure was achieved at temperature $350^{\circ} \mathrm{C}$, that is below the reported annealing temperature in the literature. The electrodeposition process was maintained at room temperature with a working potential set at $-1.05 \mathrm{~V}$ vs. $\mathbf{A g} / \mathbf{A g C l}$. The annealed CZTS films were characterized by X-ray diffraction revealed the formation of a crystalline phase CZTS with major and intense peaks. Scanning electron microscopy (SEM) analysis stick to EDS show compact and uniform surface morphology with a spherical crystalline geometry and near stoichiometry metal atomic ratio for the different samples prepared. Atomic force microscopy (AFM) analysis confirms these results. From UV-visible spectroscopy, bandgap of around $1.5 \mathbf{e V}$ was estimated for the kesterite thin films.
\end{abstract}

Keywords: Kesterite, CZTS, Electrodeposition, Complexing agent, Annealing temperature, Solar cells. 


\section{Introduction}

Photovoltaic cells working principal is based on photoelectric effect. Through a semiconductor material, the light energy of photons can be directly converted into electricity by the process of photoelectric effect [105]. Among thin film technology $\boldsymbol{\alpha}-\boldsymbol{S i}, \boldsymbol{C d T e}$ and $\boldsymbol{C I G S}$ are the three most commercialized solar cells [106,107]. Silicon $(\boldsymbol{S i})$ based solar cell has been widely studied from decades but still, the cost of $\boldsymbol{S i}$ solar cell has not been reduced [108]. Till now around 21.7\%, power conversion efficiency (PCE) had achieved from $\boldsymbol{C I G S}$ based solar cells. The commercial fabrication of these solar cells are still low because of the paucity

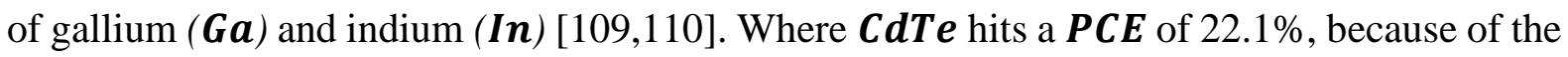
toxic nature of cadmium $(\boldsymbol{C d})$ large scale commercial production was not possible [93]. The main challenge in the fabrication of photovoltaic solar technology is to be enhancing the power conversion efficiency using earth-abundant elements, manufacturability, eco-friendly and reliability while reducing the cost.

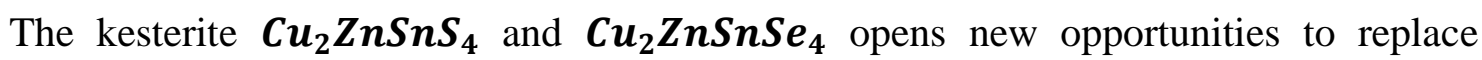
traditional photovoltaic technology for making solar cells [34,111]. Earth abundance and nontoxicity of copper zinc tin sulfide (CZTS) compositional elements, they gain prodigious interest and represent a promising approach for the next-generation solar cells. CZTS absorber is the good replacement of $\boldsymbol{C u}(\boldsymbol{I n}, \boldsymbol{G a}) \boldsymbol{S e}_{2}$ absorbers, by replacing toxic elements indium (In) and gallium ( $\boldsymbol{G a}$ ) by abundant and inexpensive elements zinc $(\boldsymbol{Z n})$ and tin (Sn) respectively [34,112,113]. CZTS is a material with high absorption coefficient of visible light about $\mathbf{1 0}^{4} \mathbf{c m}^{-1}$ and an optimum band gap of $1.5 \mathrm{eV}[114,115]$. Numerous techniques have been used to synthesize $\boldsymbol{C Z T S}$ thin films like spin coating [116], sol-gel [73], spray pyrolysis [71], chemical bath deposition [117], SILAR [118], co-sputtering [119,120], doctor-blade coating [121], photochemical deposition [122], among all these techniques, we find electrodeposition which increased the attention of researcher community. The electrodeposition is an extremely versatile and flexible technology. Moreover, this technique presents many advantages. First, there are many different metals, alloys, and composites that can be readily deposited in nano-crystalline form to meet specific application needs. Second, ease of implementation with a large surface area. Then, appropriate control system during the deposition. Finally, the low-cost industrial production [123,124]. The electrodeposition of the quaternary $\boldsymbol{C Z T S}$ from a single step always remain difficult, because the $\boldsymbol{C u}-\boldsymbol{Z n}-\boldsymbol{S n}-\boldsymbol{S}$ precursors present different oxidation-reduction potentials [125,126], which means the importance of using complexing agents to reduce the potential gaps between the elements 
$[127,128]$ The key factor of solar cell performance are the deposition potential that should be varied while deposition [126], the absorber material crystalline quality and stoichiometry $[129,130]$. There is an empirical rule for high efficiency $\boldsymbol{C Z T S}$ thin film, that the ratios of $\boldsymbol{C u} /(\boldsymbol{Z n}+\boldsymbol{S n})$ and $\boldsymbol{C u} / \boldsymbol{S n}$ should be between $0.70-1$ and 1-1.20 respectively [131]. In addition, the composition of $\boldsymbol{C Z T S}$ thin films was $\boldsymbol{C u}$-poor and $\boldsymbol{Z n}$-rich reported values for high-performance absorbers [132,133]. In order to acquire the desired phase of $\boldsymbol{C Z T S}$ with well-defined characteristics, during the deposition it is necessary to control, the bath temperature, deposition time, the $\boldsymbol{p} \boldsymbol{H}$ solution, the composition of the bath and the potential of deposition.

In this work, effect of complexing agent on annealing temperature was investigated with a structural, morphological, compositional and optical characterization. In order to obtain CZTS thin films by single bath electrodeposition technique and with low cost, we examined the effect of the addition of the complexing agent $\mathrm{Na}_{2} \mathrm{SO}_{4}$ on the temperature of annealing, which creates the originality of this study.

\section{Experimental}

\subsection{Materials}

Chemicals that were utilized for the fabrication of CZTS thin film were, Copper sulfate $\left(\mathrm{CuSO}_{4}\right)$, Zinc sulfate $\left(\mathrm{ZnSO}_{4}\right)$, Stannous sulfate $\left(\mathrm{SnSO}_{4}\right)$, Sodium thiosulfate $\left(\mathrm{Na}_{2} \mathrm{~S}_{2} \mathrm{O}_{3}\right)$, Trisodium citrate $\left(\mathrm{Na}_{3} \boldsymbol{C}_{6} \mathrm{H}_{5} \mathrm{O}_{7}\right)$, Sodium sulfate $\left(\mathrm{Na}_{2} \mathrm{SO}_{4}\right)$, Tartaric acid $\left(\mathrm{C}_{4} \mathrm{H}_{6} \mathrm{O}_{6}\right)$.

\subsection{Synthesis of CZTS thin film}

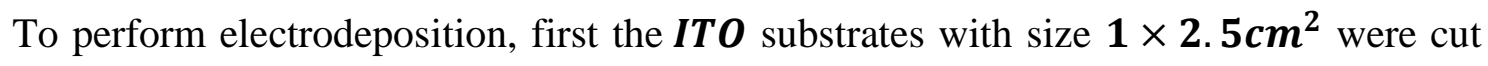
and ultrasonically pre-cleaned by sequential rinses with detergent, acetone, ethanol and distilled water for $10 \min$ each followed by drying in air. Next aqueous solution that was used for the preparation of $\boldsymbol{C Z T S}$ thin films using electrodeposition contains, 0.02M $\mathrm{CuSO}_{4} .5 \mathrm{H}_{2} \mathrm{O}, \quad 0.02 \mathrm{M} \mathrm{ZnSO}_{4} . \mathrm{H}_{2} \mathrm{O}, \quad 0.02 \mathrm{M} \mathrm{SnSO}_{4}, \quad 0.02 \mathrm{M} \mathrm{Na}_{2} \mathrm{~S}_{2} \mathrm{O}_{3}, \quad 0.2 \mathrm{M}$ $\mathrm{Na}_{3} \mathrm{C}_{6} \mathrm{H}_{5} \mathrm{O}_{7}$ and $\mathrm{Na}_{2} \mathrm{SO}_{4}$ with varied concentration $(\mathbf{0 M}, \mathbf{0 . 0 1 M})$ which specifies the composition of solution 1: without addition of $\mathrm{Na}_{2} \mathbf{S O}_{4}$ and solution 2: with the addition of $\mathrm{Na}_{2} \mathrm{SO}_{4}$. The $\boldsymbol{p H}$ of electrolyte solution was kept around 5 by adding tartaric acid $\mathbf{0 . 1} \boldsymbol{M}$. Then, the electrodeposition was carried out potentiostatically and performed using Autolab PGSTAT 302N, in a three-electrode electrochemical cell with ITO as a working electrode,

platinum wire $(\boldsymbol{P t})$ as a counter electrode and saturated calomel electrode $(\boldsymbol{S} \boldsymbol{C} \boldsymbol{E})$ as the reference electrode. The conductive surface of the ITO substrate is immersed in the solution while respecting the position of the electrodes to facilitate the change of the electrons as shown 
in Figure. 1. Subsequently, the chronoamperometry technique was used by fixing the potential at $-1.05 \mathbf{V}$ vs. $\boldsymbol{A g} / \mathbf{A g C l}$. The deposition without stirring takes place for $\mathbf{3 0 m i n}$ at room temperature. Deposited films were rinsed with deionized water after completion of the deposition cycle and dried them in air at room temperature. As-deposited thin film does not contain any $\boldsymbol{C Z T S}$ peaks since $\boldsymbol{C Z T S}$ growth requires annealing at a temperature $>350^{\circ} \mathrm{C}$. For this purpose, we apply sulfurization procedure to As-deposited samples using tubular. To perform annealing, first, we place the substrates in a graphite box with some milligrams of sulfur powder $\left(\boldsymbol{H}_{2} \boldsymbol{S}\right)$ under argon gas $(\boldsymbol{A r})$ within a temperature variant from $350^{\circ} \boldsymbol{C}$ up to $550^{\circ} \mathrm{C}$, the annealing process gets start during $45 \mathrm{~min}$ and duration of annealing procedure is given in Figure. 2.

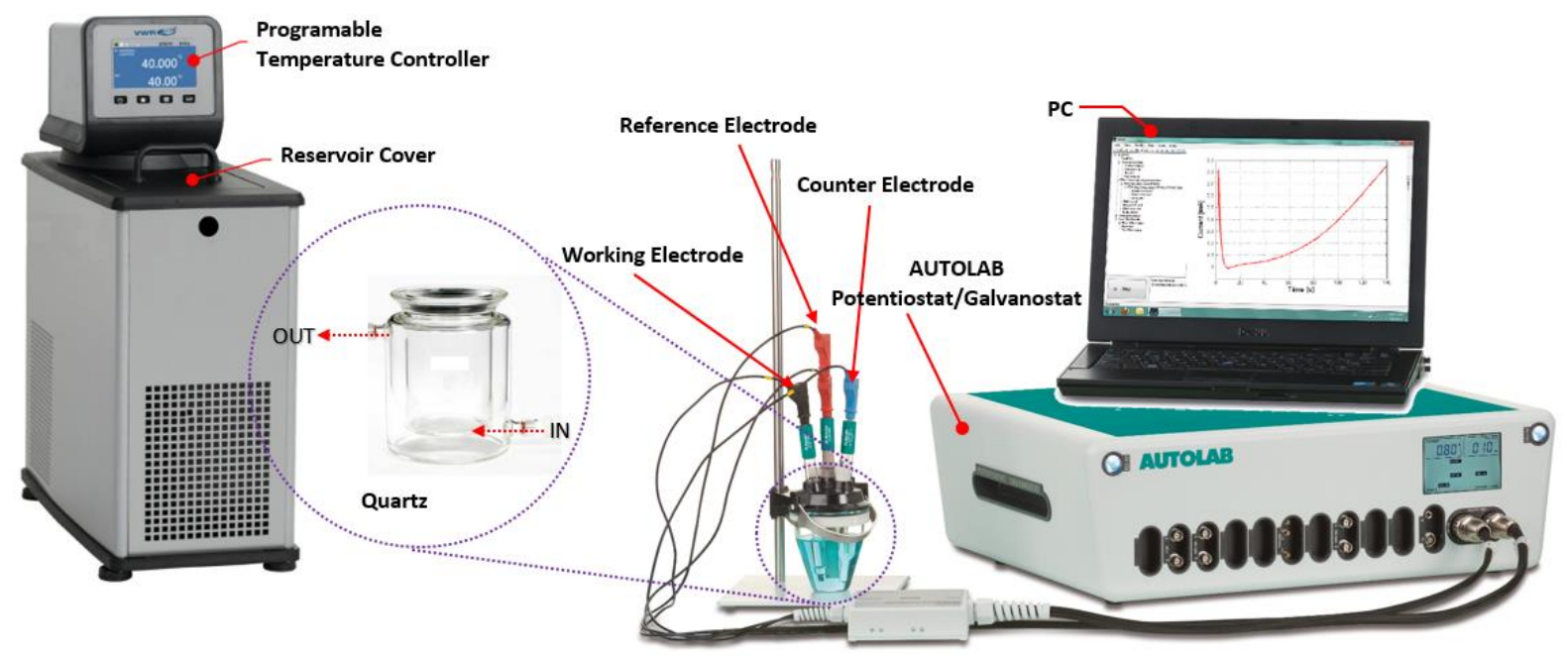

Figure 1 : Schematic diagram of electrochemical deposition setup

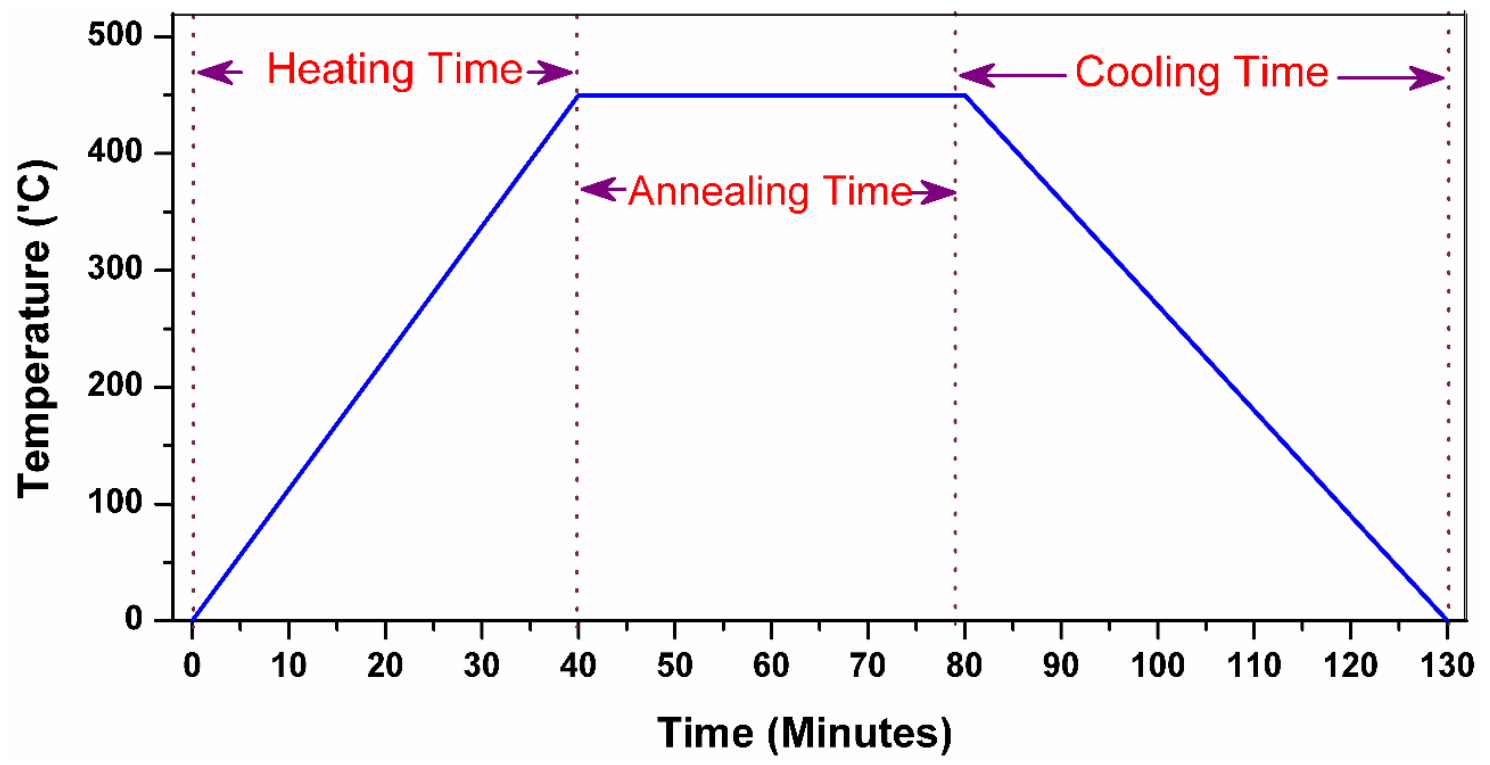

Figure 2 : Annealing process 


\subsection{Characterization of CZTS films}

The $\boldsymbol{X} \boldsymbol{R} \boldsymbol{D}$ (X-ray diffraction) technique was used to characterize the structure and the crystalline phase of the material using $\boldsymbol{C} \boldsymbol{u}-\boldsymbol{K} \boldsymbol{\alpha}$ radiation $(\boldsymbol{\lambda}=\mathbf{1 . 5 4 0 6 0} \AA)$ with Rigaku Ultima IV diffractometer in the Bragg-Bentano configuration. Then, to study the surface morphology and the composition of the samples, the scanning electron microscopy $(\boldsymbol{S E} \boldsymbol{M})$ and energy dispersive X-ray ( $\boldsymbol{E} \boldsymbol{D} \boldsymbol{S}$ ) detector was applied respectively using a Zeiss ULTRA 55 model equipped with an In-Lens SE detector. The optical properties were examined by using UV-visible optical spectroscopy and the measurement of the optical band gap $\boldsymbol{E} \boldsymbol{g}$ of the elaborate layer was carried out by the Tauc equation $\boldsymbol{\alpha h} \boldsymbol{v}=\boldsymbol{A}(\boldsymbol{h} \boldsymbol{v}-\boldsymbol{E} \boldsymbol{g})^{\boldsymbol{n}}$ and $\boldsymbol{\alpha}=$ $1 / \boldsymbol{t} \ln (1 / T)$ relation. The topology of the surface has been explored with atomic force microscopy method ( $\boldsymbol{A F} \boldsymbol{M}$ ) Bruker Multimode 8 AF $\boldsymbol{M}$ Nasoscope V controller. All of these techniques were used to identify the formation of $\boldsymbol{C Z T S}$ stoichiometry complex.

\section{Result and discussion}

\subsection{Cyclic voltammetry}

In the event of one step deposition, appears cyclic voltammetry of the bath containing $\boldsymbol{C u}-\boldsymbol{Z n}-\boldsymbol{S n}-\boldsymbol{S}$ precursors. The reduction potential for all these elements are extremely different, which is directly related to the electrochemical reactions approved by Nernst's law [134]:

$$
\begin{aligned}
& \mathrm{Cu}^{2+}+2 e^{-} \rightarrow C u \\
& E_{C u}=0.14 \mathrm{~V}-\frac{R T}{2 F} \ln \left[\mathrm{Cu}^{2+}\right] \quad(v s . \mathrm{Ag} / \mathrm{AgCl}) \\
& Z n^{2+}+2 e^{-} \rightarrow Z n \\
& E_{Z n}=-0.96 \mathrm{~V}-\frac{R T}{2 F} \ln \left[\mathrm{Zn}^{2+}\right] \quad(v s . \mathrm{Ag} / \mathrm{AgCl}) \\
& \mathrm{Sn}^{2+}+2 e^{-} \rightarrow S n \\
& E_{S n}=-0.38 \mathrm{~V}-\frac{R T}{2 F} \ln \left[\mathrm{Sn}^{2+}\right] \quad(v s . \mathrm{Ag} / \mathrm{AgCl}) \\
& S_{2} \mathrm{O}_{3}{ }^{2-}+6 H^{+}+4 e^{-} \rightarrow S+3 \mathrm{H}_{2} \mathrm{O} \\
& E_{S}=0.5 \mathrm{~V}-\frac{R T}{2 F} \ln \left[\mathrm{S}_{2} \mathrm{O}_{3}{ }^{2-}\right] \quad(v s . \mathrm{Ag} / \mathrm{AgCl})
\end{aligned}
$$

$\boldsymbol{E}_{\boldsymbol{C u}}, \boldsymbol{E}_{\boldsymbol{Z n}}, \boldsymbol{E}_{\boldsymbol{C u}}$ and $\boldsymbol{E}_{\boldsymbol{S n}}$ are the potential of reduction for the respective half reactions esteem to the $\boldsymbol{A g} / \boldsymbol{A g C l}$ reference electrode. The values of $0.14 \boldsymbol{V},-0.96 \boldsymbol{V},-0.38 \boldsymbol{V}$ and $0.5 \boldsymbol{V}$ vs $(\boldsymbol{A g} / \boldsymbol{A g C l})$ are the standard potentials of the $\boldsymbol{C u}, \boldsymbol{Z n}, \boldsymbol{S n}$ and $\boldsymbol{S}$ precursors respectively. $\boldsymbol{F}$ is Faraday's constant, $\boldsymbol{R}$ is ideal gas constant and $\boldsymbol{T}$ for the temperature in Kelvin, that is maintained at room temperature. Therefore, the value of $\boldsymbol{R T} / \boldsymbol{F}$ is around $0.025 .\left[\boldsymbol{C u}^{2+}\right]$, 
$\left[\mathrm{Zn}^{2+}\right],\left[\mathrm{Sn}^{2+}\right]$, and $\left[\mathrm{S}_{2} \mathrm{O}_{3}{ }^{2-}\right]$ returns to the concentration of the elements constituting the electrolyte [135]. According to the above equations, the great potential difference that exists between the elements constituting CZTS film creates the main challenge of the deposition process. In literature, the effect of tri-sodium citrate with the annealing temperature on the formation of $\boldsymbol{C Z T S}$ film, where they showed that the formation of the film starts at $450^{\circ} \boldsymbol{C}$ but gives a good crystalline structure at $550^{\circ} \boldsymbol{C}$ [136]. So, to shrink the potential gap and simultaneously deposit the four elements, the addition of complexing agent trisodium citrate $\left(\mathrm{Na}_{\mathbf{3}} \boldsymbol{C}_{\mathbf{6}} \mathrm{H}_{\mathbf{5}} \mathrm{O}_{\mathbf{7}}\right)$ is necessary [137]. The formation of $\boldsymbol{C Z T S}$ film with good crystallinity at 350 ${ }^{\circ} \mathrm{C}$ gives the usefulness of this work. So, adding sodium sulfate with trisodium citrate makes the bath more active. Figure..3 shows cyclic voltammetry $(\boldsymbol{C V})$ for the bath containing copperzinc-tin-sulfur precursor with (a) $\boldsymbol{N a}_{3} \boldsymbol{C}_{6} \boldsymbol{H}_{5} \boldsymbol{O}_{7}$ and $\boldsymbol{C}_{4} \boldsymbol{H}_{6} \boldsymbol{O}_{6}$ as complexing agents (b) $\mathrm{Na}_{3} \mathrm{C}_{6} \mathrm{H}_{5} \mathrm{O}_{7}, \mathrm{C}_{4} \mathrm{H}_{6} \mathrm{O}_{6}$, and $\mathrm{Na}_{2} \mathrm{SO}_{4}$ as complexing agents which is the subject of solution 1 and 2 respectively. The process of cyclic voltammetry $(\boldsymbol{C V})$ has been performed in the potential ranging from $0.2 \boldsymbol{V}$ to $-1.3 \boldsymbol{V}$ vs. $\boldsymbol{A g} / \boldsymbol{A g} \boldsymbol{C l}$. Then, according to the $\boldsymbol{C}-\boldsymbol{V}$ curve, the peaks around $0 \boldsymbol{V},-0.65 \boldsymbol{V}$ and $-0.90 \boldsymbol{V}$ vs. $\boldsymbol{A g} / \boldsymbol{A g} \boldsymbol{C l}$ specify the potential of reduction of $\boldsymbol{C \boldsymbol { u } ^ { 2 + } , \boldsymbol { S n }} \boldsymbol{n}^{2+}$ and $\boldsymbol{Z n}^{2+}$ respectively. Agreeing that the effect of $\mathrm{pH}$ and complexing agents on the reduction of the constituent elements thin films in $\operatorname{CZTS}$ [138]. They advertise that the reduction potential of copper can be reduced from $-0.2 \boldsymbol{V}$ to $-0.5 \boldsymbol{V}$ vs. $\boldsymbol{A g} / \boldsymbol{A g C l}$, as far as the value of the reduction potential of $\mathrm{Sn}$ decrease from $-0.5 \boldsymbol{V}$ to $-0.7 \boldsymbol{V}$ vs. $\boldsymbol{A g} / \boldsymbol{A g} \boldsymbol{C l}$. Furthermore, $\boldsymbol{Z n}$ potential can be displaced from $-1.2 \boldsymbol{V}$ to $-0.7 \boldsymbol{V}$ vs. $\boldsymbol{A g} / \boldsymbol{A g} \boldsymbol{C l}$. These results were further improved by the addition of some milligram of the complexing agent $\mathrm{Na}_{2} \mathrm{SO}_{4}$ with $0.2 \mathrm{M} \mathrm{Na}_{3} \mathrm{C}_{6} \mathrm{H}_{5} \mathrm{O}_{7}$ which gives action to the solution and narrowing the reduction potentials of the constituents of the electrolyte bath. Therefore, the reduction potential gap between $\boldsymbol{C u}$ and $\boldsymbol{Z n}\left(\boldsymbol{E}_{\boldsymbol{C u}}-\boldsymbol{E}_{\boldsymbol{Z n}}=\right.$ $(\mathbf{0})-(-\mathbf{0 . 9 0})=\mathbf{0 . 9 0} \mathrm{V})$ becomes lesser when compared with the value of the standard condition $(>\mathbf{1 . 1} \mathbf{V})$ [133]. The bath of the electrodeposition contains the metal cations $\left(\boldsymbol{C u}^{2+}, \boldsymbol{Z n}{ }^{2+}, \boldsymbol{S n}{ }^{2+}\right)$ which form a complex compound with citrate anion, what shows the role of citrate to provide proof of activity reducing metal cations in the electrolyte [138]. 


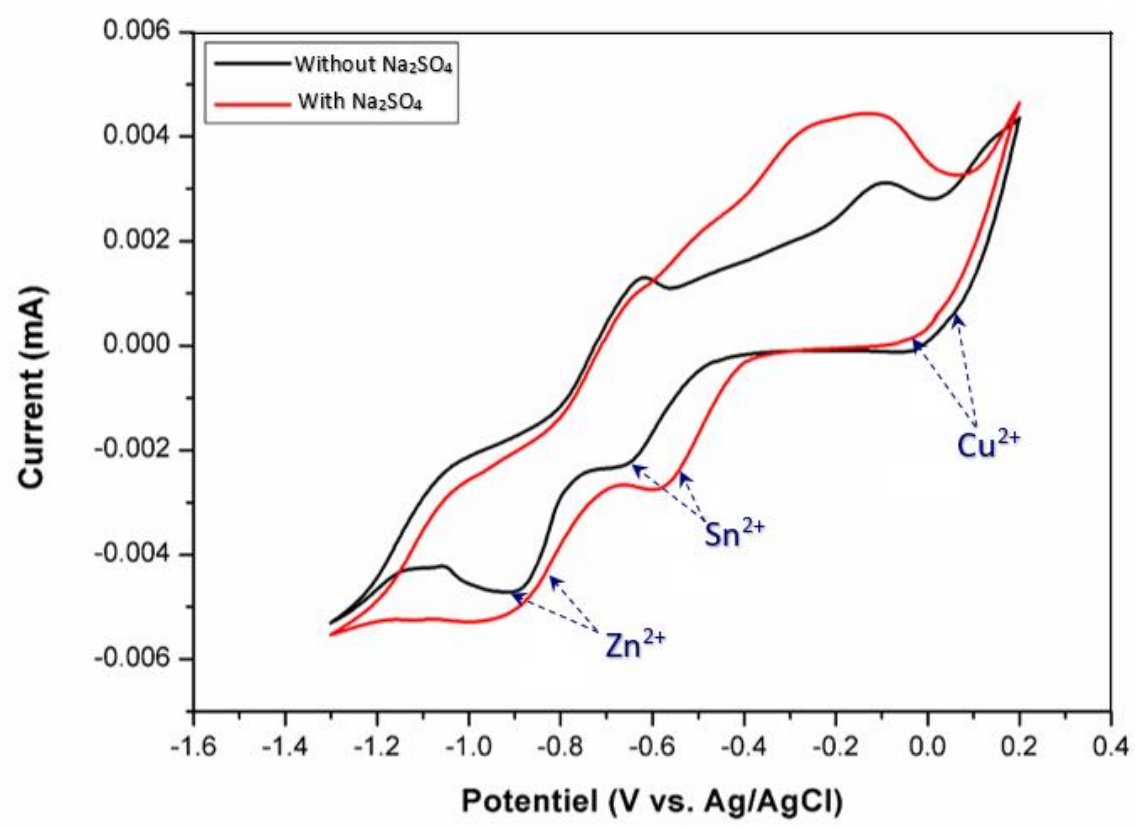

Figure 3 : Cyclic voltammetry curves of the electrolyte containing (a) Solution 1: Trisodium citrate and tartaric acid as complexing agents, (b) Solution 2: Trisodium citrate, tartaric acid, and sodium sulfate as complexing agents.

\section{2. $\quad$-ray diffraction and Raman Spectroscopy}

The X-ray diffractogram recorded in $2 \theta$ angle range $20-60^{\circ}$ shows the peaks of CZTS thin films for the different substrates are explained in Figure. 4. Observing that kesterite phase CZTS present only for annealed samples at $2 \theta$ values $23.15^{\circ}, 28.5^{\circ}, 32.9^{\circ}, 47.3^{\circ}$ and $56.1^{\circ}$ with reference JCPDS card \#26-0575 [48]. The diffraction spectrum indicates the presence of all these peaks for samples annealed at $350^{\circ} \boldsymbol{C}, 400^{\circ} \boldsymbol{C}, 450^{\circ} \mathrm{C}$ and $550^{\circ} \mathrm{C}$, whereas for as deposited sample there is no major peak observed for kesterite. This is also shown in the inset plot of Figure. 4. 


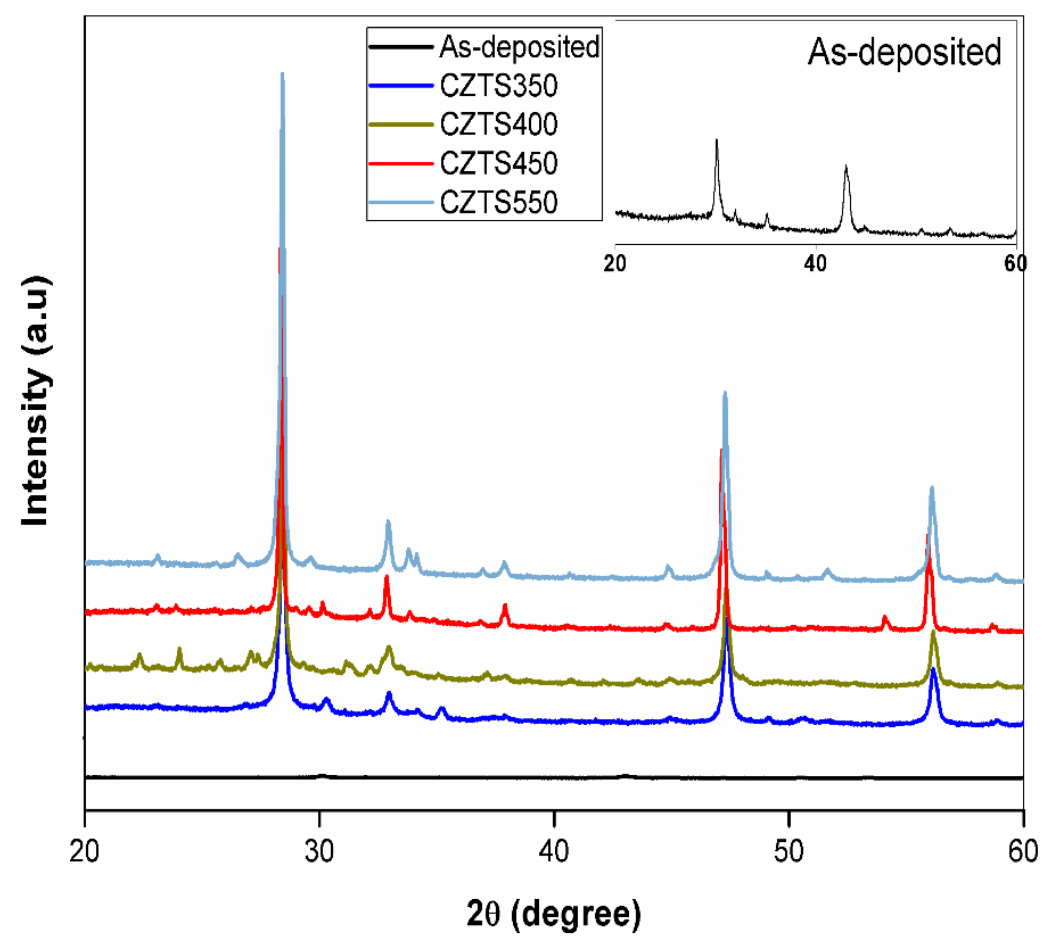

Figure 4 : X-ray diffraction patterns of $\boldsymbol{C Z T S}$ films electrodeposited at different temperature of annealing

The reticular planes (101), (112), (200), (220) and (312) correspond to kesterite structure of CZTS thin films JCPDS $\mathrm{N}^{\circ}$ : 026-0575 are distinctly observed in the sample annealed at $450^{\circ} \mathrm{C}$. Furthermore, the intensity and affinity of the peaks present by this substrate indicate that the deposit has more crystalline particles. Whereas the most important parameter for the electrodeposition of $\boldsymbol{C Z T S}$ thin films is the annealing temperature, which requires a significant energy since the technique of electrochemical deposit offers a low price for production and the ease of implementation. Decreasing the temperature more with the composition of the first solution we risk losing the crystallinity of the film which shows the spectrum(CZTS400). Consequently, the addition of a small quantity of $\boldsymbol{N a}_{2} \boldsymbol{S O}_{4}$ allows us to diminish the temperature of annealing up to $350^{\circ} \boldsymbol{C}$ while obtaining better results. Figure. 4 (CZTS350) shows the presence of $\boldsymbol{C Z T S}$ quaternary diffraction peaks. This complexing agent plays an important role in decreasing the reduction potential, which gives rise to the formation of the CZTS film even at base temperature.

The $\boldsymbol{X} \boldsymbol{R} \boldsymbol{D}$ analysis gives access to define other parameters such as the position of the peaks, interplanar distance, FWHM (Full Width at Half Maximum) and crystalline size. That is calculated by using Debye - Scherrer's formula:

$$
D=(K \lambda / \beta \operatorname{Cos} \theta)
$$


$\boldsymbol{D}$ is the crystalline size, $\boldsymbol{\lambda}$ is the wavelength of the incident beam, $\boldsymbol{K}$ is Scherrer's constant and usually takes the value $0.9, \boldsymbol{\beta}$ is the width at half height intensity of the peak and finally, $\boldsymbol{\theta}$ represents the diffraction angle.

Thus, Figure. 5 shows the value of the full width at half maximum ( $\boldsymbol{F} \boldsymbol{W} \boldsymbol{H} \boldsymbol{M})$ of the most intense peak (112) were decreased with increasing sulfurization temperature to an optimal value and after a small increase was observed which may be due to lack of sulfur. A slight variation of the lattice parameter was observed for the annealed sample at $550^{\circ} \boldsymbol{C}$. This change in peak intensity can be attributed to the distortion of $\boldsymbol{C Z T S}$ thin films. As well as the grain size of the crystals increased as a function of temperature as though if it varied in contrast with the $\boldsymbol{F} \boldsymbol{W} \boldsymbol{H} \boldsymbol{M}$ that are shown in Table 1.

Table 1: The $\boldsymbol{F} \boldsymbol{W} \boldsymbol{H} \boldsymbol{M}$ and the grain size of the different samples

\begin{tabular}{ccccc}
\hline Sample name & $\begin{array}{c}\text { Annealing } \\
\text { Temperature }\end{array}$ & $\begin{array}{c}\text { Position of the } \\
\text { peak (112) }\end{array}$ & FWHM (deg) & Size $($ nm) \\
\hline CZTS550 & 550 & 28.4002 & 0.1338 & 63.945 \\
CZTS450 & 450 & 28.3565 & 0.1125 & 76.046 \\
CZTS400 & 400 & 28.4142 & 0.1371 & 62.438 \\
CZTS350 & 350 & 28.4153 & 0.187 & 45.775 \\
\hline
\end{tabular}

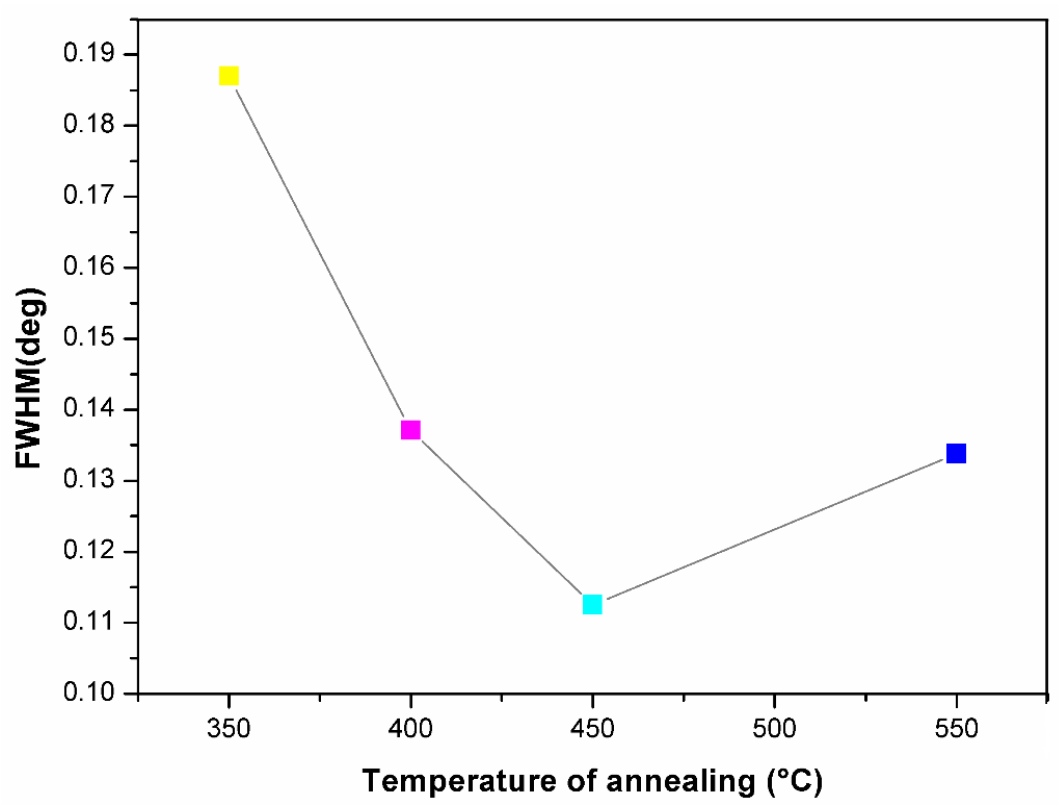

Figure 5 : FWHM of (112) peak of CZTS samples 


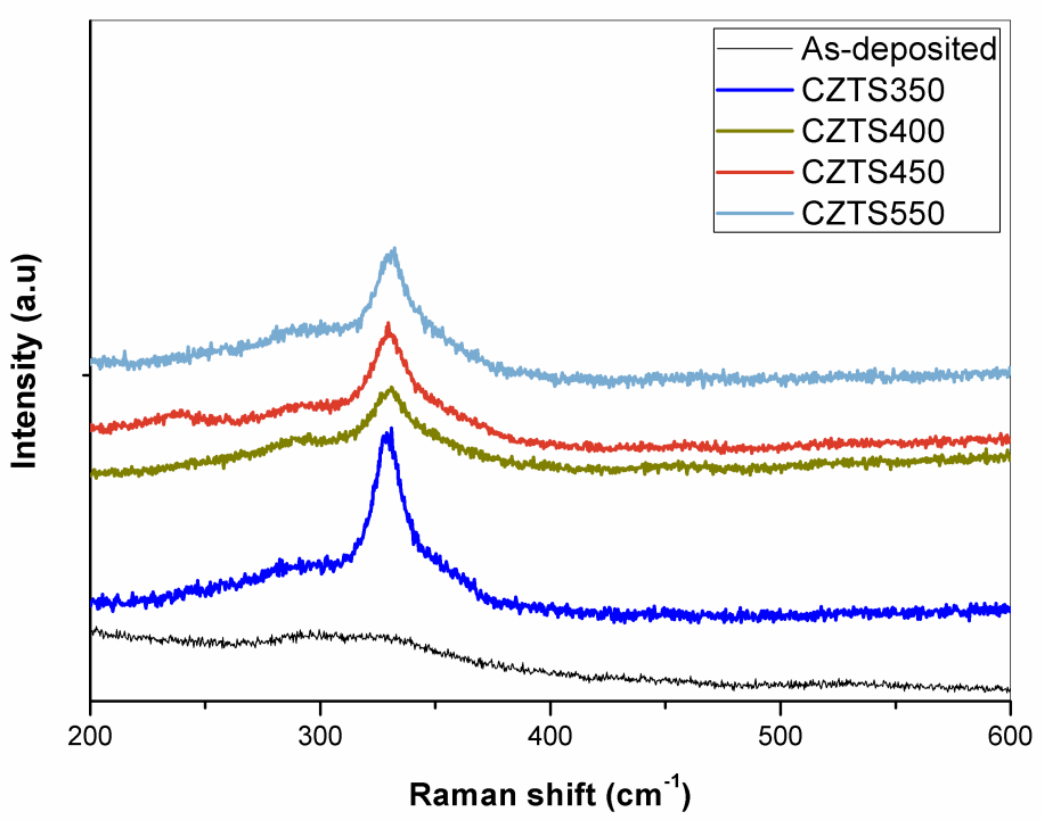

Figure 6 : Raman spectra of CZTS thin films at different annealing temperature

The zincblende structure of tetragonal $\mathrm{Cu}_{2} \mathrm{SnS}_{3}$ and cubic $\mathrm{ZnS}$ as secondary phases has the same structure as kesterite phases of CZTS and they are very difficult to distinguish with X-ray diffraction characterization technique [139]. Raman spectra of kesterite CZTS thin films annealed at different temperatures were recorded in the range of $200-600 \mathrm{~cm}^{-1}$ and was shown in Figure. 6. The main peaks at $330 \mathrm{~cm}^{-1}$ and the weak peaks at $286 \mathrm{~cm}^{-1}$ does not corresponds to the principal peaks of $Z n S\left(356 \mathrm{~cm}^{-1}\right)$ and $\mathrm{Cu}_{2} S n S_{3}\left(337 \mathrm{~cm}^{-1}, 351 \mathrm{~cm}^{-1}\right)$ but perfectly matched with kesterite structure. Raman peaks characteristics of CZTS kesterite phase shows the formation of high purity crystalline CZTS thin films [140,141]. Along with XRD results, Raman spectra evolve with the annealing temperature and indicate the formation of CZTS phase at low temperature. The combined analysis $X R D$ and Raman spectroscopy, shows that the films annealed at different temperatures are kesterite CZTS rather than a mixture of $\mathrm{Cu}_{2} \mathrm{SnS}_{3}$ and $\mathrm{ZnS}$.

\subsection{SEM, AFM and EDS studies}

The SEM surface images of the As-deposited and the annealed CZTS thin films are revealed in Figure. 7. We notice that there is a very large morphological difference between the CZTS thin films. The morphology of the As-deposited film shows in (Figure. 7a) deduces that the film has a non-uniform texture with the presence of some voids or cavities. Thereafter, the annealing of the As-deposited films in a place rich in sulfur render up the film more compact and more uniform which explains the annealing process. 
From Figure. 7, it is observed that the surface morphologies of the films obviously change by increasing the annealing temperature from $350^{\circ} \boldsymbol{C}$ to $550^{\circ} \boldsymbol{C}$. The surface $\boldsymbol{S E M}$ image of the sulfurized $\boldsymbol{C Z T S}$ thin film at $350^{\circ} \boldsymbol{C}$, derived from the co-electrodeposition of $\boldsymbol{C u}_{2} \boldsymbol{Z n S n S}$ precursors with two complexing agents, is shown in (Figure. 7b) the presence of a homogeneous compact morphology is beneficial for the separation and transport of charge carriers and whereof for the application of solar cells. The annealed film at $350^{\circ} \mathrm{C}$ shows a homogeneous morphology with a small grain size. By increase in temperature arround $100^{\circ} \boldsymbol{C}$, the morphology of the film becomes more homogeneous with a crystalline disposition of uniform thickness and resultantly the grain shape becomes in more spherical geometries [142]. The size of the grains constituting the film grew gradually with the increase of the annealing temperature up to $450^{\circ} \boldsymbol{C}$ as optimal value and this shown from the Figure. 7. However, if we increase the temperature more, up to $550^{\circ} \mathrm{C}$ with the composition used, the surface image has densely packed large grains and the morphology becomes disrupted. Therefore, the size growth was endorsed to a temperature of annealing and the composition of sulfur. The morphological study by $\boldsymbol{F E S E M}$ made it possible to conclude that the morphology of the CZTS thin film surface depends strongly on the annealing temperature and this is confirmed also with the results of $\boldsymbol{X} \boldsymbol{R} \boldsymbol{D}$, as mentioned above. 


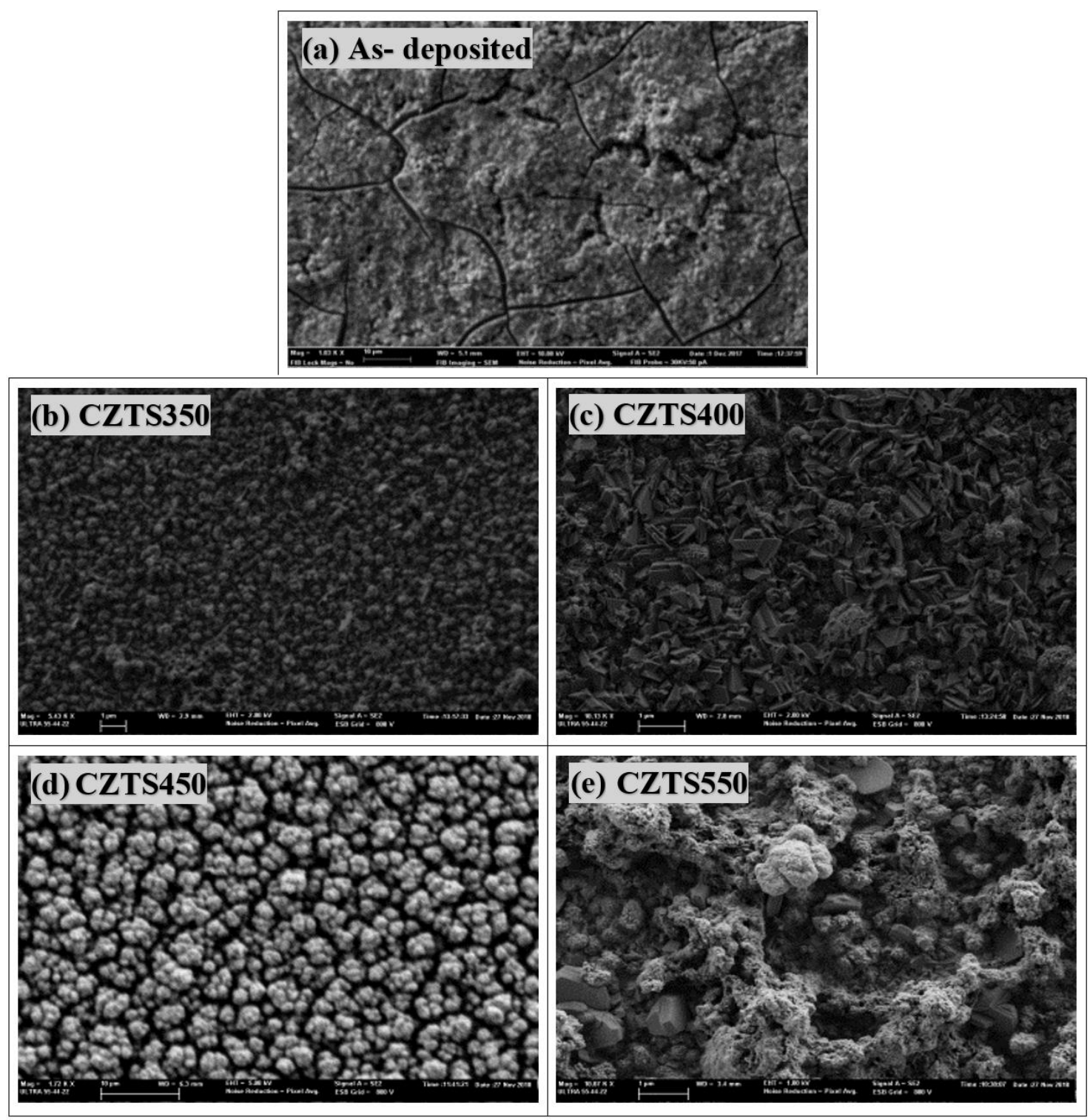

Figure $7: \boldsymbol{S E M}$ surface morphological images of $\boldsymbol{C Z T S}$ films at different annealing temperatures

Figure. 8 shows $2 \boldsymbol{D}$ atomic force microscopy ( $\boldsymbol{A F M}$ ) images of $\boldsymbol{C Z T S}$ thin films

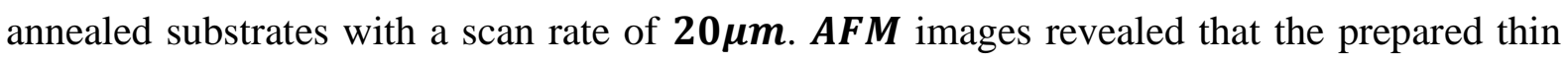
films have a uniform and rough surface topography and observation is basically harmonic with the $\boldsymbol{S E M}$ images. These are clearly observed from Figure. 8(b-c-d) that the topography of the samples is similar by that given by $\boldsymbol{S E M}$ and the size of the crystalline increases with the temperature. We noticed that, there is agglomeration at higher temperatures; a consequence of this agglomeration is the formation of clusters. Similarly, for the sample prepared at low temperature $\left(350^{\circ} \boldsymbol{C}\right)$, it was realized that it had the same properties offered by $\boldsymbol{S} \boldsymbol{M}$ technique. 


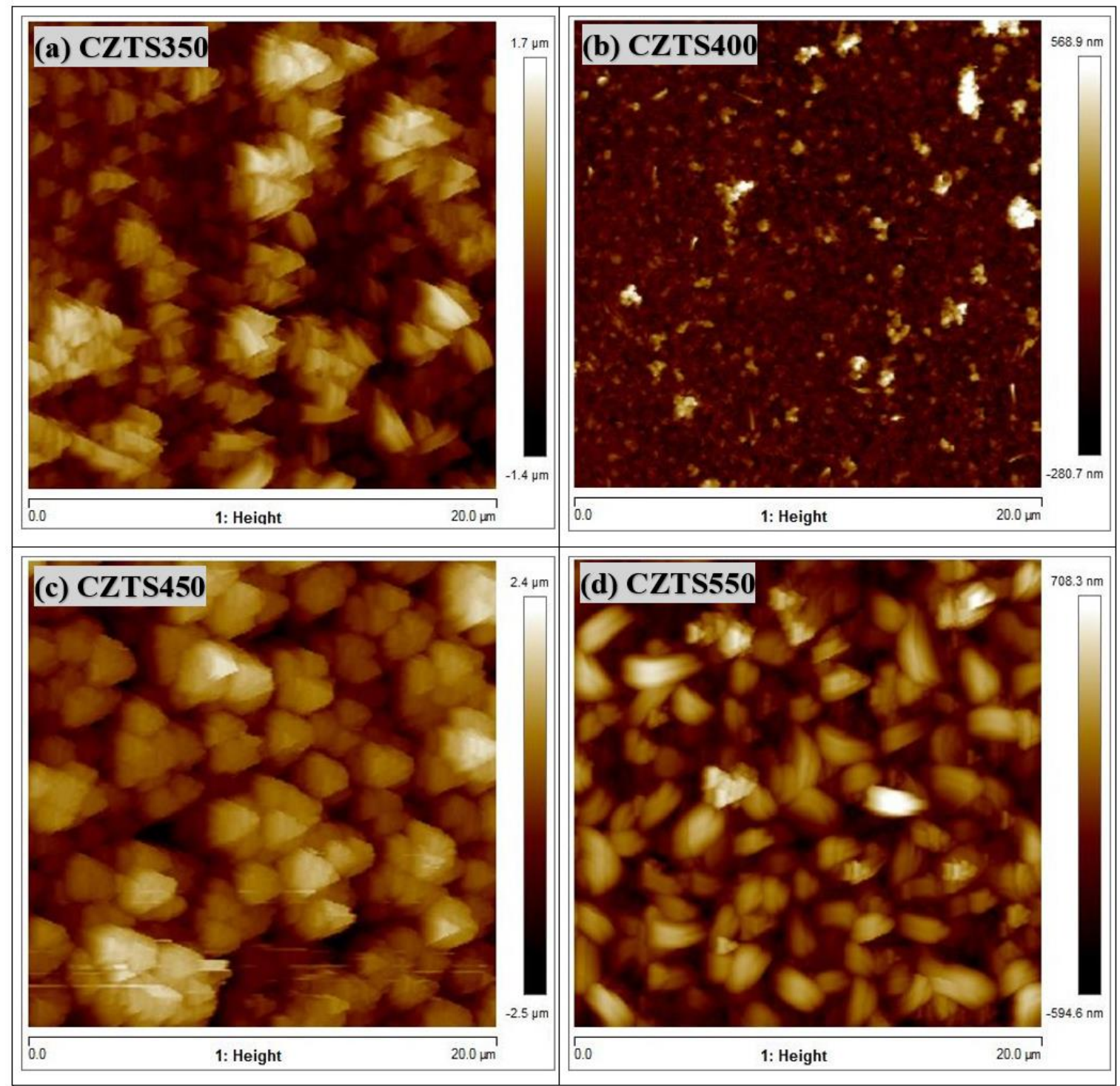

Figure 8 : Two-dimensional topographical spatial maps of $\boldsymbol{C Z T S}$ thin films

The $\boldsymbol{E D S}$ data disclosed the existence of an elemental composition in thin films deposited for different complexing agents under different annealing temperatures. This is obviously shown in Table 2.

Table 2 : Elemental and composition ratios of prepared CZTS thin films

\begin{tabular}{cccccc}
\hline \multirow{2}{*}{ Sample ID } & \multicolumn{5}{c}{ Elements } \\
\cline { 2 - 6 } & $\mathbf{C u}$ & $\mathbf{Z n}$ & Sn & $\mathbf{S}$ & $\mathbf{C u} /(\mathbf{Z n + S n})$ \\
\hline As-deposited & 35.24 & 12.27 & 17.26 & 35.22 & 1.193363 \\
CZTS350 & 24.04 & 7.73 & 19.38 & 48.85 & 0.88675765 \\
CZTS400 & 21.53 & 9.79 & 19.94 & 48.73 & 0.72418433 \\
CZTS450 & 21.83 & 9.67 & 20.25 & 48.26 & 0.7296123 \\
CZTS550 & 21.06 & 9.32 & 23 & 46.62 & 0.65160891 \\
\hline
\end{tabular}


Table 2 shows that all the thin films present a near stoichiometry metal atomic ratio. The $\boldsymbol{C u} /(\boldsymbol{Z n}+\boldsymbol{S n})$ ratio of annealed samples at different temperature has a range between 0.65 and 0.89, what suits with the literature [47]. In order to avoid the appearance of a secondary phase in the CZTS thin films, we have precisely controlled the chemical composition with the temperature variation in a zone from $350^{\circ} \mathrm{C}$ to $550^{\circ} \mathrm{C}$. But since at low temperature it is possible to lose the crystalline structure, therefore, the addition of complexing agent $\mathrm{Na}_{2} \mathrm{SO}_{4}$ to strengthen the film becomes necessary. Similarly, the amount of sulfur in the sulfurized films decreases with increasing annealing temperature. Therefore, the evaporation temperature of the sulfur is about $450^{\circ} \mathrm{C}$. Consequently, this can be due to a loss of sulfur during annealing specifically for sample CZTS550.

\section{4. $\quad \underline{U V \text {-visible spectroscopy }}$}

The power conversion efficiency of a photovoltaic device is highly depended upon band gap of the material. Therefore, to find optical energy band gap of the material the optical absorption spectra were used. The value of the band gap energy is carried out by the measured transmittance spectra data using the following relation given in equation:

$$
(\alpha h v)^{2}=A(h v-E g)^{n} / h v
$$

The Tauc's relation enforce relation between absorption and energy, where $\boldsymbol{\alpha}$ is the absorption coefficient, $\boldsymbol{h}$ is a Plank's constant, $\boldsymbol{v}$ is the frequency of incident light, $\boldsymbol{A}$ is a constant interrelated with the effective masses of electron and as well as holes and also to the reactive index, $\boldsymbol{h} \boldsymbol{v}$ is the photon energy, the energy band gap of the material is designated by $\boldsymbol{E} \boldsymbol{g}$ and finally $\boldsymbol{n}$ is a constant that depends on the nature of the optical transition ( $\mathrm{n}=1 / 2$ for direct band gap transitions). The optical absorption spectra for the CZTS thin films were recorded in the wavelength range of 350-1200nm at room temperature. The difference between higher valence band levels and conduction band levels gives us access to determine a fundamental value of band gap energy. According to the graph delineate between $(\boldsymbol{\alpha h \boldsymbol { h }})^{\mathbf{2}}$ as $\mathrm{Y}$-axis and $\boldsymbol{h} \boldsymbol{v}$ as $\mathrm{X}$-axis, the value of the band gap energy is estimated by plotting the extrapolation of the linear part of the spectrum to the horizontal photon energy axis [143]. Figure. 9 shows the band gaps of the annealed $\mathrm{CZTS}$ thin films, ranged between $1.46 \mathrm{eV}$ and $1.54 \mathrm{eV}$, which is decreased with increasing the temperature of annealing. The modification of structural properties, including grain size and crystallinity, has played a role in varying optical properties [144]. The band gap value of samples CZTS350, CZTS400, CZTS450 and CZTS550 are closed to $1.52 \mathrm{eV}, 1.54 \mathrm{eV}, 1.50 \mathrm{eV}$ and $1.47 \mathrm{eV}$ respectively. From the obtained band gap values, we 
deduced that the $\boldsymbol{C Z T S}$ films have an optimal band gap required for high conversion efficiency thin film solar cells.

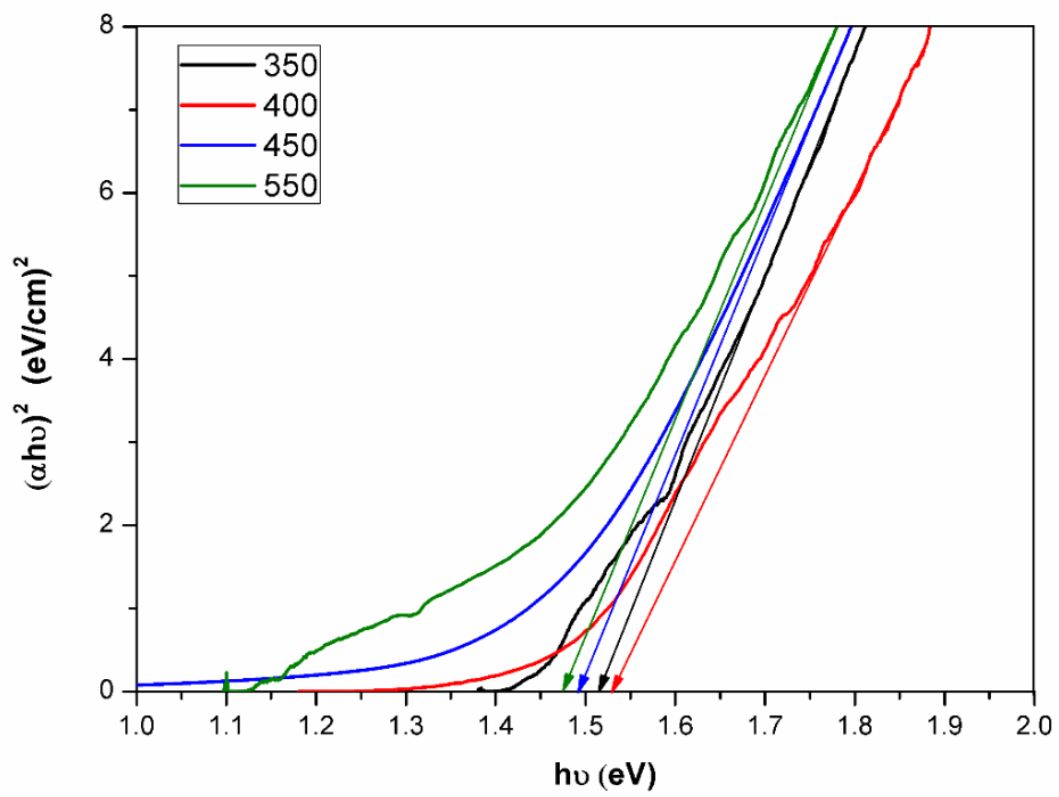

Figure 9 : Variation of $(\boldsymbol{a h} \boldsymbol{v})^{2}$ as a function of photon energy (hv) for deposited CZTS films at a different temperature of annealing

\section{Conclusion}

The one-step electrodeposition of thin films $\boldsymbol{C Z T S}$ solar cells was carried out on ITO substrates with a simple solution containing non-toxic and abundant elements, intending to reduce the temperature of annealing; we optimized the electrolyte bath composition. Foremost, a study on the influence of annealing temperature on substrate structure and morphology was carried out which shows that the use of annealing temperature around $450^{\circ} \mathrm{C}$ gives the best results and can be considered as optimal temperature for the first composition of the electrolyte. Below this temperature the crystalline structure changes and the uniformity of the morphology risks has deteriorated, although with the addition of some milligram of $\boldsymbol{N a}_{2} \boldsymbol{S O}_{4}$ which is the object of the composition 2 , it is possible to reduce the temperature to $350^{\circ} \mathrm{C}$ while retaining the characteristics of the $\boldsymbol{C Z T S}$ film. XRD, SEM and optical absorption itemize that the films are chiefly kesterite. In quality, this may be beneficial for solar cells because of lower recombination rates and wholly support an enduring technology dimension.

\section{ACKNOWLEDGMENTS}

This work was supported by Ministerio de Economía y Competitividad (Spain) through grant ENE2016-77798-C4-2-R. 
Article 2

\section{Back contact effect on electrodeposited CZTS kesterite thin films experimental and numerical investigation}

Solar Energy 194 (2019) 932-938

Contents lists available at ScienceDirect

Solar Energy

journal homepage: www.elsevier.com/locate/solener

Back contact effect on electrodeposited CZTS kesterite thin films experimental and numerical investigation

Hanae Toura $^{\mathrm{a}, \mathrm{b}, *}$, Yousaf Hameed Khattak ${ }^{\mathrm{a}, \mathrm{c}, *}$, Faisal Baig ${ }^{\mathrm{a}, \mathrm{c}}$, Bernabe Mari Soucase ${ }^{\mathrm{a}}$, Mohamed Ebn Touhami ${ }^{\mathrm{b}}$

${ }^{a}$ School of Design Engineering, Universitat Politecrica de Valencia, Cami de Vera, Spain

Vepartment of Chemistry, University Ibn Tofail, Kenitra, Morocco

Laboratory Materials and Environment Engineering: Modeling and Application, Department of Chemistry, University
${ }^{2}$ Electrical Engineering Department, Federal Urdu University of Arts, Science and Technology Islamabad, Pakistan

A R T I CLE I N F O

\section{Keywords:}

CZTS

Kesterite

Thin films

Back contact
Mo

Mo

ITO

SCAPS

\begin{abstract}
A B S T R A C T
Kesterite $\mathrm{Cu}_{2} \mathrm{ZnSnS}_{4}(\mathrm{CZTS})$ with an optimal band gap of $1.5 \mathrm{eV}$ is an auspicious material to be used as absorber layer high efficiency thin film photovoltaic cells. Effect of substrates on the morphology and structural properties of CZTS kesterite thin films were analyzed by depositing CZTS on Molybdenum, Indium doped tin oxide, and Fluorine doped tin oxide via electrochemical deposition method. The electrolyte contains $\mathrm{CuSo}_{4}, \mathrm{ZnSo}_{4}, \mathrm{SnSo}_{4}$ and $\mathrm{Na}_{2} \mathrm{~S}_{2} \mathrm{O}_{3}$ as precursors, with $\mathrm{Na}_{3} \mathrm{C}_{6} \mathrm{H}_{5} \mathrm{O}_{7}$ and $\mathrm{C}_{4} \mathrm{H}_{6} \mathrm{O}_{6}$ as complexing agents. Electrochemical depositions were carried out at room temperature with a voltage of $-1.05 \mathrm{~V}$ vs. $\mathrm{Ag} / \mathrm{AgCl}$ reference electrode. Films were annealed at a temperature around $450^{\circ} \mathrm{C}$ and then characterized by X-ray diffraction. The characterization shows the development of CZTS kesterite structure, with a good crystallinity on Mo substrates and phase purity, which were also confirmed by Raman spectroscopy and scanning electron microscopy. Then optical measurewhich were also confirmed by Raman spectroscopy and scanning electron microscopy. Then optical measure-
ments showed that the deposited thin films present a bandgap of around $1.47 \mathrm{eV}$. Correspondingly, the effect of metal contact work function for these substrates were also investigated with the aid of device modeling software SCAPS. The analysis shows that for given solar cell structure, back contact/CZTS/CdS/ZnO, Mo substrates presented better performance.
\end{abstract}




\title{
Back contact effect on electrodeposited CZTS kesterite thin films experimental and numerical investigation
}

\author{
Hanae Toura ${ }^{1,2, *}$, Yousaf Hameed Khattak ${ }^{1,3}$, Faisal Baig ${ }^{1,3}$, Bernabe Mari Soucase ${ }^{1}$, Mohamed Ebn \\ Touhami $^{2}$ \\ ${ }^{1}$ School of Design Engineering, Universitat Politecnica de Valencia, Cami de Vera, Spain \\ ${ }^{2}$ Laboratory Materials and Environment Engineering: Modeling and Application, Department of Chemistry, University Ibn Tofail, Kenitra, Morocco \\ ${ }^{3}$ Electrical Engineering Department, Federal Urdu University of Arts, Science and Technology Islamabad, Pakistan \\ *Corresponding Author: hanae.toura@gmail.com
}

\begin{abstract}
:
Kesterite $\boldsymbol{C u}_{2} \mathbf{Z n S n S}_{4}(\mathrm{CZTS})$ with an optimal band gap of $1.5 \mathrm{eV}$ is an auspicious material to be used as absorber layer high efficiency thin film photovoltaic cells. Effect of substrates on the morphology and structural properties of CZTS kesterite thin films were analyzed by depositing CZTS on Molybdenum, Indium doped tin oxide, and Fluorine doped tin oxide via electrochemical deposition method. The electrolyte contains $\mathbf{C u S o}_{\mathbf{4}}, \mathbf{Z n S o}_{\mathbf{4}}, \mathbf{S n S o}_{4}$ and $\mathrm{Na}_{2} \mathbf{S}_{2} \mathbf{O}_{3}$ as precursors, with $\mathrm{Na}_{3} \mathbf{C}_{6} \mathbf{H}_{5} \mathbf{O}_{7}$ and $\mathbf{C}_{4} \mathbf{H}_{6} \mathbf{O}_{6}$ as complexing agents. Electrochemical depositions were carried out at room temperature with a voltage of $-1.05 \mathrm{~V}$ vs. $\mathrm{Ag} / \mathrm{AgCl}$ reference electrode. Films were annealed at a temperature around $450^{\circ} \mathrm{C}$ and then characterized by X-ray diffraction. The characterization shows the development of $\boldsymbol{C Z T S}$ kesterite structure, with a good crystallinity on Mo substrates and phase purity, which were also confirmed by Raman spectroscopy and scanning electron microscopy. Then optical measurements showed that the deposited thin films present a bandgap of around $1.47 \mathrm{eV}$. Correspondingly, the effect of metal contact work function for these substrates were also investigated with the aid of device modeling software SCAPS. The analysis shows that for given solar cell structure, back contact/CZTS/CdS/ZnO, Mo substrates presented better performance.
\end{abstract}

Keywords: $\boldsymbol{C Z T S}$, Kesterite, Thin films, Back contact, Mo, ITO, FTO, SCAPS 


\section{Introduction}

Growing demand for energy to comply with human communal and economic development has inspired many researchers to develop new materials for photovoltaic applications with high power conversion efficiencies (PCE) and low cost of the manufacturing process [132]. For large scale production with low cost thin-film solar cells (SC) are suitable for photovoltaic applications. In the current economic scenario, devices without degradation of materials with high-power conversion efficiency are fabricated for the generation of electricity [145]. Copper indium gallium selenium (CIGS) and cadmium telluride (CdTe) based thin film SC received considerable attention due to their higher photo conversion efficiencies, large scale commercial production, excellent optical as well as electrical properties, simple fabricating techniques and high absorption coefficient [107,146]. Rising costs of rare earth materials and toxicity of cadmium (Cd), tellurium (Te), gallium (Ga) and indium (In) limit technological development and large-scale commercial production of these devices $[35,147,148]$. The non-toxic and abundance in nature quaternary kesterite compound gaining prominence in the manufacture of low-cost thin-film SC technology [149]. The promising quaternary compounds such as CZTS $\left(\mathrm{Cu}_{2} \mathrm{ZnSnS}_{4}\right), \mathrm{CZTSe}\left(\mathrm{Cu}_{2} \mathrm{ZnSnSe}_{4}\right)$ and their alloys (CZTSSe) $\mathrm{Cu}_{2} \mathrm{ZnSn}\left(\mathrm{S}_{\mathrm{X}} \mathrm{Se}_{1-\mathrm{x}}\right)_{4}$ having kesterite symmetrical structures are emerging as the most auspicious replacement for the chalcopyrite absorbers [49,150-155]. The outstanding features and efficient performance of these kesterite based materials made them very fascinating in the thin film research community [6,156]. In CIGS absorber substituting indium (In) with zinc (Zn) and gallium (Ga) with tin (Sn), CZTS is considered as a perfect light absorber material having a large absorption coefficient of $\alpha>10^{4} \mathrm{~cm}^{-1}$ [157-160] and direct optical bandgap ranges among $1.4 \mathrm{eV}$ to $1.5 \mathrm{eV}[73,114,115,158]$. CZTS based SC deposited by vacuum was first reported in 1997 having photo-conversion efficiency of 0.66\%[161]. With further technological development and detailed research in CZTS materials the power conversion efficiency of $6.7 \%$ was achieved in 2009 [162]. As per the Shockley-Queisser limit, theoretically, around 28\% conversion efficiency is possible from CZTS based SC by tuning the bandgap energy [163]. In recent theoretical studies of $\boldsymbol{C Z T S}$ solar cells using the Shockley-Queisser limit, it was showed that $\boldsymbol{C Z T S}$ can reach up to an efficiency of $32.4 \%$ [164]. During the last few years, the kesterite materials have attracted a lot of attention for being a good absorbent coating for thin-film SC, much research has been conducted to improve the efficiency of this layers [165]. PCE of 8.4\%, $11.6 \%$, and $12.6 \%$ was achieved with pure sulfide CZTS, pure selenide $\mathrm{Cu}_{2} \mathrm{ZnSnSe} 4$ (CZTSe) and mixed sulfoselenide $\mathrm{Cu}_{2} \mathrm{ZnSn}(\mathrm{S}, \mathrm{Se})_{4}$ (CZTSSe) SC, respectively [166][167]. In 
the sight of the toxicity problem, the use of pure sulphide (CZTS) is preferable. Various groups have tried different methods for the deposition of CZTS thin film SC. Kesterite CZTS have been deposited by spray pyrolysis [168], pulsed laser deposited [65], SILAR [169], sol-gel method [170], spin coating [171], chemical bath deposition [117] and also the electrodeposition $[172,173]$. We found that electrochemical deposition a well-known technique used by the research community because of its cost effectiveness and simplicity in implementation. Furthermore, literature is available for electrochemical deposition of CZTS onto different substrates such as Molybdenum (Mo) [132], Fluorine doped tin oxide (FT0) [174] and Indium doped tin oxide (ITO) [175].

In this work, the aim is to grow CZTS thin films onto different conductive glass substrates such as Mo, FTO, and ITO with the single step electrochemically deposited technique under room temperature using $\mathrm{Na}_{3} \mathrm{C}_{6} \mathrm{H}_{5} \mathrm{O}_{7}$ and $\mathrm{C}_{4} \mathrm{H}_{6} \mathrm{O}_{6}$ as complexing agent. The choice of the conductive substrates is very important to control the quality of the film. The utility appears in the comparison of the structure, morphology, and elemental composition of CZTS kesterite thin films. The effect of a metal work function of different substrates was also investigated with the aid of numerical analysis using SCAPS software. From the analysis it was found that for SC structure Back contact/CZTS/CdS/ZnO, Mo substrates show better performance.

\section{Experimental}

To fabricate $\mathbf{C u}_{\mathbf{2}} \mathbf{Z n S n S}_{\mathbf{4}}$ (CZTS) kesterite thin films material were purchased from Sigma Aldrich and used without further purification. List of materials used are given below

$$
\begin{aligned}
\text { i. } & \mathrm{SnSO}_{4} \\
\text { ii. } & \mathrm{CuSO}_{4} \cdot 5 \mathrm{H}_{2} \mathrm{O} \\
\text { iii. } & \mathrm{ZnSO}_{4} \cdot \mathrm{H}_{2} \mathrm{O} \\
\text { iv. } & \mathrm{Na}_{2} \mathrm{~S}_{2} \mathrm{O}_{3} \\
\text { v. } & \mathrm{Na}_{3} \mathrm{C}_{6} \mathrm{H}_{5} \mathrm{O}_{7}
\end{aligned}
$$

The above materials used were $99.99 \%$ pure.

$\mathbf{C u}_{\mathbf{2}} \mathbf{Z n S n S}_{\mathbf{4}}$ (CZTS) kesterite thin films were elaborated by using one step electrochemical deposition. The composition of the electrolyte solution is formed in water with $\mathbf{0 . 0 2} \mathbf{M}$ copper sulfate $\mathrm{CuSO}_{4} \cdot \mathbf{5 H}_{\mathbf{2}} \mathbf{O}, \mathbf{0 . 0 2} \mathrm{M}$ zinc sulfate $\mathrm{ZnSO}_{4} \cdot \mathrm{H}_{\mathbf{2}} \mathbf{O}, \mathbf{0 . 0 2} \mathrm{M}$ tin sulfate $\mathbf{S n S O}_{4}$ and 0. 02M sodium thiosulfate $\mathrm{Na}_{2} \mathrm{~S}_{2} \mathrm{O}_{3}$, on which we will add $\mathbf{0 . 2} \mathbf{M}$ sodium citrate $\mathrm{Na}_{3} \mathrm{C}_{6} \mathbf{H}_{5} \mathbf{O}_{7}$ and $\mathbf{0 . 1 M}$ tartaric acid as a complexing agent. The prepared solution with a $\mathrm{pH}$ kept at 5 was used in an electrochemical cell containing three electrodes to cause chemical reduction reactions. Saturated calomel electrode (SCE) presents the reference electrode, the platinum 
wire (Pt) used as a counter electrode and three types of working electrode substrates with dimensions $\mathbf{1} \times \mathbf{2 . 5 \mathbf { c m } ^ { 2 }}$ were used (a) indium tin oxide (ITO) coated glass, (b) fluorine doped tin oxide (FTO) coated glass and (c) molybdenum (Mo) coated. Before using the conductive substrate as a working electrode, a cleaning process is followed by scrubbing with detergent, acetone, ethanol and distilled water for $10 \mathrm{~min}$ each step. Thereafter, the electrodeposition was implemented using Autolab PGSTAT302N on which the chronoamperometry process began with fixing the potential at $-1.05 \mathrm{~V}$ vs. $\mathbf{A g} / \mathbf{A g C l}$ for $30 \mathrm{~min}$. The process of electrodeposition takes time at room temperature and without stirring. After deposition, the as deposited $\boldsymbol{C Z T S}$ films were washed with distilled water and dried in air. Subsequently, the well adhered and uniform $\boldsymbol{C Z T S}$ thin films were annealed with sulfur powder $\mathbf{S}$ which accelerates the reactions under argon gas $(\mathbf{A r})[4,176]$. As reported in our previous work by using $\mathrm{Na}_{3} \mathbf{C}_{6} \mathbf{H}_{5} \mathbf{O}_{7}$ and $\mathbf{C}_{4} \mathbf{H}_{6} \mathbf{O}_{6}$ as complexing agents good crystal structure was attained for $\boldsymbol{C Z T S}$ kesterite thin film at an annealing temperature of $450^{\circ} \mathbf{C}$ for $30 \mathrm{~min}$ [4]. The crystallographic phase of p-layers was observed by using X-ray diffractometer (XRD, Rigaku Ultima IV diffractometer) using $\mathbf{C u}-\mathbf{K} \boldsymbol{\alpha}$ radiation $(\boldsymbol{\lambda}=\mathbf{1 . 5 4 0 6 0} \AA)$ with $2 \theta$ angle ranged from $20^{\circ}$ up to $60^{\circ}$. The morphological surface was observed by using a Zeiss ULTRA 55 FE-SEM (field emission scanning electron microscopy) model, equipped with an In-Lens SE detector for energy dispersive X-ray spectroscopical (EDS) analyzer to measure the composition of samples. Eventually, the optical properties of the ITO sample were tested by using Ocean Optics HR4000 UV-Visible spectrophotometer.

\section{Result and discussion}

\section{1. X-ray diffraction and Raman spectroscopy studies}

The X-ray diffraction patterns of all sulfurized CZTS thin films derived from $\mathbf{C u}-\mathbf{Z n}-\mathbf{S n}-$ $\mathbf{S}$ precursors electrochemical deposited onto different glass substrates are shown in Figure 1. The main peaks at approximately $2 \boldsymbol{\theta}=28.5^{\circ}, 32.9^{\circ}, 47.3^{\circ}$, and $56.1^{\circ}$ correspond to the kesterite CZTS structure (reference JCPDS card: 26-0575) [177], are present on all the samples elaborated with the planes reticular which correspond respectively to (112), (200), (220) and (312). All substrates show exhibit major peaks without any secondary phases such as $\mathbf{S n} \mathbf{S}_{\mathbf{2}}$ and $\mathrm{Cu}_{\mathbf{x}} \mathbf{S}[178]$.

The sample GS-Mo which is elaborated onto the molybdenum (Mo) glass substrate presents an extra peak at around $2 \boldsymbol{\theta}=40.39^{\circ}$ which identifies the structure of Mo with (110) direction [179-181]. We note that the intensity of the Mo peak is quite small compared to that of constituting kesterite structure, which is not the case in the other studies [132]. The increased 
intensity of the peak (112) relative to the peak of Mo indicates a thicker $\boldsymbol{C Z T S}$ film and stronger fibrous texture (112) for the film elaborate onto Mo substrate [182]. Similarly for the GS-FTO sample which has peaks at around $2 \boldsymbol{\theta}=26.5^{\circ}, 37.85^{\circ}, 51.56^{\circ}$ which generally corresponds to the peaks of fluorine tin oxide (reference JCPDS card: 46-1088) [174,183]. As far as the film elaborated onto FTO shows a fairly high intensity compared to other films, which explains that the crystallinity becomes more important, but it is likely to have grain sizes as important than a loss of homogeneity. The use of Mo conducting substrates for thin film CZTS electrochemically deposited results in thin polycrystalline films with good compositional uniformity, the main peak (112) shows an intensity so important and sharpen which explain that the film presents a good homogeneity and that necessary for the production of SC with a good performance.

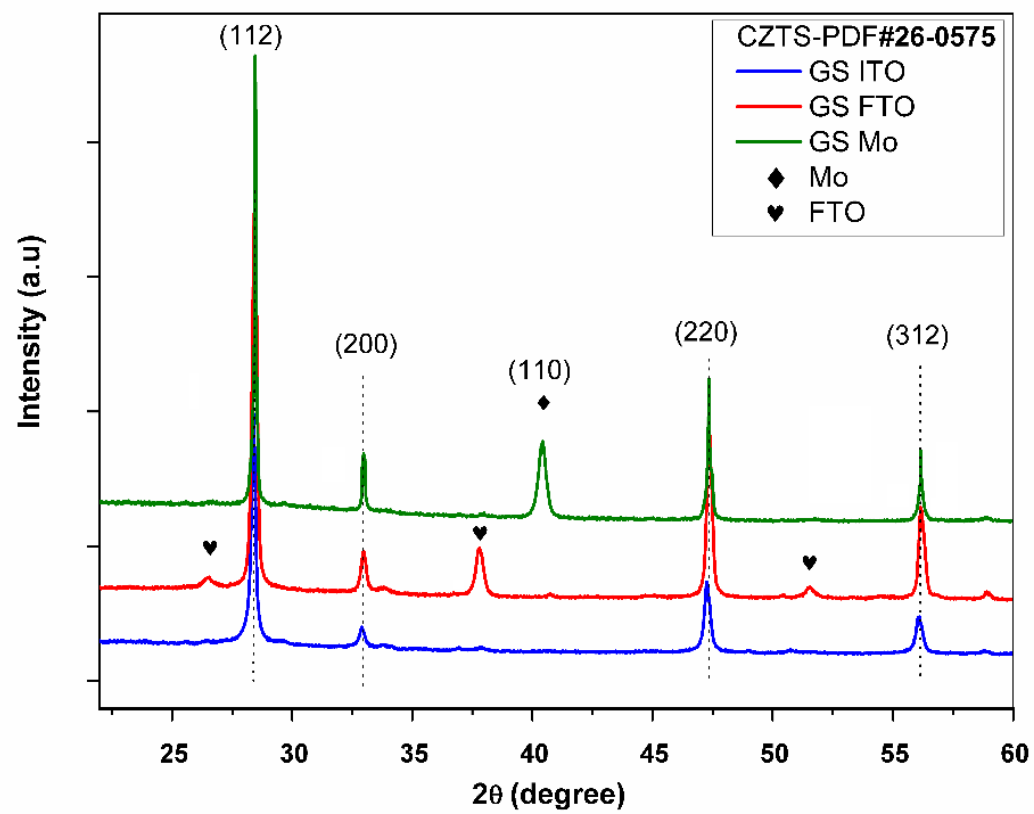

Figure 1 : XRD spectra of sulfurized CZTS samples grown at different glass supports

Figure 2 shows the Raman spectrum of the annealed CZTS thin films deposited onto different glass substrates in the range from $200 \mathrm{~cm}^{-1}$ up to $550 \mathrm{~cm}^{-1}$. The Raman spectroscopy technique is used to identify possible secondary phases of tetragonal $\mathrm{Cu}_{2} \mathrm{SnS}_{3}$ and cubic $\mathrm{ZnS}$ which are difficult to distinguish using the XRD since they represent the same fundamental zinc-blended structure as kesterite phases of $\boldsymbol{C Z T S}$. 


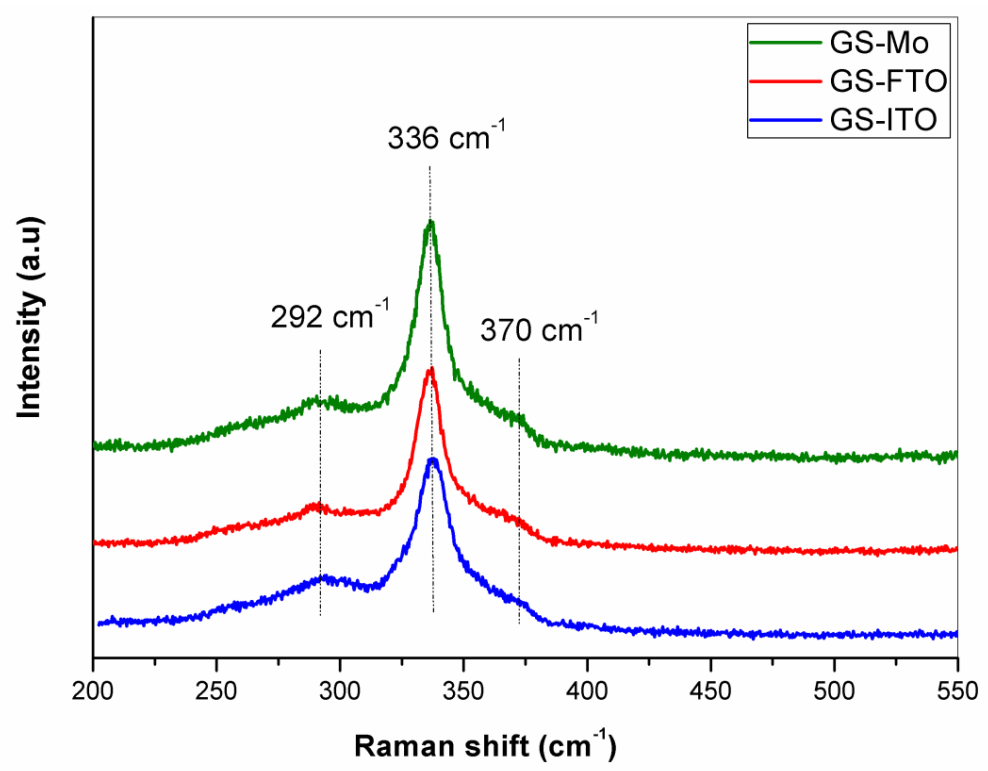

Figure 2 : Raman spectra of CZTS films deposited on diverse substrates

As Figure 2 shows, the Raman spectrums of all samples indicate the formation of the phase purity of the CZTS thin films with main peaks located at $336 \mathrm{~cm}^{-1}\left(\mathrm{~A}_{1}\right.$ peak) and other peaks around $292 \mathrm{~cm}^{-1}$ and $370 \mathrm{~cm}^{-1}$ as weak peaks. In addition, the Raman spectrum of $\boldsymbol{C Z T S}$ Mo sample exhibit formation of the tetragonal CZTS peak with a high intensity compared to the other substrate. As the substrates change from ITO to Mo, the intensity of the main peak (A1 peak) increases. Therefore, the crystallinity of the film's characteristic of the kesterite CZTS phase improved and the films show a high purity.

\section{2. Morphological and compositional studies}

The purpose of this research was to examine the influence of working electrode of $\boldsymbol{C Z T S}$ films deposited by one step electrodeposition. SEM images of thin films on different substrates, subsequently drying and annealing at $450^{\circ} \mathrm{C}$, are presented in Figure 3.

For each sample, SEM images were presented with the dimensions of 10 micrometers, 1 micrometer and samples cross section. All samples show a uniform layer of kesterite structure, with a difference in porosity ranging from ITO to Mo. It is clear that the uniformity grown grains and homogeneous thin film surface shown in Figure 3C produced onto Mo substrate is much improved as compared to those presented in Figure 3B or 3A. The CZTS thin film elaborated on ITO coated glass present some cracks on the surface, which is also the case for Figure $3 \mathrm{~b}$ (FTO substrate) but it remains less with larger grains than compared to other supports. The cross section of the substrates shows a large film diameter but this depends mainly on the deposition time and not on the basic substructure [184]. The inhomogeneity of the absorber layer will produce a distribution of the formation for the buffer layer between the 
grain's boundaries. This will also limit the efficiency of the absorber layer [185]. The film deposited on ITO glass substrate particularly presents this drawback. Therefore, the results found by XRD for thin films elaborate on Mo coated glass are likewise verified by SEM. The morphology of the film onto Mo glass substrates shows a compact and uniform morphology, with coherent grains. Because of recombination phenomena at the grain boundary, the compact morphology significantly improves the performance of the CZTS SC.

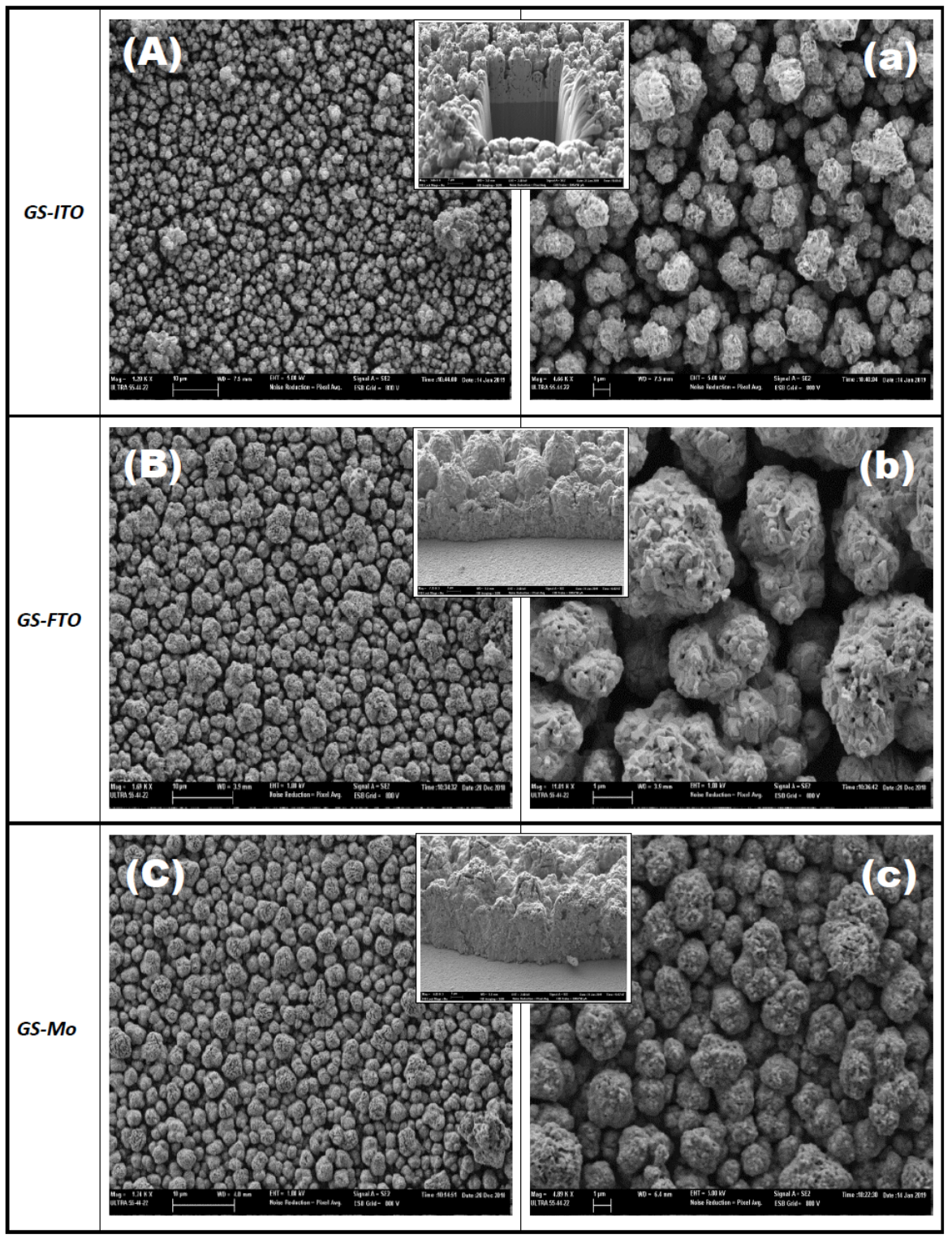

Figure 3 : CZTS films SEM images on (A) ITO, (B) FTO and (C) Mo substrates

The compositional analysis of annealed CZTS samples deposited onto different conductor substrates is shown in Table 1. 
Table 1: CZTS films composition deposited on different glass substrates

\begin{tabular}{ccccccc}
\hline Sample & \multicolumn{6}{c}{ Composition Ratio } \\
\cline { 2 - 7 } ID & $\boldsymbol{C u}$ & $\boldsymbol{Z n}$ & $\boldsymbol{S n}$ & $\boldsymbol{S}$ & $\boldsymbol{C u} / \boldsymbol{Z n}+\boldsymbol{S n}$ & $\mathbf{Z n} / \mathbf{S n}$ \\
\hline GS-ITO & 23.33 & 11.29 & 16.58 & 48.8 & 0.837101 & 0.68 \\
GS-FTO & 23.07 & 12.02 & 17.05 & 47.86 & 0.793602 & 0.70 \\
GS-Mo & 23.19 & 14.89 & 14.9 & 47.02 & 0.778449 & 0.99 \\
\hline
\end{tabular}

The EDS results depicted the existence of all elements in the deposited films which is obvious. The thin films deposited on glass substrates (FTO and Mo coated) show a closer stoichiometry which is not the case for GS-ITO thin film. The stoichiometry represented is far from the meant composition 2:1:1:4 which requires an in-depth study on the different conditions of elaboration such as sample parameters, atoms scattering power and also the comparison with standard samples to reach it; but it remains similar to previous research [186]. Namely, the choice of the working electrode in the electrodeposition technique often affects the formation of the absorber layer above which is already approved by SEM images. It was examined that the ratio $\mathrm{Cu} / \mathrm{Zn}+$ $\mathrm{Sn}$ is less than 0.9 that is proportionally near to the values for higher performance CZTS absorber [174,187].

\section{3. Optical properties}

Semiconductor materials are known by fundamental property which is the energy of the forbidden band and that is the difference of energy among the maximum level of valence bands and minimum level of the conduction band. Using the absorption data from the transmittance spectra, the bandgap energy can be found following the classic relation: [188,189]

$$
\boldsymbol{\alpha h v}=\mathbf{A}(\mathbf{h v}-\mathbf{E g})^{\mathbf{n}}
$$

Where $\alpha$ is the absorption in semiconductor, hv is photon energy, Eg offered the bandgap energy, $\mathrm{n}$ depends on the transition probability, it takes the value of $1 / 2$ or 2 correspondings to indirect and direct bandgaps, respectively. Thus, the extrapolation of the linear region to interrupt the $\mathrm{X}$-axis from the curve $(\alpha \mathrm{hv})^{2}$ according to hv describe the value of the bandgap energy. Figure 4 shows approximated $(\alpha h v)^{2}$ variation as a function of hu for CZTS films. The value of $1.47 \mathrm{eV}$ has been observed, which is consistent with Eg values previously reported for the CZTS thin film [190,191]. This value appears to be an appropriate energy bandgap for a SC since it is not reliant on the change of support but mainly on the change of electrolyte composition or the annealing temperature [164,188]. 


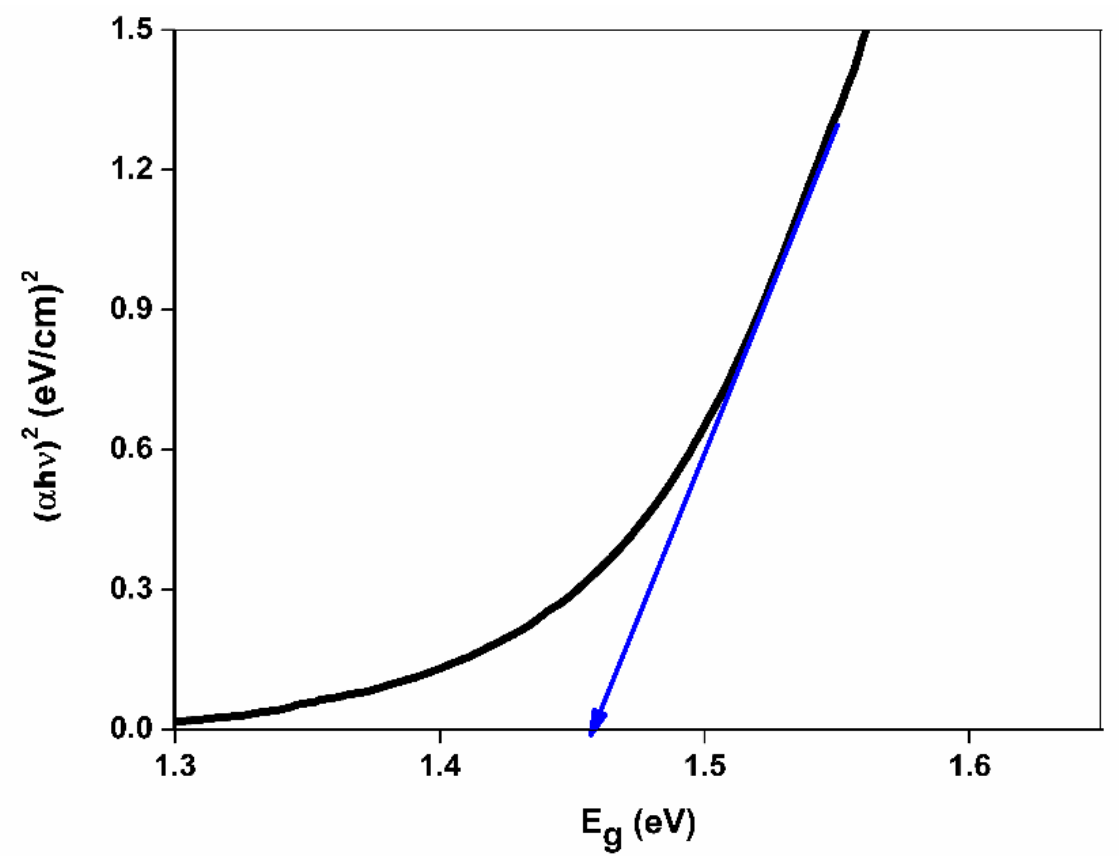

Figure $4:(\boldsymbol{\alpha} \boldsymbol{h} \boldsymbol{v})^{2}$ variation as a function of $\boldsymbol{h} \boldsymbol{v}$ for CZTS films

\section{4. Numerical Analysis}

When the semiconductor is amalgamated with the metal contact, a junction is formed between the semiconductor and metal contact. This junction formation is of two types and depending upon the p-type semiconductor bandgap, simulation parameters, electron affinity and metalwork function given in Table 2, Table 3, and Table 4.

i. Schottky junction $\chi_{\text {absorber }}+E_{g}>$ metal work function

ii. Ohmic junction $\chi_{\text {absorber }}+E_{g}<$ metal work function

The junction formed between the $p$-type CZTS kesterite and back contacts used in this study is of type 1 Schottky Junction. Therefore, when a contact is made between metal and $p$-type semiconductor material, and because of the low charge density of absorber material holes are removed from the surface of the material. The removing of holes from a surface of materials creates a vacancy for electrons and this leads to the establishing depletion region in the semiconductor. The formation of band bending with different back contacts and spike interface with CdS layer is plotted in Figure 5.

The parameters enlisted in Table 2 are used to simulate and analyze the basic characteristics of solar cells in SCAPS $-1 D$. These parameters are dielectric permittivity $\left(\varepsilon_{r}\right)$, electron affinities $(\chi)$, valance band and conduction band effective state densities $(N C, N V)$, intrinsic electron and hole carrier concentrations $(n, p)$, electron-hole mobilities $\left(\mu_{e}, \mu_{p}\right)$, thickness $(W)$ and bandgaps $\left(E_{g}\right)$. 
Table 2: Device modeling physical parameters used in $\boldsymbol{S C A P S}-\mathbf{1 D}$.

\begin{tabular}{cccc}
\hline Material parameters & $\boldsymbol{n}$-ZnO & $n$-CdS & $p$-CZTS \\
\hline$W(\boldsymbol{\mu m})$ & 0.1 & 0.1 & $1 \sim 4$ \\
$\chi(\mathbf{e V})$ & 4.6 & 4.5 & 4.5 \\
$\mathbf{E g}(\mathbf{e V})$ & 3.3 & 2.4 & 1.45 \\
$\boldsymbol{\varepsilon}_{\boldsymbol{r}}$ & 9 & 9 & 9 \\
$\mathbf{N C}\left(\mathbf{c m}^{-3}\right)$ & $2.2 \times 10^{18}$ & $1.8 \times 10^{19}$ & $2.2 \times 10^{18}$ \\
$\mathbf{N V}\left(\mathbf{c m}^{-3}\right)$ & $1.8 \times 10^{19}$ & $2.4 \times 10^{18}$ & $1.8 \times 10^{19}$ \\
$\boldsymbol{\mu}_{\boldsymbol{e}}, \boldsymbol{\mu}_{\boldsymbol{p}}\left(\mathbf{c m}^{2} / \mathbf{V s}\right)$ & $100 / 25$ & $100 / 25$ & $60 / 20$ \\
$n, p\left(\mathbf{c m}^{-3}\right)$ & $1 \times 10^{17}$ & $1 \times 10^{16}$ & $4 \times 10^{18}$
\end{tabular}

Table 3 : Physically induced defects.[192,193].

\begin{tabular}{lc}
\hline \multicolumn{1}{c}{ Defect properties } & Values \\
\hline Defect energy level $(\boldsymbol{e V})$ & 0.6 \\
Trap Density $\left(\mathrm{cm}^{-3}\right) \boldsymbol{N}_{\boldsymbol{t}}$ & $1 \times 10^{15}$ \\
Electrons Capture Cross section area $\left(\mathrm{cm}^{2}\right) \boldsymbol{\delta}_{\boldsymbol{e}}$ & $4.4 \times 10^{-15}$ \\
Holes Capture Cross section area of holes $\left(\mathrm{cm}^{2}\right) \boldsymbol{\delta}_{\boldsymbol{h}}$ & $4.4 \times 10^{-15}$
\end{tabular}

Table 4: Work function of metal and semiconductor

Semiconductors Electron Affinities, $\chi$

\begin{tabular}{lcc}
\hline \multicolumn{1}{c}{ Element } & Abbreviation & $\mathrm{eV}$ \\
\hline Copper zinc tin sulfide & $C Z T S$ & 4.5 \\
Cadmium sulfide & $C d S$ & 4.45 \\
Zinc oxide & ZnO & 4.5 \\
\hline & Metal Work function (eV) \\
\hline Indium tin oxide & ITO & 4.7 \\
Fluorine-doped tin oxide & FTO & 4.74 \\
Molybdenum & Mo & 4.95 \\
\hline
\end{tabular}




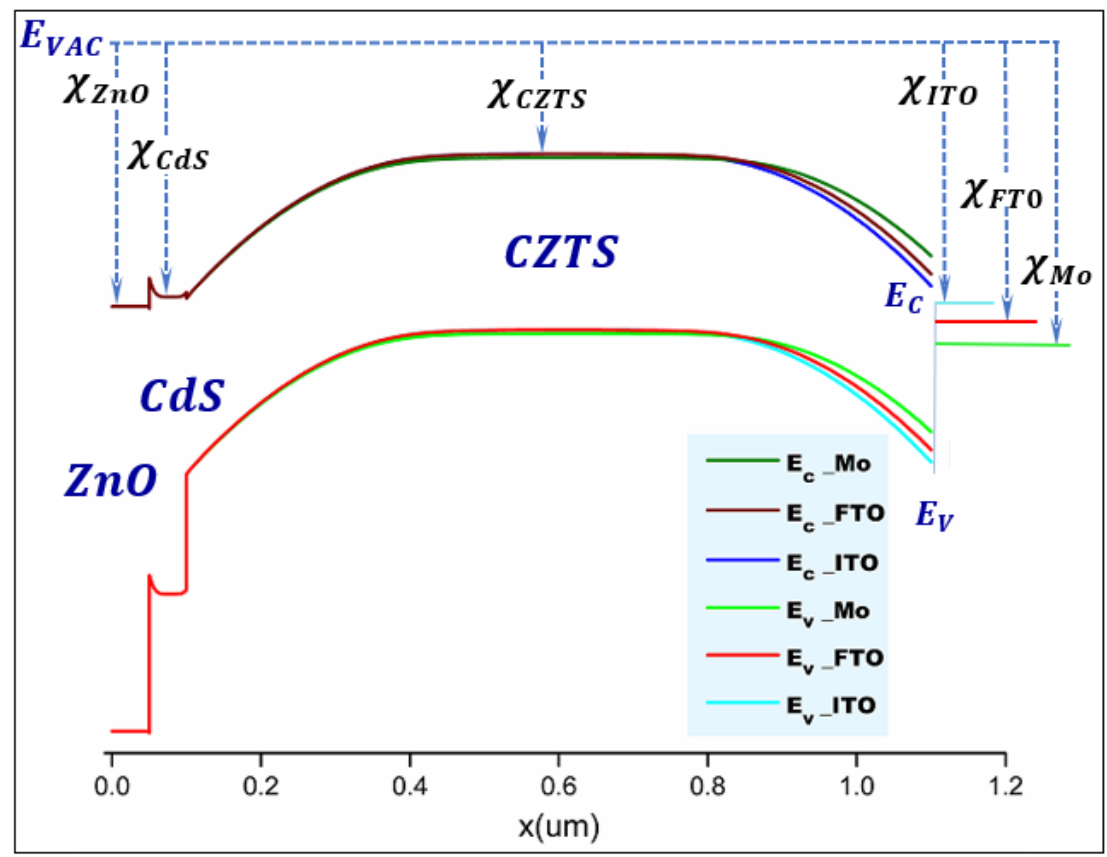

Figure 5 : Different metals and semiconductor Schottky junction and band formation From plotted band diagram different metal work function provides a different degree of band bending in CZTS layer. Now to analyze the effect of band bending on SC performance we used SCAPS - $1 D$ software. The results were evaluated based on our earlier studies for CZTS kesterite SC [34]. The major limitation in solar cell performance is recombination in a solar cell that takes place at three different regions of a solar cell. That is interface recombination between two different layers, bulk recombination, and metal contact recombination. Whereas metal contact recombination is highly depended upon metal work function and alignment of band edge of metal with absorber layer. Greater band bending at back contact will lead to higher recombination at back metal contact for solar cell. Based on results presented in Figure 6, Figure 7 and table 5, with $M o$ as back contact device performance was enhanced. Figure 6 shows the $J V$ characteristics of solar cells and Figure 7 shows the results for total recombination in SC. Based on the results with an increase in metal work function recombination near the back-contact interface is reduced and this in terms helps in enhanced device performance.

Table 5: Solar cell performance parameters

\begin{tabular}{|c|c|c|c|c|}
\hline Device & $\boldsymbol{P C E}(\%)$ & $\boldsymbol{F F}(\%)$ & $\boldsymbol{J}_{\boldsymbol{s c}}\left(\boldsymbol{m} \boldsymbol{A} / \mathbf{c m}^{\mathbf{2}}\right)$ & $\boldsymbol{V}_{\boldsymbol{o c}}(\boldsymbol{V})$ \\
\hline ITO/CZTS/CdS/ZnO & 1.93 & 55.70 & 24.76 & 0.14 \\
\hline FTO/CZTS/CdS/ZnO & 3.95 & 69.28 & 25.08 & 0.34 \\
\hline Mo/CZTS/CdS/ZnO & 8.38 & 75.93 & 25.56 & 0.44 \\
\hline
\end{tabular}




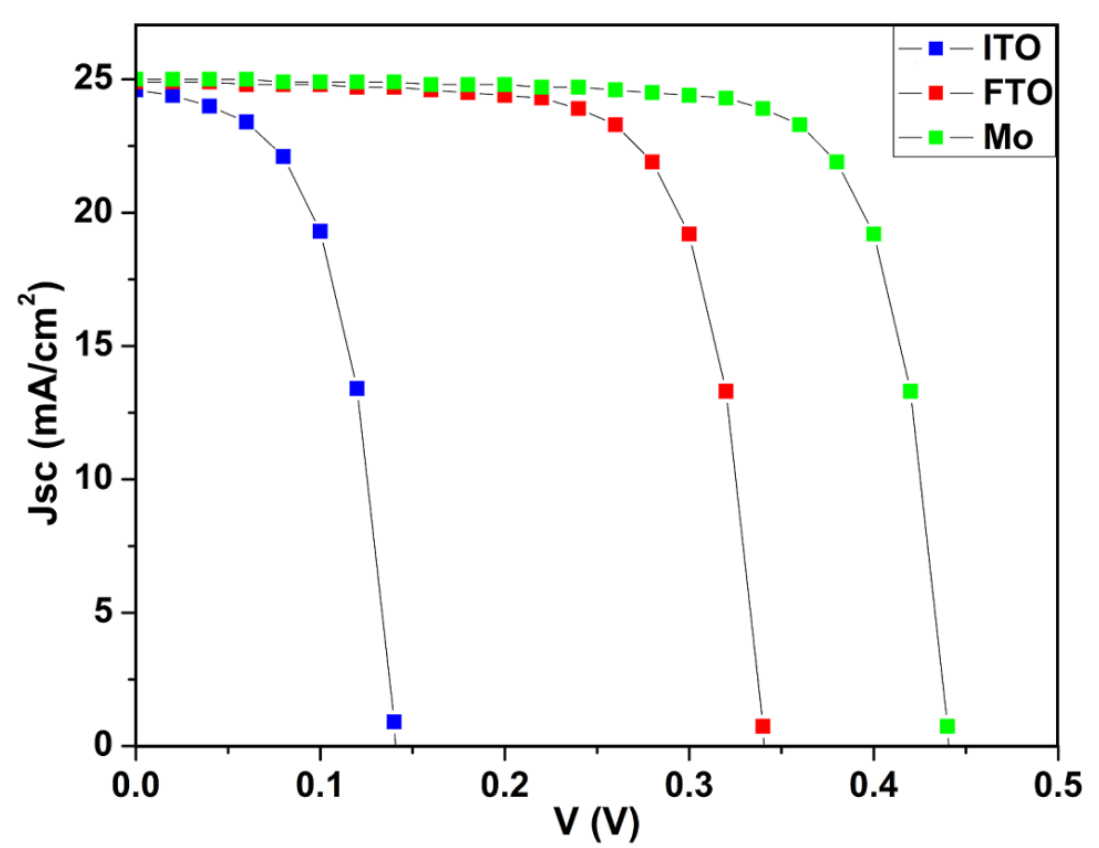

Figure $6: J-V$ characteristics of ITO, FTO, Mo used as back contacts

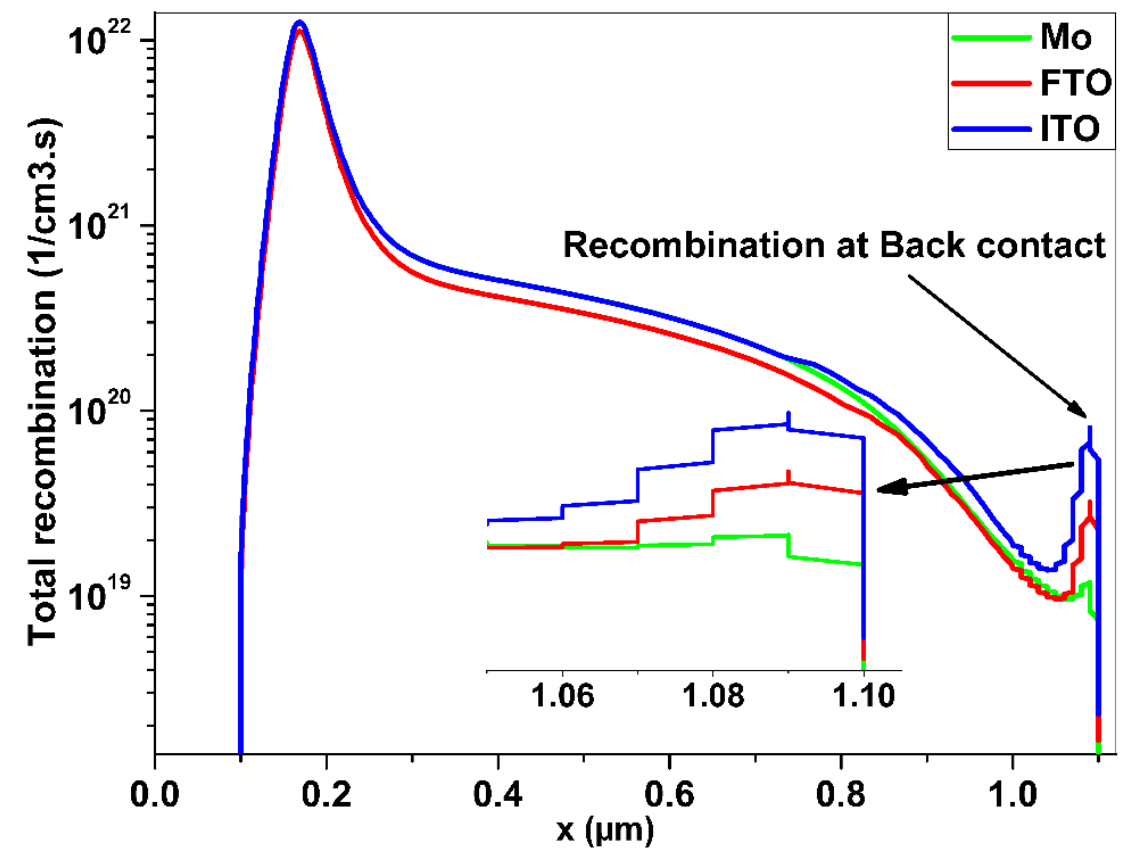

Figure 7 : Recombination profile of different metal contact.

\section{Conclusion:}

One step electrochemically deposited $\boldsymbol{C Z T S}$ kesterite thin films for SC were carried out on Mo, FTO and ITO substrates. Effect the structural properties and morphology of $\boldsymbol{C Z T S}$ deposited samples were also investigated. $\mathbf{C u S o}_{4}, \mathbf{Z n S o}_{4}, \mathbf{S n S o}_{4}$ and $\mathbf{N a}_{2} \mathbf{S}_{\mathbf{2}} \mathbf{O}_{3}$ are used as precursors in electrolyte with $\mathbf{N a}_{3} \mathbf{C}_{6} \mathbf{H}_{5} \mathbf{O}_{7}$ and $\mathbf{C}_{4} \mathbf{H}_{6} \mathbf{O}_{6}$ used as complexing agents. Different samples are deposited at room temperature with a voltage of $-1.05 \mathrm{~V}$ vs. $\mathrm{Ag} / \mathrm{AgCl}$ reference electrode. All samples were annealed at a temperature of around $450^{\circ} \mathrm{C}$. The X-ray diffraction 
characterization shows the development of $\boldsymbol{C Z T S}$ kesterite structure, with a good crystallinity onto Mo substrates and phase purity, which were also confirmed by Raman spectroscopy. SEM analysis showed the use of Mo substrate for uniform and compact morphology with grain consistency. Optical measurements showed that the deposited thin films present a bandgap of around $1.47 \mathrm{eV}$. Effect of metal back contact work function on device performance was also investigated using CZTS as an absorber layer with the aid of SCAPS software. From analysis, it was originated that the SC structure, back contact/CZTS/CdS/ZnO, with Mo as back contact showed better performance.

\section{ACKNOWLEDGMENTS}

This work was supported by Ministerio de Economía y Competitividad (Spain) through grant ENE2016-77798-C4-2-R. 


\title{
Article 3
}

\section{Single step electrochemical deposition for the fabrication of CZTS kesterite thin films for solar cells}

Applied Surface Science 497 (2019) 143794

\begin{tabular}{|c|c|c|}
\hline & Contents lists available at ScienceDirect & $\left|\begin{array}{ll}\mathbf{3} & \\
& \text { Applied } \\
\text { Surfiace Science }\end{array}\right|$ \\
\hline 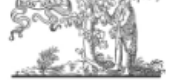 & Applied Surface Science & \\
\hline ELSEVIER & journal homepage: www.elsevier.com/locate/apsusc & \\
\hline
\end{tabular}

Full length article

Single step electrochemical deposition for the fabrication of CZTS kesterite thin films for solar cells

Yousaf Hameed Khattak ${ }^{\mathrm{a}, \mathrm{b}, *}$, Faisal Baig ${ }^{\mathrm{a}, \mathrm{b}}$, Hanae Toura ${ }^{\mathrm{a}, \mathrm{c}}$, Imen Harabi ${ }^{\mathrm{a}}$, Saira Beg ${ }^{\mathrm{d}}$, Bernabé Marí Soucase $^{a}$

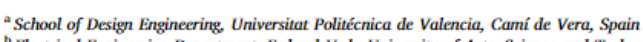

"Electrical Engineering Department, Federal Urdu University of Arts Science and Technology, Islamabad, Pakiston

'Laboratory Matrials and Environment Engineering: Modeling and Application, Department of Chemistry, University lbn Tofail, Kenitra, Moroceo

COMSATS University Islamabad, Pakistan

\section{A R T I C LE IN FO}

\section{Keywords:}

$\mathrm{Cu}_{2} \mathrm{ZnSnS}$

CZTS

Kesterite
Solar cell

Electrochemical deposition

Photovoltaics

\begin{abstract}
A B S T R A C T
The high absorption coefficient and direct optical band gap of a kesterite $\mathrm{Cu}_{2} \mathrm{ZnSnS}_{4}$ (CZTS) makes it very promising absorber material in the manufacturing of high efficiency and low-cost thin film photovoltaic cells. Single step electrochemical deposition of CZTS quaternary compound thin films on Indium tin oxide (ITO) substrates is reported in this work. The films were obtained from aqueous solutions at room temperature The key objective of this work is to examine the effect of annealing temperature on CZTS thin films. Sulfurization of thin films was performed under different temperature range from $400^{\circ} \mathrm{C}$ to $550^{\circ} \mathrm{C}$. Good crystal structure was achieved at temperature $500^{\circ} \mathrm{C}$ with the complexing agent of trisodium citrate. Deposited films material com position was evaluated by analyzing UV-visible spectroscopy, EDS, FE-SEM and XRD. The thin film with good morphological, structural and optical $(1.51 \mathrm{eV})$ properties was achieved at temperature $500{ }^{\circ} \mathrm{C}$. The results re ported in this work will provide an imperative guideline for efficient low-cost design of CZTS thin films.
\end{abstract}




\title{
Single Step Electrochemical Deposition for the Fabrication
}

$$
\text { of czrs Kesterite Thin Films for Solar Cells }
$$

\footnotetext{
Yousaf Hameed Khattak ${ }^{1,2}$, Faisal Baig ${ }^{1,2}$, Hanae Toura ${ }^{1,3}$, Imen Harabi ${ }^{1}$, Saira Beg ${ }^{4}$, Bernabé Marí Soucase ${ }^{1}$

${ }^{1}$ School of Design Engineering, Universitat Politécnica de Valencia, Camí de Vera, Spain

${ }^{2}$ Electrical Engineering Department, Federal Urdu University of Arts, Science and Technology Islamabad, Pakistan

${ }^{3}$ Laboratory Materials and Environment Engineering: Modeling and Application, Department of Chemistry, University Ibn Tofail, Kenitra, Morocco ${ }^{4}$ COMSATS University Islamabad, Pakistan
}

Corresponding Author: * yousaf.hameedk@gmail.com

\begin{abstract}
The high absorption coefficient and direct optical band gap of a kesterite $\mathrm{Cu}_{2} \mathrm{ZnSnS}_{4}(\boldsymbol{C Z T S})$ makes it very promising absorber material in the manufacturing of high efficiency and lowcost thin film photovoltaic cells. Single step electrochemical deposition of CZTS quaternary compound thin films on Indium tin oxide (ITO) substrates is reported in this work. The films were obtained from aqueous solutions at room temperature. The key objective of this work is to examine the effect of annealing temperature on CZTS thin films. Sulfurization of thin films were performed under different temperature range from $400^{\circ} \mathrm{C}$ to $550^{\circ} \mathrm{C}$. Good crystal structure was achieved at temperature $500^{\circ} \mathrm{C}$ with the complexing agent of trisodium citrate. Deposited films material composition was evaluated by analyzing UV-visible spectroscopy, EDS, FESEM and XRD. The thin film with good morphological, structural and optical $(1.51 \mathrm{eV})$ properties was achieved at temperature $500^{\circ} \mathrm{C}$. The results reported in this work will provide an imperative guideline for efficient low-cost design of $\boldsymbol{C Z T S}$ thin films.
\end{abstract}

Keywords: $\mathrm{Cu}_{2} \mathrm{ZnSnS}_{4}, \mathrm{CZTS}$, Kesterite, Solar cell, Electrochemical deposition, Photovoltaics 


\section{Introduction :}

The photovoltaic cell made from semiconductor materials plays a momentous role in power production. The solid-state semiconductor photovoltaic devices have emerged as a newer and a relatively sustainable energy source. For production purposes, thin film technology is used as the efficient and cost-effective solar cell technology. This technology is an excellent and exceptional topic of intense research and also suitable for large and low scale device application [194]. Thin film photovoltaic technologies are based on various types of light absorbers semiconductor materials. Historically in the thin film technology, amorphous silicon-based solar cells played a momentous role. Researchers move towards cadmium telluride $C d T e$ and copper indium gallium selenide CIGS based thin-film solar cell materials [35]. Commercially these materials are used for the production of thin film solar cells because of high absorption coefficient $>10^{4} \mathrm{~cm}^{-1}$, excellent optical and electrical properties and high power conversion efficiency [195,196]. For many decades great effort has been done on the optimization of CIGS and $C d T e$-based devices. The scalability of technology is limited for commercial use because of the rising cost and toxic nature of content cadmium $(C d)$ in $C d T e$ absorber and the scarcity of tellurium (Te), gallium ( $G a$ ) and indium (In). The toxic nature restricts the further advancement of these photovoltaic cells and the rare materials, gallium ( $G a$ ) and indium (In) used in these photovoltaic cells also increase the manufacturing cost. Therefore, the commercial production of CIGS based photovoltaic cell is limited [53,197].

Currently intensive research is conducting on $\mathrm{Cu}_{2} \mathrm{ZnSnS}_{4}$ (CZTS), $\mathrm{Cu}_{2} \mathrm{ZnSnSe}_{4}$ (CZTSe) and sulfur-selenium alloy $\mathrm{Cu}_{2} \mathrm{ZnSn}\left(\mathrm{S}_{x} \mathrm{Se}_{1-x}\right)_{4}$ (CZTSSe) for the development and production of low cost sustainable thin film solar cells. These materials drawing consideration because of exceptional electrical and optical properties for photovoltaic applications. These absorber materials are copper based nontoxic semiconductor materials. They are a good substitute for chalcopyrite absorbers when replaced gallium (Ga) with tin $(S n)$ and indium $(I n)$ with comparatively inexpensive zinc $(Z n)$ in the CIGS absorbers [24,147,148,198]. The optimum direct band gaps, outstanding features and efficient performance of these kesterite materials made them very fascinating in the thin film's community. Several techniques have been used to synthesize the CZTS kesterite thin films like spin coating [116], sol-gel [73], electrochemical deposition [199], spray pyrolysis [71], doctor-blade coating [121], cosputtering [119,120], chemical bath deposition [117], SILAR [118], photochemical deposition [122]. The highest power conversion efficiency (PCE) achieved for Se rich CZTSSe based solar cell was $12.6 \%$ prepared by hydrazine-based solution deposition process [3]. Because 
hydrazie is highly toxic and intensive care should be taken while handling hydrazine using proper protective equipment and this add to the cost of solar cell fabrication. $11.6 \%$ efficient CZTSSe thin film solar cell was fabricated using thermal co-evoporation method [200] and via electrodepostion a PCE of 7\% was achieved for CZTSe based solar cell [201]. For pure sulfide based kesterite solar cell with PCE of $11.01 \%$ and having high open circuit voltage of 730.6 meV was achieved using co-sputtring method with heat treatment of fabricated samples [202]. Whereas CZTS with PCE of $8.4 \%$ was also achieved by preheating an electrodepsited electrode at $310^{\circ} \mathrm{C}$ in an evacuated borosilicate glass ampoule before sulfrization [203]. Among all these techniques we find electro chemical deposition interesting for kesterite application because many composite metal alloys can be deposited on a large surface area with controlled thickness [124,177]. Although in single step electrodeposition of CZTS is quite difficult to control because the metal alloys $C u-Z n-S n-S$ presents different oxidization reduction potential $[125,126]$. To control the oxidization and reduction potential for metal alloys complexing agent play a vital role in bath solution $[128,164]$ because the key factors for kesterite performance are deposition potential, crystalline structure and stoichiometry $[129,130]$. There is an empirical rule, that $\mathrm{Cu}$ poor and $\mathrm{Zn}$ rich based CZTS thin film reported high conversion efficiency. The ratio for metal alloys should be ranged between 0.70 to $1.20(\mathrm{Cu} / \mathrm{Zn}+$ Sn) [131-133].

The effect of complexing agent concentration on annealing temperature with optical, structural and morphological characterization were investigated in this research work. In order to obtain cost effective CZTS thin films by single bath electrodeposition technique, we examined the effect of the addition of the complexing agent $\boldsymbol{C}_{6} \boldsymbol{H}_{5} \boldsymbol{N a}_{3} \boldsymbol{O}_{7}$ on the annealing temperature, which creates the originality of this study.

\section{Experimental section}

CZTS kesterite precursor film were electrochemically deposited on indium tin oxide (ITO) coated glass substrate having $\mathbf{1} \times \mathbf{2 . 5} \mathbf{c m}^{2}$ area of deposition. 50 milli litter aqueous

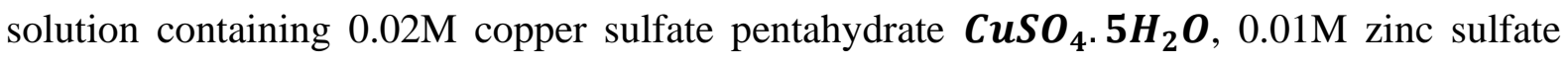
monohydrate $\mathbf{Z n S O}_{4} \cdot \mathrm{H}_{2} \boldsymbol{O}, 0.01 \mathrm{M}$ tin sulfate $\boldsymbol{S n S O}_{4}$, and $0.02 \mathrm{M}$ sodium thiosulfate $\mathrm{Na}_{2} \mathrm{~S}_{2} \mathrm{O}_{3}$ were used as electrolyte. To keep the pH of electrolyte around 5, 0.1M tartaric acid $\left(\boldsymbol{C}_{6} \boldsymbol{H}_{6} \boldsymbol{O}_{6}\right)$ was added in $C Z T S$ precursor. 0.2M trisodium citrate $\left(\boldsymbol{C}_{6} \boldsymbol{H}_{5} \boldsymbol{N a}_{3} \boldsymbol{O}_{7}\right)$ was used as complexing agent. Electrochemical deposition was carried out by using three-electrode setup in Autolab PGSTAT302N potentiostatic. Where $(\boldsymbol{A g} / \boldsymbol{A g} \boldsymbol{C l})$ saturated calomel electrode as the reference electrode, platinum wire $(\boldsymbol{P t})$ as a counter electrode, ITO were used as a working 
electrode. The working electrode is immersed in the precursor solution. Schematic diagram of electrochemical deposition setup is shown in Figure 1. CZTS precursor layer were deposited by using chronoamperometry technique at $-1.05 \mathrm{~V}$ potential (vs. $\mathrm{Ag} / \mathrm{AgCl}$ ). Without stirring deposition was taken for $30 \mathrm{~min}$ at room temperature. After deposition process ended, $\boldsymbol{C Z T S}$ deposited films were rinsed with deionized water and after that at room temperature they were dried in air. To get the required peaks from the deposited films, films were annealed at different temperatures by applying sulfurization. For the sulfurization process we use tubular setup, in which graphite posts are used for the holding of deposited films and sulfur powder $(\boldsymbol{S})$ was also used. Annealing process was done with the presence of argon ( $\boldsymbol{A r}$ ) gas in tubular setup within the temperature variant from $400^{\circ} \mathrm{C}$ to $550^{\circ} \mathrm{C}$ for $40 \mathrm{~min}$.

CZTS films samples structural characterization was carried out by using Rigaku Ultima IV Ray Diffractometer (XRD), $\boldsymbol{C u K} \boldsymbol{\alpha}$ radiation $(\boldsymbol{\lambda}=\mathbf{1 . 5 4 0 6 0} \AA$ ) in the Bragg-Bentano configuration. Field emission scanning electron microscopy (FE-SEM) analysis was done to examine the morphology and energy dispersive X-ray (EDS) analysis was done to investigate the chemical composition of the CZTS deposited samples with 0.2 M concentration of complexing agent. These analyses were performed by using Zeiss ULTRA 55 model equipped with an In-Lens SE detector. Raman spectroscopy of different annealed samples were recorded by using Horiba Jobin Yvon LabRAM HR spectrometer equipped with thermoelectrically cooled Electronically enhanced Multichannel Charge Coupled Device (EMCCD) and an edge filter that cuts Raman signals below $\sim 35 \mathbf{c m}^{-1}$. Solid-state green laser emitting at $\mathbf{5 3 3} \mathbf{n m}$ with a resolution of roughly $\mathbf{1} \mathbf{c m}^{-1}$ was used. The optical properties of $\boldsymbol{C Z T S}$ films were evaluated by using Ocean Optics HR4000 UV-Visible spectrophotometer coupled with an integrating sphere (to collect both specular and diffuse transmittance). Optical band gap ( $\boldsymbol{E g})$ estimated from Tauc Equation is $\boldsymbol{\alpha h} \boldsymbol{v}=\boldsymbol{A}(\boldsymbol{h} \boldsymbol{v}-\boldsymbol{E g})^{\boldsymbol{n}}$ where $\mathrm{n}$ is $1 / 2$ for direct band gap transition and $\alpha=1 / \boldsymbol{t} \ln (\mathbf{1} / \boldsymbol{T})$ relation [204]. 


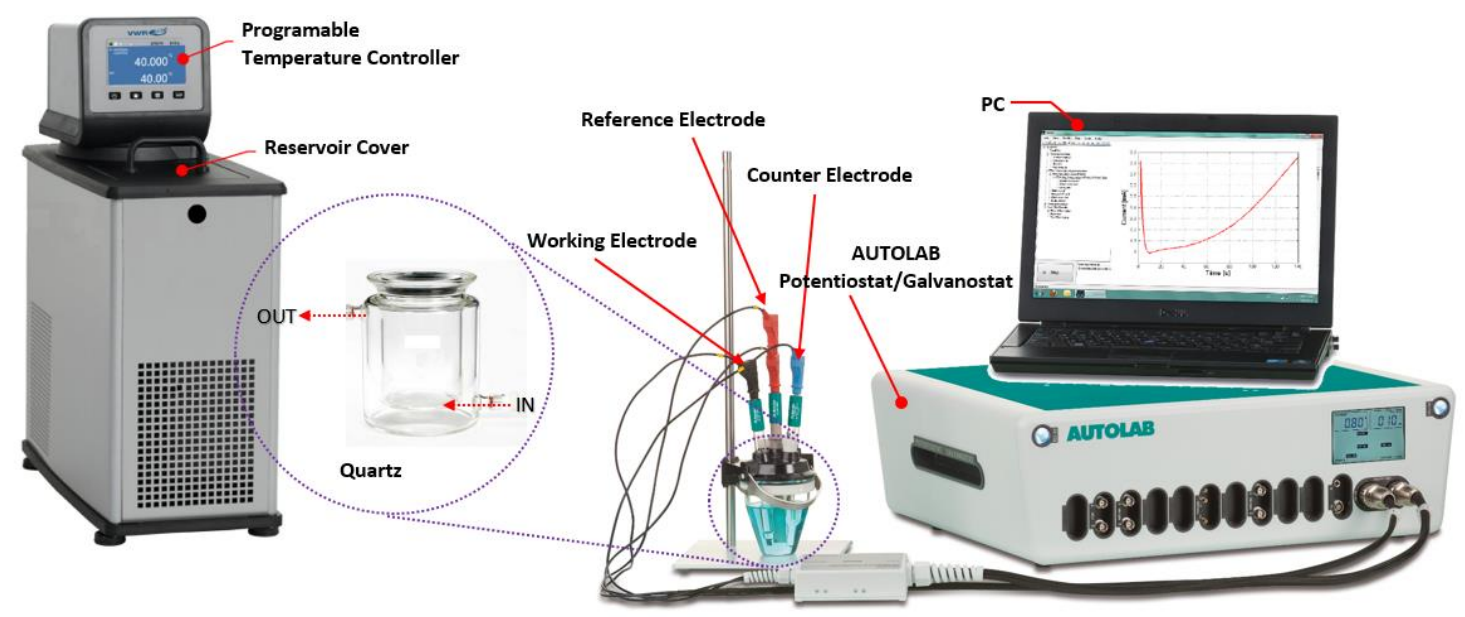

Figure 1 : Autolab PGSTAT 302N potentiostatic setup

\section{Result and Discussion}

\subsection{XRD Analysis}

Crystal structure of $\boldsymbol{C Z T S}$ precursors samples were examined by using XRD analysis. Figure 2 demonstrates the XRD diffraction spectrum pattern of $\boldsymbol{C Z T S}$ as deposited and samples annealed at temperatures of $400^{\circ} \mathrm{C}, 450^{\circ} \mathrm{C}, 500^{\circ} \mathrm{C}$ and $550^{\circ} \mathrm{C}$. The patterns were recorded in $2 \theta$ angle range $20^{\circ}-60^{\circ}$. It can be clearly observed that the as-deposited films exhibit the peaks

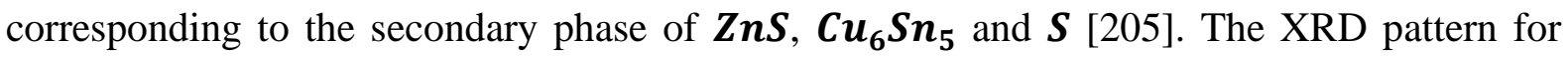
annealed sample deposited with $0.2 \mathrm{M}$ concentration of complexing agent shows strong peaks located at $28.31^{\circ}, 47.10^{\circ}$, and $55.93^{\circ}$ corresponding to the (112), (204), and (312) planes with reference JCPDS card \#26-0575 [206]. Several weaker peaks were also observed in the annealed samples at point $22.76^{\circ}, 29.51^{\circ}, 32.83^{\circ}$ for kesterite structure [207-209]. Existence of all peaks for annealed samples are shown in diffraction spectrum. 


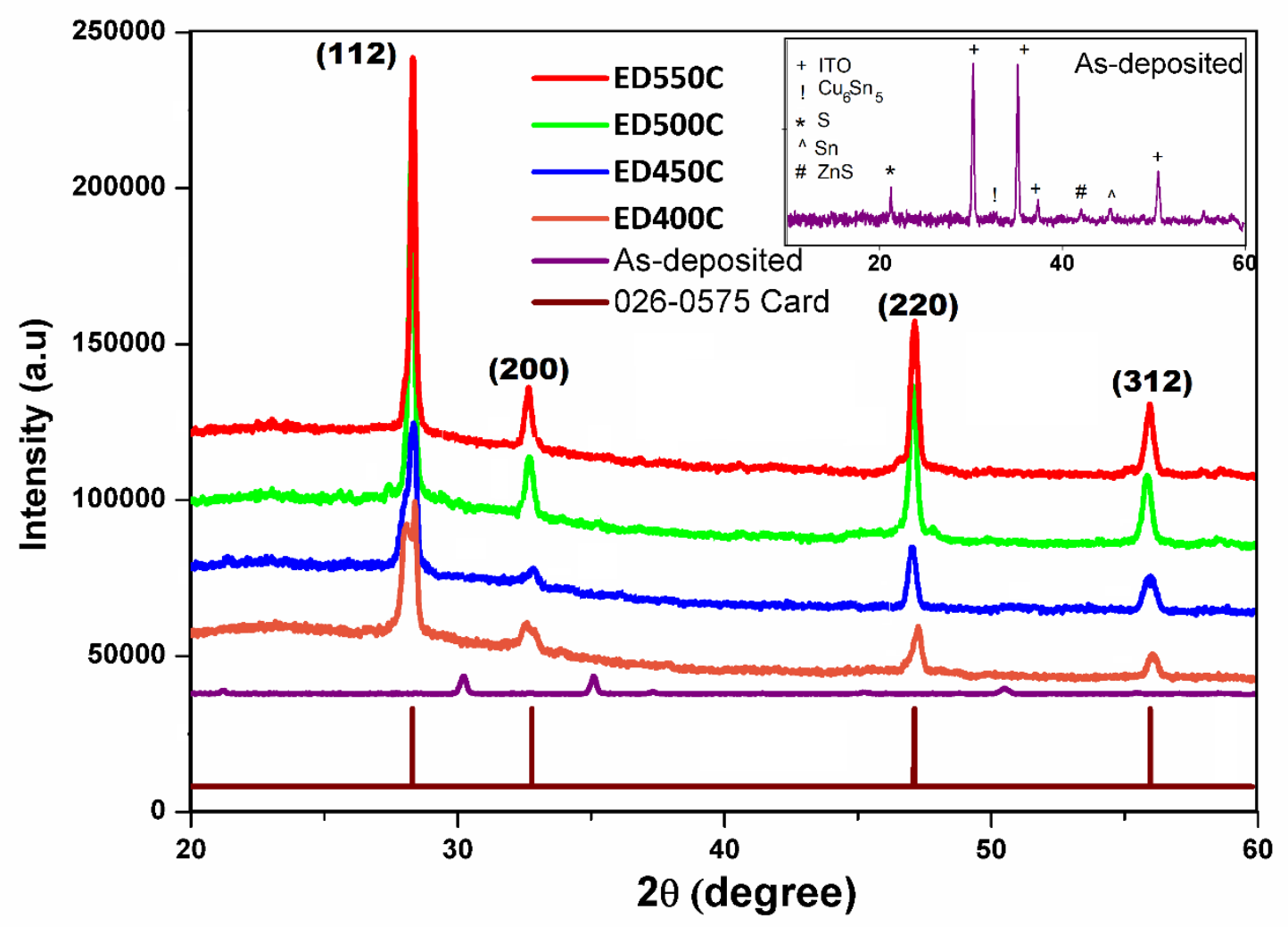

Figure 2 : X-ray diffraction spectrum of annealed samples

In the sample ED500C, CZTS kesterite structure thin films reticular planes (112), (220) and (312) are distinctly observed. Moreover, the affinity and intensity of peaks in XRD shows that the deposition had more crystalline particles. Average value of $\boldsymbol{C Z T S}$ thin film crystallite size can be obtained from Debye - Scherrer's equation given in Equation 1[210,211].

$$
D=(K \lambda / \beta \operatorname{Cos} \theta)
$$

Where $\boldsymbol{\theta}$ represents the diffraction angle, $\boldsymbol{\beta}$ is the width at half height intensity or full width half maximum (FWHM) of the peak, $\boldsymbol{\lambda}$ is the wavelength of the incident beam, $\boldsymbol{K}$ is Scherrer's constant and usually takes the value 0.9 and $\boldsymbol{D}$ is the crystalline size. XRD analysis states the peaks position, crystallite size and full width at half maximum (FWHM) as given in Table. 1 . As cubic $\mathrm{ZnS}$ and tetragonal $\mathbf{C u}_{2} \mathbf{S n S} \mathbf{S}_{3}$ has same secondary phases as kesterite $\boldsymbol{C Z T S}$ and its hard to distinguish in XRD. Therefore, Raman spectroscopy of different annealed sample was recorded out in range of 200-600 $\mathbf{c m}^{-\mathbf{1}}$ and plotted in Figure 3. The main peak of Raman spectra was at $330 \mathbf{c m}^{-\mathbf{1}}$ and this does not correspond to the principal peaks of $\mathrm{ZnS}$ and $\mathrm{Cu}_{2} \mathbf{S n S}_{3}$ [212-214].

Table 1: Structural parameters of the different annealed samples

\begin{tabular}{lllll}
\hline \multirow{2}{*}{ Sample } & Annealing & Position of the & FWHM & Crystallite Size \\
& Temperature $\left({ }^{\circ} \mathrm{C}\right)$ & peak (112) & $\beta(\mathrm{deg})$ & $D(\mathrm{~nm})$ \\
\hline
\end{tabular}




\begin{tabular}{lllll}
\hline ED400C & 400 & 28.2812 & 0.2289 & 37.37 \\
ED450C & 450 & 28.3912 & 0.1891 & 45.25 \\
ED500C & 500 & 28.3062 & 0.1848 & 46.30 \\
ED550C & 550 & 28.2845 & 0.2057 & 41.60 \\
\hline
\end{tabular}

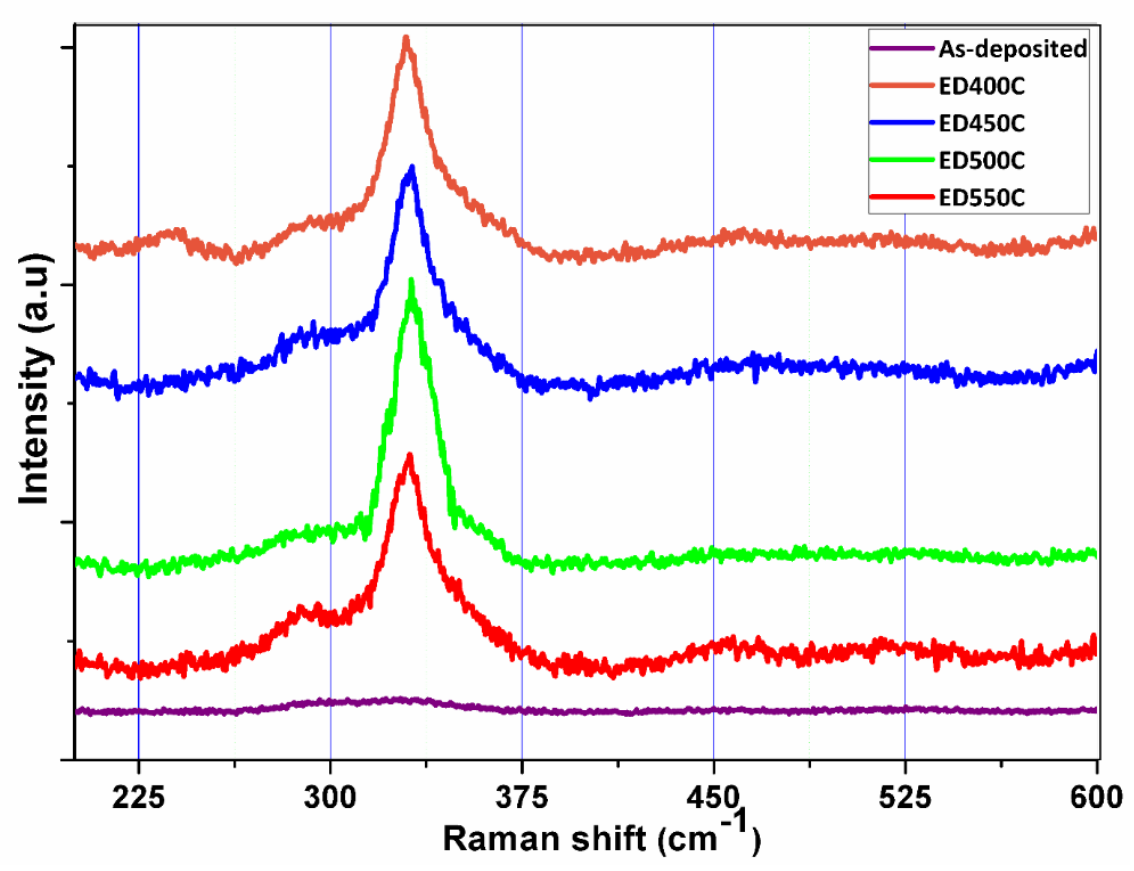

Figure 3 : Raman spectra of different CZTS thin films

\subsection{FE-SEM and EDS analysis}

FE-SEM images of CZTS film as-deposited and samples annealed on different temperature are shown in Figure 4 and Figure 5. Surface morphology of annealed samples strongly dependent on the value of temperature. From Figure 5, we examined that large surface morphological difference is present in the different annealed samples. The morphological studies show that with rising annealed temperature the grain morphology is well define and this effect can be visible by observing Figure 5. The morphology of films ED400C and ED450C shows that the film has a non-uniform surface with the presence of some voids or cavities. Samples ED450C and ED550C have a dense structure with circular grains. FE-SEM morphological analysis of CZTS thin films shows, film surface strongly depends on the annealing temperature and this is confirmed also with the results of XRD given in Figure 2. 


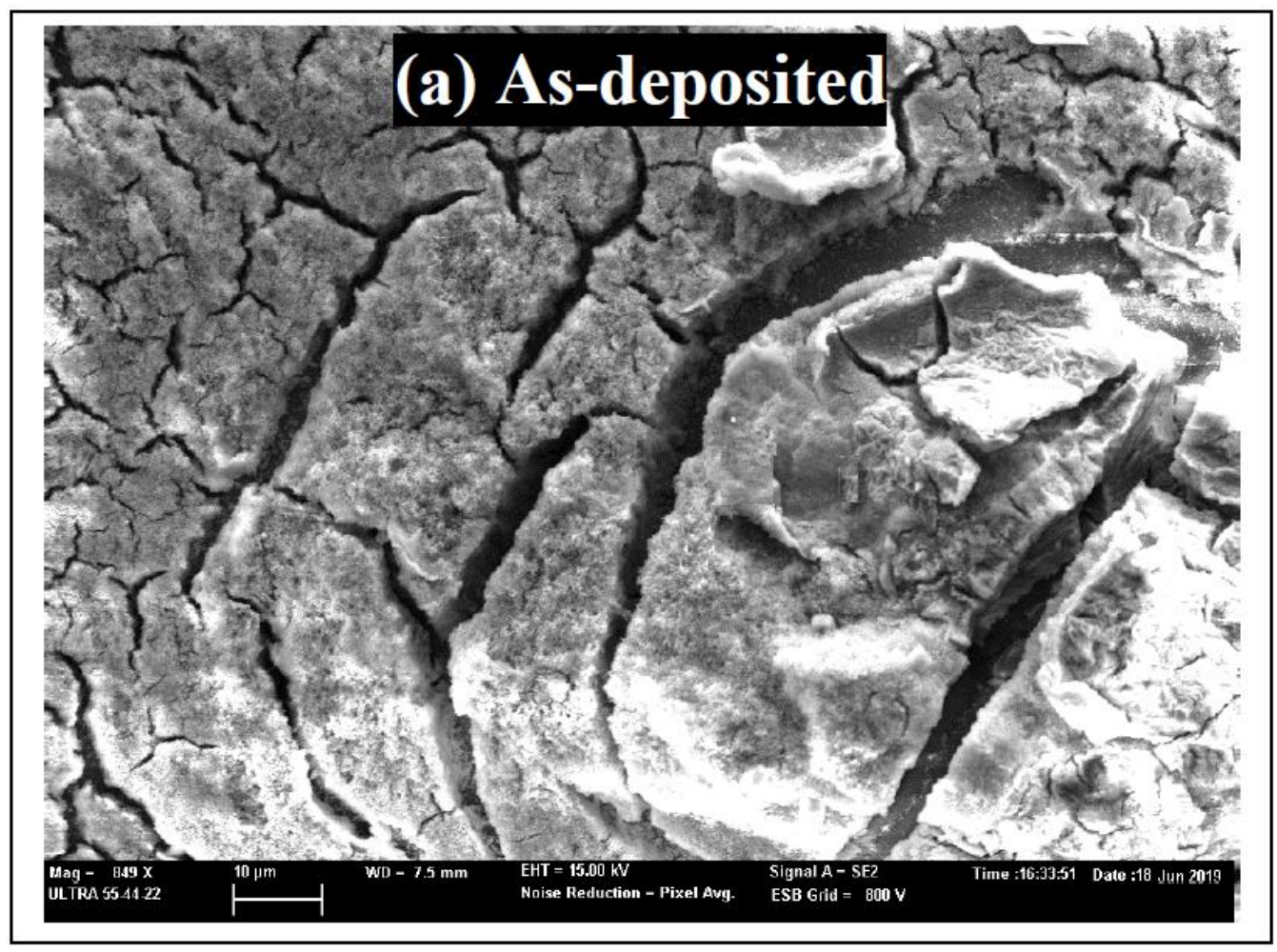

Figure 4 : FE-SEM descriptions of as-deposited CZTS film. 

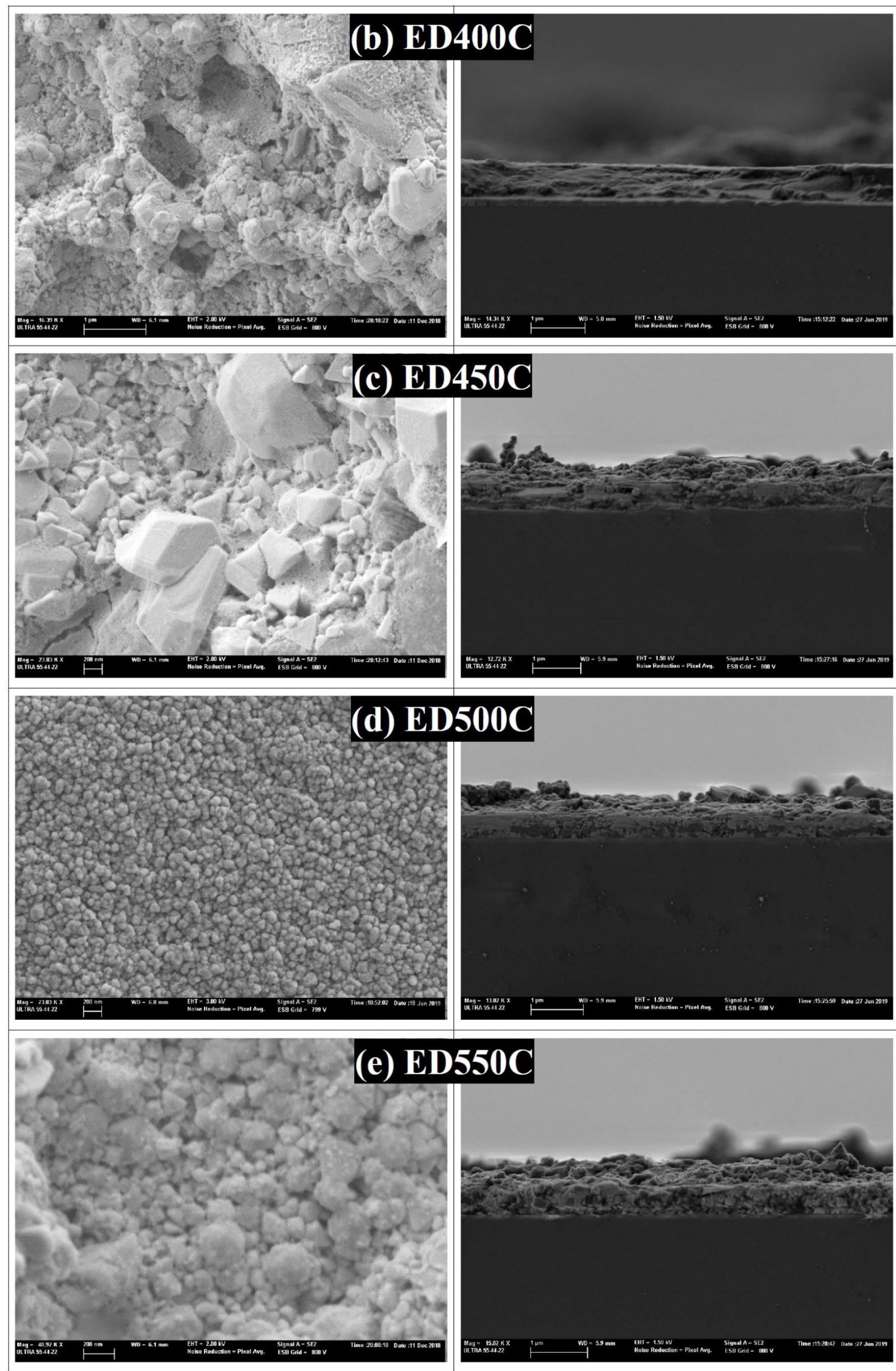
Figure 5 : FE-SEM descriptions of annealed $\boldsymbol{C Z T S}$ film samples with cross-sectional morphology

Identification of elemental composition is done by characterizing the $\mathrm{X}$-rays and the technique used for that is known as X-ray energy dispersive spectroscopy (EDS). Chemical composition can examine in a microscopic area with the help of EDS micro-analyzer. Table 2 explains the EDS analysis data with elemental composition in the electrochemically deposited $\boldsymbol{C Z T S}$ thin films with different annealing temperature. From Table 2 with increase in annealing temperature of $\boldsymbol{C Z T S}$ thin film, it become more stoichiometric. EDS spectra of different $\boldsymbol{C Z T S}$ kesterite thin film samples are shown in Figure 6.

Table 2: CZTS kesterite films composition by EDS analysis

\begin{tabular}{ccccccc}
\hline \multirow{2}{*}{ Sample ID } & \multicolumn{5}{c}{ Elements } \\
\cline { 2 - 7 } & $\mathbf{C u}$ & $\mathbf{Z n}$ & $\mathbf{S n}$ & $\mathbf{S}$ & $\mathbf{C u} /(\mathbf{Z n + S n})$ & $\mathbf{2 C u}+\mathbf{4}(\mathbf{Z n + S n}) / \mathbf{3 S}$ \\
\hline ED400C & 34.13 & 26.22 & 15.81 & 23.85 & 0.81 & 70.61 \\
ED450C & 29.75 & 14.81 & 10.98 & 44.46 & 1.15 & 60.27 \\
ED500C & 22.82 & 10.67 & 16.25 & 50.26 & 0.81 & 46.34 \\
ED550C & 25.22 & 11.33 & 13.33 & 50.11 & 1.02 & 51.09
\end{tabular}

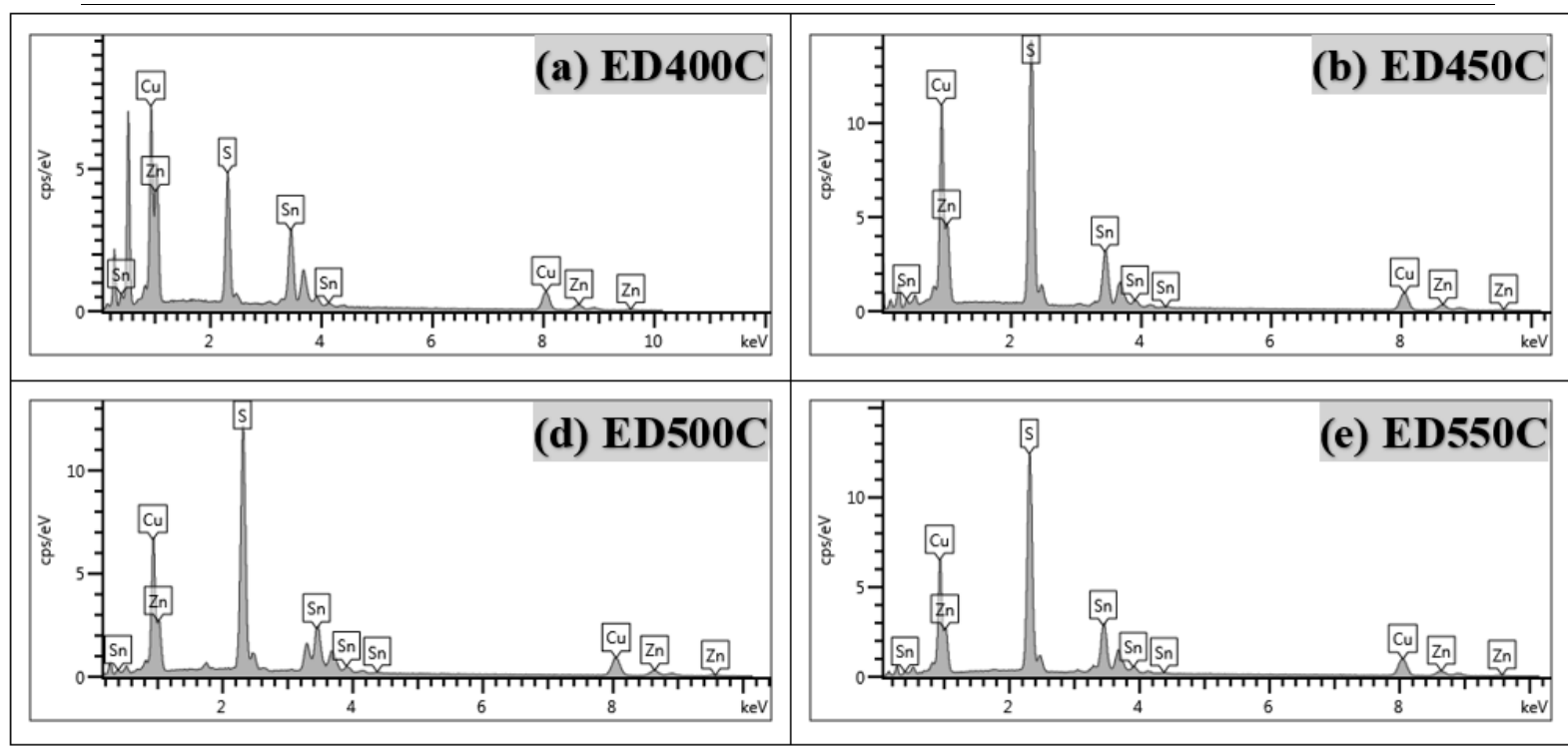

Figure 6 : EDS spectrum of annealed CZTS kesterite thin films

Values given for FWHM and crystallite size has a direct effect on strain and dislocation density of film, and this is expressed by the relation given in Equation 2 and 3.

$$
\begin{gathered}
\delta=\left(1 / D^{2}\right) \\
\varepsilon=(\beta \operatorname{Cot} \theta / 4)
\end{gathered}
$$

Results for dislocation density and strain of different annealed CZTS samples are given in Figure 5. From Table 3, with increase in temperature there is a decrease in crystal strain up to 
a value of $500^{\circ} \mathrm{C}$ but at $550^{\circ} \mathrm{C}$ there is an increase in strain indicating imperfection in crystal lattice. The results presented for strain indicates columnar grain growth of crystals as shown in Figure 5.

Table 3 : Dislocation density and strain

\begin{tabular}{ccc}
\hline $\begin{array}{c}\text { Temperature } \\
\left({ }^{\mathbf{C}}\right)\end{array}$ & $\begin{array}{c}\boldsymbol{\delta} \text { (Dislocation density) } \\
\mathbf{1 0}^{\mathbf{1 4}} \text { lin. } \boldsymbol{m}^{-\mathbf{2}}\end{array}$ & $\boldsymbol{\varepsilon}$ (strain) \\
\hline 400 & 7.16 & 0.106367 \\
450 & 4.88 & 0.08747 \\
500 & 4.67 & 0.08578 \\
550 & 5.78 & 0.095569 \\
\hline
\end{tabular}

\subsection{UV-visible spectroscopy}

Measurement of the band gap energy of the electrochemically deposited CZTS kesterite thin films annealed on different temperature was done on UV visible spectroscopy by using Ocean Optics HR4000 UV-Visible spectrophotometer coupled with an integrating sphere (to gather specular and diffuse transmittance). At room temperature optical absorption spectra recorded in the wavelength for the $\boldsymbol{C Z T S}$ kesterite thin films taken was ranging from $450 \mathrm{~nm}$ to $1000 \mathrm{~nm}$. Transmission spectrum of deposited $\boldsymbol{C Z T S}$ films are shown in Figure 7. Optical band gap energies can be determined from the transmittance data.

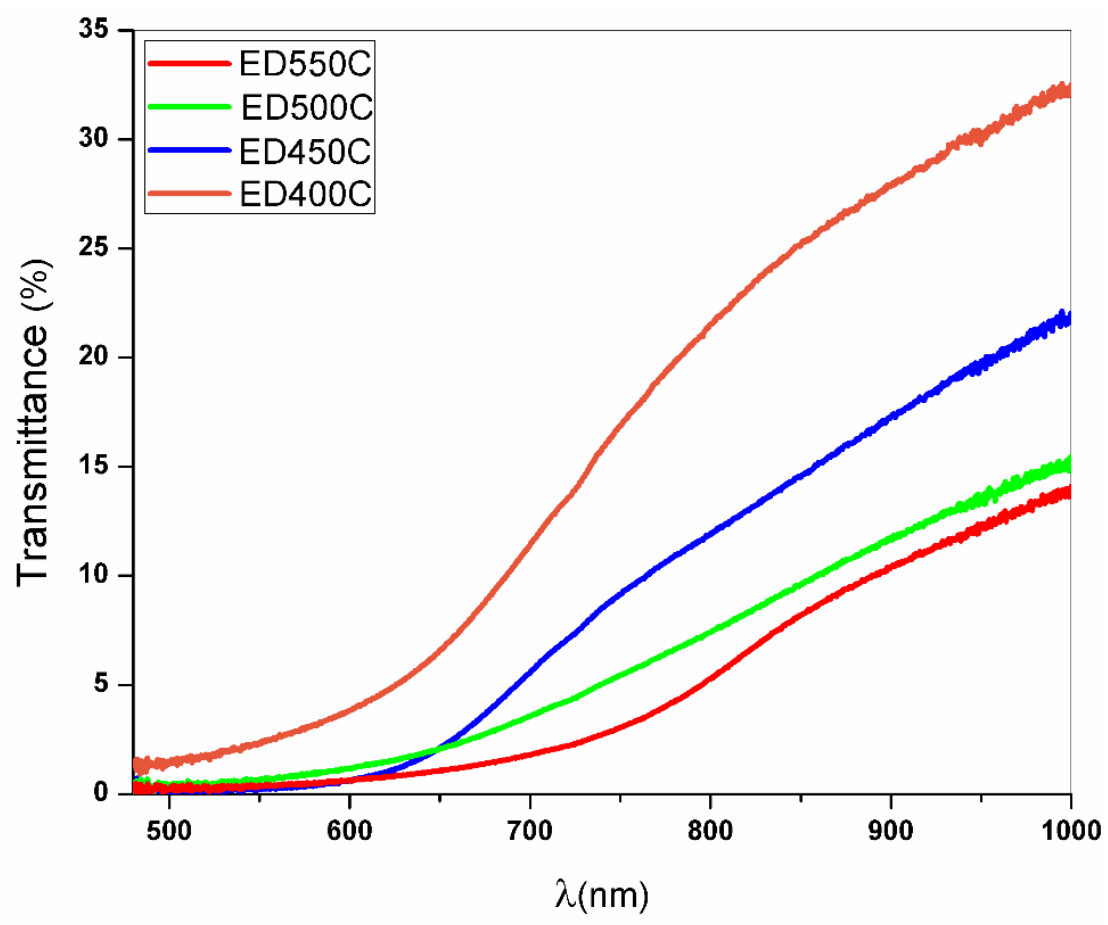

Figure 7 : Transmittance spectrum of annealed CZTS kesterite thin films 
Variation of $(\boldsymbol{a h v})^{2}$ as a function of photon energy $(\boldsymbol{h} \boldsymbol{v})$ for deposited $\boldsymbol{C Z T S}$ films at a different temperature of annealing. Photo conversion efficiency of solar cell is highly depended upon the material band gap energy. Determining the fundamental band gap energies are possible due to the difference between conduction and valence band levels. The band gap energies are determining with the help of optical absorption spectra. It can be measured by the Tauc's relation between energy and absorption and given in Equation 4

$$
(\boldsymbol{\alpha h v})^{2}=\boldsymbol{A}(\boldsymbol{h} \boldsymbol{v}-\boldsymbol{E g})
$$

where $v$ is the incident photon frequency, $h$ is the Planck's constant, $\alpha$ is the absorption coefficient, $\mathrm{n}$ is equal to $1 / 2$ for a direct transition, and to 2 for an indirect transition $E_{g}$ is the optical band gap, A is a constant. Electrochemically deposited $\boldsymbol{C Z T S}$ kesterite thin films band gap energy is shown in Figure 8. The graph was taken between $h v$ and $(\alpha h v)^{2}$ and the band gap energy was plotted by drawing a tangential line that extrapolate the linear part of the energy spectrum [143]. Figure 8. shows that different annealed CZTS thin films band gap energies are ranged between $1.48 \mathrm{eV}$ and $1.61 \mathrm{eV}$ and rising in annealing temperature decreases the band gap. The grain size, crystallinity and modification of the material structural properties played a momentous role in the variation of optical properties [144]. The band gap energy of samples ED400C, ED450C, ED500C and ED550C are $1.61 \mathrm{eV}, 1.54 \mathrm{eV}, 1.51 \mathrm{eV}$ and $1.48 \mathrm{eV}$ respectively. Figure 8 confers that the electrochemically deposited sample ED500C have an optimal band gap value which is near to the optimum band gap for designing the highpower conversion efficiency from solar cell.

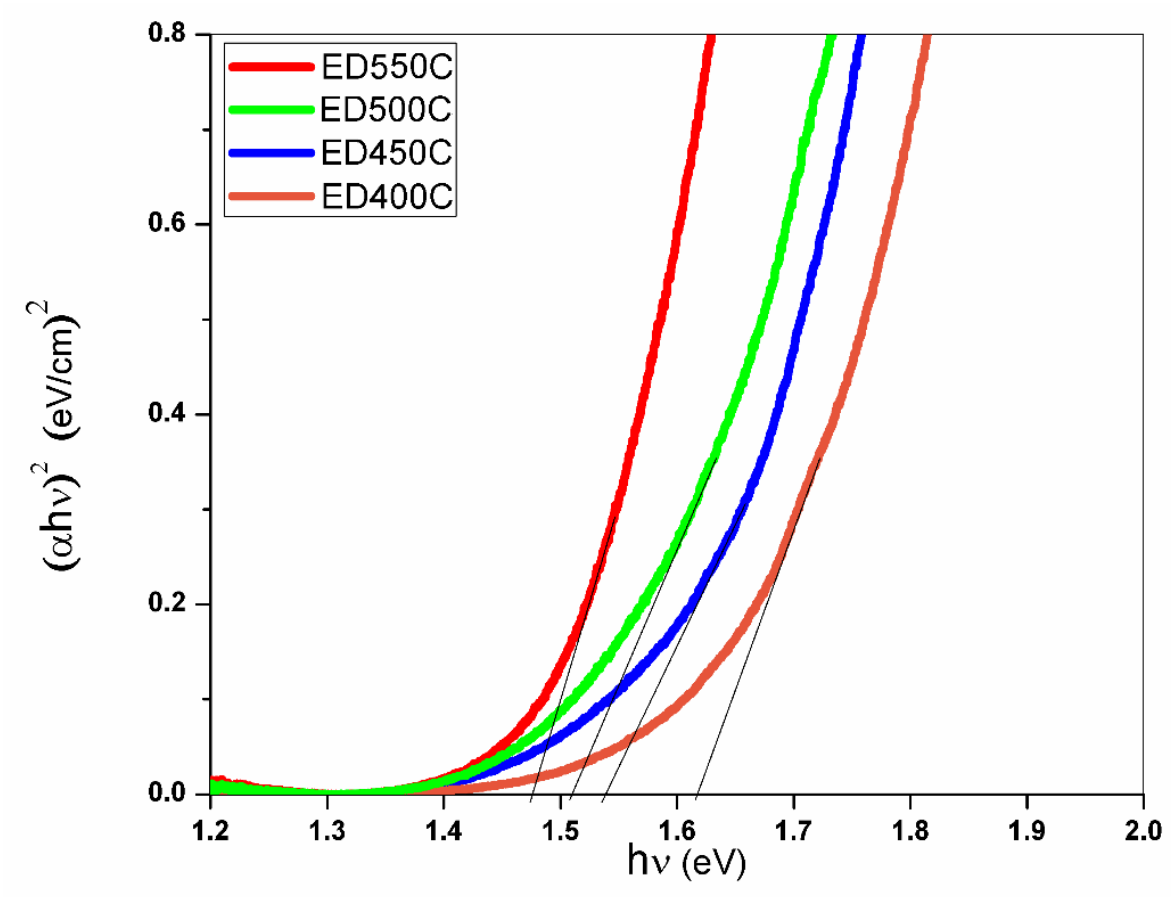


Figure 8 : CZTS thin film band gap energy

Table 4 : CZTS thin films optical band gaps

\begin{tabular}{ccc}
\hline Samples & Annealing Temperature $\left({ }^{\circ} \mathbf{C}\right)$ & Optical band gap $(\mathbf{e V})$ \\
\hline ED400C & 400 & 1.61 \\
ED450C & 450 & 1.54 \\
ED500C & 500 & 1.51 \\
ED550C & 550 & 1.48 \\
\hline
\end{tabular}

\section{Conclusion}

In this work $\boldsymbol{C Z T S}$ thin film is fabricated using electrochemical deposition. The major concern for the limitation to achieve high efficiency CZTS thin film is to control the composition of metal alloys as these alloys has different oxidization and reduction potential. To control the composition of the alloys and to get good stoichiometry of the film trisodium citrate $\mathrm{C}_{6} \mathrm{H}_{5} \mathrm{Na}_{3} \mathrm{O}_{7}$ complexing agent was added into the solution with $0.2 \mathrm{M}$ concentration. From the results presented above it was found that $0.2 \mathrm{M}$ molar concentration works well for the fabrication of CZTS thin film with good structural, morphological and optical properties at different annealing temperatures $\left(400^{\circ} \mathrm{C}-550^{\circ} \mathrm{C}\right)$. The thin film with good morphological, structural and optical $(1.51 \mathrm{eV})$ properties was achieved at temperature $500^{\circ} \mathrm{C}$.

\section{ACKNOWLEDGMENTS}

This work was supported by Ministerio de Economía y Competitividad (ENE2016-77798C4-2-R) and Generalitat Valenciana (Prometeus 2014/044). 
Chapter V

General Discussion 


\section{General discussion}

The large-scale development of photovoltaic energy remains conditional on a reduction in the cost of solar cells. In this context, the $\mathrm{Cu}_{2} \mathrm{ZnSnS}_{4}(\mathrm{CZTS})$ is a promising material based on eart abundant elements in nature and non-toxic. In terms of cost, the processes for manufacturing CZTS solar cells by chemical means are very much in demand to develop thin layers with several compounds, in particular, the electrodeposition technique.

First, we developed and studied the effects of experimental parameters such as concentration of the precursors, the deposition time, the $\mathrm{pH}$ variation, the annealing temperature and also the addition of the complexing agents in the electrolytic bath on the properties of CZTS absorbent layers. After deposition of CZTS thin film, the films underwent a series of structural, morphological and optical characterizations using the following means: X-ray diffractometer, Raman spectrometry to confirm the kesterite structure and the absence of the secondary phases, the microscope scanning electron followed by EDS to obtain the atomic composition of the layers, the atomic force microscope to confirm the morphology and the topography of the substrates and then the UV-Visible spectrophotometer.

Based on characterization results, parameters that were found which can affect the morphology and characteristic of CZTS thin film were.

1. Effect of precursor ration and annealing temperature

2. Complexing agent $\mathbf{N a}_{2} \mathrm{SO}_{4}$ effect on fabrication of CZTS thin film

The influence of precursors concentration with the annealing temperature has been executed. Taking into account a composition of the electrolyte composed by trisodium citrate $\boldsymbol{N a}_{3} \boldsymbol{C}_{6} \mathrm{H}_{5} \mathrm{O}_{7}$ and tartaric acid $\boldsymbol{C}_{4} \boldsymbol{H}_{6} \boldsymbol{O}_{6}$ as complexing agents, the annealing temperature for the as deposited CZTS thin layers cannot be below $450{ }^{\circ} \boldsymbol{C}$. Otherwise we lose the kesterite structure especially without the presence of secondary phases. Now to study the effect on complexing agent on as deposited CZTS thin film and on annealing temperature of samples, we fixed the composition of the bath as well as the other parameters. Samples deposited with complexing agent $\mathbf{N a}_{2} \mathbf{S O}_{4}$ has achieved a pure Kesterite phase at annealing temperature of $350^{\circ} \boldsymbol{C}$ with time duration of $45 \mathrm{~min}$, with a well-defined crystal structure. This made it possible to demonstrate that it is not necessary to carry out a sulfurization at $500{ }^{\circ} \boldsymbol{C}$ after the deposition in order to be able to form the CZTS phase.

The results of the XRD characterization show that, the films present the $\mathrm{Cu} 2 \mathrm{ZnSnS} 4$ phase under its kesterite structure with (112) as the preferred growth axis, these results are also confirmed by Raman spectroscopy. Afterwards, we have found that the size of the crystallites 
is an increasing function of the annealing temperature, therefore we can deduce that the annealing process controls the size of the crystallites but up to an optimal value of $500{ }^{\circ} \boldsymbol{C}$. After this value, even if the annealing temperature increases, the size of the crystalline react inversely. Among the different phases that can form during the growth of CZTS are the tetragonal or cubic $\mathrm{Cu} 2 \mathrm{SnS} 3$ or else $\mathrm{ZnS}$-cubic and Cu3SnS4-orthorhombic. From these, only the orthorhombic$\mathrm{Cu} 3 \mathrm{SnS} 4$ is easy to identify using XRD. Identifying the cubic and tetragonal phases using only the XRD technique is difficult, if not impossible. Here, Raman spectroscopy has just confirmed the Kesterite phase with a diffusion peak at around $336 \mathrm{~cm}^{-1}$.

The optical characterization of CZTS over the visible range 450 to $1000 \mathrm{~nm}$ have shown that our films are opaque, which reflects the absorbent nature of the CZTS layers. The value of the gap varies from $1.45 \mathrm{eV}$ and $1.6 \mathrm{eV}$. However, the slight differences observed between the samples could be due to the different phases present in each sample. In fact, samples with annealing temperatures between $450{ }^{\circ} \boldsymbol{C}$ and $550{ }^{\circ} \boldsymbol{C}$ showed a similar bandgap, although the $\mathrm{T} 400{ }^{\circ} \boldsymbol{C}$ sample favored shifting the band gap to a higher value. The presence of multiple and parasitic phases promotes the increase of the optical absorption edge towards higher energy values. Whereas for $\mathrm{T}=350{ }^{\circ} \boldsymbol{C}$ the value of the gap energy seems equal to the optimal even if the annealing temperature is $50{ }^{\circ} \boldsymbol{C}$ lower compared to the last sample, this confirms the role of the added complexing agent and the hypothesis that we will lose the kesterite structure if we annealed at a temperature less than $450{ }^{\circ} \mathrm{C}$ with a composition free of $\mathrm{Na}_{2} \mathrm{SO}_{4}$. Additionally, the thin layers produced in the presence of this complexing agent present a composition ratio of $\boldsymbol{C u} /(\boldsymbol{Z n}+\boldsymbol{S n})$ between $0.8-0.9$ which shows the optimized efficiency of the solar cells. The scanning electron microscope shows a uniform and consistent morphology for the films deposited at $350^{\circ} \mathrm{C}$ in the presence of the complexing agent, while without the presence of this promising the morphology tends to be non-uniform at $400{ }^{\circ} \boldsymbol{C}$.

In view of the above, an interaction between the film and the substrate can cause a strain in the deposited films, which alters the device's efficiency. Thus, it is very essential to control the film formation on the substrate surface. The preparation and characterization of CZTS thin layers were carried out on different conductive substrates by the electrodeposition method. The aim was to control the effect of back contact on the properties of CZTS solar cells. Structural analyzes by X-ray diffraction as well as Raman spectroscopy have shown that the CZTS Kesterite structure is formed without the presence of secondary phases. The intensity of the peak of kesterite (112) is more intense and sharper compared to (110) Mo peak, due to the increase in crystallinity. In addition, the optical results obtained by the technique of UV-Visible 
spectroscopy showed a gap of around $1 \mathrm{eV}$ calculated from the Tauc relation from the transmission curve.

Although, the morphology of the different substrates is composed of a large number of uniform sphere-like particles. A sufficiently compact CZTS layer uniformly covering the entire surface of the substrate exposed to the solution was obtained with the Molybdenum conductive substrate. Without any presence of crack on the surface, which is the case of ITO glass substrate. Thin layers Mo/CZTS have a uniform morphology with larger coherent grains. While the efficiency of solar cells has increased with increasing grain size in the absorbent layer. The Mo substrate plays an important role in the growth of thin layers, indicating that large grains are necessary for high-efficiency solar cells. Indeed, the nature of the contact can seriously affect the performance of the cell by increasing the series resistance which considerably reduces the fill factor.

Effect of different metal back contact was also analyzed numerically using SCAPS- 1D software. Solar cell with structure (Back contact/CZTS/CdS/ZnO) was used for analysis whereas Mo, ITO and FTO was applied as back contact. Based on the results of numerical analysis it was also confirmed that solar cell with Mo as back contact has highest power conversion efficiency. 
Chapter VI

Conclusion 


\section{Conclusion}

The aim of our study was to develop and characterize CZTS thin film by using Electrodeposition. The quaternary CZTS presents properties so important that one cannot neglect them. That are their abundance in nature, non-toxicity, high absorption coefficient and suitable energy band gap for the application of solar cell absorber layer. Whereas the choice of Electrodeposition method was justified by its simplicity of implementation, low cost, its flexibility to combine several compounds as it does not require expensive materials and therefore presents facilities for industrial transfers.

In order to develop CZTS layers and investigate the influence of deposition parameters on growth kinetics, optical, structural and morphological characteristics. Several ideas have been put forward to improve conversion yields. The results obtained shows that the devices produced on Mo glass substrate have better performance than CZTS devices based on ITO or FTO glass substrates. Similarly, the presence of the complexing agent in the electrolytic bath plays a very important role.

Finally, and to conclude, we can say that during this thesis work, we managed to synthesize by the electrodeposition technique thin layers of CZTS kesterite, good crystalline qualities, homogeneous and conductive on different substrates, which makes them very suitable for practical applications in the photovoltaic field.

\section{As perspectives for this work}

We will continue the development of thin layers of CZTS, by electrodeposition, with different concentrations of the complexing agent in order to arrive at more relevant experimental conditions.

Seek to increase the grain size for CZTS thin layers deposited in the presence of the complexing agent $\mathrm{Na}_{2} \mathrm{SO}_{4}$ which present optimal condition, in order to increase the efficiency of the solar cell. 


\section{Annexes}

\section{Published articles :}

- Toura, H., Khattak, Y. H., Baig, F., Soucase, B. M., Touhami, M. E., \& Hartiti, B. (2019). Effect of complexing agent on the morphology and annealing temperature of CZTS kesterite thin films by electrochemical deposition. Current Applied Physics, 19(5), 606-613.

- Khattak, Y. H., Baig, F., Toura, H., Ullah, S., Marí, B., Beg, S., \& Ullah, H. (2018). Effect of CZTSe BSF and minority carrier life time on the efficiency enhancement of CZTS kesterite solar cell. Current Applied Physics, 18(6), 633-641.

- Toura, H., Khattak, Y. H., Baig, F., Soucase, B. M., \& Touhami, M. E. (2019). Back contact effect on electrodeposited CZTS kesterite thin films experimental and numerical investigation. Solar Energy, 194, 932-938.

- Khattak, Y. H., Baig, F., Toura, H., Harabi, I., Beg, S., \& Soucase, B. M. (2019). Single step electrochemical deposition for the fabrication of CZTS kesterite thin films for solar cells. Applied Surface Science, 497, 143794.

- Khattak, Y. H., Baig, F., Toura, H., Beg, S., \& Soucase, B. M. (2019). Efficiency enhancement of Cu2BaSnS4 experimental thin-film solar cell by device modeling. Journal of Materials Science, 54(24), 14787-14796.

- Khattak, Y. H., Baig, F., Toura, H., Beg, S., \& Soucase, B. M. (2019). CZTSe Kesterite as an Alternative Hole Transport Layer for MASnI3 Perovskite Solar Cells. Journal of Electronic Materials, 48(9), 5723-5733.

- Hameed, K. Y., Faisal, B., Hanae, T., Marí, S. B., Saira, B., \& Kaim, K. N. A. (2019). Modelling of novel-structured copper barium tin sulphide thin film solar cells. Bulletin of Materials Science, 42(5), 231.

\section{Scientific communications :}

- Toura Hanae, Mari Soucase Bernabé \& Ebn Touhami Mohamed, "Experimental investigation of the effect of back contact on electrochemically deposited CZTS kesterite thin films", Oral presentation, 7th European Conference on Renewable Energy Systems, 10-12 June 2019 Madrid, Spain. 


\section{References}

[1] World Energy Balances 2019, (n.d.).

[2] N.T. Nassar, J. Brainard, A. Gulley, R. Manley, G. Matos, G. Lederer, L.R. Bird, D. Pineault, E. Alonso, J. Gambogi, S.M. Fortier, Evaluating the mineral commodity supply risk of the U.S. manufacturing sector, Sci. Adv. 6 (2020) eaay8647. doi:10.1126/sciadv.aay8647.

[3] W. Wang, M.T. Winkler, O. Gunawan, T. Gokmen, T.K. Todorov, Y. Zhu, D.B. Mitzi, Device Characteristics of CZTSSe Thin-Film Solar Cells with 12.6\% Efficiency, Adv. Energy Mater. 4 (2014) 1301465. doi:10.1002/aenm.201301465.

[4] H. Toura, Y.H. Khattak, F. Baig, B.M. Soucase, M.E. Touhami, B. Hartiti, Effect of complexing agent on the morphology and annealing temperature of CZTS kesterite thin films by electrochemical deposition, Curr. Appl. Phys. 19 (2019) 606-613. doi:10.1016/j.cap.2019.03.003.

[5] H. Toura, Y.H. Khattak, F. Baig, B.M. Soucase, M.E. Touhami, Back contact effect on electrodeposited CZTS kesterite thin films experimental and numerical investigation, Sol. Energy. 194 (2019) 932-938. doi:10.1016/j.solener.2019.11.017.

[6] Y.H. Khattak, F. Baig, H. Toura, I. Harabi, S. Beg, B.M. Soucase, Single step electrochemical deposition for the fabrication of CZTS kesterite thin films for solar cells, Appl. Surf. Sci. 497 (2019) 143794. doi:10.1016/j.apsusc.2019.143794.

[7] G. Déchène, Modifications de l'éclat d'un sulfure de zinc phosphorescent sous l'influence d'un courant électrique, J. Phys. Le Radium. 9 (1938) 109-119. doi:10.1051/jphysrad:0193800903010900.

[8] M.E. Becquerel, Mémoire sur les effets électriques produits sous l'influence des rayons solaires, 1839.

[9] M.A. Green, Silicon photovoltaic modules: a brief history of the first 50 years, Prog. Photovoltaics Res. Appl. 13 (2005) 447-455. doi:10.1002/pip.612.

[10] P. Hersch, K. Zweibel, Basic photovoltaic principles and methods, United States, 1982. doi:10.2172/5191389.

[11] E. Boyes, Understanding the p-n junction, Phys. Educ. 25 (1990) 009. doi:10.1088/0031-9120/25/1/009.

[12] M. Tacke, Principles of Photoelectric Conversion, in: Sensors, Wiley-VCH Verlag GmbH, Weinheim, Germany, 2008: pp. 77-95. doi:10.1002/9783527620173.ch4.

[13] Y.H. Khattak, F. Baig, B.M. Soucase, S. Beg, S.R. Gillani, S. Ahmed, Efficiency enhancement of novel CNTS/ZnS/Zn (O, S) thin film solar cell, Optik (Stuttg). 171 (2018) 453-462. doi:10.1016/j.ijleo.2018.06.001.

[14] S. Alem-Boudjemline, Realization and characterization of plastic photovoltaic cells, Université d'Angers, 2004.

[15] Y.H. Khattak, F. Baig, B.M. Soucase, S. Beg, Efficiency Enhancement of Cu 2 BaSnS 4 Thin Film Solar Cell, Mater. Focus. 7 (2018) 758-765. doi:10.1166/mat.2018.1575.

[16] Y.H. Khattak, F. Baig, B.M. Soucase, S. Beg, S.R. Gillani, S. Ahmed, Effect of Cu 2 O Back Surface Field on the Efficiency Enhancement of CZTSe Kesterite Photovoltaic Cell, Mater. Focus. 7 (2018) 604609. doi:10.1166/mat.2018.1563.

[17] Y.H. Khattak, F. Baig, B. Mari, H. Ullah, T. Ahmed, Numerical Modeling of Cd1-xZnxS/ Cd1-xZnx Te Photovoltaic Solar Cells, in: 2017 Int. Renew. Sustain. Energy Conf., IEEE, 2017: pp. 1-4. 
doi:10.1109/IRSEC.2017.8477588.

[18] J. Cubas, S. Pindado, C. de Manuel, Explicit Expressions for Solar Panel Equivalent Circuit Parameters Based on Analytical Formulation and the Lambert W-Function, in: 1st Int. e-Conference Energies, 2014 : p. c013. doi:10.3390/ece-1-c013.

[19] E.M.G. Rodrigues, R. Melício, V.M.F. Mendes, J.P.S. Catalão, Simulation of a solar cell considering single-diode equivalent circuit mode, Renew. Energy Power Qual. J. 1 (2011) 369-373. doi:10.24084/repqj09.339.

[20] K. Ranabhat, L. Patrikeev, A.A. evna Revina, K. Andrianov, V. Lapshinsky, E. Sofronova, An introduction to solar cell technology, J. Appl. Eng. Sci. 14 (2016) 481-491. doi:10.5937/jaes14-10879.

[21] H.S. Min, Y.H. Khattak, Review on silicon and thin film based solar cells, Res. J. Chem. Environ. 23 (2019) 135-142.

[22] L. Etgar, Semiconductor Nanocrystals as Light Harvesters in Solar Cells, Materials (Basel). 6 (2013) 445-459. doi:10.3390/ma6020445.

[23] M.T. Kibria, A. Ahammed, S.M. Sony, F. Hossain, A Review: Comparative studies on different generation solar cells technology, in: Proc. 5th Int. Conf. Environ. Asp. Bangladesh, 2014.

[24] Y.H. Khattak, F. Baig, B. Marí, S. Beg, S.R. Gillani, T. Ahmed, Effect of CdTe Back Surface Field on the Efficiency Enhancement of a CGS Based Thin Film Solar Cell, J. Electron. Mater. 47 (2018) 51835190. doi:10.1007/s11664-018-6405-4.

[25] R.D. Costa, F. Lodermeyer, R. Casillas, D.M. Guldi, Recent advances in multifunctional nanocarbons used in dye-sensitized solar cells, Energy Environ. Sci. 7 (2014) 1281-1296. doi:10.1039/c3ee43458c.

[26] R. Saravanan, K.R. Mu. Naushad, B. Rabah, Emerging Nanostructured Materials for Energy and Environmental Science., 2019. doi:10.1007/978-3-030-04474-9.

[27] Y. Li, G. Xu, C. Cui, Y. Li, Flexible and Semitransparent Organic Solar Cells, Adv. Energy Mater. 8 (2018) 1701791. doi:10.1002/aenm.201701791.

[28] F.W. Low, C.W. Lai, Recent developments of graphene-TiO2 composite nanomaterials as efficient photoelectrodes in dye-sensitized solar cells: A review, Renew. Sustain. Energy Rev. 82 (2018) 103125. doi:10.1016/j.rser.2017.09.024.

[29] A decade of perovskite photovoltaics, Nat. Energy. 4 (2019) 1-1. doi:10.1038/s41560-018-0323-9.

[30] S. Sharma, K.K. Jain, A. Sharma, Solar Cells: In Research and Applications-A Review, Mater. Sci. Appl. 06 (2015) 1145-1155. doi:10.4236/msa.2015.612113.

[31] The Advantages of Photovoltaic Systems, Renew. Energy World. (n.d.). https://www.renewableenergyworld.com/2011/10/22/the-advantages-of-photovoltaic-systems/\#gref.

[32] H. Wang, Progress in thin film solar cells based on Cu2ZnSnS4, Int. J. Photoenergy. 2011 (2011) 1-10. doi:10.1155/2011/801292.

[33] A. Kowsar, M. Rahaman, M.S. Islam, A.Y. Imam, S.C. Debnath, M. Sultana, M.A. Hoque, A. Sharmin, Z.H. Mahmood, S.F.U. Farhad, Progress in major thin-film solar cells: Growth technologies, layer materials and efficiencies, Int. J. Renew. Energy Res. 9 (2019) 579-597.

[34] Y.H. Khattak, F. Baig, H. Toura, S. Ullah, B. Marí, S. Beg, H. Ullah, Effect of CZTSe BSF and minority carrier life time on the efficiency enhancement of CZTS kesterite solar cell, Curr. Appl. Phys. 18 (2018) 633-641. doi:10.1016/j.cap.2018.03.013. 
[35] Y.H. Khattak, F. Baig, S. Ullah, B. Marí, S. Beg, H. Ullah, Enhancement of the conversion efficiency of thin film kesterite solar cell, J. Renew. Sustain. Energy. 10 (2018) 033501. doi:10.1063/1.5023478.

[36] H.-J. Lewerenz, H. Jungblut, Photovoltaik: Grundlagen und anwendungen, Springer-Verlag, 2013.

[37] N.B. Mortazavi Amiri, A. Postnikov, Electronic structure and lattice dynamics in kesterite-type $\mathrm{Cu} 2 \mathrm{ZnSnSe} 4$ from first-principles calculations, Phys. Rev. B. 82 (2010) 205204. doi:10.1103/PhysRevB.82.205204.

[38] S. Schorr, H.-J. Hoebler, M. Tovar, A neutron diffraction study of the stannite-kesterite solid solution series, Eur. J. Mineral. 19 (2007) 65-73. doi:10.1127/0935-1221/2007/0019-0065.

[39] S. Chen, X.G. Gong, A. Walsh, S.-H. Wei, Crystal and electronic band structure of Cu2ZnSnX4 (X=S and Se) photovoltaic absorbers: first-principles insights, Appl. Phys. Lett. 94 (2009) 41903. doi:10.1063/1.3074499.

[40] S.R. Hall, J.T. Szymanski, J.M. Stewart, Kesterite, Cu2(Zn,Fe)SnS4 and Stannite Cu2(Fe,Zn)SnS4, structurally similar but distinct minerals, Can. Mineral. 16 (1978) 131-137.

[41] K. Ito, Copper Zinc Tin Sulfide-Based Thin-Film Solar Cells, John Wiley \& Sons Ltd, Chichester, UK, 2014. doi:10.1002/9781118437865.

[42] A. Nagaoka, H. Miyake, T. Taniyama, K. Kakimoto, Y. Nose, M.A. Scarpulla, K. Yoshino, Effects of sodium on electrical properties in Cu 2 ZnSnS 4 single crystal, Appl. Phys. Lett. 104 (2014) 152101. doi:10.1063/1.4871208.

[43] T. Maeda, S. Nakamura, T. Wada, First-principles calculations of vacancy formation in In-free photovoltaic semiconductor Cu2ZnSnSe4, in: Thin Solid Films, Elsevier B.V., 2011: pp. 7513-7516. doi:10.1016/j.tsf.2011.01.094.

[44] V.G. Rajeshmon, M.R.R. Menon, C.S. Kartha, K.P. Vijayakumar, Effect of copper concentration and spray rate on the properties $\mathrm{Cu} 2 \mathrm{ZnSnS} 4$ thin films deposited using spray pyrolysis, J. Anal. Appl. Pyrolysis. 110 (2014) 448-454. doi:10.1016/j.jaap.2014.10.014.

[45] T. Kobayashi, K. Jimbo, K. Tsuchida, S. Shinoda, T. Oyanaoi, H. Katagiri, Investigation of Cu2ZnSnS4based thin film solar cells using abundant materials, Jpn. J. Appl. Phys. 44 (2005) 783-787. doi:10.1143/JJAP.44.783.

[46] S. Chen, J. Yang, X.G. Gong, A. Walsh, S. Wei, Intrinsic point defects and complexes in the quaternary kesterite semiconductor $\langle$ math display="inline" $\rangle\langle$ mrow $\rangle\langle$ msub $\rangle\langle$ mrow $\rangle\langle$ mtext $\rangle$ Cu $\langle/$ mtext $\rangle$

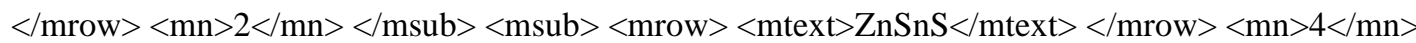
$</$ msub $></$ mrow $></$ math $>$, Phys. Rev. B. 81 (2010) 245204. doi:10.1103/PhysRevB.81.245204.

[47] S. Chen, A. Walsh, X.-G. Gong, S.-H. Wei, Classification of Lattice Defects in the Kesterite Cu $2 \mathrm{ZnSnS}$ 4 and $\mathrm{Cu} 2$ ZnSnSe 4 Earth-Abundant Solar Cell Absorbers, Adv. Mater. 25 (2013) 1522-1539. doi:10.1002/adma.201203146.

[48] S.R. Kodigala, Thin Film Solar Cells From Earth Abundant Materials, Elsevier, 2014. doi:10.1016/C2011-0-06984-3.

[49] C. Persson, Electronic and optical properties of Cu2ZnSnS4 and Cu2ZnSnSe4, J. Appl. Phys. 107 (2010) 053710. doi:10.1063/1.3318468.

[50] M.I. Amal, K.H. Kim, Optical properties of selenized Cu 2ZnSnSe 4 films from a Cu-Zn-Sn metallic precursor, Chalcogenide Lett. 9 (2012) 345-353. 
[51] Y. Miyamoto, K. Tanaka, M. Oonuki, N. Moritake, H. Uchiki, Optical Properties of Cu 2 ZnSnS 4 Thin Films Prepared by Sol-Gel and Sulfurization Method, Jpn. J. Appl. Phys. 47 (2008) 596-597. doi:10.1143/JJAP.47.596.

[52] M.Z. Ansari, N. Khare, Structural and optical properties of CZTS thin films deposited by ultrasonically assisted chemical vapour deposition, J. Phys. D. Appl. Phys. 47 (2014) 185101. doi:10.1088/0022$3727 / 47 / 18 / 185101$.

[53] Y.H. Khattak, F. Baig, S. Ullah, B. Marí, S. Beg, H. Ullah, Numerical modeling baseline for high efficiency (Cu 2 FeSnS 4 ) CFTS based thin film kesterite solar cell, Optik (Stuttg). 164 (2018) 547-555. doi:10.1016/j.ijleo.2018.03.055.

[54] H. Katagiri, K. Saitoh, T. Washio, H. Shinohara, T. Kurumadani, S. Miyajima, Development of thin film solar cell based on Cu2ZnSnS4 thin films, Sol. Energy Mater. Sol. Cells. 65 (2001) 141-148. doi:10.1016/S0927-0248(00)00088-X.

[55] G. Suresh Babu, Y.B. Kishore Kumar, P. Uday Bhaskar, S. Raja Vanjari, Effect of Cu/(Zn+Sn) ratio on the properties of co-evaporated Cu2ZnSnSe4 thin films, Sol. Energy Mater. Sol. Cells. 94 (2010) 221226. doi:10.1016/j.solmat.2009.09.005.

[56] L. Sun, J. He, Y. Chen, F. Yue, P. Yang, J. Chu, Comparative study on Cu 2ZnSnS 4 thin films deposited by sputtering and pulsed laser deposition from a single quaternary sulfide target, J. Cryst. Growth. 361 (2012) 147-151. doi:10.1016/j.jcrysgro.2012.09.023.

[57] J. Tao, K. Zhang, C. Zhang, L. Chen, H. Cao, J. Liu, J. Jiang, L. Sun, P. Yang, J. Chu, A sputtered CdS buffer layer for co-electrodeposited $\mathrm{Cu} 2 \mathrm{ZnSnS} 4$ solar cells with 6.6\% efficiency, Chem. Commun. 51 (2015) 10337-10340. doi:10.1039/C5CC01170A.

[58] D. Benmoussa, The Role of doping in the window layer on Performance of a InP Solar Cells USING AMPS-1D, IOSR J. Eng. 02 (2012) 42-46. doi:10.9790/3021-02864246.

[59] G.K. Dalapati, S. Zhuk, S. Masudy-Panah, A. Kushwaha, H.L. Seng, V. Chellappan, V. Suresh, Z. Su, S.K. Batabyal, C.C. Tan, A. Guchhait, L.H. Wong, T.K.S. Wong, S. Tripathy, Impact of molybdenum out diffusion and interface quality on the performance of sputter grown CZTS based solar cells, Sci. Rep. 7 (2017) 1-12. doi:10.1038/s41598-017-01605-7.

[60] K. Ito, T. Nakazawa, Electrical and Optical Properties of Stannite-Type Quaternary Semiconductor Thin Films, Jpn. J. Appl. Phys. 27 (1988) 2094-2097. doi:10.1143/JJAP.27.2094.

[61] K.S. Gour, A.K. Yadav, O.P. Singh, V.N. Singh, Na incorporated improved properties of Cu2ZnSnS4 (CZTS) thin film by DC sputtering, Vacuum. 154 (2018) 148-153. doi:10.1016/j.vacuum.2018.05.007.

[62] S. Zhuk, A. Kushwaha, T.K.S. Wong, S. Masudy-Panah, A. Smirnov, G.K. Dalapati, Critical review on sputter-deposited Cu2ZnSnS4 (CZTS) based thin film photovoltaic technology focusing on device architecture and absorber quality on the solar cells performance, Sol. Energy Mater. Sol. Cells. 171 (2017) 239-252. doi:10.1016/j.solmat.2017.05.064.

[63] A. Cazzaniga, A. Crovetto, C. Yan, K. Sun, X. Hao, J. Ramis Estelrich, S. Canulescu, E. Stamate, N. Pryds, O. Hansen, J. Schou, Ultra-thin Cu2ZnSnS4 solar cell by pulsed laser deposition, Sol. Energy Mater. Sol. Cells. 166 (2017) 91-99. doi:10.1016/j.solmat.2017.03.002.

[64] A.C. Cazzaniga, Fabrication of thin film CZTS solar cells with Pulsed Laser Deposition, Technical University of Denmark, 2016. 
[65] S.A. Vanalakar, G.L. Agawane, S.W. Shin, M.P. Suryawanshi, K.V. Gurav, K.S. Jeon, P.S. Patil, C.W. Jeong, J.Y. Kim, J.H. Kim, A review on pulsed laser deposited CZTS thin films for solar cell applications, J. Alloys Compd. 619 (2015) 109-121. doi:10.1016/j.jallcom.2014.09.018.

[66] J.D. Musgraves, N. Carlie, J. Hu, L. Petit, A. Agarwal, L.C. Kimerling, K.A. Richardson, Comparison of the optical, thermal and structural properties of $\mathrm{Ge}-\mathrm{Sb}-\mathrm{S}$ thin films deposited using thermal evaporation and pulsed laser deposition techniques, Acta Mater. 59 (2011) 5032-5039.

doi:10.1016/j.actamat.2011.04.060.

[67] M.E. Rincón, M. Sánchez, P.J. George, A. Sánchez, P.K. Nair, Comparison of the Properties of Bismuth Sulfide Thin Films Prepared by Thermal Evaporation and Chemical Bath Deposition, J. Solid State Chem. 136 (1998) 167-174. doi:10.1006/jssc.1997.7670.

[68] T. Prabhakar, J. Nagaraju, Ultrasonic spray pyrolysis of CZTS solar cell absorber layers and characterization studies, in: 2010 35th IEEE Photovolt. Spec. Conf., IEEE, 2010: pp. 001964-001969. doi:10.1109/PVSC.2010.5616709.

[69] A.A. Rizkalla, A.H. Lefebvre, Influence of Liquid Properties on Airblast Atomizer Spray Characteristics, J. Eng. Power. 97 (1975) 173-177. doi:10.1115/1.3445951.

[70] N. Nakayama, K. Ito, Sprayed films of stannite Cu2ZnSnS4, Appl. Surf. Sci. 92 (1996) 171-175. doi:10.1016/0169-4332(95)00225-1.

[71] N. Kamoun, H. Bouzouita, B. Rezig, Fabrication and characterization of Cu2ZnSnS4 thin films deposited by spray pyrolysis technique, Thin Solid Films. 515 (2007) 5949-5952.

doi:10.1016/j.tsf.2006.12.144.

[72] G. Bezzi, G. Celotti, E. Landi, T.M.G. La Torretta, I. Sopyan, A. Tampieri, A novel sol-gel technique for hydroxyapatite preparation, Mater. Chem. Phys. 78 (2003) 816-824. doi:10.1016/S02540584(02)00392-9.

[73] K. Tanaka, N. Moritake, H. Uchiki, Preparation of Cu2ZnSnS4 thin films by sulfurizing sol-gel deposited precursors, Sol. Energy Mater. Sol. Cells. 91 (2007) 1199-1201. doi:10.1016/j.solmat.2007.04.012.

[74] N.K. Youn, G.L. Agawane, D. Nam, J. Gwak, S.W. Shin, J.H. Kim, J.H. Yun, S. Ahn, A. Cho, Y.J. Eo, S.K. Ahn, H. Cheong, D.H. Kim, K.-S. Shin, K.H. Yoon, Cu2ZnSnS4 solar cells with a single spincoated absorber layer prepared via a simple sol-gel route, Int. J. Energy Res. 40 (2016) 662-669. doi:10.1002/er.3446.

[75] K. Patel, V. Kheraj, D. V. Shah, C.J. Panchal, N.G. Dhere, Cu2ZnSnS4 thin-films grown by dip-coating: Effects of annealing, J. Alloys Compd. 663 (2016) 842-847. doi:10.1016/j.jallcom.2015.11.233.

[76] F. Aslan, A. Tumbul, Non-vacuum processed Cu2ZnSnS4 thin films: Influence of copper precursor on structural, optical and morphological properties, J. Alloys Compd. 612 (2014) 1-4. doi:10.1016/j.jallcom.2014.05.140.

[77] N. Kanani, Electroplating: Basic Principles, Processes and Practice, Elsevier, 2004.

[78] N. Eliaz, E. Gileadi, Physical Electrochemistry: Fundamentals, Techniques, and Applications, John Wiley \& Sons, 2019.

[79] M. Mokaddem, P. Volovitch, F. Rechou, R. Oltra, K. Ogle, The anodic and cathodic dissolution of Al and Al-Cu-Mg alloy, Electrochim. Acta. 55 (2010) 3779-3786. doi:10.1016/j.electacta.2010.01.079. 
[80] F. Baig, Y.H. Khattak, B.M. Soucase, S. Beg, S. Ullah, Effect of anionic bath temperature on morphology and photo electrochemical properties of $\mathrm{Cu} 2 \mathrm{O}$ deposited by SILAR, Mater. Sci. Semicond. Process. 88 (2018) 35-39. doi:10.1016/j.mssp.2018.07.031.

[81] A. Khare, B. Himmetoglu, M. Johnson, D.J. Norris, M. Cococcioni, E.S. Aydil, Calculation of the lattice dynamics and Raman spectra of copper zinc tin chalcogenides and comparison to experiments, J. Appl. Phys. 111 (2012) 083707. doi:10.1063/1.4704191.

[82] S. Adachi, Earth-Abundant Materials for Solar Cells, John Wiley \& Sons, Ltd, Chichester, UK, 2015. doi:10.1002/9781119052814.

[83] F. Baig, Y. Hameed Khattak, S. Jemai, B. Marí Soucase, S. Beg, Hydrothermal syntheses of Vanadium doped $\langle$ math altimg="si1.gif" overflow="scroll" $\rangle\langle$ mrow $\rangle\langle$ mi $\rangle \alpha\langle$ mi $\rangle\langle$ mo $\rangle-\langle/$ mo $\rangle\langle$ msub $\rangle\langle$ mrow $\rangle$ $<$ mi mathvariant="normal" $>\mathrm{F}</ \mathrm{mi}><$ mi mathvariant="normal" $>\mathrm{e}</ \mathrm{mi}\rangle</ \mathrm{mrow}>\langle\mathrm{mn}\rangle 2</ \mathrm{mn}\rangle$ </msub $><$ msub $><$ mi mathvariant="normal">O</mi >, Sol. Energy. 182 (2019) 332-339. doi:10.1016/j.solener.2019.02.066.

[84] F. Baig, Numerical analysis for efficiency enhancement of thin film solar cells., Universitat Politècnica de València, 2019. doi:10.4995/Thesis/10251/118801.

[85] C.A. Craig, S. Feng, Exploring utility organization electricity generation, residential electricity consumption, and energy efficiency: A climatic approach, Appl. Energy. 185 (2017) 779-790. doi:10.1016/j.apenergy.2016.10.101.

[86] P. Mir-Artigues, E. Cerdá, P. del Río, Analysing the economic impact of the new renewable electricity support scheme on solar PV plants in Spain, Energy Policy. 114 (2018) 323-331. doi:10.1016/j.enpol.2017.11.048.

[87] E. Nuño, P. Maule, A. Hahmann, N. Cutululis, P. Sørensen, I. Karagali, Simulation of transcontinental wind and solar PV generation time series, Renew. Energy. 118 (2018) 425-436. doi:10.1016/j.renene.2017.11.039.

[88] A. Honrubia-Escribano, F.J. Ramirez, E. Gómez-Lázaro, P.M. Garcia-Villaverde, M.J. Ruiz-Ortega, G. Parra-Requena, Influence of solar technology in the economic performance of PV power plants in Europe. A comprehensive analysis, Renew. Sustain. Energy Rev. 82 (2018) 488-501. doi:10.1016/j.rser.2017.09.061.

[89] oecd-factbook-2015-2016, (n.d.).

[90] T. Novakov, M.O. Andreae, R. Gabriel, T.W. Kirchstetter, O.L. Mayol-Bracero, V. Ramanathan, Origin of carbonaceous aerosols over the tropical Indian Ocean: Biomass burning or fossil fuels?, Geophys. Res. Lett. 27 (2000) 4061-4064. doi:10.1029/2000GL011759.

[91] K. Caldeira, M.E. Wickett, Anthropogenic carbon and ocean pH, Nature. 425 (2003) 365-365. doi:10.1038/425365a.

[92] W.B. Lyons, E. Saelens, K.A. Welch, The impact of fossil fuel burning related to scientific activities in the McMurdo Dry Valleys, Antarctica: Revisited, Elem Sci Anth. 6 (2018) 33. doi:10.1525/elementa.288.

[93] M.A. Green, Y. Hishikawa, E.D. Dunlop, D.H. Levi, J. Hohl-Ebinger, A.W.Y. Ho-Baillie, Solar cell efficiency tables (version 52), Prog. Photovoltaics Res. Appl. 26 (2018) 427-436. doi:10.1002/pip.3040.

[94] L. Järup, A. Åkesson, Current status of cadmium as an environmental health problem, Toxicol. Appl. 
Pharmacol. 238 (2009) 201-208. doi:10.1016/j.taap.2009.04.020.

[95] N. Espinosa, M. Hösel, D. Angmo, F.C. Krebs, Solar cells with one-day energy payback for the factories of the future, Energy Environ. Sci. 5 (2012) 5117-5132. doi:10.1039/C1EE02728J.

[96] D. Wang, M. Wright, N.K. Elumalai, A. Uddin, Stability of perovskite solar cells, Sol. Energy Mater. Sol. Cells. 147 (2016) 255-275. doi:10.1016/j.solmat.2015.12.025.

[97] Y.H. Khattak, F. Baig, H. Toura, S. Beg, B.M. Soucase, Efficiency enhancement of Cu2BaSnS4 experimental thin-film solar cell by device modeling, J. Mater. Sci. 54 (2019) 14787-14796. doi:10.1007/s10853-019-03942-6.

[98] R.A. Jabr, M. Hamad, Y.M. Mohanna, Newton-Raphson Solution of Poisson's Equation in a Pn Diode, Int. J. Electr. Eng. Educ. 44 (2007) 23-33. doi:10.7227/IJEEE.44.1.3.

[99] F. Baig, Y.H. Khattak, S. Ullah, B. Marí, S. Beg, H. Ullah, Numerical Analysis of a Novel FTO/nMAPbI 3 /p-MAPbI 3 /p-MAPbBr 3 Organic-Inorganic Lead Halide Perovskite Solar Cell, J. Nanoelectron. Optoelectron. 13 (2018) 1320-1327. doi:10.1166/jno.2018.2363.

[100] Y.H. Khattak, Modeling of High Power Conversion Efficiency Thin Film Solar Cells, Universitat Politècnica de València, 2019. doi:10.4995/Thesis/10251/118802.

[101] Chenming C. Hu, Modern Semiconductor Devices for Integrated Circuits, in: 2010.

[102] F. Baig, Y.H. Khattak, B.M. Soucase, S. Beg, S.R. Gillani, S. Ahmed, A Baseline for the Numerical Study of Sb 2 Se 3 Absorber Material Based Solar Cell, J. Nanoelectron. Optoelectron. 14 (2019) 72-79. doi:10.1166/jno.2019.2451.

[103] F. Baig, Y.H. Khattak, B. Marí, S. Beg, A. Ahmed, K. Khan, Efficiency Enhancement of CH3NH3SnI3 Solar Cells by Device Modeling, J. Electron. Mater. 47 (2018) 5275-5282. doi:10.1007/s11664-0186406-3.

[104] F. Baig, Y.H. Khattak, S. Ullah, B.M. Soucase, S. Beg, H. Ullah, Numerical analysis a guide to improve the efficiency of experimentally designed solar cell, Appl. Phys. A. 124 (2018) 471. doi:10.1007/s00339018-1877-x.

[105] A.A.F. Husain, W.Z.W. Hasan, S. Shafie, M.N. Hamidon, S.S. Pandey, A review of transparent solar photovoltaic technologies, Renew. Sustain. Energy Rev. 94 (2018) 779-791. doi:10.1016/j.rser.2018.06.031.

[106] M. Minbashi, M.K. Omrani, N. Memarian, D.-H. Kim, Comparison of theoretical and experimental results for band-gap-graded CZTSSe solar cell, Curr. Appl. Phys. 17 (2017) 1238-1243. doi:10.1016/j.cap.2017.06.003.

[107] T.D. Lee, A.U. Ebong, A review of thin film solar cell technologies and challenges, Renew. Sustain. Energy Rev. 70 (2017) 1286-1297. doi:10.1016/j.rser.2016.12.028.

[108] D.M. Powell, M.T. Winkler, H.J. Choi, C.B. Simmons, D.B. Needleman, T. Buonassisi, Crystalline silicon photovoltaics: a cost analysis framework for determining technology pathways to reach baseload electricity costs, Energy Environ. Sci. 5 (2012) 5874. doi:10.1039/c2ee03489a.

[109] P. Jackson, D. Hariskos, R. Wuerz, O. Kiowski, A. Bauer, T.M. Friedlmeier, M. Powalla, Properties of $\mathrm{Cu}(\mathrm{In}, \mathrm{Ga}) \mathrm{Se} 2$ solar cells with new record efficiencies up to $21.7 \%$, Phys. Status Solidi - Rapid Res. Lett. 9 (2015) 28-31. doi:10.1002/pssr.201409520.

[110] W. Yang, H. Duan, B. Bob, H. Zhou, B. Lei, C. Chung, S. Li, W.W. Hou, Y. Yang, Novel Solution 
Processing of High-Efficiency Earth-Abundant Cu 2 ZnSn(S,Se) 4 Solar Cells, Adv. Mater. 24 (2012) 6323-6329. doi:10.1002/adma.201201785.

[111] Y. Yeh, H. Chen, S. Liu, Fabrication of Cu2ZnSnS4 (CZTS) films by one step electrochemical deposition and annealing, Chalcogenide Lett. 10 (2013) 565-571.

[112] H. Zhou, W.C. Hsu, H.S. Duan, B. Bob, W. Yang, T. Bin Song, C.J. Hsu, Y. Yang, CZTS nanocrystals: A promising approach for next generation thin film photovoltaics, Energy Environ. Sci. 6 (2013) 28222838. doi:10.1039/c3ee41627e.

[113] J.V.L. Ingrid L. Repins, Manuel J. Romero, Kesterite Successes, Ongoing Work, and Challenges: A Perspective From Vacuum Deposition, IEEE J. PHOTOVOLTAICS. 10 (2013) 439-445. doi:10.1016/0306-4522(83)90142-2.

[114] M. Beres, J. Syzdek, K.M. Yu, S.S. Mao, Growth behavior of co-electrodeposited CZTS precursor thin films from acidic baths containing tartaric acid, Mater. Chem. Phys. 204 (2018) 83-94. doi:10.1016/j.matchemphys.2017.09.071.

[115] S. Kim, J. Kim, T.R. Rana, K.-W. Kim, M.-H. Kwon, Characterization of CBO and defect states of CZTSe solar cells prepared by using two-step process, Curr. Appl. Phys. 18 (2018) 191-199. doi:10.1016/j.cap.2017.12.004.

[116] S.K. Swami, A. Kumar, V. Dutta, Deposition of Kesterite Cu2ZnSnS4 ( CZTS ) Thin Films by Spin Coating Technique for Solar Cell Application, Energy Procedia. 33 (2013) 198-202. doi:10.1016/j.egypro.2013.05.058.

[117] T.R. Rana, N.M. Shinde, J. Kim, Novel chemical route for chemical bath deposition of Cu2ZnSnS4 (CZTS) thin films with stacked precursor thin films, Mater. Lett. 162 (2016) 40-43. doi:10.1016/j.matlet.2015.09.100.

[118] J. Henry, K. Mohanraj, G. Sivakumar, Electrical and optical properties of CZTS thin films prepared by SILAR method, Asian Ceram. Soc. 4 (2016) 81-84. doi:10.1016/j.jascer.2015.12.003.

[119] T.P. Dhakal, C. Yi, R.R. Tobias, R. Dasharathy, C.R. Westgate, Characterization of a CZTS thin film solar cell grown by sputtering method, Sol. Energy. 100 (2014) 23-30. doi:10.1016/j.solener.2013.11.035.

[120] Y. Lu, S. Wang, X. Ma, X. Xu, S. Yang, Y. Li, Z. Tang, The characteristic of Cu 2 ZnSnS 4 thin fi lm solar cells prepared by sputtering CuSn and CuZn alloy targets, Curr. Appl. Phys. 18 (2018) 1571-1576. doi:10.1016/j.cap.2018.10.005.

[121] M.I. Amal, S.H. Lee, K.H. Kim, Properties of Cu2ZnSn(SxSe1-x)4 thin films prepared by one-step sulfo-selenization of alloyed metal precursors, Curr. Appl. Phys. 14 (2014) 916-921. doi:10.1016/j.cap.2014.04.005.

[122] K. Moriya, J. Watabe, K. Tanaka, H. Uchiki, Characterization of Cu2ZnSnS4 thin films prepared by photo-chemical deposition, Phys. Status Solidi. 3 (2006) 2848-2852. doi:10.1002/pssc.200669588.

[123] S. Ahmed, K.B. Reuter, O. Gunawan, L. Guo, L.T. Romankiw, A High Efficiency Electrodeposited Cu 2 ZnSnS 4 Solar Cell, (2012) 253-259. doi:10.1002/aenm.201100526.

[124] Y. Lin, S. Ikeda, W. Septina, Y. Kawasaki, T. Harada, Solar Energy Materials \& Solar Cells Mechanistic aspects of preheating effects of electrodeposited metallic precursors on structural and photovoltaic properties of $\mathrm{Cu} 2 \mathrm{Zn} \mathrm{S} \mathrm{nS} 4$ thin fi lms, Sol. Energy Mater. Sol. Cells. 120 (2014) 218-225. 
doi:10.1016/j.solmat.2013.09.006.

[125] J. Tao, J. Liu, J. He, K. Zhang, J. Jiang, L. Sun, P. Yang, J. Chu, Synthesis and characterization of Cu 2 $\mathrm{ZnSnS} 4$ thin films by the sulfurization of co-electrodeposited $\mathrm{Cu}-\mathrm{Zn}-\mathrm{Sn}-\mathrm{S}$ precursor layers for solar cell applications, RSC Adv. 4 (2014) 23977-23984. doi:10.1039/C4RA02327G.

[126] J. Tao, J. He, K. Zhang, J. Liu, Y. Dong, L. Sun, P. Yang, J. Chu, Effect of deposition potential on the properties of $\mathrm{Cu} 2 \mathrm{ZnSnS} 4$ films for solar cell applications, 135 (2014) 8-10.

doi:10.1016/j.matlet.2014.07.144.

[127] H. Kirou, L. Atourki, A. Almaggoussi, Effects of Na2SO4 on the optical and structural properties of Cu2ZnSnS4 thin films synthesized using ..., Opt. Mater. (Amst). 75 (2018) 471-482. doi:10.1016/j.optmat.2017.11.004.

[128] R. Sani, R. Manivannan, S.N. Victoria, ONE STEP ELECTROCHEMICAL DEPOSITION OF CZTS FOR SOLAR CELL APPLICATIONS, 14 (2017) 165-170.

[129] D.B. Mitzi, O. Gunawan, T.K. Todorov, K. Wang, S. Guha, Solar Energy Materials \& Solar Cells The path towards a high-performance solution-processed kesterite solar cell \$, Sol. Energy Mater. Sol. Cells. 95 (2011) 1421-1436. doi:10.1016/j.solmat.2010.11.028.

[130] J. Tao, J. Liu, J. He, K. Zhang, J. Jiang, L. Sun, RSC Advances $\mathrm{Cu}-\mathrm{Zn}-\mathrm{Sn}-\mathrm{S}$ precursor layers for solar cell, (2014) 23977-23984. doi:10.1039/c4ra02327g.

[131] A. Tang, J. Liu, J. Ji, M. Dou, Z. Li, F. Wang, Applied Surface Science One-step electrodeposition for targeted off-stoichiometry Cu 2 ZnSnS 4 thin films, Appl. Surf. Sci. 383 (2016) 253-260. doi:10.1016/j.apsusc.2016.04.189.

[132] S.G. Lee, J. Kim, H.S. Woo, Y. Jo, A.I. Inamdar, S.M. Pawar, H.S. Kim, W. Jung, H.S. Im, Structural, morphological, compositional, and optical properties of single step electrodeposited Cu2ZnSnS4 (CZTS) thin films for solar cell application, Curr. Appl. Phys. 14 (2014) 254-258. doi:10.1016/j.cap.2013.11.028.

[133] J. Tao, J. Liu, L. Chen, H. Cao, X. Meng, Y. Zhang, C. Zhang, L. Sun, P. Yang, J. Chu, 7.1\% efficient co-electroplated $\mathrm{Cu} 2 \mathrm{ZnSnS} 4$ thin film solar cells with sputtered CdS buffer layers, Green Chem. 18 (2016) 550-557. doi:10.1039/C5GC02057C.

[134] J.J. Scragg, Copper Zinc Tin Sulfide Thin Films for Photovoltaics, Springer Berlin Heidelberg, Berlin, Heidelberg, 2011. doi:10.1007/978-3-642-22919-0.

[135] M.P. Paranthaman, W. Wong-Ng, R.N. Bhattacharya, Semiconductor Materials for Solar Photovoltaic Cells, Springer International Publishing, Cham, 2016. doi:10.1007/978-3-319-20331-7.

[136] S.M. Pawar, B.S. Pawar, A.V. Moholkar, D.S. Choi, J.H. Yun, J.H. Moon, S.S. Kolekar, J.H. Kim, Single step electrosynthesis of Cu2ZnSnS4 (CZTS) thin films for solar cell application, Electrochim. Acta. 55 (2010) 4057-4061. doi:10.1016/j.electacta.2010.02.051.

[137] C. Mehta, J.M. Abbas, G.S.S. Saini, S.K. Tripathi, A.B. Garg, R. Mittal, R. Mukhopadhyay, Effect of Complexing Agent on the Properties of ZnSe Thin Films, in: AIP Conf. Proc., Elsevier B.V., 2011: pp. 617-618. doi:10.1063/1.3606009.

[138] S. Shin, C. Park, C. Kim, Y. Kim, S. Park, J.-H. Lee, Cyclic voltammetry studies of copper, tin and zinc electrodeposition in a citrate complex system for CZTS solar cell application, Curr. Appl. Phys. 16 (2016) 207-210. doi:10.1016/j.cap.2015.11.017. 
[139] P.A. Fernandes, P.M.P. Salomé, A.F. Cunha, Growth and Raman scattering of Cu2ZnSnS4 thin films . Thin Solid Films, Thin Solid Films. (2009). doi:10.1016/j.tsf.2008.11.031.

[140] Z. Su, C. Yan, K. Sun, Z. Han, F. Liu, J. Liu, Y. Lai, J. Li, Y. Liu, Preparation of Cu2ZnSnS4thin films by sulfurizing stacked precursor thin films via successive ionic layer adsorption and reaction method, Appl. Surf. Sci. 258 (2012) 7678-7682. doi:10.1016/j.apsusc.2012.04.120.

[141] S. Rondiya, A. Rokade, A. Jadhavar, S. Nair, Effect of calcination temperature on the properties of CZTS absorber layer prepared by RF sputtering for solar cell applications, Mater. Renew. Sustain. Energy. (2017). doi:10.1007/s40243-017-0092-6.

[142] L. Chen, C. Park, Effects of annealing temperature on Cu2ZnSnS4 (CZTS) films formed by electrospray technique, Korean J. Chem. Eng. 34 (2017) 1187-1191. doi:10.1007/s11814-017-0011-7.

[143] S.W. Shin, I.Y. Kim, K.V. Gurav, C.H. Jeong, J.H. Yun, P.S. Patil, J.Y. Lee, J.H. Kim, Band gap tunable and improved microstructure characteristics of $\mathrm{Cu} 2 \mathrm{ZnSn}(\mathrm{S} 1-\mathrm{x}, \mathrm{Sex}) 4$ thin films by annealing under atmosphere containing S and Se, Curr. Appl. Phys. 13 (2013) 1837-1843. doi:10.1016/j.cap.2013.06.022.

[144] A. Khare, A.W. Wills, L.M. Ammerman, D.J. Norris, E.S. Aydil, Size control and quantum confinement in Cu2ZnSnS4nanocrystals, Chem. Commun. 47 (2011) 11721-11723. doi:10.1039/c1cc14687d.

[145] K. Jimbo, R. Kimura, T. Kamimura, S. Yamada, W.S. Maw, H. Araki, K. Oishi, H. Katagiri, Cu2ZnSnS4-type thin film solar cells using abundant materials, Thin Solid Films. 515 (2007) 59975999. doi:10.1016/j.tsf.2006.12.103.

[146] T. Feurer, P. Reinhard, E. Avancini, B. Bissig, J. Löckinger, P. Fuchs, R. Carron, T.P. Weiss, J. Perrenoud, S. Stutterheim, S. Buecheler, A.N. Tiwari, Progress in thin film CIGS photovoltaics Research and development, manufacturing, and applications, Prog. Photovoltaics Res. Appl. 25 (2017) 645-667. doi:10.1002/pip.2811.

[147] I.L. Repins, M.J. Romero, J. V. Li, S.-H. Wei, D. Kuciauskas, C.-S. Jiang, C. Beall, C. DeHart, J. Mann, W.-C. Hsu, G. Teeter, A. Goodrich, R. Noufi, Kesterite Successes, Ongoing Work, and Challenges: A Perspective From Vacuum Deposition, IEEE J. Photovoltaics. 3 (2013) 439-445. doi:10.1109/JPHOTOV.2012.2215842.

[148] H. Zhou, W.-C. Hsu, H.-S. Duan, B. Bob, W. Yang, T.-B. Song, C.-J. Hsu, Y. Yang, CZTS nanocrystals: a promising approach for next generation thin film photovoltaics, Energy Environ. Sci. 6 (2013) 2822. doi:10.1039/c3ee41627e.

[149] Y. Cao, M.S. Denny, J. V Caspar, W.E. Farneth, Q. Guo, A.S. Ionkin, L.K. Johnson, M. Lu, I. Malajovich, D. Radu, H.D. Rosenfeld, K.R. Choudhury, W. Wu, High-efficiency solution-processed Cu $2 \mathrm{ZnSn}(\mathrm{S}, \mathrm{Se}) 4$ thin-film solar cells prepared from binary and ternary nanoparticles, J. Am. Chem. Soc. 134 (2012) 15644-15647. doi:10.1021/ja3057985.

[150] E.S. Jüri Krustok, Taavi Raadik, Maarja Grossberg, Sergio Giraldo, Markus Neuschitzer, Simon LópezMarino, Temperature dependent electroreflectance study of $\mathrm{Cu} 2 \mathrm{ZnSnSe} 4$ solar cells, Mater. Sci. Semicond. Process. 39 (2015) 251-254. doi:10.1016/j.mssp.2015.04.055.

[151] G. Brammertz, M. Buffie, M. Meuris, J. Poortmans, K. Ben Messaoud, S. Sahayaraj, C. K, Characterization of defects in 9.7\% efficient Cu2ZnSnSe 4 -CdS-ZnO solar cells, Appl. Phys. Lett. 103 (2013) 2-5. 
[152] Susanne Siebentritt and Susan Schorr, Solar Cells Utilizing Small Molecular Weight Organic Semiconductors, Prog. Photovoltaics Res. Appl. 20 (2012) 512-519. doi:10.1002/pip.2156.

[153] S. Delbos, Kësterite thin films for photovoltaics : a review, EPJ Photovoltaics. 3 (2012) 1-13. doi:10.1051/epjpv/2012008.

[154] K.I. and T. Nakazawa, Electrical and Optical Properties of Stannite-Type Quarternary Semiconductor Thin Films, Jpn. J. Appl. Phys. 27 (1988) 2094-2097. doi:10.1143/JJAP.27.2094.

[155] M.E. Platzer-Bjorkmann, J. Scragg, H. Flammersberger, T. Kubart, Influence of precursor sulfur content on film formation and compositional changes in $\mathrm{Cu} 2 \mathrm{ZnSnS} 4$ films and solar cells, Sol. Energy Mater. Sol. Cells. 98 (2012) 110-117. doi:10.1016/j.solmat.2011.10.019.

[156] K.-J. Yang, D.-H. Son, S.-J. Sung, J.-H. Sim, Y.-I. Kim, S.-N. Park, D.-H. Jeon, J. Kim, D.-K. Hwang, C.-W. Jeon, D. Nam, H. Cheong, J.-K. Kang, D.-H. Kim, A band-gap-graded CZTSSe solar cell with 12.3\% efficiency, J. Mater. Chem. A. 4 (2016) 10151-10158. doi:10.1039/C6TA01558A.

[157] D.B. Mitzi, O. Gunawan, T.K. Todorov, K. Wang, S. Guha, The path towards a high-performance solution-processed kesterite solar cell, Sol. Energy Mater. Sol. Cells. 95 (2011) 1421-1436. doi:10.1016/j.solmat.2010.11.028.

[158] H. Wei, W. Guo, Y. Sun, Z. Yang, Y. Zhang, Hot-injection synthesis and characterization of quaternary $\mathrm{Cu} 2 \mathrm{ZnSnSe} 4$ nanocrystals, Mater. Lett. 64 (2010) 1424-1426. doi:10.1016/j.matlet.2010.03.034.

[159] C.P. Chan, H. Lam, C. Surya, Preparation of $\mathrm{Cu} 2 \mathrm{ZnSnS} 4$ films by electrodeposition using ionic liquids, Sol. Energy Mater. Sol. Cells. 94 (2010) 207-211. doi:10.1016/j.solmat.2009.09.003.

[160] X. Wu, W. Liu, S. Cheng, Y. Lai, H. Jia, Photoelectric properties of Cu 2 ZnSnS 4 thin films deposited by thermal evaporation, J. Semicond. 33 (2012) 022002. doi:10.1088/1674-4926/33/2/022002.

[161] H. Katagiri, N. Sasaguchi, S. Hando, S. Hoshino, J. Ohashi, T. Yokota, Preparation and evaluation of $\mathrm{Cu} 2 \mathrm{ZnSnS} 4$ thin films by sulfurization of E-B evaporated precursors, Sol. Energy Mater. Sol. Cells. 49 (1997) 407-414. doi:10.1016/S0927-0248(97)00119-0.

[162] H. Katagiri, K. Jimbo, W.S. Maw, K. Oishi, M. Yamazaki, H. Araki, A. Takeuchi, Development of CZTS-based thin film solar cells, Thin Solid Films. 517 (2009) 2455-2460. doi:10.1016/j.tsf.2008.11.002.

[163] W. Shockley, H.J. Queisser, Detailed Balance Limit of Efficiency of p-n Junction Solar Cells, J. Appl. Phys. 32 (1961) 510-519. doi:10.1063/1.1736034.

[164] H. Kirou, L. Atourki, A. Almaggoussi, K. Abouabassi, A. Soltani, A. Almaggoussi, A. Elfanaoui, K. Bouabid, M. Nya, A. Ihlal, Effects of $\mathrm{Na} 2 \mathrm{SO} 4$ on the optical and structural properties of $\mathrm{Cu} 2 \mathrm{ZnSnS} 4$ thin films synthesized using co-electrodeposition technique, Opt. Mater. (Amst). 75 (2018) 471-482. doi:10.1016/j.optmat.2017.11.004.

[165] F.A. Jhuma, M.Z. Shaily, M.J. Rashid, Towards high-efficiency CZTS solar cell through buffer layer optimization, Mater. Renew. Sustain. Energy. 8 (2019) 6. doi:10.1007/s40243-019-0144-1.

[166] M.A. Green, Y. Hishikawa, E.D. Dunlop, D.H. Levi, J. Hohl-Ebinger, M. Yoshita, A.W.Y. Ho-Baillie, Solar cell efficiency tables (Version 53), Prog. Photovoltaics Res. Appl. 27 (2019) 3-12. doi:10.1002/pip.3102.

[167] S. Kim, J.-S. Park, S.N. Hood, A. Walsh, Lone-pair effect on carrier capture in Cu 2 ZnSnS 4 solar cells, J. Mater. Chem. A. 7 (2019) 2686-2693. doi:10.1039/C8TA10130B. 
[168] F.Z. Boutebakh, A. Beloucif, M.S. Aida, A. Chettah, N. Attaf, Zinc molarity effect on Cu2ZnSnS4 thin film properties prepared by spray pyrolysis, J. Mater. Sci. Mater. Electron. 29 (2018) 4089-4095. doi:10.1007/s10854-017-8353-9.

[169] M.P. Suryawanshi, S.W. Shin, U. V Ghorpade, K. V Gurav, C.W. Hong, A. V Moholkar, Electrochimica Acta Improved photoelectrochemical performance of $\mathrm{Cu} 2 \mathrm{ZnSnS} 4$ ( CZTS ) thin fi lms prepared using modi fi ed successive ionic layer adsorption and reaction ( SILAR ) sequence, Electrochim. Acta. 150 (2014) 136-145. doi:10.1016/j.electacta.2014.10.124.

[170] F. Liu, F. Zeng, N. Song, L. Jiang, Z. Han, Z. Su, C. Yan, X. Wen, X. Hao, Y. Liu, Kesterite Cu 2 $\mathrm{ZnSn}(\mathrm{S}, \mathrm{Se}) 4$ Solar Cells with beyond 8\% Efficiency by a Sol-Gel and Selenization Process, ACS Appl. Mater. Interfaces. 7 (2015) 14376-14383. doi:10.1021/acsami.5b01151.

[171] A. El, L. Nkhaili, M. Elyaagoubi, A. Elmansouri, K. Elassali, A. Outzourhit, Préparation et caractérisation de couches minces des $\mathrm{Cu} 2 \mathrm{ZnSnS} 4$ pour des cellules solaires à faible coût, Journées Int. Therm. 16 (2013).

[172] C. Zhang, J. Tao, J. Chu, An 8.7\% efficiency co-electrodeposited Cu2ZnSnS4 photovoltaic device fabricated via a pressurized post-sulfurization process, (2018) 13275-13282. doi:10.1039/c8tc05058a.

[173] X.H. Xu, F. Wang, J.J. Liu, K.C. Park, M. Fujishige, A novel one-step electrodeposition to prepare single-phase CuInS2 thin films for solar cells, Sol. Energy Mater. Sol. Cells. 95 (2011) 791-796. doi:10.1016/j.solmat.2010.10.025.

[174] B. Ananthoju, F.J. Sonia, A. Kushwaha, D. Bahadur, N. V. Medhekar, M. Aslam, Improved structural and optical properties of $\mathrm{Cu} 2 \mathrm{ZnSnS} 4$ thin films via optimized potential in single bath electrodeposition, Electrochim. Acta. 137 (2014) 154-163. doi:10.1016/j.electacta.2014.05.166.

[175] A. Tang, Z. Li, F. Wang, M. Dou, Y. Pan, J. Guan, One step electrodeposition of Cu 2 ZnSnS 4 thin films in a novel bath with sulfurization free annealing, Appl. Surf. Sci. 402 (2017) 70-77. doi:10.1016/j.apsusc.2017.01.079.

[176] B.S. Pawar, S.M. Pawar, K. V Gurav, S.W. Shin, J.Y. Lee, S.S. Kolekar, J.H. Kim, Effect of Annealing Atmosphere on the Properties of Electrochemically Deposited Cu 2 ZnSnS 4 (CZTS) Thin Films, ISRN Renew. Energy. 2011 (2011) 1-5. doi:10.5402/2011/934575.

[177] S. Ahmed, K.B. Reuter, O. Gunawan, L. Guo, L.T. Romankiw, H. Deligianni, A High Efficiency Electrodeposited Cu2ZnSnS4 Solar Cell, Adv. Energy Mater. 2 (2012) 253-259. doi:10.1002/aenm.201100526.

[178] V. Kheraj, K.K. Patel, S.J. Patel, D. V Shah, Synthesis and characterisation of Copper Zinc Tin Sulphide ( CZTS ) compound for absorber material in solar-cells, J. Cryst. Growth. 362 (2013) 174-177. doi:10.1016/j.jcrysgro.2011.10.034.

[179] J. Cha, K. Ashok, N.J.S. Kissinger, Y. Ra, J. Sim, J. Kim, C. Lee, Effect of Thermal Annealing on the Structure, Morphology, and Electrical Properties of Mo Bottom Electrodes for Solar Cell Applications, J. Korean Phys. Soc. 59 (2011) 2280-2285. doi:10.3938/jkps.59.2280.

[180] J. Zhou, N.-S. Xu, S.-Z. Deng, J. Chen, J.-C. She, Z.-L. Wang, Large-Area Nanowire Arrays of Molybdenum and Molybdenum Oxides: Synthesis and Field Emission Properties, Adv. Mater. 15 (2003) 1835-1840. doi:10.1002/adma.200305528.

[181] K.T. Ã, M. Oonuki, N. Moritake, H. Uchiki, Cu2ZnSnS 4 thin film solar cells prepared by non-vacuum 
processing, Sol. Energy Mater. Sol. Cells. 93 (2009) 583-587. doi:10.1016/j.solmat.2008.12.009.

[182] W.M. HLAING Oo, J.L. Johnson, A. Bhatia, E.A. Lund, M.M. Nowell, M.A. Scarpulla, Grain Size and Texture of Cu2ZnSnS4 Thin Films Synthesized by Cosputtering Binary Sulfides and Annealing: Effects of Processing Conditions and Sodium, J. Electron. Mater. 40 (2011) 2214-2221. doi:10.1007/s11664011-1729-3.

[183] L. MG, B. GR, Electrochemical Synthesis and Characterization of Cu2ZnSnS4 Thin Films, J. Mater. Sci. Eng. 5 (2016) 645-651. doi:10.4172/2169-0022.1000261.

[184] S. Kumar, B. Kasubosula, M. Loorits, J. Raudoja, V. Mikli, M. Altosaar, M. Grossberg, Synthesis of $\mathrm{Cu} 2 Z n S n S 4$ Solar Cell Absorber Material by Sol-gel Method, Energy Procedia. 102 (2016) 102-109. doi:10.1016/j.egypro.2016.11.324.

[185] H. ElAnzeery, O. Touayar, M. Meuris, G. Brammertz, S. Oueslati, J. Poortmans, D. Mangin, C. Köble, O. ElDaif, M. Buffière, Study of alternative back contacts for thin film Cu 2 ZnSnSe 4 -based solar cells , J. Phys. D. Appl. Phys. 48 (2014) 035103. doi:10.1088/0022-3727/48/3/035103.

[186] S. Azmi, M. Nohair, M. El Marrakchi, E.M. Khoumri, M. Dabala, Effect of the Complexing Agents on the Properties of Electrodeposited CZTS Thin Films, in: 2018 7th Int. Conf. Renew. Energy Res. Appl., IEEE, 2018: pp. 1346-1351. doi:10.1109/ICRERA.2018.8566894.

[187] Z. Wang, J. Tao, W. Xiao, T. Xu, X. Zhang, D. Hu, Z. Ma, Influence of deposition potential on Cu 2 ZnSnS 4 thin-film solar cells co-electrodeposited on fluorine-doped tin oxide substrates, J. Alloys Compd. 701 (2017) 465-473. doi:10.1016/j.jallcom.2017.01.114.

[188] S.M. Pawar, B.S. Pawar, A. V Moholkar, D.S. Choi, J.H. Yun, J.H. Moon, S.S. Kolekar, J.H. Kim, Single step electrosynthesis of $\mathrm{Cu} 2 \mathrm{ZnSnS} 4$ ( CZTS ) thin films for solar cell application, Electrochim. Acta. 55 (2010) 4057-4061. doi:10.1016/j.electacta.2010.02.051.

[189] M. Snure, A. Tiwari, CuBO2: A p-type transparent oxide, Appl. Phys. Lett. 91 (2007) 092123. doi:10.1063/1.2778755.

[190] H. Chen, Q. Ye, X. He, J. Ding, Y. Zhang, J. Han, J. Liu, C. Liao, J. Mei, W. Lau, Electrodeposited CZTS solar cells from Reline electrolyte, Green Chem. 16 (2014) 3841-3845. doi:10.1039/C4GC00142G.

[191] B.L. Guo, Y.H. Chen, X.J. Liu, W.C. Liu, A.D. Li, Optical and electrical properties study of sol-gel derived Cu 2 ZnSnS 4 thin films for solar cells, AIP Adv. 4 (2014) 097115. doi:10.1063/1.4895520.

[192] L. Yin, G. Cheng, Y. Feng, Z. Li, C. Yang, X. Xiao, Limitation factors for the performance of kesterite $\mathrm{Cu} 2 \mathrm{ZnSnS} 4$ thin film solar cells studied by defect characterization, RSC Adv. 5 (2015) 40369-40374. doi:10.1039/C5RA00069F.

[193] M. Djinkwi Wanda, S. Ouédraogo, F. Tchoffo, F. Zougmoré, J.M.B. Ndjaka, Numerical Investigations and Analysis of $\mathrm{Cu} 2 \mathrm{ZnSnS} 4$ Based Solar Cells by SCAPS-1D, Int. J. Photoenergy. 2016 (2016) 1-9. doi:10.1155/2016/2152018.

[194] M. Powalla, S. Paetel, D. Hariskos, R. Wuerz, F. Kessler, P. Lechner, W. Wischmann, T.M. Friedlmeier, Advances in Cost-Efficient Thin-Film Photovoltaics Based on Cu(In,Ga)Se 2, Engineering. 3 (2017) 445-451. doi:10.1016/J.ENG.2017.04.015.

[195] M.H. Rashid, J. Rabeya, M.H. Doha, O. Islam, P. Reith, G. Hopman, H. Hilgenkamp, Characterization of single step electrodeposited Cu2ZnSnS4 thin films, J. Opt. 47 (2018) 256-262. doi:10.1007/s12596- 
018-0463-0.

[196] F. Jiang, S. Li, C. Ozaki, T. Harada, S. Ikeda, Co-Electrodeposited Cu 2 ZnSnS 4 Thin Film Solar Cell and Cu 2 ZnSnS 4 Solar Cell - BiVO 4 Tandem Device for Unbiased Solar Water Splitting, Sol. RRL. 2 (2018) 1700205. doi:10.1002/solr.201700205.

[197] J.-M. Delgado-Sanchez, J.M. López-González, A. Orpella, E. Sánchez-Cortezon, M.D. Alba, C. LópezLópez, R. Alcubilla, Front contact optimization of industrial scale CIGS solar cells for low solar concentration using 2D physical modeling, Renew. Energy. 101 (2017) 90-95. doi:10.1016/j.renene.2016.08.046.

[198] H. Wang, Y. Liu, M. Li, H. Huang, H.M. Xu, R.J. Hong, H. Shen, Multifunctional TiO2nanowiresmodified nanoparticles bilayer film for 3D dye-sensitized solar cells, Optoelectron. Adv. Mater. Rapid Commun. 4 (2010) 1166-1169. doi:10.1039/b000000x.

[199] H. Saïdi, M.F. Boujmil, B. Durand, J.-L. Lazzari, M. Bouaïcha, Elaboration and characterization of CuInSe 2 thin films using one-step electrodeposition method on silicon substrate for photovoltaic application, Mater. Res. Express. 5 (2018) 016414. doi:10.1088/2053-1591/aaa604.

[200] Y.S. Lee, T. Gershon, O. Gunawan, T.K. Todorov, T. Gokmen, Y. Virgus, S. Guha, Cu2ZnSnSe4 thinfilm solar cells by thermal co-evaporation with $11.6 \%$ efficiency and improved minority carrier diffusion length, Adv. Energy Mater. 5 (2015). doi:10.1002/aenm.201401372.

[201] D.J. Coyle, H.A. Blaydes, R.S. Northey, J.E. Pickett, K.R. Nagarkar, R. Zhao, J.O. Gardner, Life prediction for CIGS solar modules part 2, Prog. Photovoltaics. (2013) 156-172. doi:10.1002/pip.

[202] C. Yan, J. Huang, K. Sun, S. Johnston, Y. Zhang, H. Sun, A. Pu, M. He, F. Liu, K. Eder, L. Yang, J.M. Cairney, N.J. Ekins-Daukes, Z. Hameiri, J.A. Stride, S. Chen, M.A. Green, X. Hao, Cu 2 ZnSnS 4 solar cells with over $10 \%$ power conversion efficiency enabled by heterojunction heat treatment, Nat. Energy. 3 (2018) 764-772. doi:10.1038/s41560-018-0206-0.

[203] F. Jiang, S. Ikeda, T. Harada, M. Matsumura, Pure Sulfide Cu2ZnSnS4 thin film solar cells fabricated by preheating an electrodeposited metallic stack, Adv. Energy Mater. 4 (2014) 2-5. doi:10.1002/aenm.201301381.

[204] B. Rezaei, N. Irannejad, A.A. Ensafi, 3D TiO2 self-acting system based on dye-sensitized solar cell and g-C3N4/TiO2-MIP to enhanced photodegradation performance, Renew. Energy. 123 (2018) 281-293. doi:10.1016/j.renene.2018.02.042.

[205] T. Slimani Tlemcani, F.C. El Moursli, M. Taibi, F. Hajji, E.B. Benamar, S. Colis, G. Schmerber, D. Muller, A. Slaoui, A. Dinia, M. Abd-Lefdil, One step electrodeposited CZTS thin films: Preparation and characterization, in: 2014 Int. Renew. Sustain. Energy Conf., IEEE, 2014: pp. 89-93. doi:10.1109/IRSEC.2014.7059867.

[206] S.R. Kodigala, The Role of Characterization Techniques in the Thin Film Analysis, in: Thin Film Sol. Cells From Earth Abund. Mater., Elsevier, 2014: pp. 67-140. doi:10.1016/B978-0-12-394429-0.000044.

[207] C.W. Hong, S.W. Shin, M.P. Suryawanshi, M.G. Gang, J. Heo, J.H. Kim, Chemically Deposited CdS Buffer/Kesterite $\mathrm{Cu} 2 \mathrm{ZnSnS} 4$ Solar Cells: Relationship between CdS Thickness and Device Performance, ACS Appl. Mater. Interfaces. 9 (2017) 36733-36744. doi:10.1021/acsami.7b09266.

[208] F.W. Gayle, F.S. Biancaniello, STACKING FAULTS AND CRYSTALLITE SIZE, 6 (1995) 429-432. 
[209] R. Touati, M. Ben Rabeh, M. Kanzari, Structural and Optical Properties of the New Absorber Cu2ZnSnS4 Thin Films Grown by Vacuum Evaporation Method, Energy Procedia. 44 (2014) 44-51. doi:10.1016/j.egypro.2013.12.008.

[210] H. Shang, Y. Zhang, Y. Li, Y. Qi, S. Guo, D. Zhao, Effects of adding over-stoichiometrical Ti and substituting Fe with Mn partly on structure and hydrogen storage performances of TiFe alloy, Renew. Energy. 135 (2019) 1481-1498. doi:10.1016/j.renene.2018.09.072.

[211] N. Soundaram, R. Chandramohan, S. Valanarasu, R. Thomas, A. Kathalingam, Studies on SILAR deposited $\mathrm{Cu} 2 \mathrm{O}$ and $\mathrm{ZnO}$ films for solar cell applications, J. Mater. Sci. Mater. Electron. 26 (2015) 5030-5036. doi:10.1007/s10854-015-3020-5.

[212] S. Rondiya, A. Rokade, A. Jadhavar, S. Nair, M. Chaudhari, R. Kulkarni, A. Mayabadi, A. Funde, H. Pathan, S. Jadkar, Effect of calcination temperature on the properties of CZTS absorber layer prepared by RF sputtering for solar cell applications, Mater. Renew. Sustain. Energy. 6 (2017) 8. doi:10.1007/s40243-017-0092-6.

[213] Z. Su, C. Yan, K. Sun, Z. Han, F. Liu, J. Liu, Y. Lai, J. Li, Y. Liu, Preparation of Cu2ZnSnS4 thin films by sulfurizing stacked precursor thin films via successive ionic layer adsorption and reaction method, Appl. Surf. Sci. 258 (2012) 7678-7682. doi:10.1016/j.apsusc.2012.04.120.

[214] P.A. Fernandes, P.M.P. Salomé, A.F. da Cunha, Growth and Raman scattering characterization of Cu2ZnSnS4 thin films, Thin Solid Films. 517 (2009) 2519-2523. doi:10.1016/j.tsf.2008.11.031. 